Ana Amelia de Oliveira Lavenère-Wanderley

\title{
Mobilidade Sedimentar na Plataforma Leste Brasileira entre o Rio de Contas (BA) e o Rio Doce (ES): Controle Morfológico e do Clima de Ondas
}

Tese apresentada ao Instituto Oceanográfico da Universidade de São Paulo, como parte dos requisitos para obtenção do título de Doutor em Ciências, Programa de Pós-Graduação em Oceanografia, área de Concentração em Oceanografia Geológica.

Orientador: Prof. Dr. Eduardo Siegle

São Paulo 


\title{
Universidade de São Paulo
}

Instituto Oceanográfico

\section{Mobilidade Sedimentar na Plataforma Leste Brasileira entre o Rio de Contas (BA) e o Rio Doce (ES): Controle morfológico e do Clima de ondas}

\author{
(Versão Corrigida) \\ Ana Amelia de Oliveira Lavenère-Wanderley \\ Tese apresentada ao Instituto Oceanográfico da Universidade de São Paulo, como parte dos \\ requisitos para obtenção do título de Doutor em Ciências, Programa de Pós-Graduação em \\ Oceanografia, área de Concentração em Oceanografia Geológica.
}

Julgada em 04 / 05 / 2018.

Prof. Dr. Eduardo Siegle (orientador)

Conceito

Prof. Dr. Michel Michaelovitch de Mahiques (IO-USP)

Conceito

Profa. Dra. Silvia Helena de Mello e Souza (IO-USP)

Conceito

Prof. Dr. Guilherme Borges Fernandez (UFF)

Conceito

Prof. Dr. Marcos Eduardo Cordeiro Bernardes (UFSB)

Conceito 
Essa é a história do meu doutorado, mas um rio não pode voltar para trás...

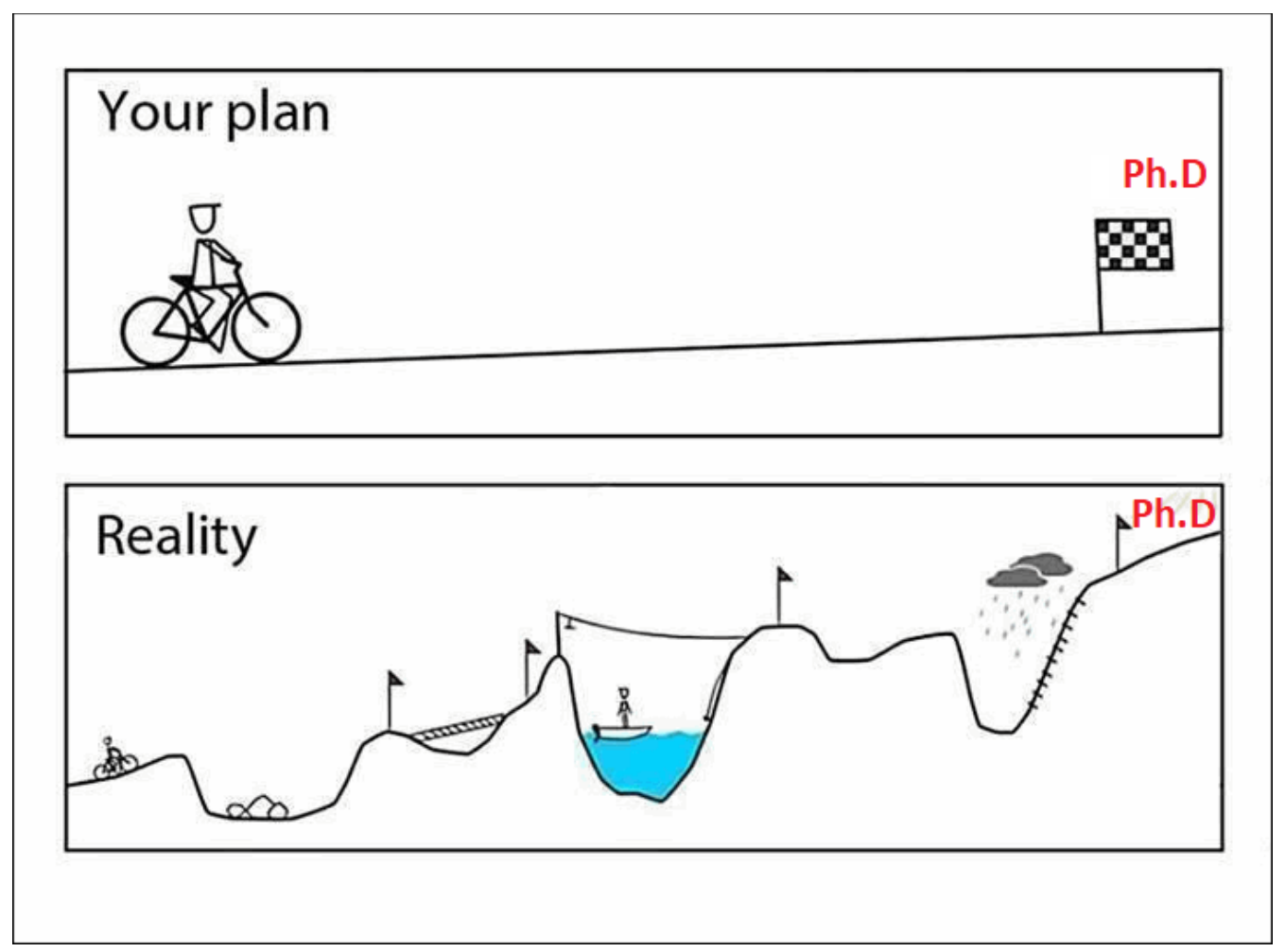

Fonte: Modificado de @ ThinkingIP

"Dizem que antes de um rio entrar no mar, ele treme de medo. Olha para trás, para toda a jornada que percorreu, para os cumes, as montanhas, para o longo caminho sinuoso que trilhou através de florestas e povoados, e vê à sua frente um oceano tão vasto, que entrar nele nada mais é do que desaparecer para sempre. Mas não há outra maneira. O rio não pode voltar. Ninguém pode voltar. Voltar é impossível na existência. $\mathrm{O}$ rio precisa se arriscar e entrar no oceano. E somente quando ele entra no oceano é que o medo desaparece, porque apenas então o rio saberá que não se trata de desaparecer no oceano, mas de tornar-se oceano."

Osho (1931 - 1990) 


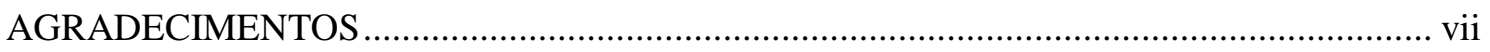

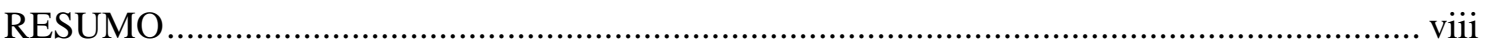

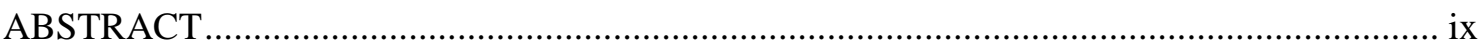

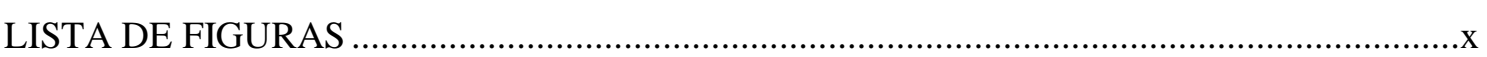

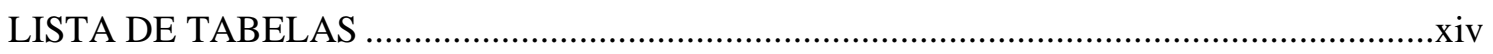

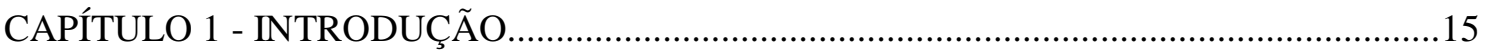

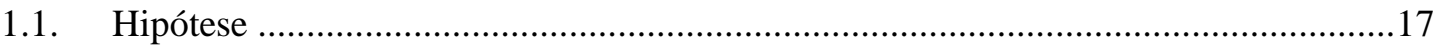

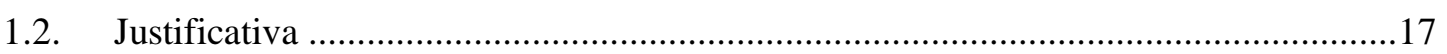

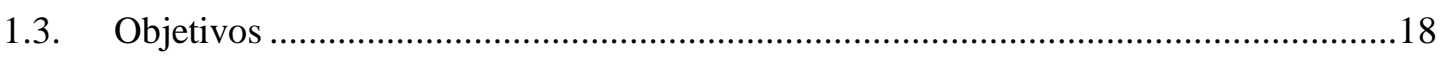

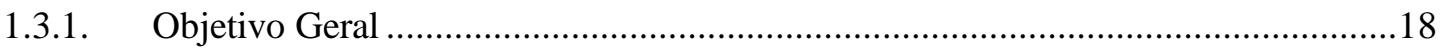

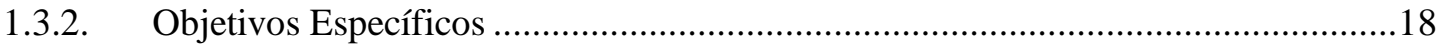

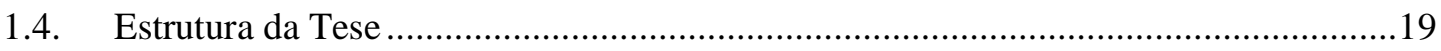

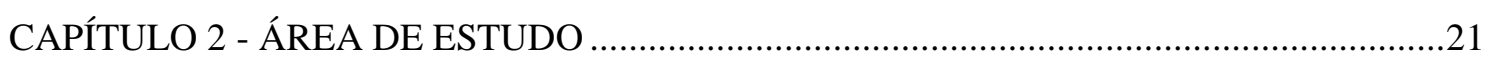

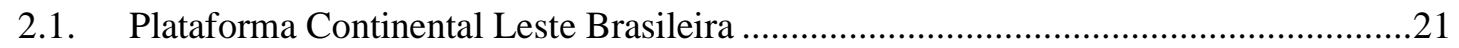

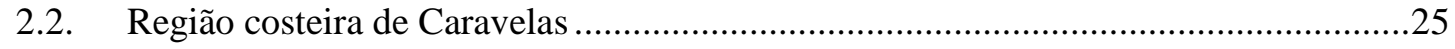

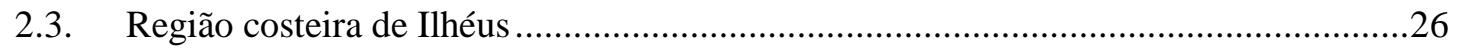

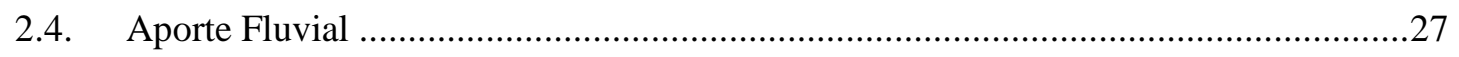

CAPÍTULO 3 - MATERIAIS E MÉTODOS …….................................................................

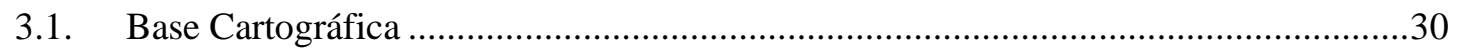

3.1.1. Linha de Costa e Batimetria …………..............................................................

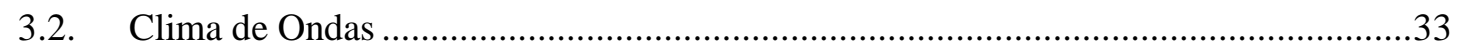

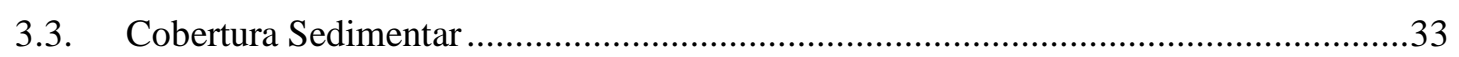

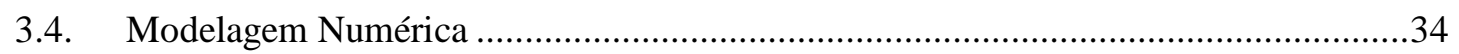

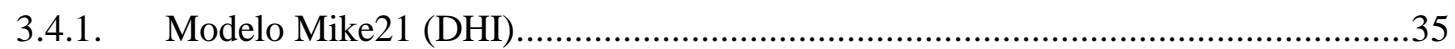

CAPÍTULO 4 - CLIMA DE ONDAS NA PLATAFORMA LESTE BRASILEIRA (ILHÉUS E CARAVELAS) BASEADO NA REANALISE DO MODELO DE ONDAS WAVEWATCH III

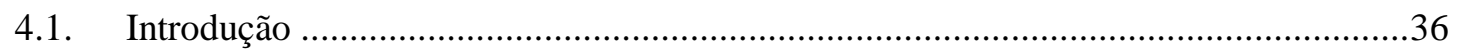

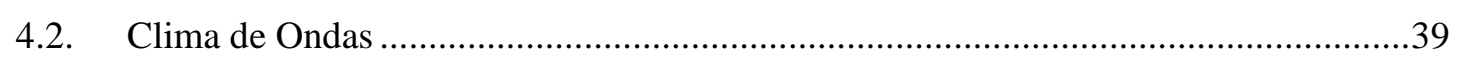

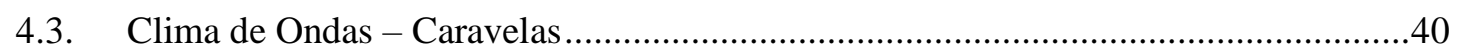

4.3.1. Estatística Anual dos Dados de Ondas de Caravelas ...............................................40

4.3.2. Estatística Sazonal de Dados de Ondas de Caravelas ...............................................42

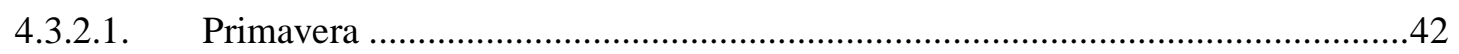

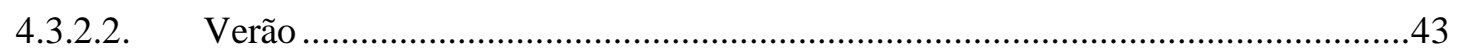

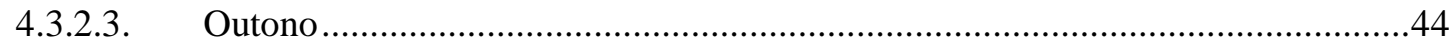

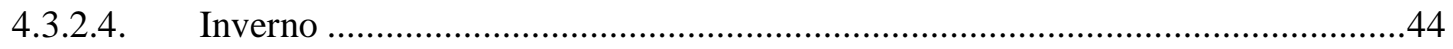




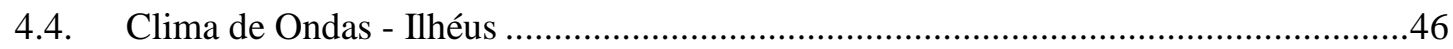

4.4.1. Estatística Anual de Dados de Ondas de Ilhéus .......................................................47

4.4.2. Estatística Sazonal de Dados de Ondas de Ilhéus ..................................................49

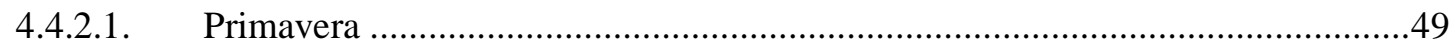

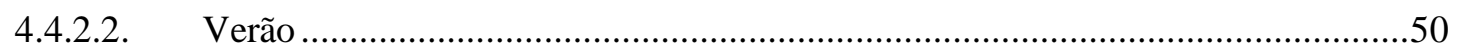

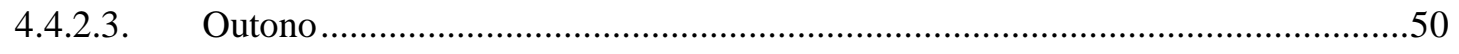

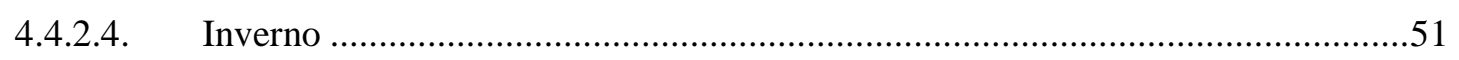

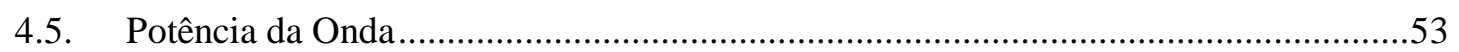

4.6. Análise Comparativa Das Estações WW3_IOS (Ilhéus) E WW3_CRV (Caravelas)..55

4.7. Influência Da Descontinuidade Na Largura Da Plataforma Leste Brasileira No Clima

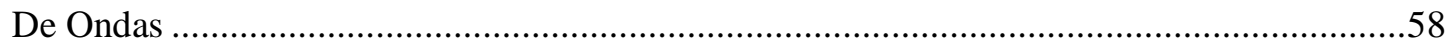

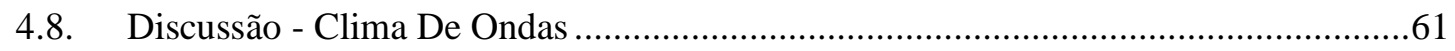

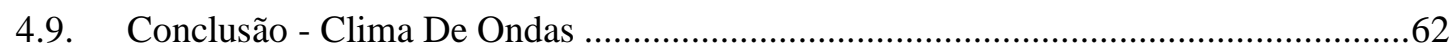

CAPÍTULO 5 - POTENCIAL DE MOBILIDADE SEDIMENTAR INDUZIDA POR ONDAS NA PLATAFORMA CONTINENTAL LESTE BRASILEIRA ................................................64

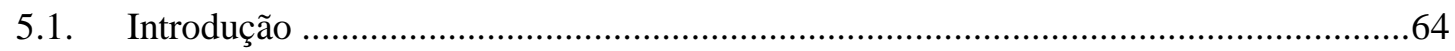

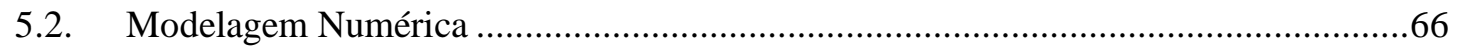

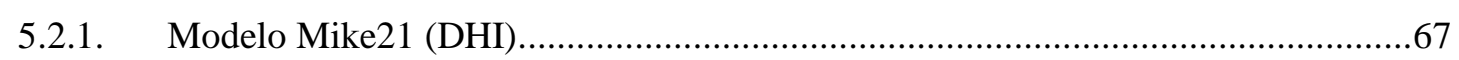

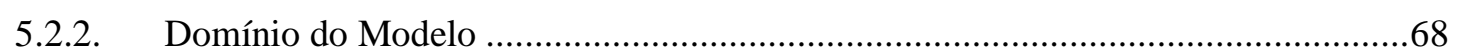

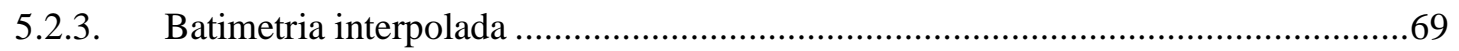

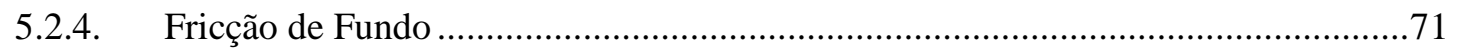

5.2.5. Condições de Contorno - Clima de Ondas ...............................................................73

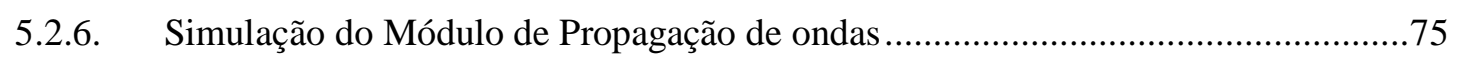

5.2.7. Validação do Modelo de Propagação das ondas (MIKE21 SW) ..............................78

5.3. Mobilidade Potencial dos Sedimentos ..........................................................................8

5.3.1. Cálculo Do Comprimento Da Onda..................................................................... 80

5.3.2. Cálculo da Velocidade Orbital Máxima....................................................................82

5.3.3. Cálculo da Velocidade Crítica de fundo .................................................................83

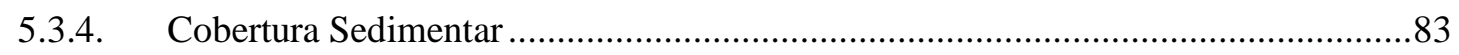

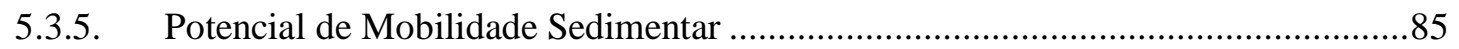

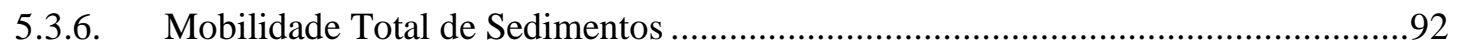

5.4. Discussão - Mobilidade Sedimentar.........................................................................101

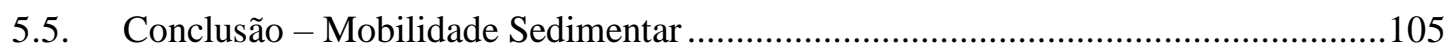

CAPÍTULO 6 - POTENCIAL DE MOBILIDADE DO CAMPO DE RODOLITOS DA PLATAFORMA CONTINENTAL EXTERNA DE ABROLHOS (CARAVELAS, BA)........107

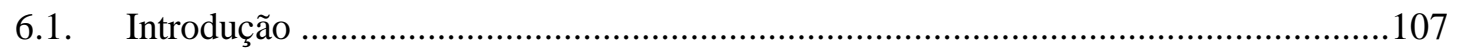

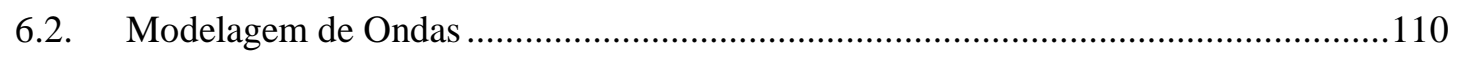

6.3. Cálculo da Mobilidade dos Rodolitos .......................................................................110

6.4. Mobilidade dos Rodolitos do Banco de Abrolhos .....................................................113 
6.5. Discussão - Mobilidade dos Rodolitos..... 121

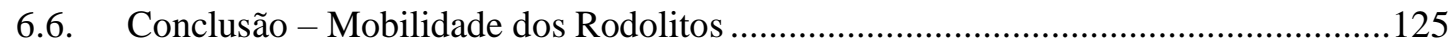

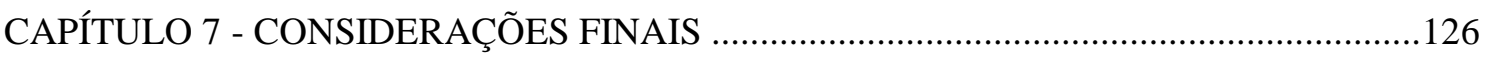

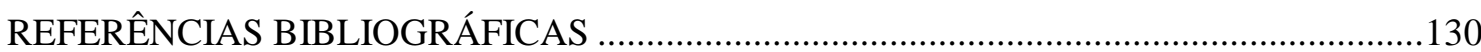




\section{AGRADECIMENTOS}

Agradeço à minha família, pela forte base matemática e pelo amor pelo mar, herdados de meu pai Gilberto (in memoriam), pela força e capacidade de superação, ensinadas por minha mãe Maria Amelia, pela bondade e exemplo dado por minha irmã Martha (in memoriam), pela energia e resistência de minha avó Guta (in memoriam) e pela alegria de viver de minha avó Salô (in memoriam). Sou fruto desta improvável combinação de fatores, totalmente aleatória.

À minha família de quatro patas Greta (in memoriam), Belinha, Pipoca e João Pequeno, que me trouxeram alegria nos períodos mais difíceis, e a seus fiéis guardadores nos momentos de necessidade Rogério Pereira (Alpha Dog Comportamento) e Denys e Priscila Carvalho (Espaço Dog), sem os quais eu não teria conseguido chegar até aqui.

A Antonio Domingues dos Santos, meu melhor amigo, companheiro, parceiro na alegria e na tristeza, pela paciência e pelo interesse em sempre perguntar: "Como anda sua tese?" Espero que você esteja ao meu lado até muito além desse doutorado.

Aos amigos, pelo apoio constante, em especial a Adriana Martini, Fabiola Amorim e Raquel Mello, por estarem ao meu lado nos melhores e nos piores momentos, a Maria Eugênia Bruck, minha irmã de coração, a Cassia Pianca, Piero Mazzini e João Maluf, que viraram amigos para a vida toda, e a tantos outros que acreditaram na minha capacidade e não me deixaram desistir.

Agradeço ao Instituto Oceanográfico da USP (IOUSP) pela oportunidade de estudar e me qualificar em Oceanografia, em especial ao meu orientador Eduardo Siegle pela compreensão e apoio durante toda minha jornada, às cobranças sempre oportunas, mesmo quando eu as achava inoportunas.

À Comissão de Pós-graduação pelo suporte nas difíceis decisões que precisei tomar ao longo do curso e à Secretaria da Pós-graduação do IOUSP pelo acompanhamento nessas minhas idas e vindas.

Agradeço à equipe médica que me manteve viva durante esses anos de doutorado, em especial ao Dr. Roberto Abramoff, oncologista, Dr. João Paulo Mancusi de Carvalho, cirurgião, Dra. Luciana Bagatella, psiquiatra, e Ana Lúcia Toledo, psicóloga que virou amiga, pela dedicação e por acreditarem na minha capacidade de superação.

Aos meus ex-alunos que sempre foram inspiração para mim, em especial a Lucas Nascimento, Adeylan Santos, Renata Cardia Rebouças, Matheus Lobo e Bárbara Savina, entre tantos outros que sempre me deram motivo para levantar todos os dias e energia para seguir em frente.

Aos professores do Departamento de Ciências Agrárias e Ambientais e do Colegiado de Geografia pela amizade, apoio e suporte quando mais precisei; em especial a amiga Tereza Torezani, que não me deixou desistir alegando que eu seria sua orientadora de doutorado.

À Universidade Estadual de Santa Cruz (UESC) pela oportunidade e pelo suporte durante o afastamento para a realização do doutorado, em especial a Magnifica Reitora Adélia Maria Carvalho de Melo Pinheiro (2012/2018) e ao Magnifico Reitor Antônio Joaquim Bastos da Silva (2004/2012) pelo apoio constante, pela confiança depositada e pela preciosa amizade.

À empresa FIBRIA pela disponibilização dos dados de onda coletados na região de Abrolhos, através de Programas de Monitoramento exigidos pelo Licenciamento Ambiental Federal (IBAMA).

Ao Conselho Nacional de Desenvolvimento Científico e Tecnológico (CNPq) pela concessão de bolsa de doutorado.

À todos aqueles, que direta ou indiretamente, contribuíram para a realização desta tese de doutorado, meu sincero agradecimento. 
A dinâmica sedimentar sobre um trecho da plataforma continental leste brasileira foi analisada através da abordagem combinada entre a análise do clima de ondas (WAVEWATCH III), modelagem da propagação das ondas para águas rasas (MIKE 21 SW) e aplicação de equações que estimam o transporte de partículas em função da tensão de cisalhamento causada pelas ondas sobre o fundo marinho. Assim, baseado no clima de ondas da região, são estimados os potenciais de mobilidade sedimentar como resposta a diversas condições forçantes. O clima de ondas em frente a Ilhéus é caracterizado pela predominância de ondas do quadrante leste $(60 \%)$, com $20 \%$ provenientes de sudeste e $15 \%$ de sul. Em frente a Caravelas, o espectro de ondas é caracterizado por $40 \%$ de ondas de leste, $15 \%$ do quadrante sudeste e $35 \%$ provenientes de sul. O clima de ondas é influenciado pelas descontinuidades na largura da plataforma continental nesse trecho da costa, atenuando a influência das ondas de swell provenientes do quadrante sul em frente a Ilhéus. Os resultados indicam mobilidade sedimentar até $50 \mathrm{~m}$ de profundidade na plataforma de Ilhéus e até $20 \mathrm{~m}$ na plataforma de Abrolhos ao longo do ano, no entanto, eventos esporádicos mais energéticos são capazes de mobilizar sedimentos até cerca de $200 \mathrm{~m}$ de profundidade na plataforma de Ilhéus e até $100 \mathrm{~m}$ na plataforma de Caravelas. A mobilidade de partículas de maiores dimensões, como os rodolitos da plataforma de Abrolhos, maior campo de rodolitos conhecido do mundo, foi analisada através do parâmetro de Shields, que leva em consideração tamanho e densidade das partículas. Os resultados indicam que a mobilidade dos rodolitos de Abrolhos está principalmente condicionada pela ocorrência de eventos mais energéticos, especialmente no outono. As regiões com maior mobilidade são a porção norte, próxima a quebra da plataforma e a porção centro-sul da plataforma, ambas com profundidades entre 20 e $40 \mathrm{~m}$. O detalhamento do conhecimento sobre o transporte de sedimentos na plataforma continental leste brasileira contribui para o entendimento na dinâmica sedimentar na região. A morfologia complexa da plataforma, combinada com o clima de ondas incidente, são fatores fundamentais no potencial de mobilização de sedimentos.

Palavras-chave: Plataforma Continental, Ilhéus, Abrolhos, Rodolitos, Modelagem Numérica, Propagação de Ondas 
The sedimentary dynamics on a stretch of the Brazilian continental shelf was analyzed through a combined approach between wave climate analysis (WAVEWATCH III), shallow water wave propagation modeling (MIKE $21 \mathrm{SW}$ ) and equations estimating the transport of particles as a function of bed shear stress by the waves. Thus, based on the wave climate of the region, sediment mobility potentials are estimated in response to several forcing conditions. Wave climate is characterized by the predominance of east waves in front of Ilhéus (60\%), 20\% from southeast quadrant and 15\% from south. In front of Caravelas a wave spectrum is characterized by $40 \%$ from east quadrant, $15 \%$ from southeast and $35 \%$ from south. Continental shelf width discontinuity influences wave climate at Ilhéus, attenuating waves from south quadrant. The results indicate sediment mobility up to $50 \mathrm{~m}$ depth on the Ilhéus shelf and up to $20 \mathrm{~m}$ on the Abrolhos shelf along the entire year; however, more sporadic energetic events are able to mobilize sediments up to $200 \mathrm{~m}$ depth on the Ilhéus shelf and up to $100 \mathrm{~m}$ on the Caravelas shelf. Larger particle mobility, such as the rhodoliths of the Abrolhos shelf, the largest known rhodolite field in the world, was analyzed using the Shields parameter, which takes into account particle size and density. The results indicate that the mobility of Abrolhos rhodolites is mainly conditioned by the occurrence of more energetic events, especially in autumn. The regions with the greatest mobility are the northern portion, near the shelf break and the center-south portion of the shelf, both with depths between 20 and $40 \mathrm{~m}$. The detailed knowledge on sediment transport in the Brazilian continental shelf contributes to the understanding of sedimentary dynamics in the region. The complex morphology of the continental shelf, combined with the incident wave climate, are fundamental factors in sediment mobilization potential.

Key-words: Continental Shelf, Ilhéus, Abrolhos, Rhodoliths, Numerical Modeling, Wave Propagation 
Figura 1: Mapa de localização da área de estudo. Os pontos WW3-CRV (quadrado branco) e WW3-IOS (triângulo branco) representam os pontos de aquisição dos parâmetros de onda do modelo WAVEWATCH III (Tolman, 1999), situados em frente a Caravelas e Ilhéus, respectivamente.

Figura 2: Principais rios da Bacia Hidrográfica do Atlântico Leste.

Figura 3: Grade do Modelo com destaque para a área não abrangida pelas cartas náuticas e preenchida pelas informações obtidos da base de dados ETOPO 1 (quadrado preto).

Figura 4: Grade do modelo com destaque para a área não abrangida pelas cartas náuticas e preenchida pelas informações da base de dados ETOPO 1 (quadrado preto).

Figura 5: Fluxograma de processamento do módulo de ondas (SW) do modelo MIKE 21, apresentando os dados de entrada e de saída.

Figura 6: Distribuição anual (1997-2009) das alturas e períodos de ondas por quadrante de aproximação, na região de Caravelas - BA.

Figura 7: Diagrama direcional de ondas para o período de primavera (set-nov) da série temporal de 13 anos, Caravelas-BA.

Figura 8: Diagrama direcional de ondas para o período de verão (dez-fev) da série temporal de 13 anos, Caravelas-BA.

Figura 9: Diagrama direcional de ondas para o período de outono (mar-mai) da série temporal de 13 anos, Caravelas-BA.

Figura 10: Diagrama direcional de ondas para o período de inverno (jun-ago) da série temporal de 13 anos, Caravelas-BA.

Figura 11: Distribuição anual (1997-2009) das alturas e períodos de ondas por quadrante de aproximação, na região de Ilhéus (BA).

Figura 12: Diagrama direcional de ondas para o período de primavera (set-nov) da série temporal de 13 anos, Ilhéus-BA.

Figura 13: Diagrama direcional de ondas para o período de verão (dez-fev) da série temporal de 13 anos, Ilhéus-BA.

Figura 14: Diagrama direcional de ondas para o período de outono (mar-mai) da série temporal de 13 anos, Ilhéus-BA.

Figura 15: Diagrama direcional de ondas para o período de inverno (jun/ago) da série temporal de13 anos, Ilhéus - BA.

Figura 16: Comparação entre os diagramas de dispersão dos parâmetros de ondas (altura significativa e período) no outono, entre as estações de Caravelas e Ilhéus.

Figura 17: Comparação entre os diagramas de dispersão dos parâmetros de ondas (altura significativa e período) no inverno, entre as estações de Ilhéus e Caravelas.

Figura 18: Comparação entre os diagramas de dispersão dos parâmetros de ondas (altura significativa e período) na primavera, entre as estações de Ilhéus e Caravelas.

Figura 19: Comparação entre os diagramas de dispersão dos parâmetros de ondas (altura significativa e período) no verão, entre as estações de Ilhéus e Caravelas. 
Figura 20: Morfologia da Plataforma Continental Leste Brasileira. Os pontos identificados pelos prefixos WW3 representam as estações de aquisição dos parâmetros das ondas do modelo WAVEWATCH III.

Figura 21: Diagrama direcional da altura significativa (Hs) e do período de pico (Tp) das ondas obtidas do modelo de ondas no ponto WW3-CRV (Caravelas - BA).

Figura 22: Diagrama direcional da altura significativa (Hs) e período de pico (Tp) das ondas obtidas do modelo de ondas no ponto WW3-IOS (Ilhéus - BA).

Figura 23: Diagrama direcional da altura significativa (Hs) e período de pico (Tp) das ondas obtidas no ponto WW3-IOSoff (Ilhéus - BA), fora da influência do Banco de Abrolhos.

Figura 24: Malha flexível do Modelo Mike 21 com adensamento sobre a plataforma continental, na região de Caravelas - BA,

Figura 25: Malha flexível do Modelo Mike $21 \mathrm{com}$ adensamento sobre a plataforma continental, na região de Ilhéus - BA.

Figura 26: Batimetria da Plataforma Continental de Caravelas, interpolada pelo programa MIKE 21.

Figura 27: Batimetria da Plataforma Continental de Ilhéus, interpolada pelo programa MIKE 21.

Figura 28: Distribuição das Alturas da onda sobre a plataforma continental de Caravelas (Bahia), durante o verão, Parâmetros da onda: $\mathrm{Hs}=1,28 \mathrm{~m}, \mathrm{Tp}=6,63 \mathrm{~s}$ e Dir_med=88,84 (Leste).

Figura 29: Distribuição das Alturas da onda sobre a plataforma continental de Caravelas (Bahia), durante o inverno, Parâmetros da onda: $\mathrm{Hs}=2,71 \mathrm{~m}, \mathrm{Tp}=11,64 \mathrm{~s}$ e Dir_med=188,08 (Sul).

Figura 30: Distribuição das Alturas da onda sobre a plataforma continental de Ilhéus (Bahia), durante o verão, Parâmetros da onda: $\mathrm{Hs}=0,91 \mathrm{~m}, \mathrm{Tp}=6,19 \mathrm{~s}$ e Dir_med=93,85

Figura 31: Distribuição das Alturas da onda sobre a plataforma continental de Ilhéus (Bahia), durante o inverno, Parâmetros da onda: $\mathrm{Hs}=2,69 \mathrm{~m}, \mathrm{Tp}=8,54 \mathrm{~s}$ e Dir_med $=100,69^{\circ}$.

Figura 32: Batimetria da Plataforma de Abrolhos com a localização do ponto de coleta de dados de ondas \#506 da Fibria.

Figura 33: Série temporal comparativa entre dados medidos e modelados de altura significativa de onda (Hs) para o ponto \#506 (Fibria), entre junho e setembro de 2011.

Figura 34: Mobilidade dos sedimentos em condições de ondas, durante o verão, na plataforma continental de Caravelas. A linha vermelha indica o limite para a movimentação de sedimentos com diâmetro de grão $0,031 \mathrm{~mm}$. Parâmetros da onda: $\mathrm{Hs}=1,28 \mathrm{~m} T=6,63 \mathrm{~s}$ Dir $=88,84^{\circ} \ldots . . .87$

Figura 35: Mobilidade dos sedimentos em condições de ondas, durante o inverno, na plataforma continental de Caravelas. A linha vermelha indica o limite para a movimentação de sedimentos com diâmetro de grão 0,031 mm. Parâmetros da onda: $\mathrm{Hs}=2,71 \mathrm{~m} \mathrm{~T}=11,64 \mathrm{~s}$ Dir= 188,08 .88

Figura 36: Mobilidade dos sedimentos sob condições de ondas, durante o verão na plataforma continental de Ilhéus. A linha vermelha indica o limite para a movimentação de sedimentos com diâmetro de grão 0,063 mm. Parâmetros da onda: $\mathrm{Hs}=0,91 \mathrm{~m} \quad \mathrm{~T}=6,19 \mathrm{~s} \quad \operatorname{Dir}=93,85^{\circ}$

Figura 37: Mobilidade dos sedimentos sob condições de ondas, durante o inverno na plataforma continental de Ilhéus. A linha vermelha indica o limite para a movimentação de sedimentos com

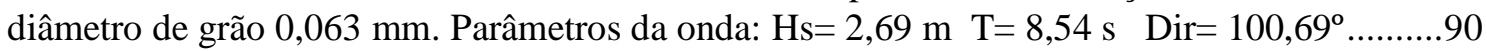


Figura 38: Somatório da taxa de mobilidade dos sedimentos: percentual de tempo em que o sedimento depositado na plataforma continental de Caravelas é mobilizado pelas ondas durante o outono.

Figura 39: Somatório da taxa de mobilidade dos sedimentos: percentual de tempo em que o sedimento depositado na plataforma continental de Caravelas é mobilizado pelas ondas durante o inverno.

Figura 40: Somatório da taxa de mobilidade dos sedimentos: percentual de tempo em que o sedimento depositado na plataforma continental de Caravelas é mobilizado pelas ondas durante a primavera.

Figura 41: Somatório da taxa de mobilidade dos sedimentos: percentual de tempo em que o sedimento depositado na plataforma continental de Caravelas é mobilizado pelas ondas durante o verão

Figura 42: Somatório da taxa de mobilidade dos sedimentos: percentual de tempo em que o sedimento depositado na plataforma continental de Ilhéus é mobilizado pelas ondas durante o outono.

Figura 43: Somatório da taxa de mobilidade dos sedimentos: percentual de tempo em que o sedimento depositado na plataforma continental de Ilhéus é mobilizado pelas ondas durante o inverno.

Figura 44: Somatório da taxa de mobilidade dos sedimentos: percentual de tempo em que o sedimento depositado na plataforma continental de Ilhéus é mobilizado pelas ondas durante a primavera.

Figura 45: Somatório da taxa de mobilidade dos sedimentos: percentual de tempo em que o sedimento depositado na plataforma continental de Ilhéus é mobilizado pelas ondas durante o verão,

Figura 46: Área de estudo, entre o Rio de Contas (BA) e o Rio Doce (ES), apresentando a posição dos perfis batimétricos e de variação da mobilidade sedimentar mostrados na Figura 47 (Imagem Google Earth).

Figura 47: Perfis de mobilidade sedimentar (\%) para Caravelas (a) e Ilhéus (c), para cada estação do ano. (b) e (c) representam o perfil batimétrico para Caravelas e Ilhéus, respectivamente.

Figura 48: Área de Estudo entre o Rio de Contas (BA) e o Rio Doce (ES) apresentando a localização do Banco de Abrolhos. A área pontilhada representa o campo de rodolitos na região (de acordo com Bastos et al., 2015).

Figura 49: Potencial de mobilidade de rodolitos durante o outono para partículas com tamanho de a. $2 \mathrm{~cm}$; b. $4 \mathrm{~cm}$; c. $6 \mathrm{~cm}$; d. $8 \mathrm{~cm}$.

Figura 50: Potencial de mobilidade de rodolitos durante o inverno para partículas com tamanho de a. $2 \mathrm{~cm}$; b. $4 \mathrm{~cm}$; c. $6 \mathrm{~cm}$; d. $8 \mathrm{~cm}$.

Figura 51: Potencial de mobilidade de rodolitos durante a primavera para partículas com tamanho de a. $2 \mathrm{~cm}$; b. $4 \mathrm{~cm}$; c. $6 \mathrm{~cm}$; d. $8 \mathrm{~cm}$.

Figura 52: Potencial de mobilidade de rodolitos durante o verão para partículas com tamanho de a. $2 \mathrm{~cm}$; b. $4 \mathrm{~cm}$; c. $6 \mathrm{~cm}$; d. $8 \mathrm{~cm}$.

Figura 53: Potencial de mobilidade de rodolitos para cenários de ondas extremas para tamanho de partículas de $3 \mathrm{~cm}$ (a; c; e) e de $6 \mathrm{~cm}$ (b; d; f)

Figura 54: Testes de sensibilidade do parâmetro de Shields em relação ao tamanho da partícula (a) e em relação à densidade da partícula (b). Azul: teste realizado para onda com $\mathrm{Hs}=2,7 \mathrm{~m}$; $\mathrm{T}$ 
$=11 \mathrm{~s}$; Preto: teste realizado para onda com $\mathrm{Hs}=2 \mathrm{~m} ; \mathrm{T}=10 \mathrm{~s}$, em profundidade de $20 \mathrm{~m} . \mathrm{Na}$ relação com o tamanho do rodolito (a), a densidade foi considerada foi de $1400 \mathrm{~kg} . \mathrm{m}^{-3}$; na relação com a densidade, o tamanho da partícula é $6 \mathrm{~cm}$.

Figura 55: Esquema representativo de áreas com maior ou menor potencial de mobilidade de rodolitos por ondas. 
Tabela 1: Vazão fluvial mensal e média anual dos principais rios da área de estudo. .29

Tabela 2: Frequência anual (1997 - 2009) de ocorrência das alturas de ondas por setor de aproximação, na região ao largo de Caravelas.

Tabela 3: Frequência anual (1997 - 2009) de ocorrência dos períodos de ondas por setor de aproximação, na região ao largo de Caravelas.

Tabela 4: Estatística sazonal de alturas de ondas, na região de Caravelas (BA).

Tabela 5: Estatística sazonal dos períodos de ondas, na região de Caravelas (BA).

Tabela 6: Estatística sazonal das direções de aproximação das ondas, na região de Caravelas (BA).

Tabela 7: Frequência anual (1997-2009) de ocorrência das alturas de ondas por setor de aproximação, na região ao largo de Ilhéus.

Tabela 8: Frequência anual (1997-2009) de ocorrência dos períodos de ondas por setor de aproximação, na região ao largo de Ilhéus,

Tabela 9: Estatística sazonal de alturas de ondas, na região de Ilhéus.

Tabela 10: Estatística sazonal dos períodos de ondas, na região de Ilhéus.

Tabela 11: Estatística sazonal das direções de aproximação das ondas, na região de Ilhéus. .....53

Tabela 12: Distribuição sazonal dos parâmetros estatísticos das ondas modeladas na estação WW3_CRV, com frequência de ocorrência superior a 5\%, e valores calculados da sua potência $\mathrm{P}\left(\mathrm{kW} \cdot \mathrm{m}^{-1}\right)$.

Tabela 13: Distribuição sazonal dos parâmetros estatísticos das ondas modeladas na estação WW3_IOS, com frequência de ocorrência superior a 5\%, e valores calculados da potência da onda $\mathrm{P}\left(\mathrm{kW} \cdot \mathrm{m}^{-1}\right)$.

Tabela 14: Valores de fricção de fundo utilizados no modulo de ondas do Modelo MIKE 21 (Spectral Wave Module FM) para calibração do modelo. Hsig é a altura significativa da onda, T01 é o período médio da onda, $\mathrm{kN}$ é a rugosidade de Nikuradse.

Tabela 15: Caravelas: distribuição sazonal das alturas de onda com ocorrência superior a $5 \%$ (e seu respectivo período) por direção de aproximação, da série temporal de 13 anos (1997 - 2009) utilizadas como condição de contorno nas simulações do Módulo de Ondas do Modelo Mike21.

Tabela 16: Ilhéus: distribuição sazonal das alturas de onda com ocorrência superior a $5 \%$ ( e seu respectivo período) por direção de aproximação, da série temporal de 13 anos (1997 - 2009) utilizadas como condição de contorno nas simulações do Módulo de Ondas do Modelo Mike21.

Tabela 17: Características das ondas extremas utilizadas como condição de contorno para os experimentos numéricos. 


\section{CAPÍTULO 1 - INTRODUÇÃO}

O ambiente costeiro é altamente dinâmico e responde às condições forçantes como ondas, correntes e marés, geralmente apresentando um comportamento altamente complexo. Adicionalmente, a morfologia costeira é caracterizada por uma variedade de estruturas e feições em várias escalas, o que contrasta com a aparentemente pequena variabilidade espacial de ondas, marés e correntes (Dronkers, 2005).

O processo central que causa mudanças morfológicas é o transporte de sedimentos. $\mathrm{O}$ transporte efetivo pode ser diretamente relacionado às magnitudes das condições forçantes, mas também podem ser transportes líquidos residuais relacionados à assimetria de fluxos.

Como os processos morfodinâmicos são dependentes do tempo, ocorrendo em diferentes escalas temporais, baseado na ideia da "relação primária de escalas" proposta por De Vriend (1991), para cada nível de escala é possível identificar um sistema morfodinâmico específico. De forma geral, em escalas espaço-temporais pequenas, as flutuações individuais nas condições forçantes são importantes, enquanto que em escalas maiores, a evolução é uma resposta média à tendência das condições ambientais.

A privilegiada situação geográfica e a diversidade de recursos naturais que a zona costeira oferece às atividades fundamentais do homem tais como alimentação, energia, recreação e transporte, motivaram a concentração da população nesta zona (Andrade e Domingues 2002). Segundo Small e Nicholls (2003), aproximadamente $23 \%$ da população mundial vivem a uma distância horizontal inferior a $100 \mathrm{~km}$ da linha de costa. No Brasil, de acordo com o Censo Demográfico 2010 (IBGE, 2011), 26,58\% da população vive em municípios costeiros, normalmente a uma distância inferior a $20 \mathrm{~km}$ da linha de costa.

Sob o ponto de vista geomórfico, a linha de costa se caracteriza pela instabilidade dinâmica decorrente de alterações por efeitos naturais e antrópicos, que se traduzem em modificações na disponibilidade de sedimentos, no clima de ondas e na altura do nível relativo do mar. O litoral, especialmente as praias, responde com mudanças de forma e 
de posição em função da atuação de parâmetros oceanográficos, como ondas, marés e correntes costeiras; e meteorológicos e hidrológicos, como precipitação, direção e intensidade dos ventos e descarga fluvial (Muehe, 1996).

Nesse contexto é necessário incluir a plataforma continental interna como parte integrante da zona costeira, onde os processos de transporte de sedimentos e modificação da morfologia de fundo constituem parte integrante dos processos costeiros (Muehe, 1998). No entanto, considerando que a plataforma continental da Bahia, no trecho em frente a Ilhéus, possui apenas $10 \mathrm{~km}$ de largura, com profundidade média de quebra da plataforma de $60 \mathrm{~m}$, a definição de plataforma interna fica descaracterizada.

Cerca de $80 \%$ das plataformas continentais mundiais tem sua dinâmica dominada pela ação de ondas de tempestade (Walker, 1984; Swift et al., 1986 apud Harris e Coleman, 1998), sendo a ressuspensão por ondas e correntes o mecanismo dominante de transporte de sedimentos sobre as plataformas mundiais (Harris e Wiberg, 2001).

A profundidade a partir da qual as ondas sofrem influência do fundo marinho está relacionada ao comprimento das ondas em superfície. Ondas geradas por ventos induzem o movimento orbital na coluna d'água até uma profundidade igual à metade do seu comprimento de onda, ou seja, em profundidades menores que metade do comprimento da onda este movimento orbital entende-se até o fundo (Wiberg e Sherwood, 2008).

O efeito da velocidade orbital das ondas sobre o fundo marinho, na mobilização dos sedimentos, depende do comprimento e altura das mesmas e da granulometria, peso específico e forma dos sedimentos. Desse modo, o limite entre plataforma continental interna e intermediária é definido pela profundidade a partir da qual as ondas têm competência para mobilizar sedimentos de fundo, sendo, portanto influenciada pelo clima de ondas.

O presente trabalho visa o entendimento qualitativo e quantitativo da dinâmica da plataforma continental leste brasileira, no trecho compreendido entre o Rio de Contas (BA) e o Rio Doce (ES), com ênfase em duas regiões características, a plataforma de Ilhéus (Costa do Cacau) e a plataforma de Abrolhos (Costa das Baleias). Ilhéus apresenta uma plataforma estreita, com largura média de cerca de $50 \mathrm{~km}$, enquanto que a plataforma de Abrolhos é ampla, atingindo mais de $240 \mathrm{~km}$ de largura, resultado de processos vulcânicos que geraram afloramentos, posteriormente colonizados por recifes 
de corais. Em Abrolhos, a presença de construções coralíneas sobre a plataforma continental modifica a forma de aproximação das ondas e interfere na sedimentação costeira. Tendo em vista esta diversidade de características surge o interesse no entendimento do processo de mobilidade sedimentar induzida por ondas geradas por ventos nessa região.

\subsection{HIPÓTESE}

A dinâmica sedimentar da plataforma leste brasileira é delineada pela presença de controles morfológicos que interagem com o clima de ondas atuante na região, modificando seu comportamento e gerando ambientes morfodinâmicos diferenciados. O entendimento da importância da ação das ondas na dinâmica do ambiente de plataforma é fundamental para a compreensão dos processos atuais, incluindo a definição de habitats e balanço sedimentar.

\subsection{JUSTIFICATIVA}

A costa leste brasileira apresenta cerca de $1200 \mathrm{~km}$ de extensão, representando aproximadamente $20 \%$ de toda a costa brasileira e apresentando características peculiares quanto à morfologia e sedimentação. A largura da plataforma continental neste trecho varia de cerca de $10 \mathrm{~km}$ no limite norte até mais de $200 \mathrm{~km}$ na parte sul, ao largo de feições morfológicas de destaque como o Banco de Abrolhos. Neste trecho, a zona costeira passa por uma transição desde uma costa caracterizada pela presença de ambientes estuarinos de grande porte na parte norte para as regiões caracterizadas por um aporte sedimentar pouco significativo, até o trecho mais a sul onde o rio Doce (ES) contribui para a sedimentação costeira. A cobertura sedimentar apresenta uma associação de sedimentos relíquia e atuais, onde ocorrem sedimentos siliciclásticos atuais, associados às desembocaduras fluviais, sedimentação carbonática atual relacionada à presença de formações coralíneas e sedimentação carbonática relíquia. 
Devido a essa diversidade e complexidade, o entendimento da influência das ondas na mobilidade dos sedimentos na plataforma leste brasileira é de grande importância no cenário nacional e permitirá a utilização da experiência adquirida nos demais trechos do litoral brasileiro.

\subsection{OBJETIVOS}

\subsubsection{OBJETIVO GERAL}

O objetivo do presente trabalho é proporcionar o entendimento qualitativo e quantitativo da influência das ondas de gravidade na mobilidade dos sedimentos depositados na Plataforma Continental Leste Brasileira, no trecho compreendido entre o rio de Contas (BA) e o rio Doce (ES).

\subsubsection{OBJETIVOS ESPECÍFICOS}

- Caracterizar o Clima de Ondas atuante em dois pontos da plataforma leste brasileira;

- avaliar o comportamento sazonal das ondas na plataforma continental de Ilhéus e de Abrolhos;

- identificar a influência do controle morfológico no clima de ondas;

- determinar as características das ondas propagadas sobre a plataforma continental nos dois trechos da costa;

- caracterizar a mobilidade dos sedimentos litogênicos e carbonáticos sobre a plataforma continental leste brasileira;

- investigar a influência da ação das ondas sobre a mobilidade dos rodolitos presentes na região. 


\subsection{ESTRUTURA DA TESE}

Seguindo esse capítulo introdutório (Capítulo 1), o Capítulo 2 do trabalho apresenta a descrição da área de estudo, na Plataforma Leste da costa Brasileira. A descrição inclui aspectos físicos e geológicos que controlam o ambiente, incluindo alguns aspectos importantes da zona costeira adjacente e do aporte fluvial que chega à região.

No Capítulo 3 são apresentados os métodos utilizados para o trabalho. Nesse capítulo são descritos aspectos mais gerais dos métodos, comuns aos demais capítulos. No entanto, em cada capítulo ainda são apresentados os detalhes específicos dos métodos utilizados para alcançar os objetivos propostos.

Resultados relacionados à análise do clima de ondas são apresentados no Capítulo 4. A análise inclui aspectos estatísticos do clima de ondas e uma análise comparativa entre a porção sul (Banco de Abrolhos) e norte (Ilhéus), influenciado pela grande variabilidade da morfologia da plataforma.

Esses resultados a respeito do clima de ondas são aplicados como condição de contorno para a modelagem numérica que avalia a mobilidade sedimentar da plataforma no Capítulo 5. Nesse capítulo, é realizada a avaliação da propagação das ondas sobre a plataforma, com tantas diferenças ao longo da área de estudo. Esses resultados são utilizados na aplicação de equações que visam obter o potencial de mobilidade de sedimentos pelas ondas, tão importante para aspectos morfodinâmicos da plataforma e litoral adjacente.

Como o Banco de Abrolhos possui o maior campo de rodolitos do mundo, resultados do Capítulo 5 levantam algumas questões a eles relacionados, e o Capítulo 6 apresenta uma análise sobre o potencial de mobilidade dessas "partículas" únicas, com tamanho variando entre 1 e $14 \mathrm{~cm}$ e densidade bastante menor que a do quartzo (entre $1200 \mathrm{e}$ 1600 kg.m-3). Para tanto, a aplicação de equações que permitem a variação da densidade em sua formulação são aplicadas com base nos resultados do modelo 
numérico de propagação de ondas aplicado (Capítulo 5) com as condições de contorno estabelecidas no Capítulo 4. Resultados interessantes foram obtidos a respeito da influência das ondas na definição de habitats bentônicos.

Por fim, o Capítulo 7 apresenta as conclusões gerais do estudo, com uma análise integrada dos principais resultados do trabalho. 


\subsection{PLATAFORMA CONTINENTAL LESTE BRASILEIRA}

A margem continental brasileira é do tipo Atlântico e apresenta inúmeras feições fisiográficas características, relacionadas às unidades morfoestruturais continentais (Martins e Coutinho, 1981), como os cinturões orogênicos dos Planaltos e Serras do Atlântico Leste-Sudeste e as Planícies e Tabuleiros do Nordeste.

A área de estudo compreende a Plataforma Continental Leste Brasileira, entre as coordenadas $14^{\circ}$ e $20^{\circ} \mathrm{S}$ e $37^{\circ}$ e $40^{\circ} \mathrm{W}$, apresentando uma largura média de $50 \mathrm{~km}$ (Figura 1). Neste trecho do litoral, a circulação sobre a plataforma continental e zona costeira é influenciada pela massa de água tropical (AT) associada à Corrente do Brasil e suas oscilações que resultam em vórtices e meandros (Leipe et al., 1999). A plataforma continental leste brasileira pode ser subdividida em dois setores com características morfológicas distintas.

A plataforma continental em Ilhéus é bastante estreita, com média de $18 \mathrm{~km}$ de largura e apresenta um mínimo de menos de $10 \mathrm{~km}$ ao largo da baía de Todos os Santos e em frente à cidade de Ilhéus. Em direção ao sul, a plataforma se alarga, atingindo cerca de 60 quilômetros na frente de Belmonte, cuja feição fisiográfica de destaque é o Banco Royal Charlotte. A plataforma continental ao largo de Caravelas é bastante ampla, atingindo a largura expressiva de cerca de $250 \mathrm{~km}$ devido à presença do Banco dos Abrolhos. A região é caracterizada pela ocorrência de recifes de corais, onde as isóbatas apresentam contornos muito irregulares (Bittencourt et al., 2000). A quebra da plataforma continental está a uma profundidade variando entre 40 e 60 m (Knoppers et al., 1999). 


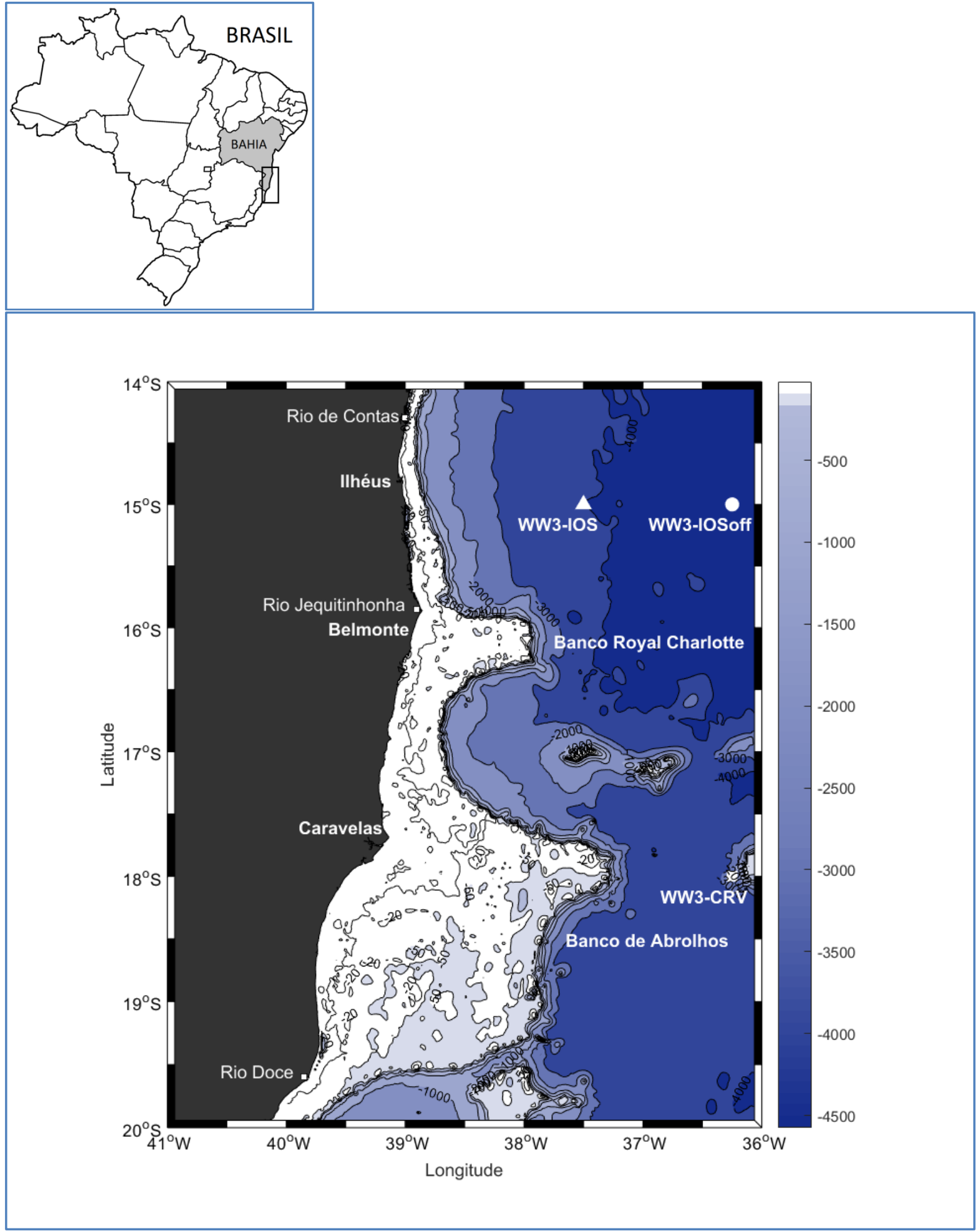

Figura 1: Mapa de localização da área de estudo. Os pontos WW3-CRV (quadrado branco) e WW3-IOS (triângulo branco) representam os pontos de aquisição dos parâmetros de onda do modelo WAVEWATCH III (Tolman, 1999), situados em frente a Caravelas e Ilhéus, respectivamente. 
A variabilidade da largura da plataforma continental no trecho estudado exerce importante controle geomorfológico à propagação das ondas e, consequentemente, à mobilidade dos sedimentos. A área abriga o maior sistema de recifes tropicais do Atlântico Sul, o Banco de Abrolhos (Leão et al., 1988), e devido às características morfológicas da sua plataforma externa, o maior campo de rodolitos conhecido do mundo (Amado-Filho et al., 2010, 2012), além de diversos estuários (Schettini et al., 2013; Andutta et al., 2013; Paiva et al., 2016; Silva et al., 2018). Silva et al. (2013) demonstraram que na ultima década, a taxa de deposição de sedimentos de origem continental tem aumentado no entorno dos recifes costeiros, provavelmente como resultado de processos locais associados a atividades antropogênicas. Além disso, é importante ressaltar que o limite sul da área de estudo está representado pela desembocadura do rio Doce, o qual foi afetado pelo rompimento de uma barragem de rejeitos de mineração que ocorreu a uma distância de cerca de $600 \mathrm{~km}$ da costa, resultando numa grande pluma de sedimentos que atingiu o oceano em 22 de novembro de 2015 (Fernandes et al., 2016; Carmo et al., 2017; Hatje et al., 2017). Esses sedimentos ainda são redistribuídos na plataforma continental, e as ondas podem ser um importante fator na sua ressuspensão.

A plataforma continental leste brasileira é formada pela mistura de três massas d'água: a aquecida e salina Água Tropical, a fria Água Central do Atlântico Sul e a Água Costeira, caracterizada por altas temperaturas e baixas salinidades, devido à influência do aporte fluvial (Castro e Miranda, 1998). A região oceânica próxima à quebra da plataforma está sob a influência do transporte para sul da Corrente do Brasil, ao qual a presença do Banco de Abrolhos representa uma barreira topográfica, induzindo a mudanças nas feições físicas, químicas e biológicas ao longo da plataforma e seu limite externo. Outros três mecanismos forçantes agem sobres as correntes da plataforma leste brasileira: o estresse do vento, gradientes de pressão baroclínica próximos à costa e as marés (Castro e Brandini, 2005).

A maior parte do litoral brasileiro, do estado de Alagoas ao Rio Grande do Sul, apresenta amplitudes de maré inferiores a 2 metros (micromarés), sendo significativas apenas onde a geomorfologia propicia um aumento da velocidade da corrente de maré (Tessler, Cazzoli y Goya, 2005). 
O regime de marés atuante na costa leste brasileira, no trecho compreendido entre o rio de Contas (BA) e o rio Doce (ES) é caracterizado pela ocorrência de marés semi-diurnas com alturas variando entre 1,5 e $2,1 \mathrm{~m}$, o que corresponde ao limite micro/ meso-marés.

A interação da maré com a complexa morfologia da costa nesta região, onde a plataforma continental apresenta larguras variando de cerca de $10 \mathrm{~km}$ em frente a Ilhéus, para 35 km em Canavieiras, alargando para 110 km no Banco Royal Charlotte, novamente estreitando para $42 \mathrm{~km}$ para novamente expandir na presença do Banco de Abrolhos para mais de $200 \mathrm{~km}$, faz com que o comportamento da maré barotrópica interfira na região da plataforma continental, incrementando a quantidade de nutrientes especialmente no flanco sul das formações recifais em decorrência de fenômenos de ressurgência (Pereira et al., 2005). A assinatura oceanográfica de uma frente de maré foi observada em imagens SAR (Synthetic-Aperture Radar), sobre os bancos de Royal Charlotte e Abrolhos, indicando o regime de maré semi-diurna com amplitude máxima de 3,2 m (Cabral et al., 2001).

Ventos anticiclônicos associados ao Centro de Alta Pressão do Atlântico Sul incidem principalmente dos quadrantes leste e nordeste, forçando o fluxo para sul das correntes induzidas por ventos em direção à plataforma continental leste, especificamente nos bancos Royal Charlotte e Abrolhos (Castro e Brandini, 2005). Perturbações atmosféricas que carregam frentes frias do sul da América do Sul em direção a latitudes menores podem causar ventos do quadrante sul tão fortes e persistentes que chegam a inverter a circulação sobre a plataforma, gerando correntes que se deslocam para norte (Castro, 1990).

As ondas no Oceano Atlântico Sul são geradas principalmente em duas regiões: o cinturão temperado de alta latitude e o cinturão dos ventos alísios (Davies, 1972 apud Dominguez et al., 1992). O regime de ondas da plataforma leste brasileira é caracterizado predominantemente por ondas geradas pelos ventos alísios de nordeste; entretanto, seu padrão pode ser modificado por ondas geradas pelo avanço de frentes frias em direção a norte, e ainda por fortes eventos $E l$ Niño que bloqueiam o avanço das frentes e fazem com que ondas geradas pelos ventos dos sistemas frontais não atinjam o litoral leste brasileiro (Martin et al., 1998). 


\subsection{REGIÃO COSTEIRA DE CARAVELAS}

A linha de costa sul da Bahia, entre Mucuri e Ilhéus, é caracterizada pela presença do Grupo Barreiras que, em alguns setores, alcança o litoral formando falésias ativas, e pela presença de recifes de coral, sendo o Banco dos Abrolhos a formação mais significativa. A planície costeira quaternária, com terraços marinhos e acumulações deltaicas, apresenta largura expressiva, alcançando $17 \mathrm{~km}$ em Caravelas (Bittencourt et al., 2005).

Nesta região, o desenvolvimento dos recifes de coral em associação com as variações do nível relativo do mar desempenharam um importante papel na dispersão e acumulação de sedimentos ao longo da linha de costa, determinando a evolução quaternária da planície costeira de Caravelas (Andrade et al., 2003).

As desembocaduras fluviais são parcialmente obstruídas por pontais arenosos e apresentam um complexo padrão de mudanças relacionadas à própria dinâmica de funcionamento destas desembocaduras. Nestas áreas, flutuações nas vazões dos rios ou correntes de maré alteram a dinâmica costeira provocando erosão e deposição localizadas, que não estão necessariamente relacionadas às tendências apresentadas pela linha de costa em regiões afastadas da desembocadura (Andrade e Dominguez, 2002).

O estuário do rio Caravelas, com aproximadamente $66 \mathrm{~km}^{2}$ de área, corresponde ao segundo maior estuário da região Nordeste do Brasil e abriga um importante ecossistema de manguezal (Herz, 1991). O estuário de Caravelas é caracterizado por uma pequena drenagem através de cursos de água que cobrem uma área de apenas de $600 \mathrm{~km}^{2}$. O estuário possui conexão com a desembocadura do rio Peruípe, localizada a aproximadamente $27 \mathrm{~km}$ ao sul, através de pequenos canais meandrantes. A hidrodinâmica e o balanço sedimentar no sistema estuarino de Caravelas são principalmente modulados pela altura da maré, sofrendo pouca influência do aporte de água doce (Santos, 2010). 
O rio Peruípe, com bacia de drenagem de $4.600 \mathrm{~km}^{2}$ apresenta vazão que varia de $15 \mathrm{~m}^{3} \cdot \mathrm{s}^{-1}$ na estação seca a $30 \mathrm{~m}^{3} \cdot \mathrm{s}^{-1}$ na chuvosa (Schettini et al., 2013). Sua descarga para o estuário de Caravelas é estimada em $4 \mathrm{~m}^{3} . \mathrm{s}^{-1}$ (Pereira al., 2010).

\subsection{REGIÃO COSTEIRA DE ILHÉUS}

O trecho norte do litoral de Ilhéus é caracterizado pela presença do embasamento cristalino precambriano em contato ou, próximo ao mar. Os depósitos quaternários são pouco desenvolvidos, com exceção da região da bacia sedimentar do Almada, onde existia uma baía na época dos altos níveis marinhos quaternário, da qual a lagoa de ltaipe (Lagoa Encantada) é o último testemunho (Martin et al., 1980).

A drenagem continental é formada principalmente pelos rios Cachoeira e Almada. A Bacia Hidrográfica do Rio Cachoeira apresenta área da drenagem de $4.600 \mathrm{~km}^{2}$, e junto com os rios Santana e Fundão, afluente do rio Almada, formam a Baía do Pontal, principal acidente geográfico da cidade de Ilhéus. O rio Almada, junto com seus afluentes, ocupa uma superfície de cerca de $1.910 \mathrm{~km}^{2}$. A lagoa de Itaípe (Lagoa Encantada) se liga ao rio Almada através do córrego Itaípe, com 700 m de extensão (SEI, 1999).

A Lagoa Encantada é um corpo de água ovóide, irregular, com o eixo maior alinhado na direção E-O. Na sua maior dimensão tem 3,4 km e na direção N-S em torno de 2,5 km. $\mathrm{Na}$ época da seca sua profundidade média está em torno de $2 \mathrm{~m}$, variando com as marés, porém, na época da cheias fluviais chega a mais de 2,5 m. Seu espelho d'água apresenta uma área de 7 km² (Barros, 2005).

Ao sul, o litoral é caracterizado pelo reaparecimento dos sedimentos da Formação Barreiras em contato com o mar. Entretanto, os depósitos quaternários bem desenvolvidos caracterizam regiões próximas a desembocaduras fluviais de grande porte, como o caso do rio Jequitinhonha, formando a planície costeira CanavieirasBelmonte (Martin et al., 1980). 
A área de estudo é limitada a norte pela desembocadura do rio de Contas, que apresenta bacia de drenagem de cerca de $55.000 \mathrm{~km}^{2}$ e vazão média de cerca de $100 \mathrm{~m}^{3} \cdot \mathrm{s}^{-1}$, podendo atingir $4.800 \mathrm{~m}^{3} \cdot \mathrm{s}^{-1}$ no período úmido (Campos, 2002). O limite sul da área de estudo corresponde à desembocadura do rio Doce, com bacia de drenagem de 85.000 $\mathrm{km}^{2}$ e vazão média de $900 \mathrm{~m}^{3} \cdot \mathrm{s}^{-1}$.

As bacias hidrográficas, que drenam para a plataforma da área da Costa do Cacau (Ilhéus), dissecam rochas cristalinas de natureza básica a ácida, além de solos de diversas classes, arenosos e argilosos. O material dissecado por estes rios fica retido, na sua grande maioria, nas porções médias e altas de seus cursos, fazendo com que apenas o material fino chegue às suas desembocaduras (Freire, 2006). O alto índice pluviométrico da região favorece o intemperismo químico e libera minerais ferromagnesianos, principais formadores de argilas e colóides. A matéria orgânica aportada para a plataforma, em função da Mata Atlântica e do plantio de cacau na região, que ocorre no sistema cabruca (sombreado pela Mata Atlântica original), torna escuros os sedimentos lamosos (Freire, op. cit.).

A região de Ilhéus é drenada por diversos fluxos d'água de pequeno porte, com destaque para os rios Almada, com bacia de drenagem de cerca de $1.500 \mathrm{~km}^{2}$ e vazão de apenas $14 \mathrm{~m}^{3} \cdot \mathrm{s}^{-1}$, e o rio Cachoeira, com drenagem aproximada de $5.000 \mathrm{~km}^{2}$ e vazão de $24 \mathrm{~m}^{3} \cdot \mathrm{s}^{-1}$ (BAHIA, 2001). Rios de menor porte se distribuem ao longo da costa, entre os quais podemos citar o rio Tijuipe, com vazão de apenas $2 \mathrm{~m}^{3} \cdot \mathrm{s}^{-1}$ (Brandão, 2013); os rios Cururupe e Acuipe, ainda no município de Ilhéus; e o rio Una com vazão média anual de $16 \mathrm{~m}^{3} \cdot \mathrm{s}^{-1}$ (de Paula et al., 2012). Em direção a sul temos o rio Pardo, com bacia hidrográfica de cerca de $50.000 \mathrm{~km}^{2}$ e vazão média anual de $210 \mathrm{~m}^{3} . \mathrm{s}^{-1}$ (Chierice Junior, 2013), e o rio Jequitinhonha, com área de drenagem de cerca de $70.000 \mathrm{~km}^{2}$ e vazão média de $438 \mathrm{~m}^{3} \cdot \mathrm{s}^{-1}$ (Genz et al., 2003). 
$\mathrm{O}$ rio Buranhém, que deságua em Porto Seguro, tem área da bacia hidrográfica com $2.500 \mathrm{~km}^{2}$ e vazão média em torno dos $22 \mathrm{~m}^{3} \cdot \mathrm{s}^{-1}$; o rio Jurucuçu, que desemboca em Prado, após reunir águas de uma bacia de $3.000 \mathrm{~km}^{2}$ com uma vazão média de $26 \mathrm{~m}^{3} \cdot \mathrm{s}^{-1}$ e o rio Itanhém, que deságua em Alcobaça, após percorrer uma bacia com área de 5.000 $\mathrm{km}^{2}$, apresenta vazão média de $31 \mathrm{~m}^{3} \cdot \mathrm{s}^{-1}$, todos têm suas nascentes no estado de Minas Gerais, mas despejam suas águas no litoral extremo sul da Bahia (Genz et al. 2003).

À exceção dos rios Pardo e Jequitinhonha, os demais rios que ocorrem na área podem ser considerados pouco significantes em relação ao aporte de sedimentos para a linha de costa (Nascimento et al., 2007), no entanto, sedimentos em suspensão são por eles aportados e espalhados na plataforma continental.

Recentemente, Oliveira et al. (2018) utilizaram modelos estatísticos para estimar o aporte fluvial na plataforma continental brasileira a partir de dados da Agência Nacional de Águas (ANA). As informações servem de referência para qualquer análise da influência do aporte fluvial na dinâmica costeira (Tabela 1).

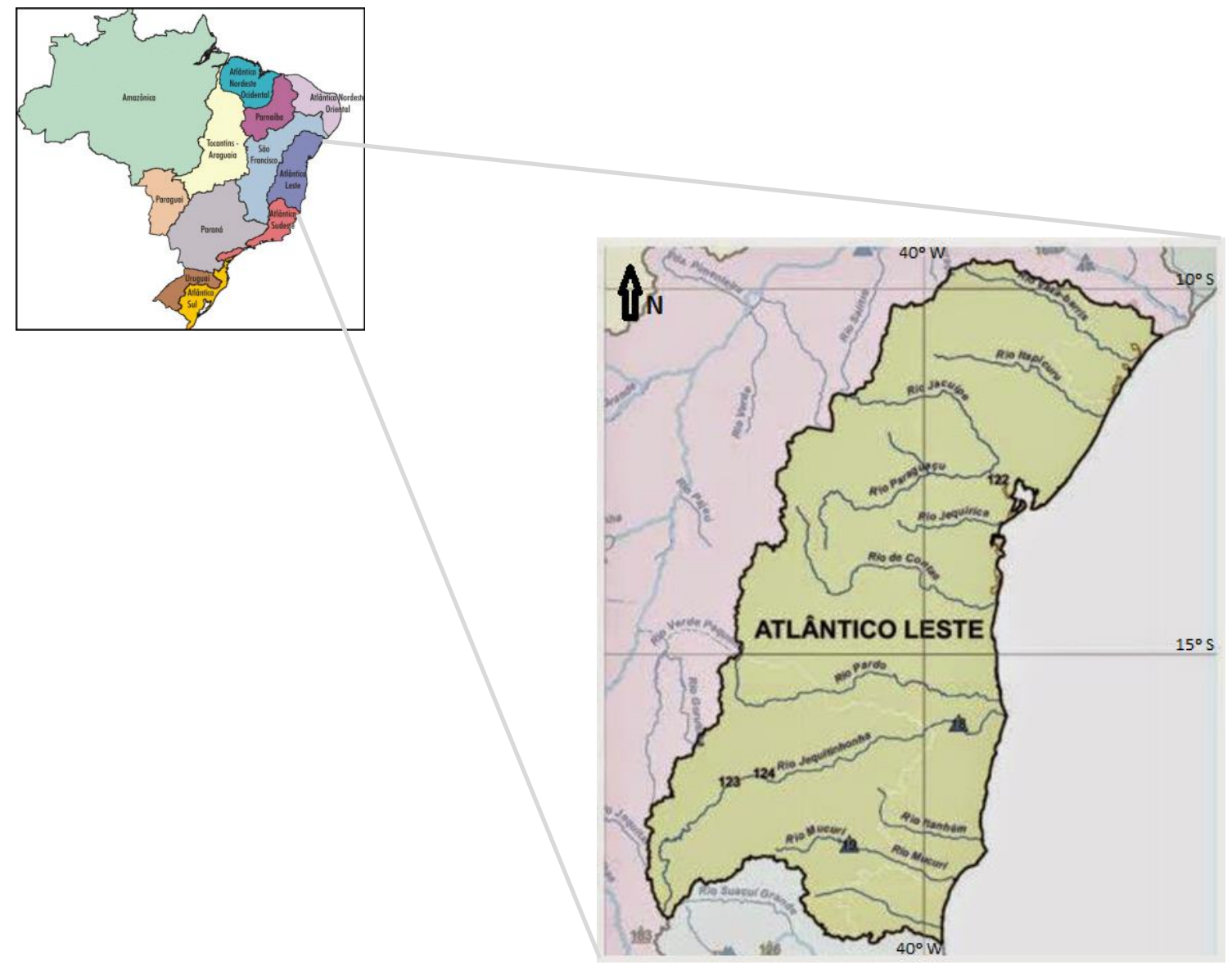

Figura 2: Principais rios da Bacia Hidrográfica do Atlântico Leste. 
Tabela 1: Vazão fluvial mensal e média anual dos principais rios da área de estudo.

\begin{tabular}{|c|c|c|c|c|c|c|c|c|c|c|c|c|c|c|c|c|}
\hline \multirow[t]{2}{*}{ Rio } & \multirow{2}{*}{$\begin{array}{l}\text { Bacia de } \\
\text { Drenagem } \\
\text { Total }\left(\mathrm{km}^{2}\right)\end{array}$} & \multirow[t]{2}{*}{ Long } & \multirow[t]{2}{*}{ Lat } & \multicolumn{12}{|c|}{ Descarga Mensal $\left(\mathrm{m}^{3} . \mathrm{s}-1\right)$} & \multirow{2}{*}{$\begin{array}{l}\text { Descarga } \\
\text { Média } \\
\text { Anual } \\
\left(\mathrm{m}^{3} . \mathrm{s}-1\right)\end{array}$} \\
\hline & & & & JAN & FEV & MAR & ABR & MAI & JUN & JUL & AGO & SET & OUT & NOV & DEZ & \\
\hline De Contas & 56414 & $-38,99$ & $-14,27$ & 124,9 & 183,6 & 125,5 & 99,4 & 77,7 & 78,5 & 74,9 & 72,7 & 61,6 & 60,7 & 84,1 & 166,9 & 100,9 \\
\hline Cachoeira & 4158 & $-39,02$ & $-14,79$ & 28,1 & 33,3 & 30,0 & 21,5 & 12,3 & 9,4 & 11,1 & 9,5 & 6,5 & 10,9 & 24,2 & 47,1 & 20,3 \\
\hline Pardo & 32466 & $-38,94$ & $-15,63$ & 120,3 & 96,3 & 96,4 & 83,8 & 51,5 & 45,7 & 45,4 & 36,7 & 32,2 & 45,1 & 88,6 & 118,1 & 71,7 \\
\hline Jequitinhonha & 72710 & $-38,88$ & $-15,84$ & 932,8 & 632,4 & 575,3 & 429,1 & 263,1 & 217,5 & 190,3 & 168,4 & 155,4 & 212,9 & 490,0 & 767,3 & 419,5 \\
\hline Buranhém & 3250 & $-39,06$ & $-16,46$ & 47,5 & 36,3 & 29,8 & 27,7 & 21,0 & 17,9 & 18,3 & 16,2 & 15,5 & 22,3 & 38,6 & 48,1 & 28,3 \\
\hline Jucuruçú & 6420 & $-39,22$ & $-17,34$ & 131,1 & 103,5 & 94,9 & 79,8 & 63,0 & 55,4 & 51,6 & 44,7 & 43,9 & 54,4 & 87,1 & 117,8 & 77,3 \\
\hline Alcobaça & 7022 & $-39,20$ & $-17,53$ & 70,8 & 54,6 & 53,4 & 49,8 & 39,3 & 35,4 & 34,3 & 26,9 & 27,2 & 34,6 & 58,6 & 77,2 & 46,8 \\
\hline Perúpe & 4840 & $-39,16$ & $-17,75$ & 27,4 & 25,0 & 24,6 & 23,6 & 20,9 & 19,5 & 18,7 & 16,5 & 15,2 & 17,6 & 23,5 & 30,2 & 21,9 \\
\hline Mucuri & 16310 & $-39,55$ & $-18,10$ & 155,0 & 128,3 & 137,6 & 115,5 & 77,2 & 63,7 & 62,1 & 47,6 & 42,2 & 62,6 & 137,0 & 190,6 & 101,6 \\
\hline São Mateus & 13428 & $-39,74$ & $-18,71$ & 148,1 & 114,6 & 108,0 & 88,3 & 64,1 & 54,1 & 46,9 & 38,9 & 34,2 & 46,6 & 93,7 & 139,8 & 81,4 \\
\hline Doce & 90030 & $-39,81$ & $-19,65$ & 1865,4 & 1388,8 & 1230,1 & 998,3 & 732,0 & 632,1 & 571,9 & 514,1 & 494,9 & 660,1 & 1133,2 & 1580,5 & 983,4 \\
\hline
\end{tabular}

Fonte: Oliveira et al. (2018)

Através da análise da Tabela 1 é possível identificar que apenas os rios Jequitinhonha e

Doce apresentam vazão média superior a $400 \mathrm{~m}^{3} \cdot \mathrm{s}^{-1}$, sendo considerados os mais importantes da região. 


\section{CAPÍTULO 3 - MATERIAIS E MÉTODOS}

Os dados de entrada para a análise do transporte de sedimentos na plataforma leste brasileira incluem a construção de uma base cartográfica, baseada em cartas náuticas e em dados ETOPO 1; a aquisição de informações sobre a altura, período e direção de aproximação das ondas, geradas pelo modelo WAVEWATCH III, que alimentam o modelo de propagação de ondas sobre a plataforma continental, MIKE21; e da compilação de dados secundários sobre a cobertura sedimentar sobre a plataforma continental. Os procedimentos para a obtenção dos dados necessários é descrita a seguir.

\subsection{BASE CARTOGRÁFICA}

A Base Cartográfica utilizada foi gerada a partir das cartas náuticas abaixo enumeradas:

- Carta Náutica 1100 - Do Rio Itariri a Ilhéus (Datum: Córrego Alegre) - Escala 1: 308.541

- Carta Náutica 1200 - Do Porto de Ilhéus a Ponta de Cumuruxatiba (Datum: Córrego Alegre) - Escala 1: 305.090

- Carta Náutica 1210 - Proximidades do Porto de Ilhéus (Datum: WGS-84) Escala 1:50.000

- Carta Náutica 1201 - Porto de Ilhéus (Datum: WGS-84) - Escala 1: 12.500

- Carta Náutica 1300 - Da Ponta de Cumuruxatiba ao Rio Doce (Datum: Córrego Alegre) - Escala 1: 301.039

As cartas náuticas 1200, 1210 e 1201 foram obtidas em formato digital (raster ou geotiff) do Centro de Hidrografia da Marinha - CHM da Marinha do Brasil, no endereço:

https://www.marinha.mil.br/chm/chm/dados-do-segnav/cartas-raster

(Acesso em 25/06/2018) 
As cartas 1100 e 1300 foram digitalizadas a partir da versão impressa disponível na biblioteca do Instituto Oceanográfico da USP. Atualmente as cartas náuticas números 1100, 1200 e 1300 tem a área coberta pelas cartas no 22.500 (2015) De Salvador a Barra do Poxim, escala 1: 300.000; no 22.600 (2016) Da Barra do Poxim à Ponta Cumuruxatiba, escala 1: 300.000; no 22.700 (2008) Da Ponta Cumuruxatiba à Conceição da Barra, escala 1: 300.000 e nº 22.800 (2008/2013) De Conceição da Barra a Vitória, escala 1: 300.000, disponíveis em formato raster e geotiff.

\subsubsection{LINHA DE COSTA E BATIMETRIA}

As cartas náuticas foram digitalizadas para a extração da linha de costa e dos dados batimétricos da região de interesse. Os dados extraídos das cartas 1100, 1200 e 1300 foram convertidos para o datum WGS84, para padronização das informações.

Em regiões mais profundas, para complementar os dados obtidos das cartas náuticas, foi utilizada a base de dados do Global Topography - Measured and Estimated Seafloor Topography - ETOPO 1 (1 Arc-Minute Global Relief Model), da National Oceanic and Atmospheric Administration - NOAA (Amante e Eakins, 2009).

Os dados da Base ETOPO1 - NOAA foram extraídos através do endereço abaixo. http://topex.ucsd.edu/cgi-bin/get_data.cgi

A base de dados ETOPO é um banco de dados topográficos do oceano global, onde a batimetria digital possui uma resolução horizontal de 1 a $12 \mathrm{~km}$ e é obtida a partir de dados de sondagens batimétricas disponíveis e estimada através de dados gravimétricos de alta resolução provenientes dos satélites GEOSAT (Geodetic Satellite) da Marinha Americana e ERS-1 (European Remote Sensing Satellite 1) da Agência Espacial Européia. A base foi usada para complementar dados de áreas mais profundas, sem cobertura nas cartas náuticas utilizadas, objetivando ampliar a abrangência do domínio do modelo numérico (Figura 3 e Figura 4). 


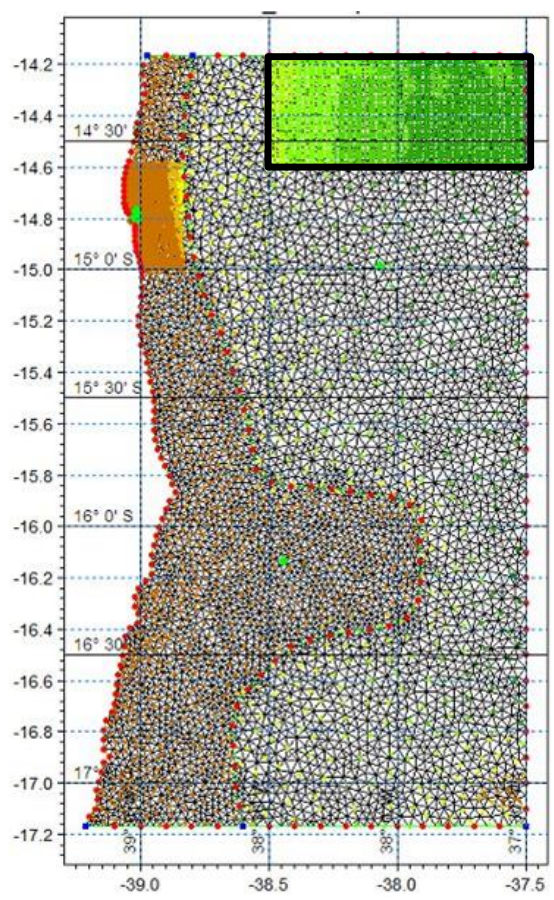

Figura 3: Grade do Modelo com destaque para a área não abrangida pelas cartas náuticas e preenchida pelas informações obtidos da base de dados ETOPO 1 (quadrado preto).

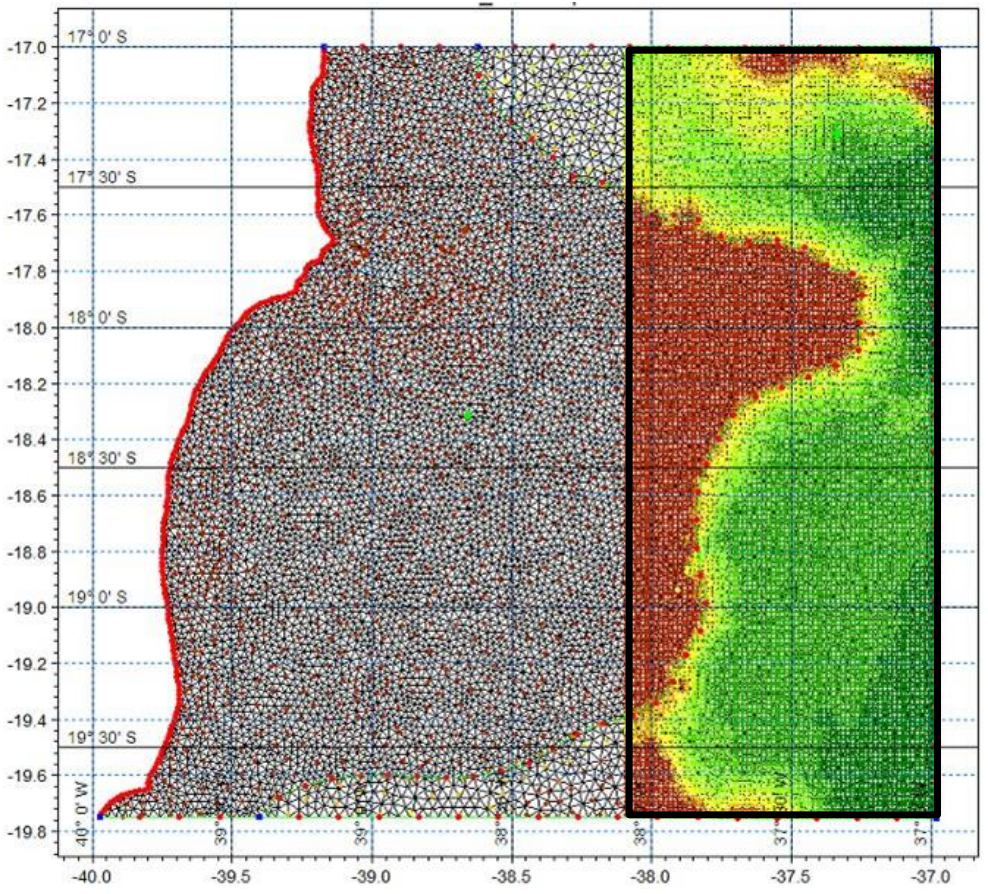

Figura 4: Grade do modelo com destaque para a área não abrangida pelas cartas náuticas e preenchida pelas informações da base de dados ETOPO 1 (quadrado preto). 
Os parâmetros das ondas foram obtidos do National Center for Environment Prediction (NCEP) pertencente à National Oceanic and Atmospheric Administration (NOAA) dos Estados Unidos, a partir do modelo global de propagação de ondas denominado WAVEWATCH III que resolve a equação do balanço de densidade espectral (espectro direcional da onda) e inclui crescimento, decaimento, interações não lineares, dissipação, fricção com o fundo, arrebentação e espalhamento da onda.

Os resultados do modelo global foram obtidos a partir do banco de dados da NOAA, no endereço: ftp://polar.ncep.noaa.gov/pub/history/waves

A distribuição estatística dos dados de ondas (clima de ondas) foi obtida através da análise de 13 anos de dados de altura significativa, direção média e período de pico das ondas geradas por vento extraídas do modelo WAVEWATCH III (NOAA) de 1997 a 2009. Utilizando uma rotina na linguagem computacional Matlab foram calculadas as alturas mais frequentes e o período médio associado a essa altura, por direção de aproximação das ondas na série temporal.

\subsection{COBERTURA SEDIMENTAR}

A textura dos sedimentos na plataforma continental varia entre areias siliciclásticas e depósitos biogênicos. Em frente a Ilhéus, os sedimentos da plataforma continental interna são compostos principalmente por lamas, associadas à foz dos rios Cachoeira e Almada, e areias e cascalhos nas regiões entre as desembocaduras (Freire, 2006). Areias e lamas siliciclásticas estão presentes em águas rasas, em profundidades inferiores a 10m, sedimentos carbonáticos são formações rochosas perto da quebra da plataforma, enquanto uma região de transição que apresenta uma mistura de sedimentos siliciclásticos e carbonáticos, ocorre entre 10 e $20 \mathrm{~m}$ de profundidade (Apoluceno, 1998). 
Na plataforma de Caravelas, sedimentos na plataforma continental externa e média, no Banco de Abrolhos e a área ao redor dos recifes de coral são principalmente carbonáticos, enquanto os sedimentos siliciclásticos estão concentrados na plataforma continental interna (Leão, 1982). Em contraste com a predominância de sedimentação carbonática na maioria dos recifes dos mares tropicais, os recifes costeiros de Abrolhos estão circundados por sedimentos lamosos com 40 a $70 \%$ de areias quartzosas e minerais de argilas (Leão, 2002).

Em Abrolhos a produção de sedimentos carbonáticos ocorre a partir dos organismos recifais, gerando uma transição de fácies sedimentares entre a predominância de sedimentos siliciclásticos, na zona costeira, e de sedimentos carbonáticos recifais costa afora. Assim, podem ser distintos três tipos de sedimento: (i) areias quartzosas ao longo da costa; (ii) material biogênico nas áreas dos recifes, e (iii) sedimentos mistos na área intermediária entre os arcos recifais costeiro e externo" (Leão, 2002).

Em direção a sul, a plataforma novamente se estreita na região adjacente a desembocadura do rio Doce, no Espírito Santo, com largura média de $50 \mathrm{~km}$, onde a influência da sedimentação siliciclástica atual, principalmente lamosa, predomina (Quaresma et al., 2015).

\subsection{MODELAGEM NUMÉRICA}

O modelo numérico aplicado no presente trabalho foi o modelo de área para o estudo da hidrodinâmica e morfodinâmica costeira MIKE21 FM (desenvolvido pela DHI Water \& Environment). O desenvolvimento do MIKE21 iniciou em 1970, e desde então tem sido estendido para diferentes aplicações (Abbott et al., 1981; Abbott e Larsen, 1985). O módulo do modelo numérico que foi aplicado no presente trabalho foi o modelo de propagação de ondas (SW), sendo que o modelo MIKE21 FM gera informações que poderão retroalimentar o módulo morfodinâmico, integrando a evolução morfológica com a hidrodinâmica ao longo da simulação. 
O modelo Mike 21 é um modelo numérico 2D (fluxos barotrópicos) aplicado a áreas costeiras e estuarinas.

O modelo utiliza malha flexível não estruturada, independente da profundidade, que é gerada pela interface gráfica denominada Mike Zero que através do ambiente de trabalho Mesh Generator cria uma malha com os seguintes atributos:

- Área máxima do triângulo

- Máxima obliqüidade (ângulo interno) do triângulo

- Número máximo de pontos de malha

Foi utilizado o módulo de Ondas do modelo Mike 21, que representa o crescimento, transformação e decaimento (refração, empinamento, dissipação, interação não-linear, interação com corrente, variação temporal da profundidade - maré) das ondas de oceano profundo na aproximação da costa. O módulo de ondas do modelo MIKE 21 tem como dados de entrada a batimetria, os parâmetros das ondas e a fricção com o fundo, conforme é mostrado na figura 5 .

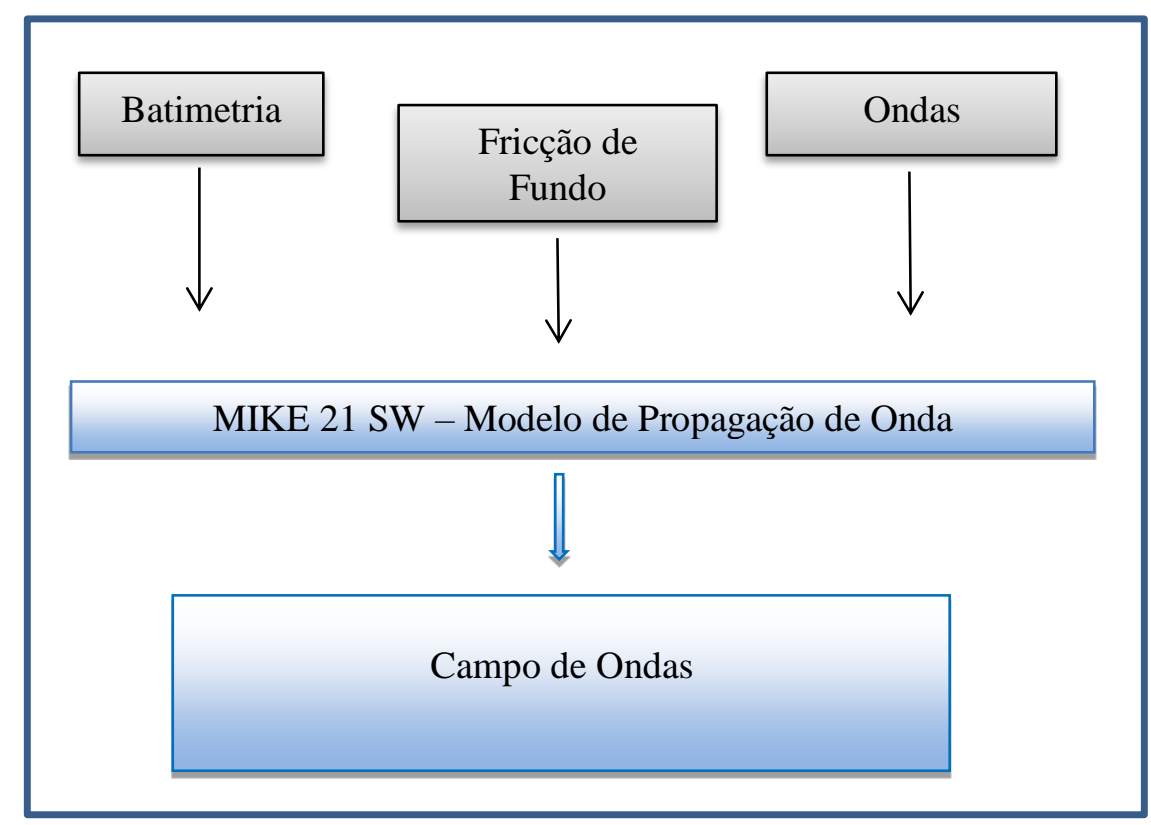

Figura 5: Fluxograma de processamento do módulo de ondas (SW) do modelo MIKE 21, apresentando os dados de entrada e de saída. 


\section{CAPÍTULO 4 - CLIMA DE ONDAS NA PLATAFORMA LESTE BRASILEIRA (ILHÉUS E CARAVELAS) BASEADO NA REANALISE DO MODELO DE ONDAS WAVEWATCH III}

\subsection{INTRODUÇÃO}

O clima de ondas pode ser definido como a análise estatística de longo período das características das ondas no oceano, a saber, altura significativa $(\mathrm{Hs})$, período de pico (Tp) e direção média de aproximação (Dir) para uma determinada posição geográfica (Wiegel, 1964). Em águas profundas, o clima de ondas pouco varia espacialmente, junto a costa, no entanto, variações significativas podem ocorrer em função da interação com a batimetria e a morfologia da costa.

As ondas de gravidade são geradas pela ação dos ventos na superfície do oceano e suas características dependem da intensidade e duração do vento e do tamanho da área livre do oceano sobre a qual o vento atua. À medida que deixam a área de geração, elas se propagam a velocidades que dependem do comprimento de onda, viajando longas distâncias sem uma significativa dissipação de energia. Assim, a análise do clima de ondas pode ser detalhada pelo entendimento da ação das ondas locais (sea) e a influência das ondas propagadas para fora da zona de atuação do vento (swell).

Os sistemas atmosféricos responsáveis pela geração dos ventos no Oceano Atlântico Sul são controlados por três grandes sistemas atmosféricos: a Zona de Convergência Intertropical (ZCIT), responsável pela circulação do litoral mais ao norte do Brasil; o Anticiclone Tropical do Atlântico Sul (ATAS), centro de alta pressão responsável pela origem dos ventos alísios; e Anticiclones Polares Migratórios (APM), centros de alta pressão responsáveis pela passagem dos sistemas frontais. (Tessler e Cazzoli y Goya, 2005).

O clima de ondas é a principal variável indutora dos processos costeiros de curto e de médio prazo, sendo responsável pelo transporte nos sentidos longitudinal e transversal à linha de costa (Muehe, 1998). É a energia das ondas, a intensidade e a recorrência das 
tempestades que comandam a dinâmica dos processos de erosão e acúmulo na interface entre continente e oceano.

Neste contexto, séries temporais de dados e a análise estatística da incidência das ondas de gravidade na costa (clima de ondas) são fundamentais ao entendimento da dinâmica costeira. No litoral brasileiro, o registro de dados de altura, período e direção das ondas ainda é esparso e incipiente, o que demanda a utilização de outras fontes de informação.

No estudo realizado por Silva et al. (2001) com o objetivo de compreender o comportamento da dispersão de sedimentos ao longo da Costa do Descobrimento (Bahia), o modelo de clima de ondas utilizado foi baseado em Bittencourt et al. (2000), considerando os dados de vento segundo a Diretoria de Hidrografia e Navegação da Marinha do Brasil (1993), dados de frentes de onda ( período e altura) fornecidos pela US Navy (1978) e dados de batimetria retirados das cartas náuticas da Marinha do Brasil.

Junto aos Bancos Royal Charlote e Abrolhos, análises de dados de altura significativa de onda dos altímetros ERS-2 (European Remote Sensing Satellite, 1995) e TOPEXPOSEIDON (Topography Experiment / Poseidon - NASA / CNES, 1992) obtidos entre 1997 e 2000, mostraram que a altura média varia 1 e 2,5 m, com valores mais altos no inverno $(3,8 \mathrm{~m})$, com período variando entre 6 e $9 \mathrm{~s}$, e direção predominante de leste. A presença de swell também é marcante, com maior incidência durante o inverno, tendo direção predominante de SW, com período entre 10 e 12 s (Cabral et al., 2001).

Bittencourt et al. (2005) utilizaram para o modelo de climas de onda os dados de estatística de onda (período e altura) de Hogben e Lumb (1967) e os dados de batimetria extraídos das cartas náuticas em uma escala 1:300.000 da Marinha do Brasil. A finalidade do trabalho foi a identificação das possíveis áreas afetadas pela erosão ou deposição de sedimentos ao longo da costa nordeste brasileira de acordo com sua dinâmica de transporte.

Posteriormente, Nascimento et al. (2007) também utilizaram dados estatísticos de onda (altura e período) de Hogben e Lumb (1967) e uma serie temporal de 1951 a 1972 de dados locais de ventos alísios extraídos da Diretoria de Hidrografia e Navegação da Marinha do Brasil (1993) para obter as frequências relativas das frentes de onda que incidem na linha de costa, através da refração da onda sobre a plataforma continental. $\mathrm{O}$ 
objetivo do trabalho era apontar as praias com evidências de erosão e pouca/nenhuma deposição de sedimentos ao longo dos 164 km da Costa do Cacau, litoral sul da Bahia.

Recentemente, modelos matemáticos de geração e propagação de ondas através da utilização de dados de ventos têm sido aplicados em estudos de dinâmica costeira e de plataforma. Dentre eles podemos citar o modelo WAVEWATCH (Tolman, 1999) que resolve a equação do balanço de densidade espectral (espectro direcional da onda) e inclui crescimento, decaimento, interações não lineares, dissipação, fricção com o fundo, arrebentação e espalhamento da onda, a partir da reanálise de dados de vento do National Center for Environment Prediction (NCEP) do National Oceanic and Atmospheric Administration (NOAA) - Estados Unidos.

A aplicabilidade do modelo WAVEWATCH III tem sido destacado na literatura, como verificamos em Pianca et al. (2010), que utilizando parâmetros de altura, período, e direção de onda numa série temporal de onze anos, analisou seis pontos do litoral brasileiro e ainda procedeu à comparação qualitativa com dados obtidos pelo LAHIMAR/UFSC apresentados por Araujo et al. (2003) para o litoral sul do Brasil, atestando sua similaridade em termos de clima de onda.

No trabalho produzido por Campos e Dominguez (2010) foram utilizadas como condições de contorno do Modelo de Propagação de Ondas MIKE 21 SW, a série temporal de 11 anos analisada estatisticamente por Pianca et al. (2010), com o objetivo de avaliar a mobilidade dos sedimentos de fundo na plataforma continental nordeste da Bahia, induzida pela ação das ondas.

Romeu et al. (2015) estabeleceram seis cenários típicos do regime de ondas atuantes na região sudeste brasileira através da análise de 30 anos de dados do estado do mar obtidos do modelo WAVEWATCH III.

O presente capítulo visa determinar o clima de ondas atuante em dois pontos da costa leste brasileira, em Ilhéus e Caravelas, litoral sul do Estado da Bahia, bem como estabelecer a variabilidade sazonal do regime de ondas através da análise de uma série temporal de 13 anos (1997 - 2009). 
O clima de ondas foi determinado a partir do modelo global de propagação de ondas WAVEWATCH III (Tolman, 1999), que resolve a equação do balanço de densidade espectral (espectro direcional) da onda, a partir da reanálise de dados de vento do National Center for Environment Prediction (NCEP) do National Oceanic and Atmospheric Administration (NOAA) - Estados Unidos.

O banco de dados formado pelos resultados do modelo pode ser obtido no endereço: ftp://polar.ncep.noaa.gov/pub/history/waves

O modelo global WAVEWATCH III é simulado quatro vezes ao dia, tendo como dados de saída os seguintes parâmetros espectrais da onda: altura significativa (Hs), período de pico da onda (Tp) e a direção média para o período de pico (Dp) a cada 3 horas. Sua resolução é de $1,25^{\circ}$ em longitude e $1^{\circ}$ em latitude, até uma profundidade mínima de 25 metros. A partir do ano de 2012, as informações produzidas pelo modelo foram detalhadas para uma escala de $1^{\circ}$ tanto em latitude quanto em longitude, foram incorporados novos dados de ventos medidos e ainda foi gerada uma série temporal de 30 anos (1979 a 2009).

No presente trabalho foi utilizado o banco de dados inicial, com informações a partir do ano de 1997. Foram utilizadas duas estações para a aquisição dos parâmetros espectrais da onda simulada, afastadas do continente para evitar a influência das irregularidades da batimetria da plataforma continental da região, a uma profundidade superior a $3.000 \mathrm{~m}$. As séries temporais foram obtidas dos pontos WW3_IOS $\left(15^{\circ} \mathrm{S}, 37^{\circ} 15^{\prime} \mathrm{W}\right)$ na região de Ilhéus e WW3_CRV $\left(18^{\circ} \mathrm{S}, 36^{\circ} 15^{\prime} \mathrm{W}\right)$ na região de Caravelas (Figura 1).

A distribuição estatística dos dados de ondas (clima de ondas) foi obtida através da análise estatística de 13 anos de dados de altura significativa, direção e período das ondas geradas por vento extraídas do modelo WAVEWATCH III (Tolman, 1999), de 1997 a 2009. Utilizando uma rotina na linguagem computacional Matlab foram calculadas as alturas mais frequentes e o período médio associado a essa altura, por direção de aproximação das ondas. 
O clima de ondas na região de Caravelas foi determinado a partir da análise estatística dos parâmetros das ondas no ponto WW3-CRV (Caravelas). Os resultados desta análise são apresentados a seguir.

\subsubsection{ESTATÍSTICA ANUAL DOS DADOS DE ONDAS DE} CARAVELAS

Os parâmetros espectrais das ondas, da série temporal de 13 anos (1997 a 2009), obtidos no ponto WW3_CRV $\left(18^{\circ} \mathrm{S}, 36^{\circ} 15^{\prime} \mathrm{W}\right)$ foram analisados estatisticamente, com o objetivo de determinar o clima de ondas. A distribuição estatística anual do clima de ondas na região de Caravelas é apresentada nas tabelas 2 e 3.

Tabela 2: Frequência anual (1997 - 2009) de ocorrência das alturas de ondas por setor de aproximação, na região ao largo de Caravelas.

\begin{tabular}{c|cccccccc|c}
\hline direção & $\mathbf{N}$ & $\mathbf{N E}$ & $\mathbf{E}$ & $\mathbf{S E}$ & $\mathbf{S}$ & SW & $\mathbf{W}$ & NW & $\begin{array}{l}\text { Total } \\
(\mathbf{\%})\end{array}$ \\
\hline Altura (m) & & & & & & & & & \\
$\mathbf{0 , 5}-\mathbf{1 , 0}$ & 0,04 & 0,18 & 1,45 & 0,32 & 0,28 & 0,03 & 0,00 & 0,00 & $\mathbf{2 , 3 0}$ \\
$\mathbf{1 , 0}-\mathbf{1 , 5}$ & 0,99 & 1,86 & 12,08 & 4,43 & 6,09 & 0,54 & 0,01 & 0,02 & $\mathbf{2 6 , 0 2}$ \\
$\mathbf{1 , 5}-\mathbf{2 , 0}$ & 0,83 & 2,50 & 16,85 & 5,65 & 11,22 & 1,18 & 0,01 & 0,02 & $\mathbf{3 8 , 2 6}$ \\
$\mathbf{2 , 0}-\mathbf{2 , 5}$ & 0,28 & 0,66 & 6,65 & 3,69 & 8,67 & 1,02 & 0,00 & 0,00 & $\mathbf{2 0 , 9 7}$ \\
$\mathbf{2 , 5}-\mathbf{3 , 0}$ & 0,09 & 0,08 & 1,67 & 1,54 & 4,53 & 0,58 & 0,00 & 0,00 & $\mathbf{8 , 4 9}$ \\
$\mathbf{3 , 0}-\mathbf{3 , 5}$ & 0,05 & 0,03 & 0,63 & 0,45 & 1,59 & 0,20 & 0,00 & 0,00 & $\mathbf{2 , 9 5}$ \\
$\mathbf{3 , 3}-\mathbf{4 , 0}$ & 0,02 & 0,01 & 0,12 & 0,13 & 0,51 & 0,05 & 0,00 & 0,00 & $\mathbf{0 , 8 4}$ \\
$\mathbf{4 , 0}-\mathbf{4 , 5}$ & 0,00 & 0,00 & 0,02 & 0,01 & 0,11 & 0,02 & 0,00 & 0,00 & $\mathbf{0 , 1 6}$ \\
$\mathbf{4 , 5}-\mathbf{5 , 0}$ & 0,00 & 0,00 & 0,00 & 0,00 & 0,00 & 0,01 & 0,00 & 0,00 & $\mathbf{0 , 0 1}$ \\
\hline Total (\%) & $\mathbf{2 , 3 0}$ & $\mathbf{5 , 3 2}$ & $\mathbf{3 9 , 4 7}$ & $\mathbf{1 6 , 2 2}$ & $\mathbf{3 3 , 0 0}$ & $\mathbf{3 , 6 3}$ & $\mathbf{0 , 0 2}$ & $\mathbf{0 , 0 4}$ & $\mathbf{1 0 0}$ \\
\hline
\end{tabular}

Os resultados indicam a predominância de ondas dos quadrantes E, SE e S totalizando $88,69 \%$ de todo o registro, Em termos de altura significativa, predominam ondas de 1 a $2,5 \mathrm{~m}$, correspondendo a 85,26\% do registro, e períodos de 6 a $9 \mathrm{~s} ; 51,16 \%$ dos registros, indicando o predomínio de ondas sea, ondas geradas em outras regiões do oceano (swell) representam cerca de $30 \%$ dos dados. 
Tabela 3: Frequência anual (1997 - 2009) de ocorrência dos períodos de ondas por setor de aproximação, na região ao largo de Caravelas.

\begin{tabular}{l|rrrrrrrr|r}
\hline \multicolumn{1}{c|}{ direção } & N & NE & E & SE & S & SW & W & NW & \multicolumn{1}{c}{$\begin{array}{c}\text { Total } \\
\text { período }\end{array}$} \\
1-2s & 0,00 & 0,00 & 0,00 & 0,00 & 0,00 & 0,00 & 0,00 & 0,00 & $\mathbf{0 , 0 0}$ \\
$\mathbf{2 - 3 s}$ & 0,00 & 0,00 & 0,00 & 0,00 & 0,00 & 0,00 & 0,00 & 0,00 & $\mathbf{0 , 0 0}$ \\
$\mathbf{3 - 4 s}$ & 0,03 & 0,04 & 0,03 & 0,00 & 0,00 & 0,00 & 0,00 & 0,00 & $\mathbf{0 , 1 0}$ \\
$\mathbf{4 - 5 s}$ & 0,68 & 0,73 & 0,16 & 0,05 & 0,02 & 0,00 & 0,00 & 0,02 & $\mathbf{1 , 6 6}$ \\
$\mathbf{5 - 6 s}$ & 0,92 & 2,90 & 2,40 & 0,37 & 0,08 & 0,01 & 0,00 & 0,01 & $\mathbf{6 , 6 9}$ \\
$\mathbf{6 - 7 s}$ & 0,29 & 1,33 & 13,22 & 1,43 & 0,42 & 0,01 & 0,00 & 0,00 & $\mathbf{1 6 , 7 0}$ \\
$\mathbf{7 - 8 s}$ & 0,08 & 0,16 & 14,79 & 4,09 & 0,92 & 0,02 & 0,00 & 0,00 & $\mathbf{2 0 , 0 6}$ \\
$\mathbf{8 - 9 s}$ & 0,01 & 0,03 & 6,79 & 5,13 & 2,34 & 0,10 & 0,00 & 0,00 & $\mathbf{1 4 , 4 0}$ \\
$\mathbf{9 - 1 0 s}$ & 0,09 & 0,05 & 1,60 & 3,16 & 5,13 & 0,27 & 0,01 & 0,01 & $\mathbf{1 0 , 3 2}$ \\
$\mathbf{1 0 - 1 1 s}$ & 0,02 & 0,03 & 0,42 & 1,03 & 7,04 & 0,91 & 0,01 & 0,00 & $\mathbf{9 , 4 6}$ \\
$\mathbf{1 1 - 1 2 s}$ & 0,06 & 0,02 & 0,02 & 0,53 & 7,35 & 1,06 & 0,00 & 0,00 & $\mathbf{9 , 0 4}$ \\
$\mathbf{1 2 - 1 3 s}$ & 0,06 & 0,01 & 0,01 & 0,30 & 5,25 & 0,79 & 0,00 & 0,00 & $\mathbf{6 , 4 2}$ \\
$\mathbf{1 3 - 1 4 s}$ & 0,03 & 0,02 & 0,00 & 0,10 & 3,02 & 0,33 & 0,00 & 0,00 & $\mathbf{3 , 5 0}$ \\
$\mathbf{1 4 - 1 5 s}$ & 0,02 & 0,00 & 0,01 & 0,03 & 1,11 & 0,10 & 0,00 & 0,00 & $\mathbf{1 , 2 7}$ \\
$\mathbf{1 5 - 1 6 s}$ & 0,01 & 0,00 & 0,00 & 0,00 & 0,27 & 0,02 & 0,00 & 0,00 & $\mathbf{0 , 3 0}$ \\
$\mathbf{1 6 - 1 7 s}$ & 0,01 & 0,00 & 0,00 & 0,00 & 0,05 & 0,01 & 0,00 & 0,00 & $\mathbf{0 , 0 7}$ \\
$\mathbf{1 7 - 1 8 s}$ & 0,00 & 0,00 & 0,00 & 0,00 & 0,01 & 0,00 & 0,00 & 0,00 & $\mathbf{0 , 0 1}$ \\
\hline Total $\mathbf{( \% )}$ & $\mathbf{2 , 3 1}$ & $\mathbf{5 , 3 2}$ & $\mathbf{3 9 , 4 5}$ & $\mathbf{1 6 , 2 2}$ & $\mathbf{3 3 , 0 1}$ & $\mathbf{3 , 6 3}$ & $\mathbf{0 , 0 2}$ & $\mathbf{0 , 0 4}$ & $\mathbf{1 0 0}$ \\
\hline & & & & & & & & & \\
\hline
\end{tabular}

A análise do diagrama direcional das ondas atuantes na região (Figura 6), segundo os parâmetros espectrais dos 13 anos de modelagem, destacam a predominância de ondas dos quadrantes leste e sul, e secundariamente do setor sudeste na dinâmica da região.
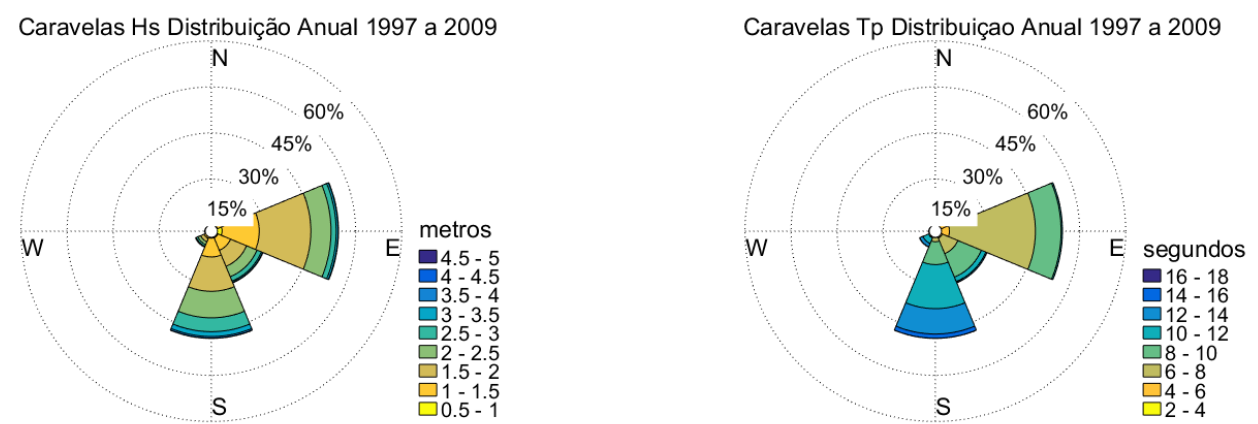

Figura 6: Distribuição anual (1997-2009) das alturas e períodos de ondas por quadrante de aproximação, na região de Caravelas - BA. 
As ondas provenientes do quadrante sul apresentam períodos mais elevados, indicando a influência de ondas provenientes das tempestades do Atlântico Sul (swell).

\subsubsection{ESTATÍSTICA SAZONAL DE DADOS DE ONDAS DE CARAVELAS}

A distribuição da frequência de ocorrência dos parâmetros espectrais das ondas, obtidos do modelo WAVEWATCH III, também foi analisada sazonalmente. Foi considerado o período de três meses para cada estação do ano, sendo dezembro, janeiro e fevereiro, correspondente ao verão; março, abril e maio, ao outono; junho, julho e agosto, inverno; e setembro, outubro e novembro, primavera. A distribuição estatística dos parâmetros espectrais indica uma mudança no padrão de aproximação das ondas, com ondas mais altas e longos períodos predominando nas estações de transição (primavera e outono) com mudança do quadrante de aproximação de leste, durante a primavera e o verão, para sul durante o outono e inverno.

Os diagramas direcionais da distribuição estatística dos parâmetros espectrais das ondas por estação do ano, para a região de Caravelas, são apresentados abaixo (Figuras 7 a $10)$.

\subsubsection{PRIMAVERA}

$\mathrm{Na}$ primavera, ondas do quadrante leste predominam no registro $(40 \%)$, com alturas que variam de 1,0 a $2,5 \mathrm{~m}$ e períodos entre 6 e $8 \mathrm{~s}$ (Figura 7). Entre as ondas provenientes do quadrante sul, predominam maiores alturas (1,5 a 2,5 m) e períodos acima dos $10 \mathrm{~s}$, destacando a influência de ondas geradas nas altas latitudes do hemisfério sul (swell). 

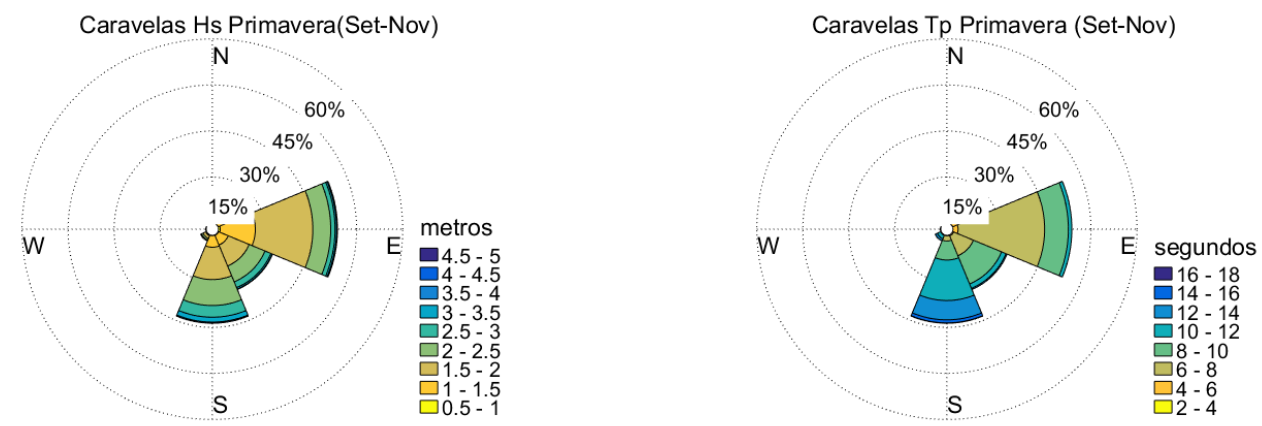

Figura 7: Diagrama direcional de ondas para o período de primavera (set-nov) da série temporal de 13 anos, Caravelas-BA.

\subsubsection{VER ÃO}

No verão, as ondas de leste se tornam mais frequentes, correspondendo a aproximadamente $45 \%$ do registro, enquanto as ondas provenientes do quadrante sul correspondem a apenas $25 \%$. As alturas significativas ficam entre 1,0 a $2,0 \mathrm{~m}$ e $80 \%$ das ondas com períodos entre 4 e $10 \mathrm{~s}$ e quase $20 \%$ com períodos acima dos $10 \mathrm{~s}$ (Figura 8).
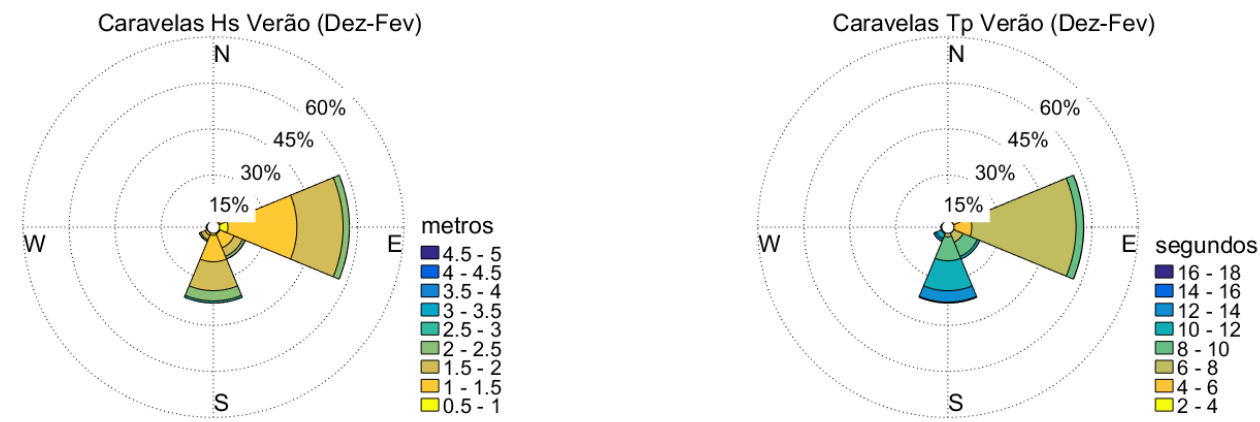

Figura 8: Diagrama direcional de ondas para o período de verão (dez-fev) da série temporal de 13 anos, Caravelas-BA. 
No outono, a mudança nos padrões de ventos e o aumento da influência dos sistemas frontais na geração de ondas que atingem a região se refletem no clima de ondas com um aumento significativo das ondas do quadrante sul, que nesta estação correspondem a mais de $40 \%$ do registro. Outro aspecto importante a se observar é que durante o outono, a predominância de direção de aproximação das ondas se inverte, deixando de ser do quadrante leste, como é observada nas demais estações do ano. A altura das ondas também aumenta e ondas acima de 2,5 m e períodos acima dos $11 \mathrm{~s}$ passam a ser significativas (Figura 9).
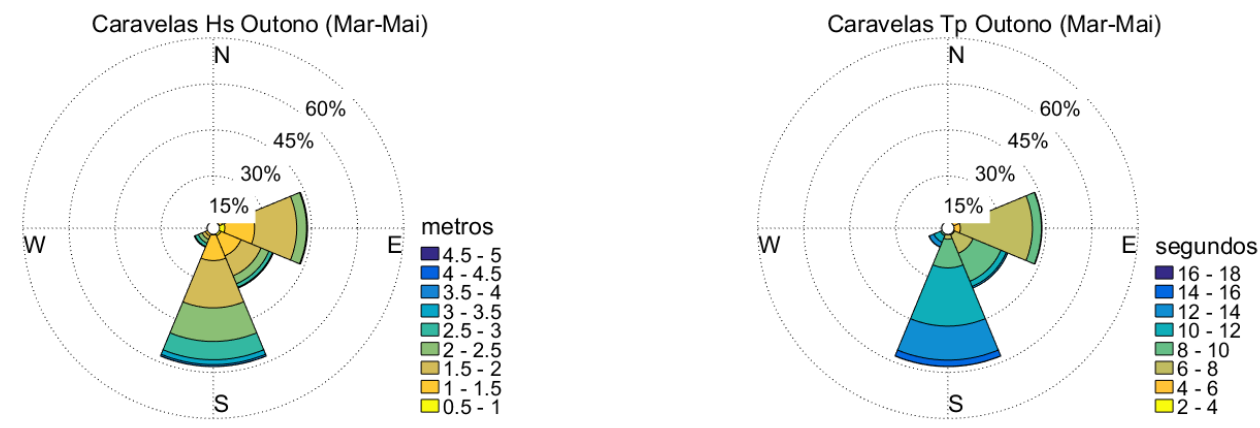

Figura 9: Diagrama direcional de ondas para o período de outono (mar-mai) da série temporal de 13 anos, Caravelas-BA.

\subsubsection{INVERNO}

No inverno a influência das ondas de sul se consolida, com alturas superiores a 2,0 m e períodos acima de 11 segundos, mas a importância das ondas de leste no registro volta a ser significativa (Figura 10). No entanto, períodos acima dos $10 \mathrm{~s}$ (swell) estão concentradas no quadrante sul, indicando sua associação com ondas geradas pelas tempestades do Atlântico Sul. 

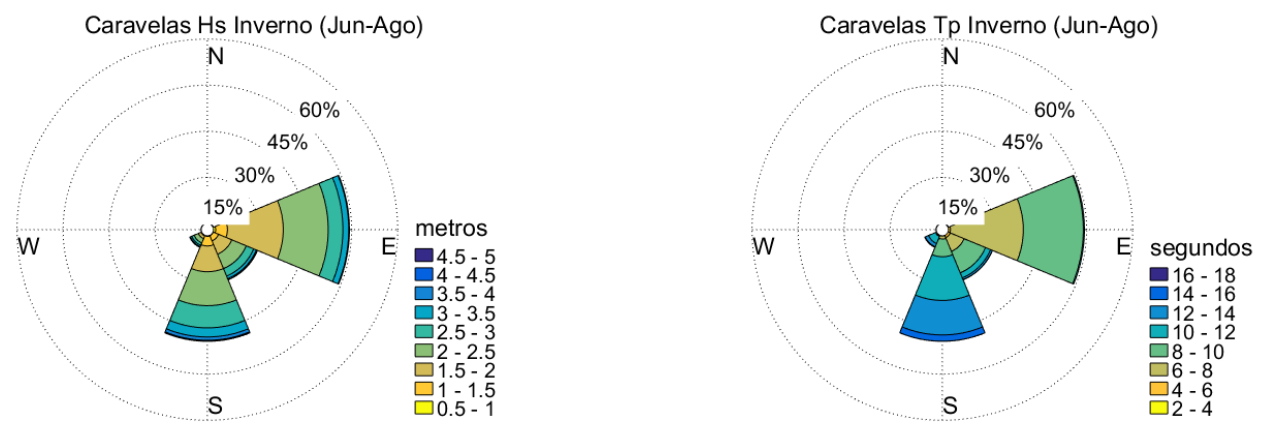

Figura 10: Diagrama direcional de ondas para o período de inverno (jun-ago) da série temporal de 13 anos, Caravelas-BA.

A tabela 4 destaca a variação da altura da onda no registro do modelo WAVEWATCH III do período analisado (1997-2009). Podemos observar a ocorrência de ondas acima de 5 metros na primavera, enquanto que valores mais altos de altura média $(2,2 \mathrm{~m})$ ocorrem no inverno, quando o registro é mais homogêneo. No outono, a passagem de sistemas frontais ocorre com mais frequência deixando o registro mais irregular, com picos de altura e período das ondas (Tabela 5), quando também predominam ondas do quadrante Sul.

Tabela 4: Estatística sazonal de alturas de ondas, na região de Caravelas (BA).

\begin{tabular}{l|llllll}
\hline \multicolumn{7}{|c}{ Caravelas } \\
\hline Período & Hmin (m) & Hmax (m) & Variação (m) & Média (m) & $\begin{array}{l}\text { Desvio } \\
\text { padrão (m) }\end{array}$ & Variância \\
\hline Anual & 0,47 & 4,79 & 4,32 & 1,89 & 0,56 & 0,32 \\
\hline Outono & 0,47 & 4,52 & 4,05 & 1,83 & 0,54 & 0,30 \\
\hline Inverno & 0,55 & 4,79 & 4,24 & 2,20 & 0,59 & 0,35 \\
\hline Primavera & 0,76 & 5,51 & 3,75 & 1,93 & 0,52 & 0,27 \\
\hline Verão & 0,73 & 3,87 & 3,14 & 1,57 & 0,37 & 0,14 \\
\hline
\end{tabular}

Hmin= altura mínima da série temporal de ondas, Hmax=altura máxima da série temporal de ondas.

A direção média de aproximação das ondas caracteriza a importância das ondas de leste e de sul, determinando o predomínio do quadrante sudeste em todo o registro, e 
indicando a baixa representatividade da direção média de aproximação das ondas no clima de ondas (Tabela 6).

Tabela 5: Estatística sazonal dos períodos de ondas, na região de Caravelas (BA).

\begin{tabular}{l|llllll}
\hline \multicolumn{7}{|c}{ Caravelas } \\
\hline Período & Tmin (s) & Tmax (s) & Variação (s) & Média (s) & $\begin{array}{l}\text { Desvio } \\
\text { padrão (s) }\end{array}$ & Variância \\
\hline Anual & 3,15 & 21,40 & 18,25 & 9,10 & 2,40 & 5,80 \\
\hline Outono & 3,27 & 21,40 & 18,13 & 9,67 & 2,45 & 6,02 \\
\hline Inverno & 3,97 & 19,44 & 15,47 & 9,69 & 2,23 & 4,98 \\
\hline Primavera & 3,29 & 18,77 & 15,48 & 8,81 & 2,21 & 4,89 \\
\hline Verão & 3,15 & 19,92 & 16,77 & 8,19 & 2,39 & 5,73 \\
\hline
\end{tabular}

Tmin = período mínimo da série temporal de ondas, Tmax = período máximo da série temporal de ondas.

Tabela 6: Estatística sazonal das direções de aproximação das ondas, na região de Caravelas (BA).

\begin{tabular}{l|ll}
\hline \multicolumn{3}{|c}{ Caravelas } \\
\hline Direção da Onda & Média & Desvio padrão \\
\hline Anual & 134,0 & 52,04 \\
\hline Outono & 150,6 & 47,00 \\
\hline Inverno & 140,1 & 46,48 \\
\hline Primavera & 128,8 & 50,37 \\
\hline Verão & 115,9 & 57,38 \\
\hline
\end{tabular}

\subsection{CLIMA DE ONDAS - ILHÉUS}

Os parâmetros espectrais das ondas, da série temporal de 13 anos (1997 a 2009), obtidos da estação WW3_IOS (Ilhéus), foram analisados estatisticamente, com o objetivo de determinar o clima de ondas atuante na região. A distribuição estatística dos parâmetros espectrais da onda é apresentada nas tabelas a seguir. 


\subsubsection{ESTATÍSTICA ANUAL DE DADOS DE ONDAS DE ILHÉUS}

A distribuição estatística anual do clima de ondas na região de Ilhéus apresenta uma predominância de ondas provenientes do quadrante leste, com alturas variando de 1,0 a 2,0 m e períodos de 6 a 8 s (tabelas 7 e 8).

Tabela 7: Frequência anual (1997-2009) de ocorrência das alturas de ondas por setor de aproximação, na região ao largo de Ilhéus.

\begin{tabular}{l|rrrrrrrr|r}
\hline direção & $\mathbf{N}$ & $\mathbf{N E}$ & $\mathbf{E}$ & $\mathbf{S E}$ & $\mathbf{S}$ & $\mathbf{S W}$ & $\mathbf{W}$ & $\mathbf{N W}$ & $\begin{array}{r}\text { Total } \\
(\boldsymbol{\%})\end{array}$ \\
\hline altura & & & & & & & & & \\
\hline $\mathbf{0 , 5}-\mathbf{1}$ & 0,01 & 0,22 & 2,54 & 0,54 & 0,35 & 0,00 & 0,00 & 0,00 & $\mathbf{3 , 6 5}$ \\
$\mathbf{1}-\mathbf{1 , 5}$ & 0,04 & 2,71 & 22,98 & 5,53 & 4,66 & 0,00 & 0,00 & 0,00 & $\mathbf{3 5 , 9 2}$ \\
$\mathbf{1 , 5}-\mathbf{2}$ & 0,08 & 2,92 & 22,55 & 7,01 & 5,69 & 0,00 & 0,00 & 0,00 & $\mathbf{3 8 , 2 5}$ \\
$\mathbf{2}-\mathbf{2 , 5}$ & 0,02 & 0,39 & 8,03 & 4,27 & 3,10 & 0,00 & 0,00 & 0,00 & $\mathbf{1 5 , 8 2}$ \\
$\mathbf{2 , 5}-\mathbf{3}$ & 0,00 & 0,04 & 1,76 & 1,68 & 1,11 & 0,00 & 0,00 & 0,00 & $\mathbf{4 , 6 0}$ \\
$\mathbf{3 - 3 , 5}$ & 0,00 & 0,00 & 0,55 & 0,48 & 0,44 & 0,00 & 0,00 & 0,00 & $\mathbf{1 , 4 7}$ \\
$\mathbf{3 , 5}-\mathbf{4}$ & 0,00 & 0,00 & 0,12 & 0,06 & 0,06 & 0,00 & 0,00 & 0,00 & $\mathbf{0 , 2 5}$ \\
$\mathbf{4 - 4 , 5}$ & 0,00 & 0,00 & 0,01 & 0,00 & 0,02 & 0,00 & 0,00 & 0,00 & $\mathbf{0 , 0 3}$ \\
$\mathbf{4 , 5}-\mathbf{5}$ & 0,00 & 0,00 & 0,00 & 0,00 & 0,00 & 0,00 & 0,00 & 0,00 & $\mathbf{0 , 0 0}$ \\
\hline Total (\%) & $\mathbf{0 , 1 5}$ & $\mathbf{6 , 2 8}$ & $\mathbf{5 8 , 5 5}$ & $\mathbf{1 9 , 5 9}$ & $\mathbf{1 5 , 4 3}$ & $\mathbf{0 , 0 0}$ & $\mathbf{0 , 0 0}$ & $\mathbf{0 , 0 0}$ & $\mathbf{1 0 0}$ \\
\hline
\end{tabular}

Ondas provenientes dos quadrantes sudeste e sul também são importantes na dinâmica da região, apresentado 19 e $15 \%$ de representatividade no registro, com alturas variando de 1,0 a $2,5 \mathrm{~m}$ e períodos de 7 a $9 \mathrm{~s}$,

A análise do diagrama direcional das ondas atuantes na região (Figura 11), segundo os parâmetros espectrais da onda obtidos do modelo WAVEWATCH III, demonstra a expressiva predominância de ondas do quadrante leste, com quase $60 \%$ do registro, e secundariamente dos setores sudeste e sul na dinâmica da região de Ilhéus. 
Tabela 8: Frequência anual (1997-2009) de ocorrência dos períodos de ondas por setor de aproximação, na região ao largo de Ilhéus,

\begin{tabular}{|c|c|c|c|c|c|c|c|c|c|}
\hline direção & $\mathbf{N}$ & $\mathbf{N E}$ & $\mathbf{E}$ & SE & $\mathbf{S}$ & SW & $\mathbf{W}$ & NW & $\begin{array}{l}\text { Total } \\
(\%)\end{array}$ \\
\hline \multicolumn{10}{|l|}{ período } \\
\hline $1-2 s$ & 0,00 & 0,00 & 0,00 & 0,00 & 0,00 & 0,00 & 0,00 & 0,00 & $\mathbf{0 , 0 0}$ \\
\hline $2-3 s$ & 0,00 & 0,00 & 0,00 & 0,00 & 0,00 & 0,00 & 0,00 & 0,00 & 0,00 \\
\hline $3-4 s$ & 0,01 & 0,06 & 0,01 & 0,02 & 0,00 & 0,00 & 0,00 & 0,00 & 0,09 \\
\hline $4-5 s$ & 0,04 & 1,45 & 0,33 & 0,18 & 0,04 & 0,00 & 0,00 & 0,00 & 2,04 \\
\hline $5-6 s$ & 0,07 & 3,46 & 4,07 & 1,07 & 0,41 & 0,00 & 0,00 & 0,00 & 9,08 \\
\hline $6-7 s$ & 0,02 & 1,25 & 20,37 & 2,83 & 0,75 & 0,00 & 0,00 & 0,00 & 25,21 \\
\hline $7-8 s$ & 0,00 & 0,03 & 22,46 & 5,34 & 0,54 & 0,00 & 0,00 & 0,00 & 28,37 \\
\hline $8-9 s$ & 0,00 & 0,00 & 9,12 & 5,27 & 0,64 & 0,00 & 0,00 & 0,00 & 15,03 \\
\hline $9-10 s$ & 0,00 & 0,01 & 1,80 & 3,03 & 1,88 & 0,00 & 0,00 & 0,00 & 6,73 \\
\hline $10-11 s$ & 0,00 & 0,02 & 0,39 & 1,03 & 2,47 & 0,00 & 0,00 & 0,00 & 3,91 \\
\hline $11-12 s$ & 0,00 & 0,00 & 0,00 & 0,36 & 2,88 & 0,00 & 0,00 & 0,00 & 3,23 \\
\hline $12-13 s$ & 0,01 & 0,00 & 0,00 & 0,31 & 2,75 & 0,00 & 0,00 & 0,00 & 3,07 \\
\hline $13-14 s$ & 0,01 & 0,00 & 0,00 & 0,13 & 2,01 & 0,00 & 0,00 & 0,00 & 2,16 \\
\hline $14-15 s$ & 0,00 & 0,00 & 0,00 & 0,03 & 0,75 & 0,00 & 0,00 & 0,00 & 0,77 \\
\hline 15 - 16s & 0,00 & 0,00 & 0,00 & 0,00 & 0,24 & 0,00 & 0,00 & 0,00 & 0,24 \\
\hline $16-17 s$ & 0,00 & 0,00 & 0,00 & 0,00 & 0,06 & 0,00 & 0,00 & 0,00 & 0,06 \\
\hline $17-18 s$ & 0,00 & 0,00 & 0,00 & 0,00 & 0,01 & 0,00 & 0,00 & 0,00 & 0,01 \\
\hline Total (\%) & 0,15 & 6,28 & 58,55 & 19,59 & 15,43 & 0,00 & 0,00 & 0,00 & 100 \\
\hline
\end{tabular}
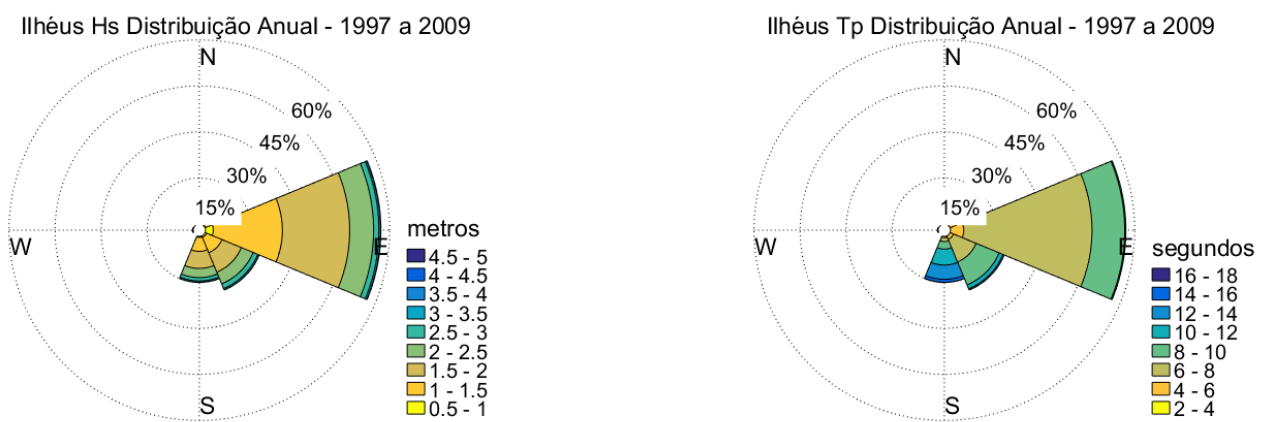

Figura 11: Distribuição anual (1997-2009) das alturas e períodos de ondas por quadrante de aproximação, na região de Ilhéus (BA). 


\subsubsection{ESTATÍSTICA SAZONAL DE DADOS DE ONDAS DE ILHÉUS}

A distribuição da frequência de ocorrência dos parâmetros espectrais das ondas, obtidos do modelo WAVEWATCH III para a estação WW3_IOS (Ilhéus), também foi analisada sazonalmente. Em Ilhéus, a predominância de ondas de leste é constante em todas as estações, no entanto, a ocorrência de ondas de sudeste e secundariamente de sul, se torna mais significativa durante o outono e a primavera.

Os diagramas direcionais da distribuição estatística dos parâmetros espectrais das ondas por estação do ano, para a região de Ilhéus, são apresentados nas Figuras 12 a 15.

\subsubsection{PRIMAVERA}

Durante a primavera, as ondas predominantes são provenientes do quadrante leste, representando $57 \%$ do registro, apresentando alturas de 1,0 a 2,0 m e períodos de 6 a $10 \mathrm{~s}$. As ondas de nordeste representam $8 \%$ do registro e as provenientes do quadrante sudeste $20 \%$ do registro, enquanto as provenientes de sul representam $13 \%$ do registro e destas, $10 \%$ são representativas de ondas de swell, com períodos acima de $10 \mathrm{~s}$ (Figura 12).
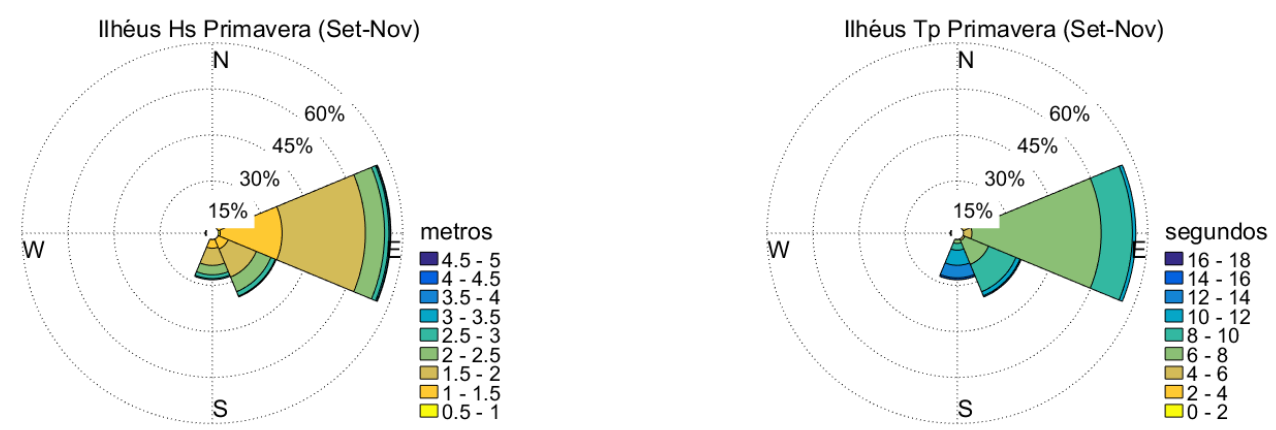

Figura 12: Diagrama direcional de ondas para o período de primavera (set-nov) da série temporal de 13 anos, Ilhéus-BA. 
No verão, as ondas de leste representam $66 \%$ do registro, sendo $42 \%$ com alturas entre 1,0 e $1,5 \mathrm{~m}$ e períodos de 6 a $8 \mathrm{~s}$. As ondas provenientes do quadrante nordeste passam a ser mais representativas, totalizando $15 \%$ das ondas. O verão é a única estação do ano em que as ondas de nordeste representam mais de 10\% do registro de dados (Figura 13).
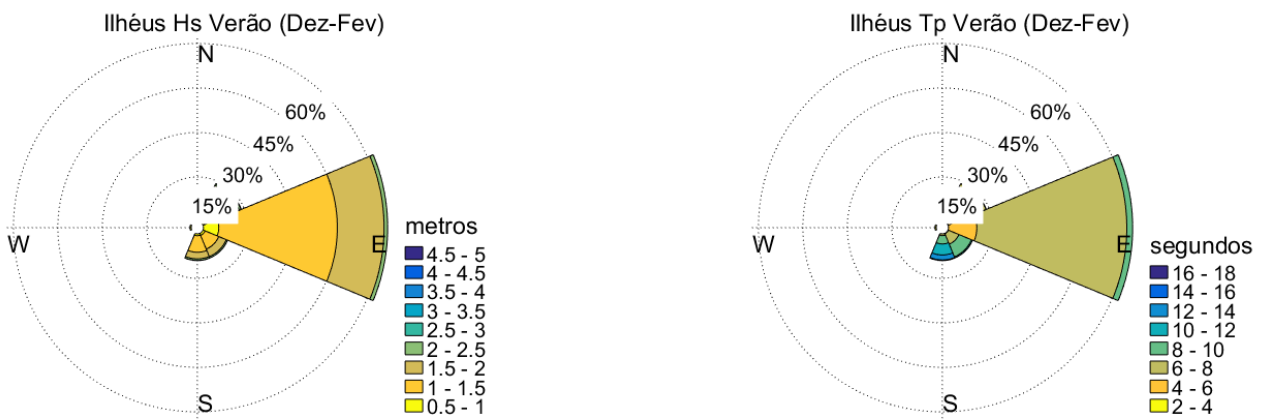

Figura 13: Diagrama direcional de ondas para o período de verão (dez-fev) da série temporal de 13 anos, Ilhéus-BA.

\subsubsection{OUTONO}

O outono é a estação do ano em que as características das ondas apresentam um padrão mais heterogêneo, com $47 \%$ do registro representado por ondas de leste, $26 \%$ por ondas de sudeste, $25 \%$ por ondas de sul e $2 \%$ por ondas de nordeste. As alturas mais frequentes estão entre 1,0 e 2,0 m e os períodos entre 4 e $8 \mathrm{~s}$. As ondas de swell estão representadas no registro pelas ondas de sul, com períodos superiores a $10 \mathrm{~s}$ (Figura 14). 

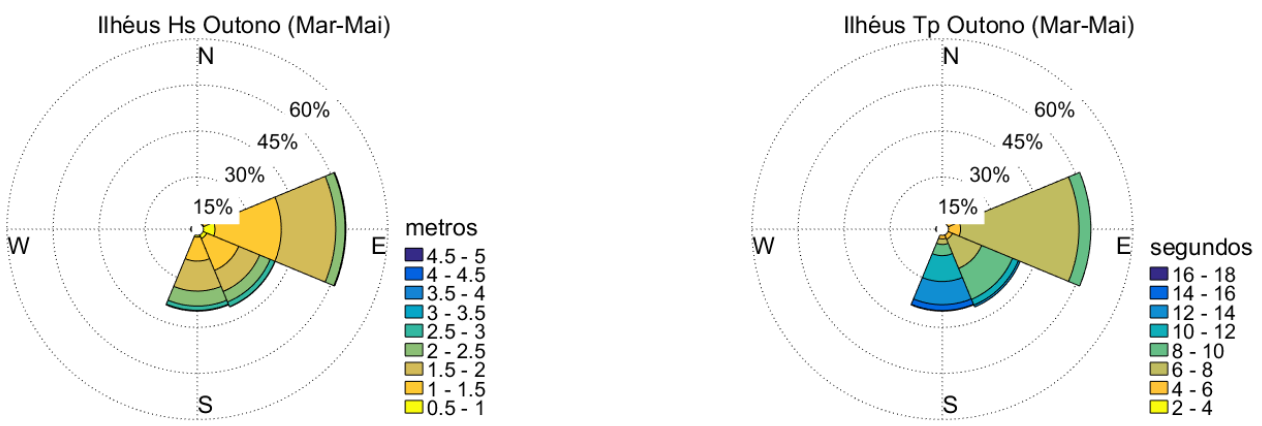

Figura 14: Diagrama direcional de ondas para o período de outono (mar-mai) da série temporal de 13 anos, Ilhéus-BA.

\subsubsection{INVERNO}

O inverno é a estação do ano caracterizada pela ocorrência de ondas mais altas, entre 2,5 e 3,0 m, representando $15 \%$ das ondas incidentes. Os períodos acima de $10 \mathrm{~s}$ estão associados a ondas provenientes do quadrante sul (Figura 15).
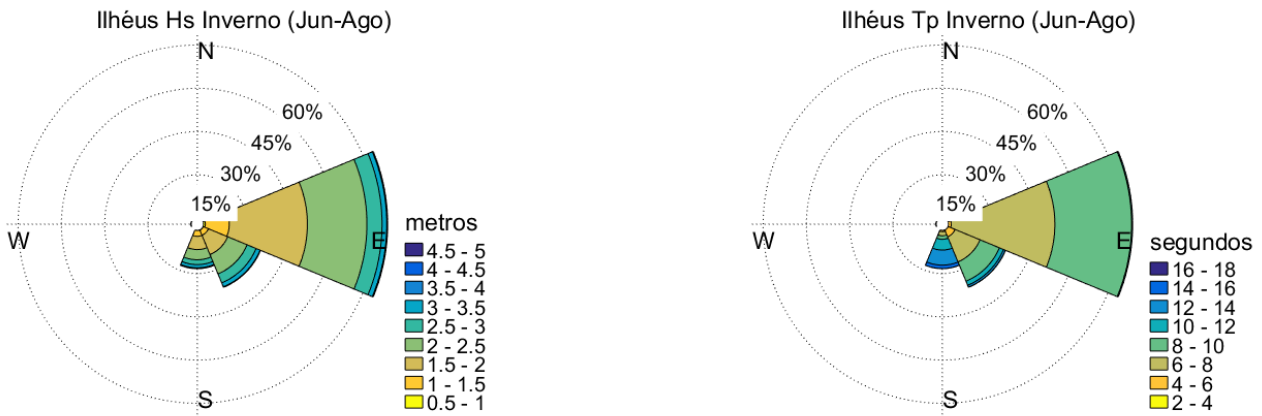

Figura 15: Diagrama direcional de ondas para o período de inverno (jun/ago) da série temporal de13 anos, Ilhéus - BA. 
A Tabela 9 apresenta a análise do registro de ondas para a região de Ilhéus, com destaque para ondas com mais de $4 \mathrm{~m}$ de altura significativa, sendo as estações mais energéticas a primavera e o inverno. No outono, a passagem de sistemas frontais altera a energia das ondas de maior período, indicando a influência das ondas de swell nessa estação (Tabela 10). Apesar disso, na costa de Ilhéus predominam as ondas de leste, a exceção do outono, quando as ondas de sudeste e sul tem frequência significativa (Tabela 11).

Tabela 9: Estatística sazonal de alturas de ondas, na região de Ilhéus.

\begin{tabular}{l|llllll}
\hline \multicolumn{7}{c}{ Ilhéus } \\
\hline Período & Hmin (m) & Hmax (m) & Variação (m) & Média (m) & $\begin{array}{l}\text { Desvio } \\
\text { Padrão (m) }\end{array}$ & Variância \\
\hline Anual & 0,64 & 4,5 & 3,86 & 1,72 & 0,49 & 0,25 \\
\hline Outono & 0,69 & 3,7 & 3,01 & 1,59 & 0,44 & 0,20 \\
\hline Inverno & 0,64 & 4,5 & 3,86 & 2,05 & 0,51 & 0,27 \\
\hline Primavera & 0,85 & 4,3 & 3,48 & 1,79 & 0,45 & 0,21 \\
\hline Verão & 0,68 & 3,0 & 2,3 & 1,42 & 0,29 & 0,09 \\
\hline
\end{tabular}

Hmin = altura mínima da série temporal de ondas, Hmax = altura máxima da série temporal de ondas.

Tabela 10: Estatística sazonal dos períodos de ondas, na região de Ilhéus.

\begin{tabular}{l|llllll}
\hline \multirow{2}{*}{ Período } & Tmin (s) & Tmax (s) & Variação (s) & Média (s) & $\begin{array}{l}\text { Desvio } \\
\text { Padrão (s) }\end{array}$ & Variância \\
& & & & & 2,10 & 4,42 \\
\hline Anual & 3,17 & 19,60 & 16,43 & 8,14 & 2,42 & 5,86 \\
\hline Outono & 3,24 & 17,77 & 14,53 & 8,63 & 1,94 & 3,78 \\
\hline Inverno & 3,17 & 19,60 & 16,43 & 8,60 & 1,87 & 3,50 \\
\hline Primavera & 3,56 & 17,82 & 14,26 & 8,10 & 1,79 & 3,22 \\
\hline Verão & 3,30 & 17,75 & 14,45 & 7,21 & & \\
\hline
\end{tabular}

Tmin = período mínimo da série temporal de ondas, Tmax = período máximo da série temporal de ondas. 
Tabela 11: Estatística sazonal das direções de aproximação das ondas, na região de Ilhéus.

\begin{tabular}{l|ll}
\hline \multicolumn{2}{c}{ llhéus } \\
\hline Direção da Onda & Média & Desvio Padrão \\
\hline Anual & 114,4 & 35,3 \\
\hline Outono & 128,5 & 35,5 \\
\hline Inverno & 116,5 & 30,6 \\
\hline Primavera & 111,7 & 34,5 \\
\hline Verão & 100,6 & 34,9 \\
\hline
\end{tabular}

\subsection{POTÊNCIA DA ONDA}

Alturas de onda com frequência de ocorrência superior a 5\% foram utilizadas para calcular a sinergia entre altura e período da onda através da quantificação da potência da onda. As ondas utilizadas neste cálculo correspondem a cerca de $80 \%$ da totalidade das ondas atuantes em Ilhéus e cerca de $70 \%$ do clima de ondas em Caravelas. A potência da onda $\mathrm{P}$ (wave power) foi calculada através da equação, extrapolada a partir da Teoria da Onda de Airy:

$$
P=\frac{\rho g^{2} H s^{2} T}{32 \pi}
$$

onde $\rho$ corresponde à densidade da água $\left(1,027 \mathrm{~kg} \cdot \mathrm{m}^{-3}\right)$, g é a aceleração da gravidade $\left(9,81 \mathrm{~m} . \mathrm{s}^{-2}\right)$, Hs a altura significativa da onda $(\mathrm{m})$ e T o período da onda (s). P é dado em $\mathrm{kW} \cdot \mathrm{m}^{-1}$. As tabelas 12 e 13 apresentam os parâmetros espectrais da onda e a potência da onda na região oceânica do sul da Bahia.

O cálculo da potência da onda para as ondas mais frequentes, atuantes nas plataformas continentais de Caravelas e Ilhéus foi utilizado na identificação dos períodos mais e menos energéticos. Na plataforma de Caravelas, o período de inverno é o mais energético, com a potência da onda elevada durante toda a estação, estando o valor 
máximo associado às ondas do quadrante sul, com altura significativa $2,71 \mathrm{~m}$ e período correspondente de $11,64 \mathrm{~s}\left(\mathrm{P}=8,40 \times 10^{4} \mathrm{~kW} \cdot \mathrm{m}^{-1}\right)$, enquanto que o período menos energético corresponde ao verão, com valor mínimo associado às ondas de leste, com altura significativa de 1,28 m e período de 6,63 s $\left(\mathrm{P}=1,07 \times 10^{4} \mathrm{~kW} \cdot \mathrm{m}^{-1}\right)$. Em Ilhéus, ondas do quadrante leste, atuantes durante as estações de inverno e de verão correspondem às mais e menos energéticas, respectivamente. Os valores máximos da potência da onda estão associados às ondas de leste com altura significativa de 2,69 m e período de $8,54 \mathrm{~s}\left(\mathrm{P}=6,08 \times 10^{4} \mathrm{~kW} \cdot \mathrm{m}^{-1}\right)$, que atuam no período de inverno, enquanto que os menores valores ocorrem no verão, associados a ondas com altura significativa de $0,91 \mathrm{~m}$ e período de $6,19 \mathrm{~s}\left(\mathrm{P}=5,04 \times 10^{3} \mathrm{~kW} \cdot \mathrm{m}^{-1}\right)$.

Tabela 12: Distribuição sazonal dos parâmetros estatísticos das ondas modeladas na estação WW3_CRV, com frequência de ocorrência superior a 5\%, e valores calculados da sua potência P $\left(\mathrm{kW} \cdot \mathrm{m}^{-1}\right)$.

\begin{tabular}{|c|c|c|c|c|c|c|c|c|c|c|c|c|c|}
\hline \multicolumn{7}{|c|}{ Primavera } & \multicolumn{7}{|c|}{ Verão } \\
\hline & Hs (m) & $\%$ & Ts (s) & $P(\mathrm{~kW} / \mathrm{m})$ & Dir & Dir_med & & Hs (m) & $\%$ & Ts (s) & $P(k W / m)$ & Dir & Dir_med \\
\hline Caso 1: & 1,71 & 19,14 & 7,33 & $2,11 E+04$ & $E$ & 91,10 & Caso 1: & 1,28 & 23,70 & 6,63 & $1,07 E+04$ & $E$ & 88,84 \\
\hline Caso 2: & 1,32 & 11,61 & 6,87 & $1,18 \mathrm{E}+04$ & $E$ & 89,30 & Caso 2: & 1,69 & 15,96 & 6,89 & $1,93 E+04$ & $E$ & 89,45 \\
\hline Caso 3: & 1,75 & 10,77 & 10,87 & $3,27 E+04$ & $S$ & 184,53 & Caso 3: & 1,72 & 9,98 & 10,67 & $3,10 E+04$ & $S$ & 187,98 \\
\hline Caso 4: & 2,22 & 8,65 & 10,89 & $5,28 \mathrm{E}+04$ & $S$ & 183,55 & Caso 4: & 1,32 & 9,10 & 10,04 & $1,72 E+04$ & $S$ & 184,1 \\
\hline Caso 5: & 1,74 & 7,52 & 8,54 & $2,54 \mathrm{E}+04$ & SE & 135,86 & Caso 5: & 1,70 & 5,70 & 5,89 & $1,67 E+04$ & $\mathrm{NE}$ & 43,32 \\
\hline Caso 6: & 2,19 & 6,06 & 8,09 & $3,81 E+04$ & $E$ & 95,28 & Caso 6: & 1,26 & 5,23 & 8,17 & $1,28 E+04$ & SE & 132,02 \\
\hline Caso 7: & 2,22 & 5,74 & 8,33 & $4,04 \mathrm{E}+04$ & SE & 135,04 & Caso 7: & - & - & - & - & - & - \\
\hline $\boldsymbol{\Sigma} \%$ & --------- & 69,49 & --------- & --------- & --------- & --------- & $\boldsymbol{\Sigma} \%$ & --------- & 69,67 & --------- & --------- & ---------- & --------- \\
\hline \multicolumn{7}{|c|}{ Outono } & \multicolumn{7}{|c|}{ Inverno } \\
\hline & Hs (m) & $\%$ & Ts (s) & $P(\mathrm{~kW} / \mathrm{m})$ & Dir & Dir_med & & Hs (m) & $\%$ & Ts (s) & $P(\mathrm{~kW} / \mathrm{m})$ & Dir & Dir_med \\
\hline Caso 1: & 1,76 & 15,61 & 11,11 & $3,38 \mathrm{E}+04$ & $S$ & 185,45 & Caso 1: & 1,76 & 18,38 & 7,75 & $2,36 E+04$ & $E$ & 91,29 \\
\hline Caso 2: & 1,70 & 13,91 & 7,18 & $2,04 \mathrm{E}+04$ & $E$ & 93,17 & Caso 2: & 2,21 & 14,84 & 8,06 & $3,87 E+04$ & $E$ & 92,84 \\
\hline Caso 3: & 2,22 & 11,13 & 11,34 & $5,49 \mathrm{E}+04$ & $S$ & 186,68 & Caso 3: & 2,24 & 11,13 & 11,51 & $5,68 \mathrm{E}+04$ & $S$ & 188,54 \\
\hline Caso 4: & 1,30 & 9,71 & 7,08 & $1,18 \mathrm{E}+04$ & $E$ & 92,46 & Caso 4: & 1,77 & 8,46 & 10,93 & $3,37 E+04$ & $S$ & 187,16 \\
\hline Caso 5: & 1,30 & 8,38 & 10,36 & $1,72 E+04$ & $\mathrm{~S}$ & 181,63 & Caso 5: & 2,71 & 7,32 & 11,64 & $8,40 E+04$ & $S$ & 188,08 \\
\hline Caso 6: & 1,27 & 7,16 & 8,29 & $1,31 E+04$ & SE & 133,47 & Caso 6: & 2,23 & 5,13 & 8,89 & $4,35 E+04$ & SE & 135,81 \\
\hline Caso 7: & 1,70 & 7,12 & 8,56 & $2,43 E+04$ & SE & 136,11 & Caso 7: & - & - & - & - & - & - \\
\hline Caso 8: & 2,71 & 6,04 & 11,51 & $8,31 \mathrm{E}+04$ & $\mathrm{~S}$ & 186,3 & Caso 8: & - & - & - & - & - & - \\
\hline $\boldsymbol{\Sigma} \%$ & --------- & 79,06 & -------- & -------- & -------- & ------- & $\boldsymbol{\Sigma} \%$ & -------- & 65,26 & -------- & -------- & --------- & -------- \\
\hline
\end{tabular}

*Hs corresponde à altura significativa da onda e \% sua frequência de ocorrência, Ts é o período médio da onda para cada intervalo de altura considerado, Dir é o quadrante de aproximação da onda e Dir_med o ângulo médio de aproximação das ondas do respectivo quadrante. $\mathrm{P}$ corresponde à potência da onda (wave power) dada em kW.m-1. 
Tabela 13: Distribuição sazonal dos parâmetros estatísticos das ondas modeladas na estação WW3_IOS, com frequência de ocorrência superior a 5\%, e valores calculados da potência da onda $\mathrm{P}\left(\mathrm{kW} \cdot \mathrm{m}^{-1}\right)$.

\begin{tabular}{|c|c|c|c|c|c|c|c|c|c|c|c|c|c|}
\hline \multicolumn{7}{|c|}{ Primavera } & \multicolumn{7}{|c|}{ Verão } \\
\hline & $\mathrm{Hs}(\mathrm{m})$ & $\%$ & Ts (s) & $P(\mathrm{~kW} / \mathrm{m})$ & Dir & Dir_med & & Hs (m) & $\%$ & Ts (s) & $\mathrm{P}(\mathrm{kW} / \mathrm{m})$ & Dir & Dir_med \\
\hline Caso 1: & 1,70 & 27,89 & 7,39 & $2,10 E+04$ & $\mathrm{E}$ & 94,71 & Caso 1: & 1,27 & 42,22 & 6,54 & $2,03 E+03$ & $\mathrm{E}$ & 92,42 \\
\hline Caso 2: & 1,34 & 20,41 & 6,83 & $1,21 E+04$ & $E$ & 92,29 & Caso 2: & 1,66 & 16,82 & 6,94 & $3,47 E+03$ & $E$ & 94,5 \\
\hline Caso 3: & 1,72 & 10,18 & 8,33 & $2,42 E+04$ & SE & 132,23 & Caso 3: & 1,28 & 6,90 & 5,15 & $2,06 E+03$ & $\mathrm{NE}$ & 50,51 \\
\hline Caso 4: & 2,18 & 6,40 & 8,08 & $3,78 E+04$ & $E$ & 99,12 & Caso 4: & 1,70 & 6,58 & 5,76 & $3,64 E+03$ & NE & 47,38 \\
\hline Caso 5: & 1,74 & 5,71 & 11,39 & $3,39 E+04$ & $S$ & 177,39 & Caso 5: & 1,27 & 5,92 & 10,90 & $2,03 E+03$ & $S$ & 179,67 \\
\hline Caso 6: & 2,22 & 5,27 & 8,04 & $3,90 E+04$ & SE & 134,87 & Caso 6: & 0,91 & 5,33 & 6,19 & $1,04 E+03$ & $E$ & 93,85 \\
\hline Caso 7: & - & - & - & - & - & - & Caso 7: & 1,23 & 5,29 & 8,11 & $1,91 \mathrm{E}+03$ & SE & 130,72 \\
\hline $\boldsymbol{\Sigma} \%$ & --------- & 75,86 & --------- & --------- & ---------- & ---------- & $\boldsymbol{\Sigma} \%$ & ---------- & 89,06 & --------- & ---------- & ---------- & --------- \\
\hline \multicolumn{7}{|c|}{ Outono } & \multicolumn{7}{|c|}{ Inverno } \\
\hline & Hs (m) & $\%$ & Ts (s) & $\mathrm{P}(\mathrm{kW} / \mathrm{m})$ & Dir & Dir_med & & Hs (m) & $\%$ & Ts (s) & $P(\mathrm{~kW} / \mathrm{m})$ & Dir & Dir_med \\
\hline Caso 1: & 1,28 & 21,78 & 6,89 & $1,11 \mathrm{E}+04$ & $\mathrm{E}$ & 97,81 & Caso 1: & 1,76 & 27,35 & 7,75 & $2,36 \mathrm{E}+04$ & $\mathrm{E}$ & 96,86 \\
\hline Caso 2: & 1,70 & 17,96 & 7,24 & $2,06 E+04$ & $\mathrm{E}$ & 99,41 & Caso 2: & 2,21 & 20,94 & 8,08 & $3,88 \mathrm{E}+04$ & $E$ & 97,23 \\
\hline Caso 3: & 1,25 & 11,35 & 8,21 & $1,26 E+04$ & SE & 132,89 & Caso 3: & 1,32 & 8,33 & 7,05 & $1,21 E+04$ & $E$ & 94,18 \\
\hline Caso 4: & 1,72 & 9,86 & 11,40 & $3,32 E+04$ & $S$ & 178,35 & Caso 4: & 2,22 & 7,36 & 8,03 & $3,89 E+04$ & SE & 132,1 \\
\hline Caso 5: & 1,30 & 7,87 & 11,28 & $1,87 \mathrm{E}+04$ & $S$ & 177,5 & Caso 5: & 1,76 & 7,31 & 7,83 & $2,38 \mathrm{E}+04$ & SE & 129,19 \\
\hline Caso 6: & 1,71 & 7,54 & 8,19 & $2,35 E+04$ & SE & 136,04 & Caso 6: & 2,69 & 5,31 & 8,54 & $6,08 \mathrm{E}+04$ & $E$ & 100,69 \\
\hline Caso 7: & 2,20 & 5,01 & 10,81 & $5,14 \mathrm{E}+04$ & $S$ & 173,87 & Caso 7: & - & - & - & - & - & - \\
\hline $\boldsymbol{\Sigma} \%$ & ---------- & 81,37 & ---------- & |--------- & ---------- & --------- & $\boldsymbol{\Sigma}$ \% & --------- & 76,60 & ---------- & --------- & --------- & --------- \\
\hline
\end{tabular}

*Hs corresponde à altura significativa da onda e \% sua frequência de ocorrência, Ts é o período médio da onda para cada intervalo de altura considerado, Dir é o quadrante de aproximação da onda e Dir_med o ângulo médio de aproximação das ondas do respectivo quadrante. $\mathrm{P}$ corresponde à potência da onda (wave power) dada em kW.m-1.

\subsection{ANÁLISE COMPARATIVA DAS ESTAÇÕES WW3_IOS (ILHÉUS) E WW3_CRV (CARAVELAS)}

Os parâmetros espectrais das ondas gerados pelo modelo WAVEWATCH III a paretir da reanálise de informações de ventos foram obtidos em duas estações oceânicas, onde a influência da batimetria da margem continental é minimizada. Os pontos de aquisição dos parâmetros de onda distam cerca de $350 \mathrm{~km}$ entre si, no entanto, o padrão das ondas que atuam em cada ponto é diferenciado. Em Ilhéus, predominam as ondas de leste, enquanto que em Caravelas, a influência das ondas de sul é mais expressiva, principalmente no outono.

A plataforma continental leste brasileira está sujeita a ondas baixas provenientes de leste durante o verão e ondas mais altas provenientes dos quadrantes sul e sudeste durante o inverno. O litoral de Ilhéus está exposto às ondas de nordeste e leste, enquanto que 
Caravelas se encontra protegida pelos recifes de coral do Banco de Abrolhos, gerando uma região com alturas de onda inferiores a $0,5 \mathrm{~m}$.

Quanto à variabilidade das ondas, o diagrama de dispersão dos parâmetros de onda (sazonal) demonstra um maior espalhamento na região de Caravelas, onde os períodos apresentam variação maior, enquanto que em Ilhéus o gráfico é mais concentrado em períodos que variam de 4 a $10 \mathrm{~s}$ (Figuras 16 a 19). Este aspecto pode ser observado através da presença de um percentual elevado de ondas com períodos superiores a $10 \mathrm{~s}$ em todos os diagramas de dispersão na estação de aquisição de informações localizada a frente de Caravelas, enquanto que em Ilhéus, essa representatividade é reduzida.
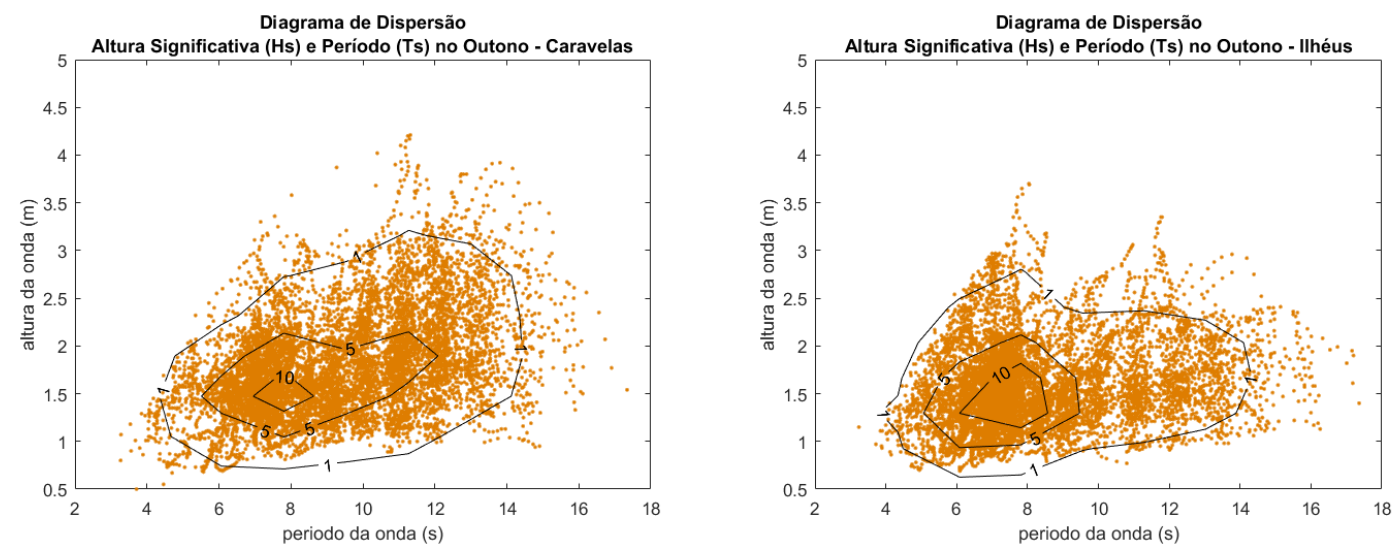

Figura 16: Comparação entre os diagramas de dispersão dos parâmetros de ondas (altura significativa e período) no outono, entre as estações de Caravelas e Ilhéus.
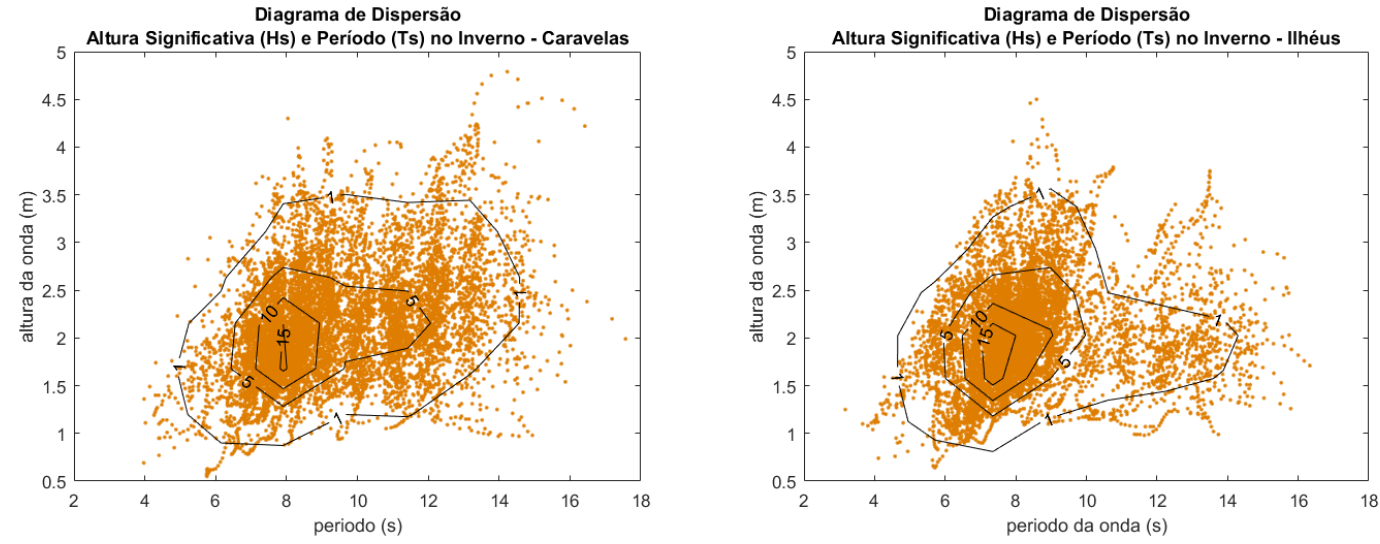

Figura 17: Comparação entre os diagramas de dispersão dos parâmetros de ondas (altura significativa e período) no inverno, entre as estações de Ilhéus e Caravelas. 

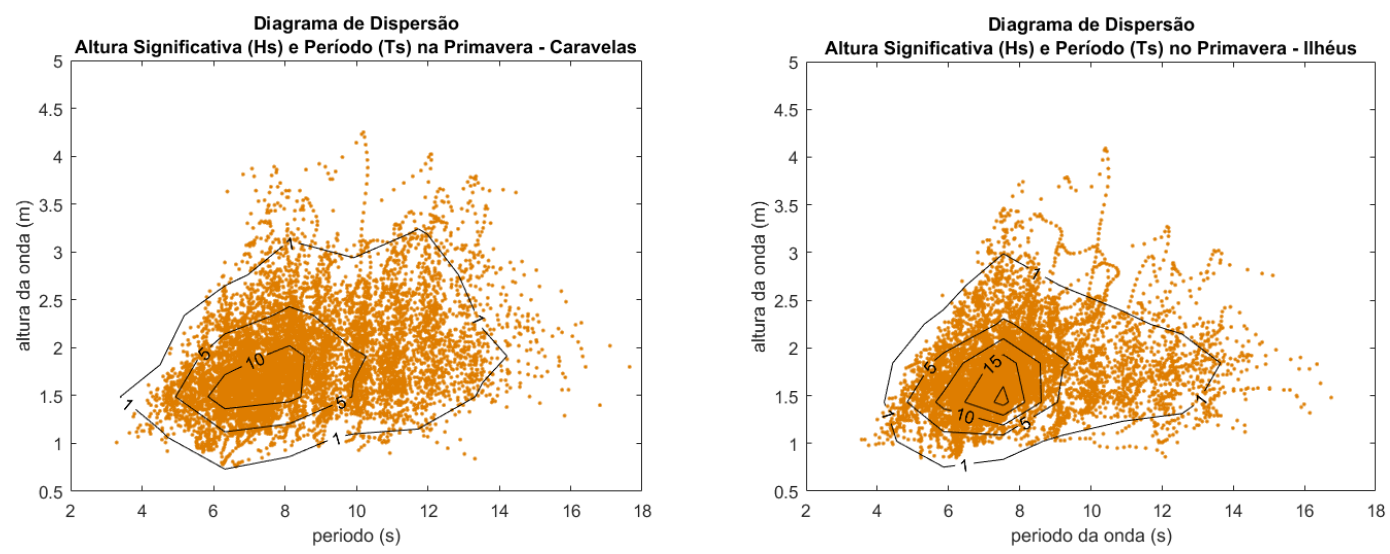

Figura 18: Comparação entre os diagramas de dispersão dos parâmetros de ondas (altura significativa e período) na primavera, entre as estações de Ilhéus e Caravelas.
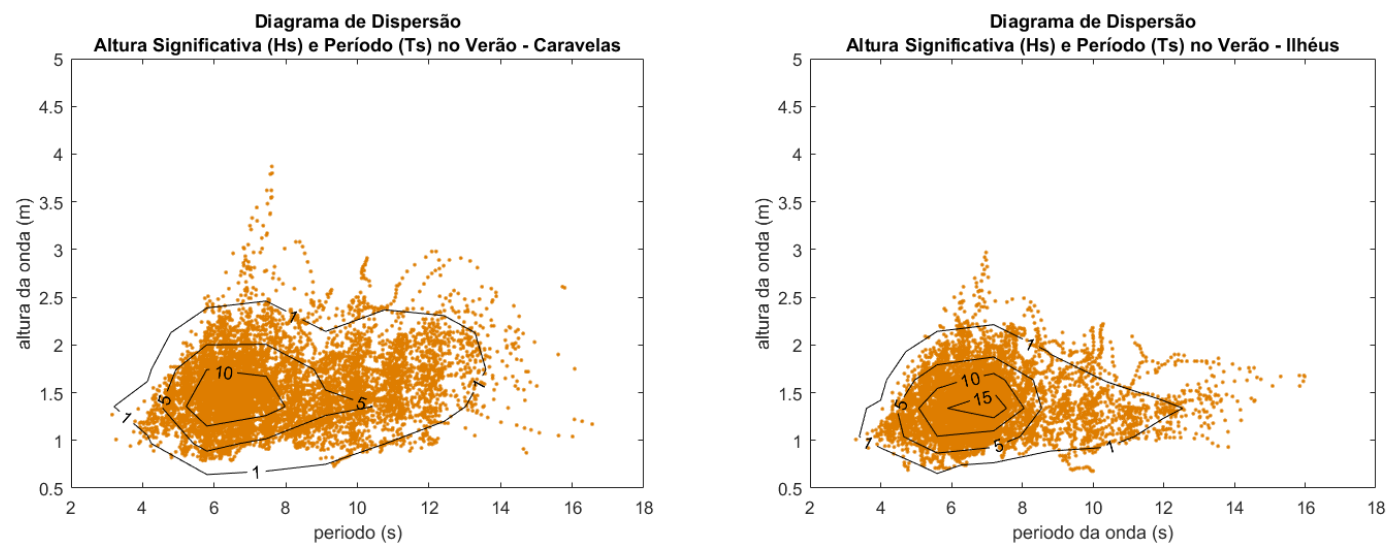

Figura 19: Comparação entre os diagramas de dispersão dos parâmetros de ondas (altura significativa e período) no verão, entre as estações de Ilhéus e Caravelas.

Esta variabilidade está provavelmente relacionada à influência do Anticiclone do Atlântico Sul e da entrada de sistemas frontais na região de Caravelas, ponto de aquisição localizado mais a sul, e à proteção que o Banco de Abrolhos proporciona à propagação de ondas de swell para a região de Ilhéus. 


\subsection{INFLUENNCIA DA DESCONTINUIDADE NA LARGURA DA PLATAFORMA LESTE BRASILEIRA NO CLIMA DE ONDAS}

A Plataforma Continental Leste Brasileira apresenta um geomorfologia complexa, variando de um setor estreito, com cerca de $9 \mathrm{~km}$ de largura, e gradiente batimétrico aproximadamente paralelo à linha de costa em frente a Ilhéus (BA), para um setor largo, atingindo $240 \mathrm{~km}$ em frente Caravelas (BA) onde o padrão batimétrico é irregular, caracterizado pela presença da mais importante formação recifal do Atlântico Sul, o Banco de Abrolhos. Outro aspecto importante é que este alargamento não se dá de forma contínua, mas intercalado com trechos de menor dimensão, partindo de cerca de $10 \mathrm{~km}$ em frente a Ilhéus, alargando até $100 \mathrm{~km}$ em frente a Belmonte, formando o Banco Royal Charlotte, sofrendo outro estreitamento até cerca de $50 \mathrm{~km}$ de largura, para atingir sua largura máxima em frente a Caravelas, sobre o Banco de Abrolhos (Figura 20).

Essa variabilidade na largura da plataforma pode ter influência no padrão de ondas, atenuando ondas do quadrante sul que atingem a região a norte da formação. Com o objetivo de verificar a influência do Banco de Abrolhos no clima de ondas na região de Ilhéus foi realizada a aquisição de parâmetros da onda em estação do modelo WAVEWATCH III, na mesma longitude do ponto de aquisição de Caravelas (WW3CRV) e na mesma latitude do ponto de aquisição em frente a Ilhéus (WW3-IOS) para avaliar se a diferença no padrão de ondas se deve apenas a uma variação latitudinal, mudando a influência relativa da Zona de Convergência do Atlântico Sul e dos Ventos Alíseos em relação à influência do anticiclone do Atlântico Sul e do avanço de sistemas frontais, ou se a variabilidade tem relação com a atenuação das ondas de swell, provenientes principalmente do quadrante sul, no clima de ondas da região de Ilhéus.

A influência da descontinuidade da plataforma continental no clima de ondas, afastado da costa em Ilhéus e Caravelas, pôde ser determinada através da análise estatística de uma série temporal de ondas modeladas para a região. Informações de altura significativa das ondas (Hs), período de pico (Tp) e direção média de aproximação das ondas (Dir_med) foram obtidas do modelo WAVEWATCH III, que é processado através da reanálise de dados de vento do National Center for Environment Prediction 
(NCEP) do National Oceanic and Atmospheric Administration (NOAA) dos Estados Unidos.

Três pontos de aquisição de informações de ondas foram utilizados para a comparação: WW3-IOS em frente a Ilhéus $\left(15^{\circ} \mathrm{S}, 37,5^{\circ} \mathrm{W}\right)$, WW3-CRV em frente a Caravelas $\left(18^{\circ} \mathrm{S}\right.$, $\left.36,5^{\circ} \mathrm{W}\right)$ e o ponto WW3-IOSoff fora da influência do Banco de Abrolhos, em frente a Ilhéus $\left(15^{\circ} \mathrm{S}, 36,5^{\circ} \mathrm{W}\right)$. Uma série temporal de 30 anos (1979 - 2009) de informações de ondas dos pontos WW3-IOS, WW3-CRV e WW3-IOSoff foi utilizada para a comparação entre os climas de ondas em Ilhéus e Caravelas, fora da influência do Banco de Abrolhos (Figura 20).

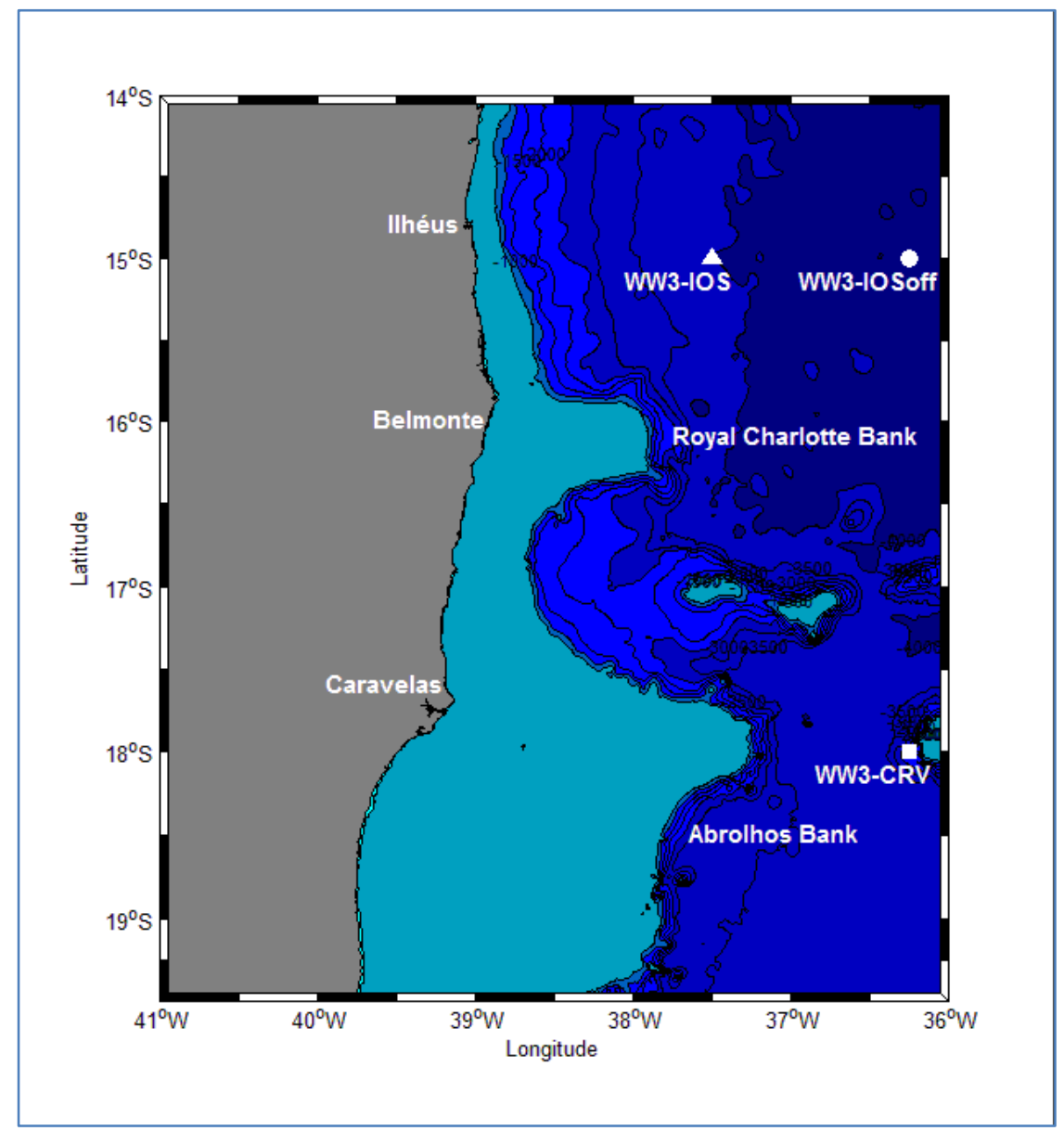

Figura 20: Morfologia da Plataforma Continental Leste Brasileira. Os pontos identificados pelos prefixos WW3 representam as estações de aquisição dos parâmetros das ondas do modelo WAVEWATCH III.

Diagramas direcionais de ondas indicaram que em Ilhéus (WW3-IOS) cerca de 60\% das informações do modelo de ondas corresponde a ondas do quadrante leste, com $20 \%$ procedentes do quadrante Sudeste e 15\% do Sul (Figura 21). Em Caravelas (WW3- 
CRV) o espectro de onda é representado por $40 \%$ de ondas de leste, $15 \%$ do quadrante Sudeste e $35 \%$ representado por ondas de Sul, apresentando uma maior dispersão dos parâmetros (Figura 22).

Em Ilhéus, na estação offshore (WW3-IOSoff) o padrão de aproximação das ondas é disperso entre as direções leste, sudeste e sul, apresentando grande semelhança com o padrão observado na estação de Caravelas. Apesar de estar localizada na mesma latitude da estação WW3-IOS a predominância das ondas provenientes do quadrante leste é menos observada (Figura 23).
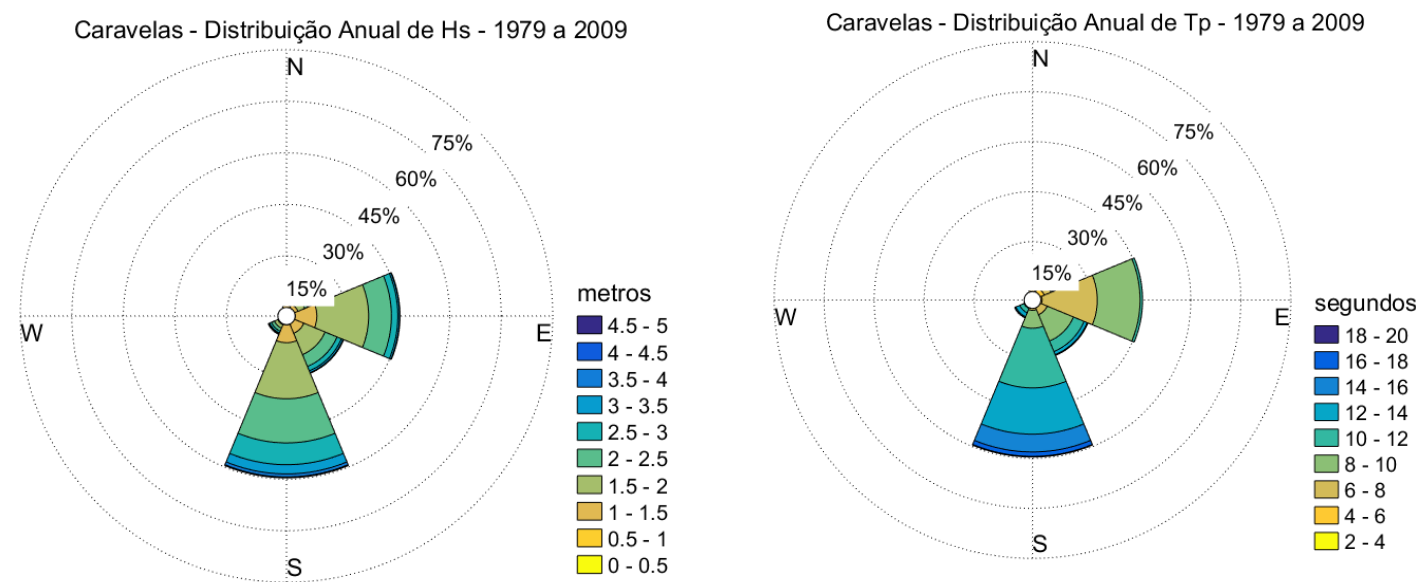

Figura 21: Diagrama direcional da altura significativa (Hs) e do período de pico (Tp) das ondas obtidas do modelo de ondas no ponto WW3-CRV (Caravelas BA).
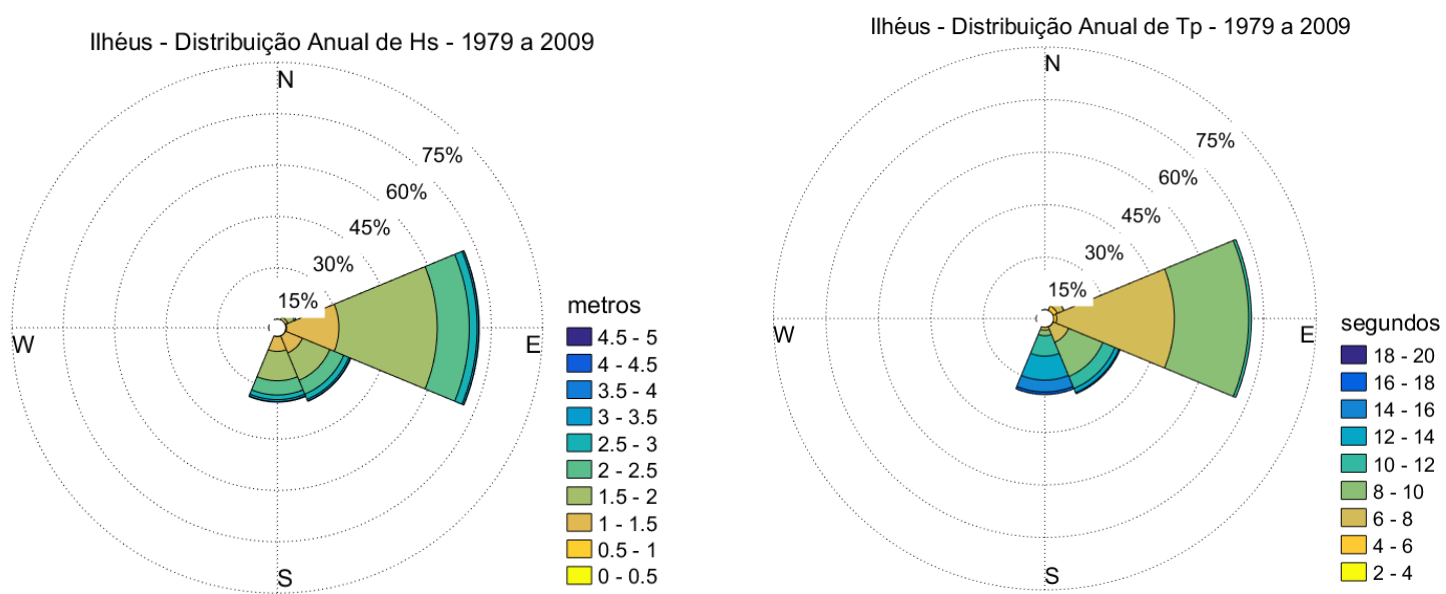

Figura 22: Diagrama direcional da altura significativa (Hs) e período de pico (Tp) das ondas obtidas do modelo de ondas no ponto WW3-IOS (Ilhéus - BA). 

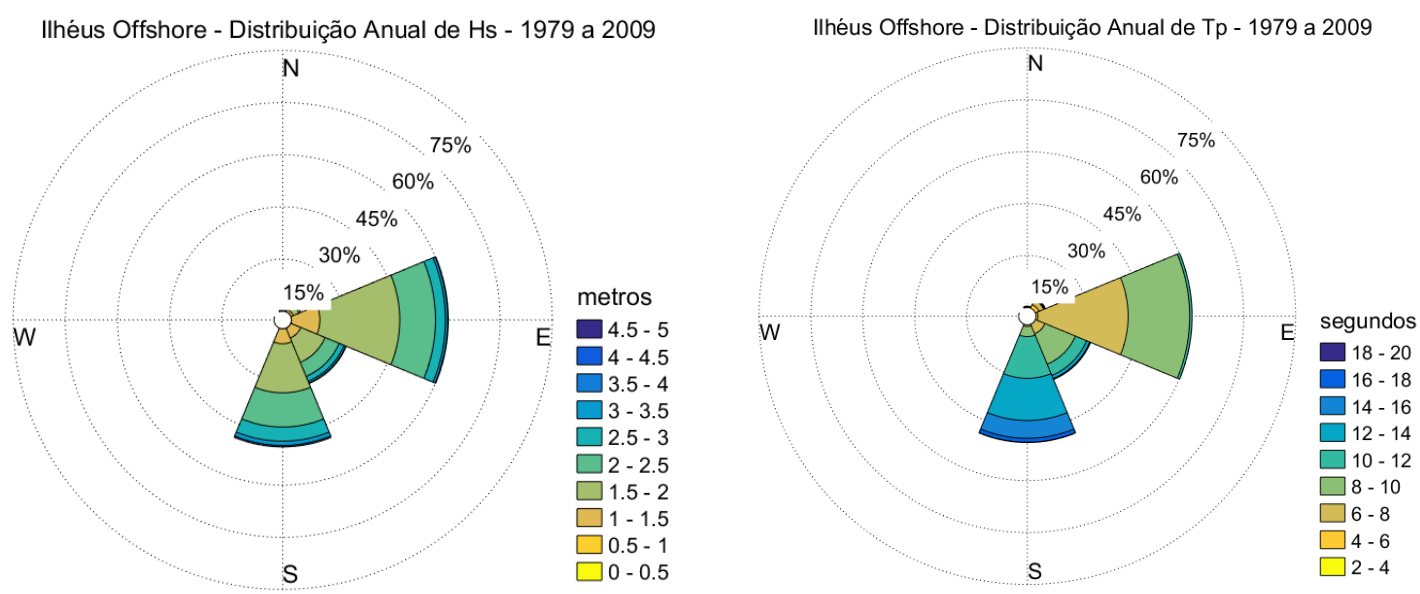

Figura 23: Diagrama direcional da altura significativa (Hs) e período de pico (Tp) das ondas obtidas no ponto WW3-IOSoff (Ilhéus - BA), fora da influência do Banco de Abrolhos.

A descontinuidade da plataforma continental modifica o clima de ondas modelado costa afora em Ilhéus e Caravelas, indicando uma forte influência de ondas de swell no clima de ondas em Caravelas, o que não é observado em Ilhéus, onde ondas locais formadas por ventos do quadrante leste predominam no registro.

A comparação entre as ondas modeladas em Ilhéus, fora da área de influência do Banco de Abrolhos (WW3-IOSoff) demonstra que à mesma longitude de aquisição das informações de Caravelas, o comportamento do registro de ondas apresenta influência significativa das ondas de swell, indicando que a descontinuidade geomorfológica da plataforma continental leste brasileira afeta o clima de ondas atuante na costa.

\subsection{DISCUSSÃO - CLIMA DE ONDAS}

A análise estatística das ondas em dois pontos da costa leste brasileira permitiu um melhor entendimento da variabilidade do clima de ondas atuante ao largo da plataforma continental. A escolha das estações WW3_IOS (Ilhéus) e WW3_CRV (Caravelas) demonstrou que não apenas a posição geográfica define o padrão de ondas na região. A 
variabilidade da morfologia da plataforma continental nesse trecho da costa também interfere na propagação de ondas, determinando uma maior exposição a ondas dos quadrantes sul e sudeste em Caravelas, enquanto que em Ilhéus predominam as ondas de leste durante todo o tempo.

A interferência do alargamento da plataforma de Abrolhos no clima de ondas observado em frente a Ilhéus fica clara na análise comparativa das informações dos parâmetros da onda na estação WW3_IOSoff. Ela apresenta padrão bem diferenciado em relação a estação WW3_IOS, localizada na zona protegida pelo banco de Abrolhos, em frente a Ilhéus, apesar de se localizarem na mesma latitude. Ondas nessa estação apresentam comportamento semelhante ao observado em Caravelas, ambas fora da zona de influência do banco de Abrolhos.

Os resultados corroboram trabalhos realizados anteriormente, apresentando a mesma distribuição estatística. Pianca et al. (2010) obtiveram a mesma distribuição do clima de ondas na estação em frente a Caravelas (W3), no entanto, diferenças pouco expressivas podem ser observadas, provavelmente em decorrência da posição de aquisição das informações e por ter trabalhado com uma série temporal menor (11 anos). Siegle e Costa (2017) também indicam o mesmo padrão do clima de ondas para uma série temporal de 18 anos.

A importância do detalhamento do comportamento das ondas, fora da zona de interferência da plataforma continental, na região de Caravelas representa uma importante fonte de informações para o entendimento da dinâmica costeira, servindo de referência a trabalhos de modelagem desenvolvidos na região.

\subsection{CONCLUSÃO - CLIMA DE ONDAS}

O clima de ondas obtido a partir da análise estatística dos parâmetros espectrais das ondas geradas pelo modelo WAVEWATCH III em dois pontos da costa leste brasileira indicam a predominância da ação de ondas do quadrante leste durante todo o ano, em 
Ilhéus, e em todas as estações a exceção do outono em Caravelas, quando as ondas do quadrante $S$ representam mais de $40 \%$ das informações.

A análise da potência da onda indica como estação mais energética o inverno em ambos os pontos de aquisição das informações de onda, no entanto, em Ilhéus as ondas mais e menos energéticas são provenientes do quadrante leste, enquanto que em Caravelas, as ondas mais energéticas se aproximam do quadrante sul.

O controle morfológico da plataforma rasa do Banco de Abrolhos influencia o clima de ondas da área ao norte, atenuando as ondas dos quadrantes S e SE. Esse aspecto acaba compensando os efeitos da menor atenuação das ondas na região norte de plataforma estreita.

Apesar de a análise estar baseada em informações de modelo global de geração de ondas, os resultados aqui apresentados preenchem uma lacuna na descrição do clima de ondas na região. Importante ressaltar que não existem séries medidas de longo termo em águas profundas nas regiões estudadas, o que faz da análise realizada uma importante contribuição para trabalhos futuros. 


\author{
CAPÍTULO 5 - POTENCIAL DE MOBILIDADE \\ SEDIMENTAR INDUZIDA POR ONDAS NA PLATAFORMA \\ CONTINENTAL LESTE BRASILEIRA
}

\title{
5.1.INTRODUÇÃO
}

A dinâmica sedimentar é um tema importante em estudos ambientais e de engenharia. $\mathrm{O}$ entendimento do transporte de sedimentos é essencial na previsão da dispersão de sedimentos e contaminantes em sistemas costeiros superficiais (James et al., 2010).

A plataforma continental interna é permanentemente esculpida pela ação das ondas e correntes, cuja ação combinada pode produzir extensas feições erosivas com altas taxas de transporte de sedimento junto ao fundo (Cacchione et al., 1994).

A estimativa do transporte de sedimentos junto ao fundo marinho demanda um modelo computacional que permita uma correta estimativa da rugosidade de fundo e da tensão de cisalhamento por correntes; o efeito dinâmico da turbulência induzida por ondas e a necessidade de avaliar mudanças na rugosidade de fundo causadas pela ação de fortes correntes, atividade biológica e episódios de erosão e deposição, tornam essa estimativa um tema de alta complexidade (Drake e Cacchione, 1992).

Cerca de $80 \%$ das plataformas continentais mundiais tem sua dinâmica dominada pela ação de ondas de tempestade, $17 \%$ por correntes de maré e $3 \%$ pela interação com correntes oceânicas (Walker, 1984; Swift et al., 1986 apud Harris e Coleman, 1998). A ressuspensão por ondas e correntes é o mecanismo dominante de transporte de sedimentos sobre grande parte das plataformas continentais do mundo (Harris \& Wiberg, 2001).

A profundidade a partir da qual as ondas sofrem influência do fundo marinho está relacionada ao comprimento das ondas de superfície. Ondas geradas por ventos induzem o movimento orbital na coluna d'água até uma profundidade igual à metade do seu comprimento de onda. Em profundidades menores que metade do comprimento da onda 
este movimento orbital estende-se até o fundo (Wiberg e Sherwood, 2008). A importância da ação das ondas na mobilidade dos sedimentos marinhos é significativa quando se considera a estabilidade do fundo e o balanço de sedimentos.

O efeito da velocidade orbital das ondas sobre o fundo marinho, na mobilização dos sedimentos, depende do comprimento e altura das mesmas e da granulometria, peso específico e forma dos sedimentos. Desse modo, o limite entre plataforma continental interna e intermediária é definido pela profundidade a partir da qual as ondas têm competência para mobilizar sedimentos de fundo, sendo, portanto definida pelo clima de ondas. No Brasil, apesar da falta de consenso quanto ao limite distal da plataforma continental interna, este foi fixado em $50 \mathrm{~m}$. Esta profundidade, entretanto, quando aplicada à região nordeste do país, está muito acima da competência de ação das ondas, que apresentam menor altura e período, onde o limite distal se situa entre 20 e $30 \mathrm{~m}$ (Muehe, 1998).

No contexto global, poucos trabalhos abordam a mobilidade de sedimentos induzida por ondas na plataforma continental; na australiana, Porter-Smith et al. (2004) utilizaram estimativas de altura e período da onda, em conjunto com a velocidade da corrente de maré para prever a área da plataforma onde os sedimentos inconsolidados são mobilizados; Griffin et al. (2008) incorporaram a distribuição granulométrica do sedimento na análise do transporte de sedimentos na plataforma sudeste australiana, dominada por ondas; Storlazzi e Reid (2010) avaliaram a influência da oscilação sul do El Niño (ENSO) no transporte de sedimentos induzido por ondas, na plataforma central da Califórnia; na plataforma leste da Nova Zelândia, Moriarty et al. (2014) utilizaram um modelo acoplado hidrodinâmico e de transporte de sedimentos para complementar o entendimento do transporte de sedimentos marinhos e processos deposicionais associados; já Oberle et al. (2014) utilizaram diferentes cenários de mobilização de sedimentos, representando a média sazonal e condições de tempestade, para avaliar o transporte de sedimentos na plataforma noroeste da Península Ibérica; enquanto Dalyander e Butman (2015), investigaram padrões espaciais e temporais do transporte de sedimentos associados a eventos de tempestade, na costa leste dos Estados Unidos.

No Brasil, o transporte de sedimentos sobre a Plataforma Continental também é um importante tema de pesquisas. Muehe e Carvalho (1993) interpretaram o transporte de sedimentos através da análise granulométrica de sedimentos na plataforma continental interna do Rio de Janeiro; Nittrouer et al. (1995) inferiram a dispersão de sedimentos 
sobre a plataforma continental amazônica correlacionando flutuações sazonais das condições ambientais (descarga fluvial, ventos) com processos de alta frequência (correntes de maré, ondas de superfície); Cabral et al. (2001), estudando a região dos bancos Royal Charlotte e Abrolhos, identificaram que a recirculação na área da plataforma e ao longo dos recifes é marcante, promovendo o retrabalhamento de sedimentos e transporte de matéria orgânica para dentro e fora da plataforma; Campos e Dominguez (2010) utilizaram a altura significativa da onda, período e frequência de ocorrência com tamanho médio do grão de sedimento para estimar a mobilidade sedimentar induzida por ondas na plataforma continental norte da Bahia.

Neste capítulo, foi aplicada a relação apresentada por Potter-Smith et al. (2004) para determinar a velocidade de fundo induzida pelas ondas e equações simplificadas de Clifton e Dingler (1984) para determinar a condição limite para a movimentação dos sedimentos de fundo na plataforma continental leste brasileira.

\subsection{MODELAGEM NUMÉRICA}

Modelos de ondas de terceira geração têm sido intensamente utilizados para descrever crescimento, decaimento e transformação de ondas geradas por ventos em oceano profundo e sobre plataformas continentais, os quais recentemente têm sido adaptados para aplicação em áreas costeiras, incluindo fenômenos físicos importantes para águas rasas (Sorensen et al., 2004).

O modelo numérico aplicado no presente trabalho foi o modelo de área para o estudo da hidrodinâmica e morfodinâmica costeira MIKE21 FM (desenvolvido pela DHI Water \& Environment). O desenvolvimento do MIKE21 se iniciou em 1970, e desde então tem sido estendido para diferentes aplicações (Abbott et al., 1981; Abbott e Larsen, 1985). O módulo do modelo numérico que foi aplicado nesta etapa do trabalho foi o modelo de propagação de ondas (SW), com o objetivo de propagar a onda obtida pelo modelo WAVEWATCH III em águas profundas até a costa. 


\subsubsection{MODELO MIKE21 (DHI)}

O modelo Mike 21 é um modelo numérico 2D (fluxos barotrópicos) aplicado a áreas costeiras e estuarinas.

O modelo utiliza malha flexível não estruturada, independente da profundidade, que é gerada pela interface gráfica denominada Mike Zero que através do ambiente de trabalho Mesh Generator cria uma malha com os seguintes atributos:

- Área máxima do triângulo

- Máxima obliqüidade (ângulo interno) do triângulo

- Número máximo de pontos de malha

O módulo de Ondas, utilizado nesta etapa, representa o crescimento, transformação e decaimento (refração, empinamento, dissipação, interação não-linear, interação com corrente, variação temporal da profundidade - maré) das ondas de oceano profundo na aproximação da costa. O modelo utiliza dados de batimetria, ondas oceânicas e fricção de fundo como dados de entrada, gerando o campo de ondas resultante.

O Módulo de ondas (MIKE21 FM, SW) é um modelo espectral para ondas geradas pelo vento, que descreve a propagação, crescimento e decaimento de ondas de curto período $(\mathrm{T}<20 \mathrm{~s})$ em áreas costeiras. $\mathrm{O}$ modelo inclui os efeitos de refração e empinamento de ondas em função da profundidade, geração de ondas pelo vento, e dissipação de energia em função da fricção com o fundo e quebra de onda. Os efeitos de correntes sobre estes fenômenos também estão incluídos. As equações básicas do MIKE21 SW são derivadas da equação de conservação para a densidade da ação espectral baseada na abordagem proposta por Holthuijsen et al. (1989). 


\subsubsection{DOMÍNIO DO MODELO}

A malha flexível utilizada no modelo Mike 21 foi gerada a partir da interface gráfica MIKE Zero no ambiente de trabalho Mesh Generator.

A malha gerada para o módulo de ondas na plataforma continental foi configurada com área máxima de 0,01 graus quadrados, $30^{\circ}$ de obliquidade máxima e 1.000 .000 de pontos de malha.

A área modelada foi subdividida em duas principais áreas de interesse, a área sobre a plataforma continental, com maior detalhamento, e a área oceânica, com profundidades superiores a $200 \mathrm{~m}$, onde o detalhamento dos resultados não é significativo para a análise em questão. Na configuração descrita acima, a área média de célula, estabelecida para a região fora da plataforma continental de Ilhéus e Caravelas foi de cerca de $3 \mathrm{~km}^{2}$. Na área sobre a plataforma, a dimensão das células foi reduzida para cerca de $1 \mathrm{~km}^{2}$ (Figuras 24 e 25).

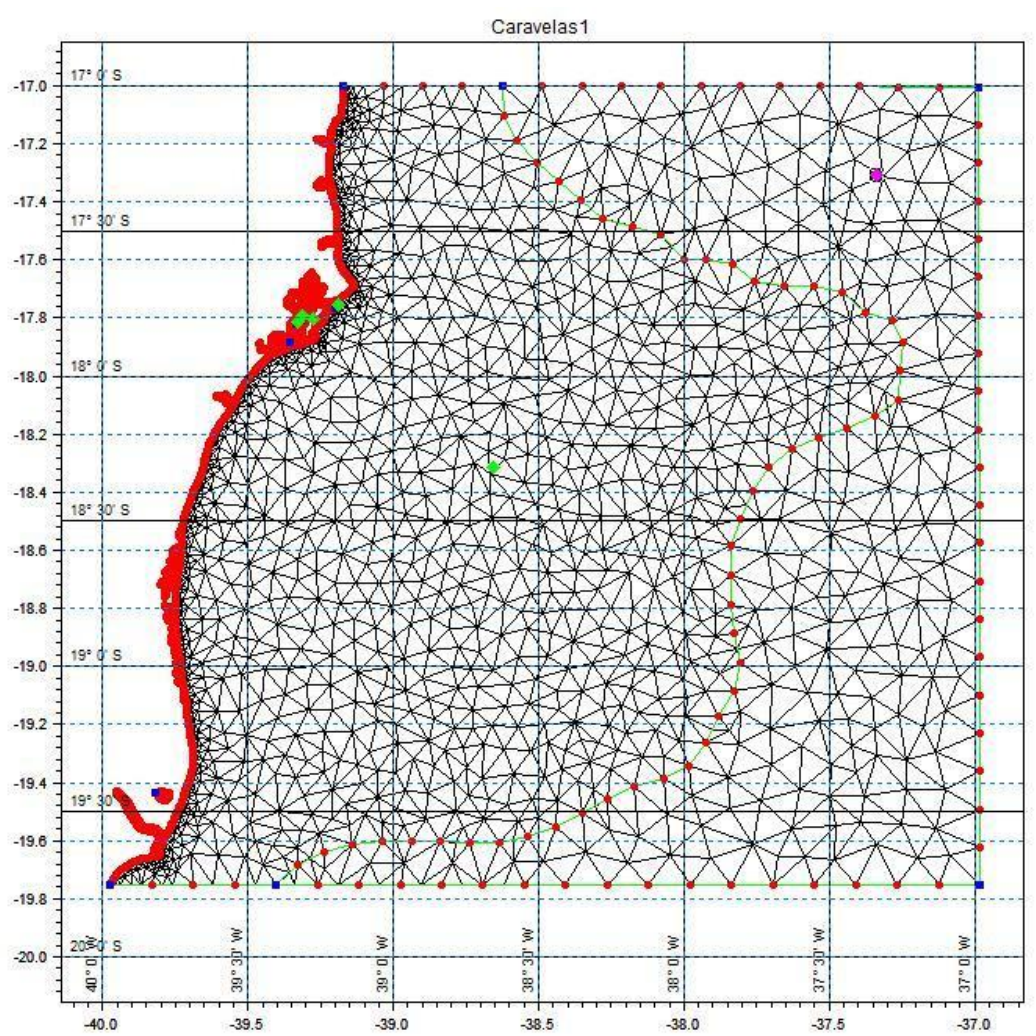

Figura 24: Malha flexível do Modelo Mike 21 com adensamento sobre a plataforma continental, na região de Caravelas - BA, 


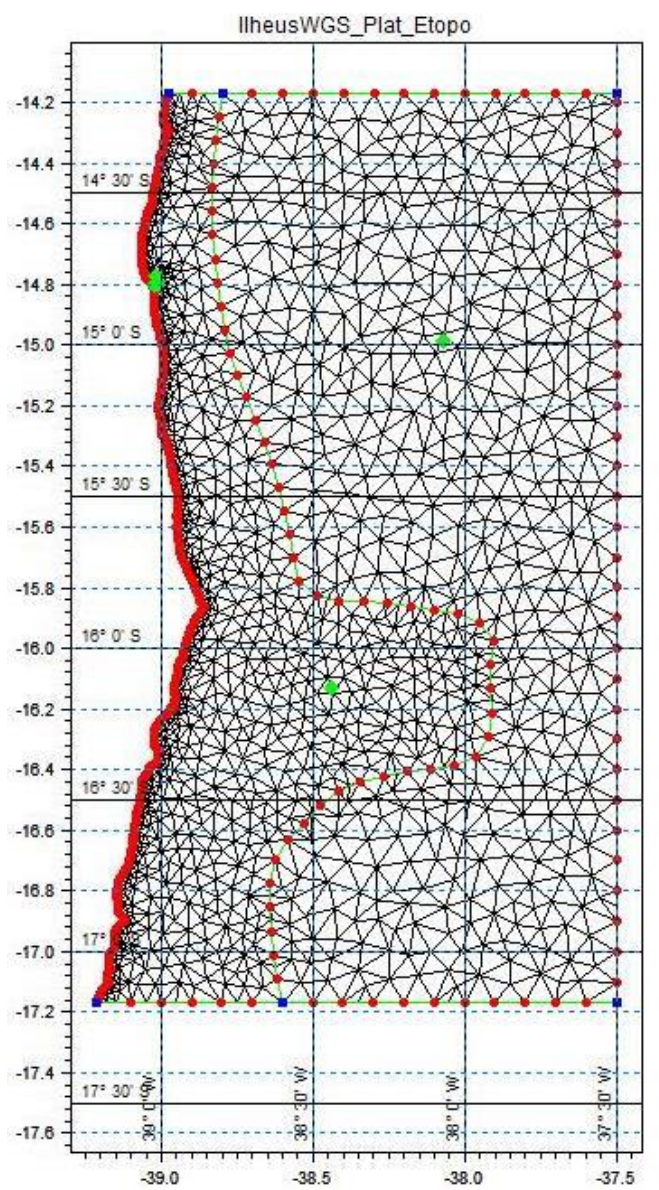

Figura 25: Malha flexível do Modelo Mike 21 com adensamento sobre a plataforma continental, na região de Ilhéus - BA.

\subsubsection{BATIMETRIA INTERPOLADA}

Os dados batimétricos obtidos da digitalização das cartas náuticas da DHN e do arquivo de dados ETOPO 1 foram interpoladas no modelo MIKE 21 como condição de contorno para a propagação de ondas sobre a plataforma continental de Caravelas e Ilhéus. A batimetria da plataforma continental de Caravelas é apresentada na figura 26, enquanto que a de Ilhéus na figura 27. 


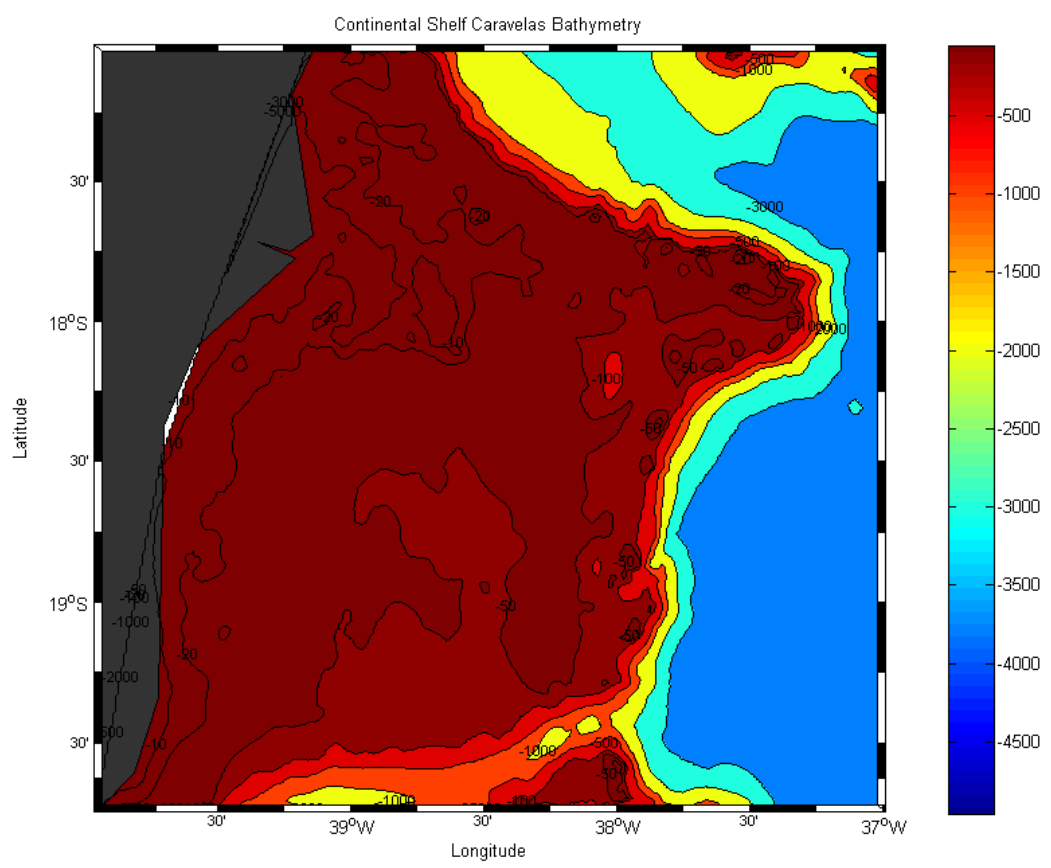

Figura 26: Batimetria da Plataforma Continental de Caravelas, interpolada pelo programa MIKE 21.

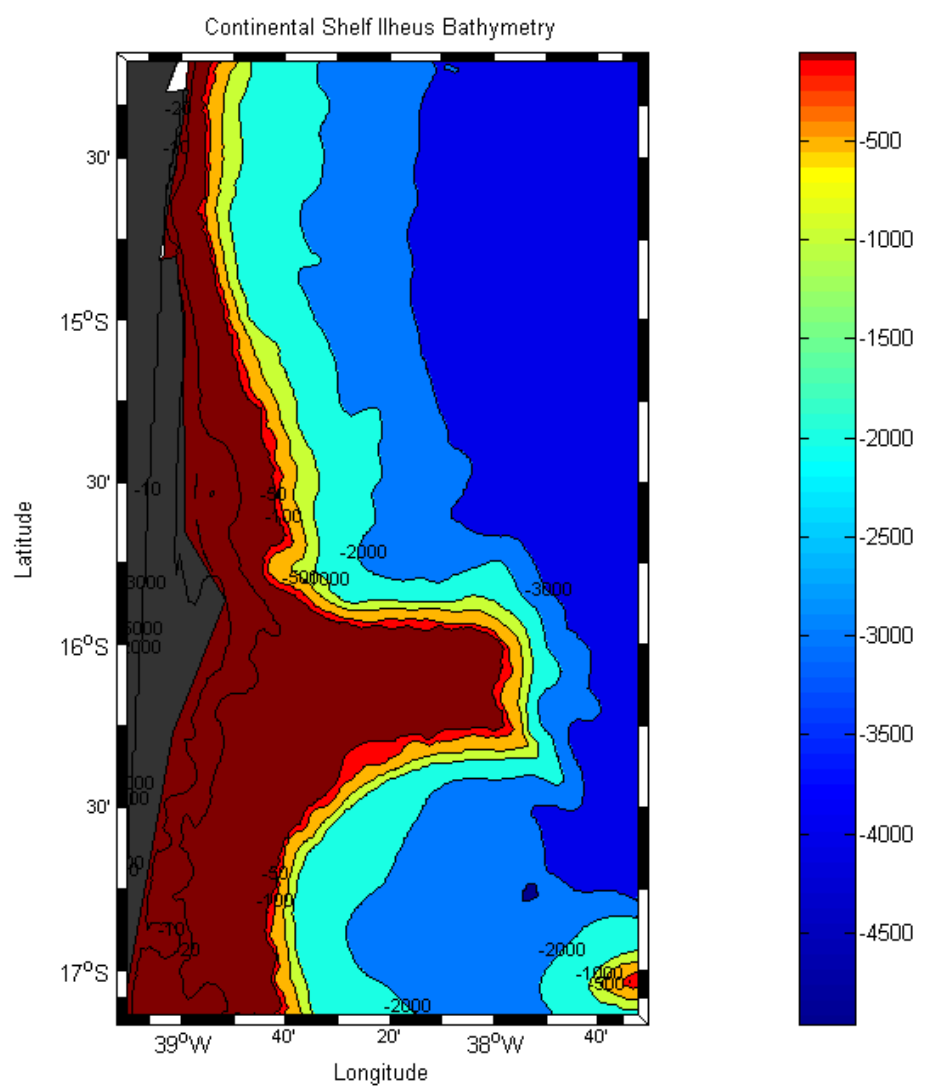

Figura 27: Batimetria da Plataforma Continental de Ilhéus, interpolada pelo programa MIKE 21. 


\subsubsection{FRICÇÃO DE FUNDO}

As ondas, ao se aproximarem da costa, geram correntes de fundo capazes de transportar sedimentos. Quando a velocidade orbital máxima (Maximum Orbital Velocity) das correntes ultrapassa o valor da velocidade crítica de fundo (Critical Bottom Velocity) para a movimentação do sedimento (Threshold), causam mobilidade do sedimento de fundo.

O transporte de sedimentos é função da força aplicada pela corrente sobre o fundo o que o torna função da velocidade da corrente e da resistência do fundo (Dix et al. 2007). Neste caso, a velocidade de corrente é representada pela velocidade orbital junto ao fundo e a dissipação de energia sobre o fundo é representada pelo coeficiente de fricção do fundo.

A fricção do fundo, em áreas dominadas por sedimentação arenosa, depende do diâmetro do grão e da presença de formas de fundo. Segundo Shemdin et al. (1978), a fricção é o processo de interação com o fundo dominante quando o sedimento é composto de areia fina ou na presença de marcas onduladas (Ripple marks).

No modelo MIKE 21, a fricção com o fundo pode ser definida de cinco formas diferentes, as quais podem ser dependentes tanto das condições hidrodinâmicas da onda quanto das características do sedimento.

A escolha do coeficiente de fricção com o fundo afeta a taxa de mobilização do sedimento no domínio do modelo. O coeficiente de fricção com o fundo utilizado nestas simulações foi o parâmetro de rugosidade de Nikuradse $(\mathrm{kN})$ no qual o coeficiente de dissipação depende das condições hidrodinâmicas da onda. Segundo Nielsen (1979), quando não há formas de fundo, o parâmetro de rugosidade de Nikuradse $(\mathrm{kN})$ pode ser estimado por $\mathrm{kN}=2,5 \mathrm{D}_{50}$, onde $\mathrm{D}_{50}$ é a mediana do diâmetro do grão de sedimento. No entanto, com a presença de marcas onduladas (ripples) este valor pode ser muito maior e deve ser estimado incluindo as características destas ondulações. 
A rugosidade de fundo é considerada a variável primária de calibração do módulo hidrodinâmico, sendo também essencial para a modelagem de outros processos como o transporte de sedimentos e a atenuação das ondas (Dix et al., 2007).

Em Caravelas, dados de onda coletados por Lessa et al. (2005), durante um projeto de monitoramento de três anos (2002 - 2004), foram utilizados na calibração do módulo de ondas (Tabela 14). Lessa et al. (2005) obtiveram valores médios de altura significativa da onda de $0,40 \mathrm{~m}$ e período de $5 \mathrm{~s}$, comparáveis aos valores obtidos pelo módulo de ondas do modelo MIKE 21, utilizando o coeficiente de rugosidade de Nikuradse $(\mathrm{kN})$ com valor de 0,022 m na região do Banco de Abrolhos. Em Ilhéus, onde não há dados de ondas disponíveis, o valor do parâmetro de Nikuradse (kN) utilizado foi o padrão indicado pelo manual do modelo $(0,04 \mathrm{~m})$, o qual é frequentemente utilizado em simulações oceânicas de formulações de espectro amplo.

Tabela 14: Valores de fricção de fundo utilizados no modulo de ondas do Modelo MIKE 21 (Spectral Wave Module FM) para calibração do modelo. Hsig é a altura significativa da onda, T01 é o período médio da onda, kN é a rugosidade de Nikuradse.

\begin{tabular}{l|c|c|c}
\hline Dado & $\mathrm{H}_{\text {sig }}$ & $\mathrm{T}_{01}$ & Fricção do Fundo \\
\hline \hline Lessa et al. (2005) & $\mathbf{0 , 4 0 m}$ & $5 \mathrm{~s}$ & - \\
\hline Mike 21 & $0,31 \mathrm{~m}$ & $5,8 \mathrm{~s}$ & $\mathrm{kN}=0,040 \mathrm{~m}$ \\
\hline Mike 21 & $0,35 \mathrm{~m}$ & $6,2 \mathrm{~s}$ & $\mathrm{kN}=0,030 \mathrm{~m}$ \\
\hline Mike 21 & $0,38 \mathrm{~m}$ & $6,4 \mathrm{~s}$ & $\mathrm{kN}=0,025 \mathrm{~m}$ \\
\hline Mike 21 & $\mathbf{0 , 4 0 m}$ & $6,5 \mathrm{~s}$ & $\mathrm{kN}=\mathbf{0 , 0 2 2 m}$ \\
\hline Mike 21 & $0,41 \mathrm{~m}$ & $6,6 \mathrm{~s}$ & $\mathrm{kN}=0,020 \mathrm{~m}$ \\
\hline Mike 21 & $0,45 \mathrm{~m}$ & $6,8 \mathrm{~s}$ & $\mathrm{kN}=0,015 \mathrm{~m}$ \\
\hline Mike 21 & $0,50 \mathrm{~m}$ & $7,0 \mathrm{~s}$ & $\mathrm{kN}=0,010 \mathrm{~m}$ \\
\hline Mike 21 & $0,92 \mathrm{~m}$ & $8,0 \mathrm{~s}$ & Sem fricção de fundo \\
\hline \hline
\end{tabular}

Os parâmetros espectrais da onda (altura significativa, Hs, Período médio, T01 e direção média de aproximação das ondas, Mean_dir), sobre a plataforma continental de Caravelas e Ilhéus, dados de saída das simulações do módulo de ondas do modelo MIKE 21, foram utilizados na determinação da Velocidade Orbital Máxima 
das Ondas junto ao fundo e da Velocidade Crítica de Fundo, a partir da qual ocorre movimentação do sedimento.

\subsubsection{CONDIÇÕES DE CONTORNO - CLIMA DE ONDAS}

As informações obtidas na análise estatística das ondas foram utilizadas como condição de contorno nas simulações do modulo de ondas (Spectral Waves FM).

Alturas de onda com frequência de ocorrência superior a 5\% foram utilizadas como diferentes cenários para o cálculo das modificações das caraterísticas das ondas que se propagam sobre a plataforma continental. O percentual de ocorrência das alturas significativas das ondas para cada quadrante de aproximação é apresentado na Tabela 15 para Caravelas e na Tabela 16 para Ilhéus. Os parâmetros da onda foram analisados sazonalmente com o objetivo de determinar a distribuição de frequência de cada altura e período da onda, em cada estação do ano.

Em Caravelas, ondas com frequência de ocorrência superior a $5 \%$, representam cerca de $70 \%$ do registro, indicando que os parâmetros das ondas são mais dispersos. Já em Ilhéus, estes representam cerca de 80\% do registro, indicando dados mais concentrados em torno da média.

As condições iniciais do modelo MIKE21 SW são baseadas na expressão de crescimento do programa JONSWAP (Joint North Sea Wave Atmosphere Program). O espectro JONSWAP é uma relação empírica que define a distribuição de energia com a frequência nos oceanos, o qual nunca é plenamente desenvolvido devido a interações não lineares entre as ondas que mantêm seu desenvolvimento por longo tempo. 
Tabela 15: Caravelas: distribuição sazonal das alturas de onda com ocorrência superior a $5 \%$ ( e seu respectivo período) por direção de aproximação, da série temporal de 13 anos (1997 - 2009) utilizadas como condição de contorno nas simulações do Módulo de Ondas do Modelo Mike21.

\begin{tabular}{|c|c|c|c|c|c|c|c|c|c|c|c|}
\hline \multicolumn{6}{|c|}{ Primavera } & \multicolumn{6}{|c|}{ Verão } \\
\hline & Hs (m) & $\%$ & Ts (s) & Dir & Dir_med & & $\mathrm{Hs}(\mathrm{m})$ & $\%$ & Ts (s) & Dir & Dir_med \\
\hline Caso 1: & 1,71 & 19,14 & 7.33 & $\mathrm{E}$ & 91,1 & Caso 1: & 1,28 & 23,70 & 6,63 & $\mathrm{E}$ & 88,84 \\
\hline Caso 2: & 1,32 & 11,61 & 6.87 & $\mathrm{E}$ & 89,3 & Caso 2: & 1,69 & 15,96 & 6,89 & $\mathrm{E}$ & 89,45 \\
\hline Caso 3: & 1,75 & 10,77 & 10.87 & $S$ & 184,53 & Caso 3: & 1,72 & 9,98 & 10,67 & $S$ & 187,98 \\
\hline Caso 4: & 2,22 & 8,65 & 10.89 & $S$ & 183,55 & Caso 4: & 1,32 & 9,10 & 10,04 & $S$ & 184,1 \\
\hline Caso 5: & 1,74 & 7,52 & 8.54 & SE & 135,86 & Caso 5: & 1,70 & 5,70 & 5,89 & NE & 43,32 \\
\hline Caso 6: & 2,19 & 6,06 & 8.09 & $E$ & 95,28 & Caso 6: & 1,26 & 5,23 & 8,17 & SE & 132,02 \\
\hline Caso 7: & 2,22 & 5,74 & 8.33 & SE & 135,04 & Caso 7: & - & - & - & - & - \\
\hline$\Sigma$ \% & -------- & 69,49 & -------- & -------- & -------- & $\Sigma \%$ & ------- & 69,67 & -------- & -------- & -------- \\
\hline \multicolumn{6}{|c|}{ Outono } & \multicolumn{6}{|c|}{ Inverno } \\
\hline & $\mathrm{Hs}(\mathrm{m})$ & $\%$ & Ts & Dir & Dir_med & & $\mathrm{Hs}(\mathrm{m})$ & $\%$ & Ts (s) & Dir & Dir_med \\
\hline Caso 1: & 1,76 & 15,61 & $11.11 \mathrm{~s}$ & $S$ & 185,45 & Caso 1: & 1,76 & 18,38 & 7,75 & $E$ & 91,29 \\
\hline Caso 2: & 1,70 & 13,91 & $7.18 \mathrm{~s}$ & $E$ & 93,17 & Caso 2: & 2,21 & 14,84 & 8,06 & $E$ & 92,84 \\
\hline Caso 3: & 2,22 & 11,13 & $11.34 \mathrm{~s}$ & $S$ & 186,68 & Caso 3: & 2,24 & 11,13 & 11,51 & $S$ & 188,54 \\
\hline Caso 4: & 1,30 & 9,71 & $7.08 \mathrm{~s}$ & $E$ & 92,46 & Caso 4: & 1,77 & 8,46 & 10,93 & $S$ & 187,16 \\
\hline Caso 5: & 1,30 & 8,38 & $10.36 \mathrm{~s}$ & $\mathrm{~S}$ & 181,63 & Caso 5: & 2,71 & 7,32 & 11,64 & $\mathrm{~S}$ & 188,08 \\
\hline Caso 6: & 1,27 & 7,16 & $8.29 \mathrm{~s}$ & SE & 133,47 & Caso 6: & 2,23 & 5,13 & 8,89 & SE & 135,81 \\
\hline Case 7: & 1,70 & 7,12 & $8.56 \mathrm{~s}$ & SE & 136,11 & Case 7: & - & - & - & - & - \\
\hline Case 8: & 2,71 & 6,04 & 11,51 & $\mathrm{~S}$ & 186,3 & Case 8: & - & - & - & - & - \\
\hline$\Sigma$ 웅 & -------- & 79,06 & -------- & -------- & ------- & $\Sigma$ \& & -------- & 65,26 & -------- & -------- & -------- \\
\hline
\end{tabular}

*Hs corresponde à altura significativa da onda e \% sua frequência de ocorrência, Ts é o período médio da onda para cada intervalo de altura considerado, Dir é o quadrante de aproximação da onda e Dir_med o ângulo médio de aproximação das ondas do respectivo quadrante.

Tabela 16: Ilhéus: distribuição sazonal das alturas de onda com ocorrência superior a $5 \%$ ( e seu respectivo período) por direção de aproximação, da série temporal de 13 anos (1997 - 2009) utilizadas como condição de contorno nas simulações do Módulo de Ondas do Modelo Mike21.

\begin{tabular}{|c|c|c|c|c|c|c|c|c|c|c|c|}
\hline \multicolumn{6}{|c|}{ Primavera } & \multicolumn{6}{|c|}{ Verão } \\
\hline & Hs (m) & $\%$ & Ts (s) & Dir & Dir_med & & Hs (m) & $\%$ & Ts (s) & Dir & Dir_med \\
\hline Caso 1: & 1,70 & 27,89 & 7,39 & $E$ & 94,71 & Caso 1: & 1,27 & 42,22 & 6,54 & $E$ & 92,42 \\
\hline Caso 2: & 1,34 & 20,41 & 6,83 & $\mathrm{E}$ & 92,29 & Caso 2: & 1,66 & 16,82 & 6,94 & $\mathrm{E}$ & 94,5 \\
\hline Caso 3: & 1,72 & 10,18 & 8,33 & SE & 132,23 & Caso 3: & 1,28 & 6,90 & 5,15 & NE & 50,51 \\
\hline Caso 4: & 2,18 & 6,40 & 8,08 & $\mathrm{E}$ & 99,12 & Caso 4: & 1,70 & 6,58 & 5,76 & NE & 47,38 \\
\hline Caso 5: & 1,74 & 5,71 & 11,39 & $\mathrm{~s}$ & 177,39 & Caso 5: & 1,27 & 5,92 & 10,90 & $S$ & 179,67 \\
\hline Caso 6: & 2,22 & 5,27 & 8,04 & SE & 134,87 & Caso 6: & 0,91 & 5,33 & 6,19 & $\mathrm{E}$ & 93,85 \\
\hline Caso 7: & - & - & - & - & - & Caso 7: & 1,23 & 5,29 & 8,11 & SE & 130,72 \\
\hline$\Sigma$ \% & -------- & 75,86 & ------- & ------- & -------- & $\Sigma$ 递 & -------- & 89,06 & -------- & -------. & -------- \\
\hline \multicolumn{6}{|c|}{ Outono } & \multicolumn{6}{|c|}{ Inverno } \\
\hline & Hs (m) & $\%$ & Ts (s) & Dir & Dir_med & & $\mathrm{Hs}(\mathrm{m})$ & $\%$ & Ts (s) & Dir & Dir_med \\
\hline Caso 1: & 1,28 & 21,78 & 6,89 & $\mathrm{E}$ & 97,81 & Caso 1: & 1,76 & 27,35 & 7,75 & $\mathrm{E}$ & 96,86 \\
\hline Caso 2: & 1,70 & 17,96 & 7,24 & $\mathrm{E}$ & 99,41 & Caso 2: & 2,21 & 20,94 & 8,08 & $\mathrm{E}$ & 97,23 \\
\hline Caso 3: & 1,25 & 11,35 & 8,21 & SE & 132,89 & Caso 3: & 1,32 & 8,33 & 7,05 & $\mathrm{E}$ & 94,18 \\
\hline Caso 4: & 1,72 & 9,86 & 11,40 & $S$ & 178,35 & Caso 4: & 2,22 & 7,36 & 8,03 & SE & 132,1 \\
\hline Caso 5: & 1,30 & 7,87 & 11,28 & $\mathrm{~s}$ & 177,5 & Caso 5: & 1,76 & 7,31 & 7,83 & SE & 129,19 \\
\hline Caso 6: & 1,71 & 7,54 & 8,19 & SE & 136,04 & Caso 6: & 2,69 & 5,31 & 8,54 & $\mathrm{E}$ & 100,69 \\
\hline Caso 7: & 2,20 & 5,01 & 10,81 & $\mathrm{~s}$ & 173,87 & Caso 7: & - & - & - & - & - \\
\hline$\Sigma \%$ & -------- & 81,37 & ------- & -------- & -------- & $\Sigma \%$ & -------- & 76,60 & -------- & -------- & -------- \\
\hline
\end{tabular}

*Hs corresponde à altura significativa da onda e \% sua frequência de ocorrência, Ts é o período médio da onda para cada intervalo de altura considerado, Dir é o quadrante de aproximação da onda e Dir_med o ângulo médio de aproximação das ondas do respectivo quadrante. 


\subsubsection{SIMULAÇÃO DO MÓDULO DE PROPAGAÇÃO DE ONDAS}

A simulação do modulo de ondas do modelo MIKE 21 (MIKE21 FM SW) calculou a propagação da onda sobre a plataforma continental leste brasileira, permitindo a determinação dos parâmetros espectrais da onda em cada ponto da grade do modelo. As simulações foram realizadas para cada um dos casos descritos nas Tabelas $15 \mathrm{e}$ 16, onde as características da onda em região oceânica (altura significativa, período e direção média) representaram os dados de entrada do modelo, mantidos constantes ao longo de todas as bordas abertas da malha do modelo, por um período de 4 dias (8640 passos de tempo de 30 segundos).

A Figura 28 apresenta o resultado da simulação da propagação de ondas na plataforma continental de Caravelas, durante o verão, num período de baixa energia (estação menos energética - Tabela 15, Caso 1), e a Figura 29, o resultado da simulação no período de inverno (Tabela 15, Caso 5), quando as ondas mais energéticas tem aproximação do quadrante sul. É importante destacar que a presença de formações coralinas na plataforma continental, com destaque para o Banco de Abrolhos, gera uma região de baixa energia junto à costa. 


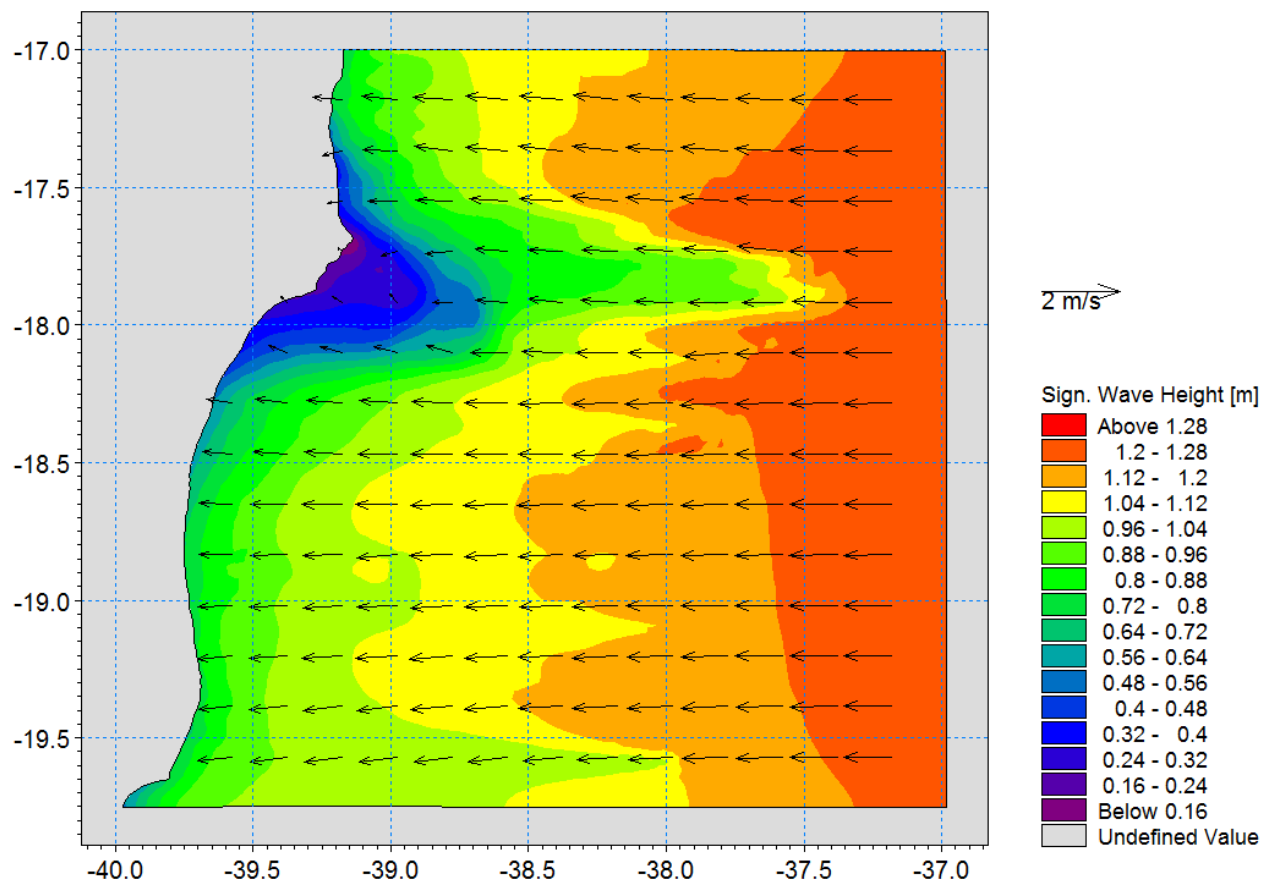

Figura 28: Distribuição das Alturas da onda sobre a plataforma continental de Caravelas (Bahia), durante o verão, Parâmetros da onda: $\mathrm{Hs}=1,28 \mathrm{~m}, \mathrm{Tp}=6,63 \mathrm{~s}$ e Dir_med $=88,84^{\circ}$ (Leste) .

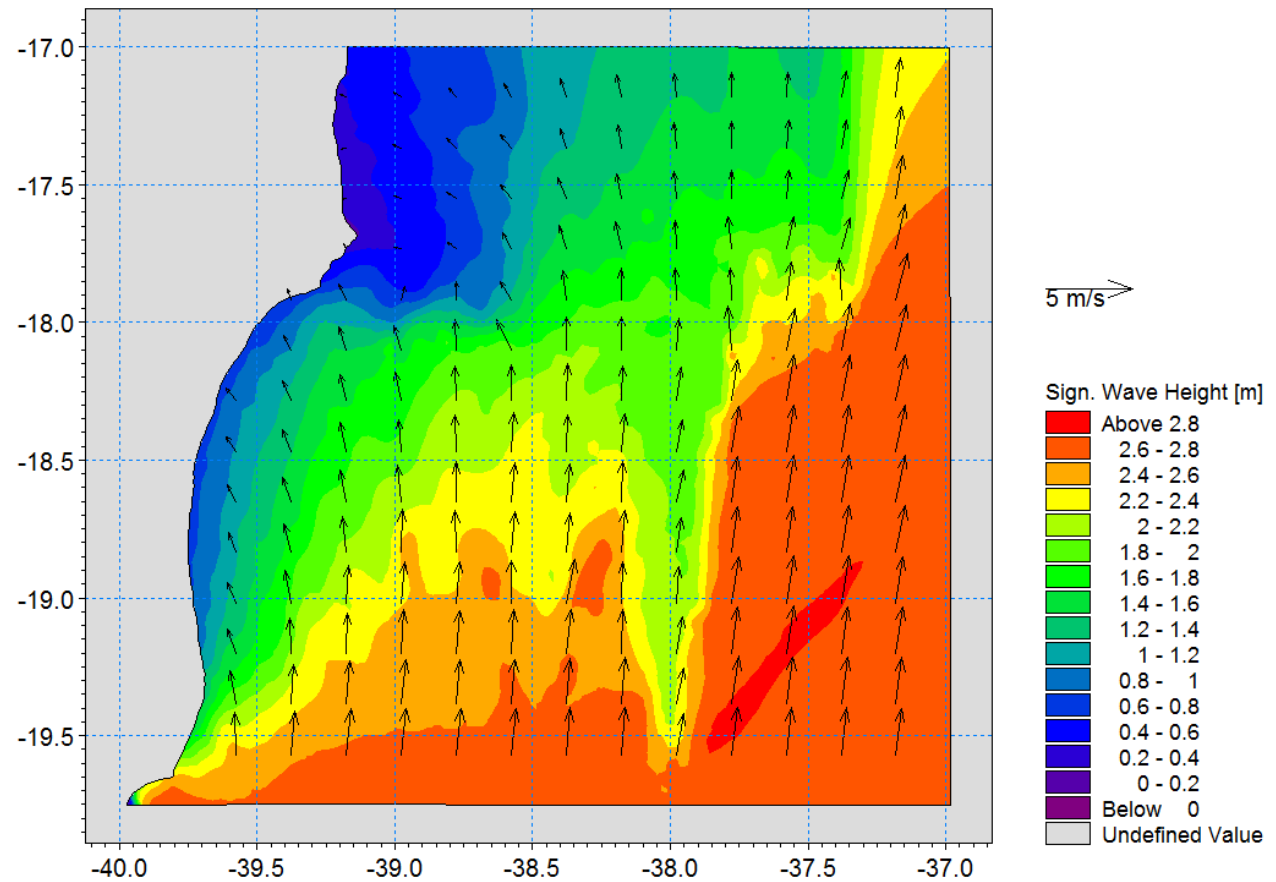

Figura 29: Distribuição das Alturas da onda sobre a plataforma continental de Caravelas (Bahia), durante o inverno, Parâmetros da onda: Hs=2,71 m, $\mathrm{Tp}=11,64$ s e Dir_med=188,08 (Sul). 
Em Ilhéus, tanto as ondas mais energéticas quanto as menos energéticas têm aproximação do quadrante leste; no período de inverno atuam as ondas mais energéticas (Caso 6 da Tabela 16) e no período do verão as menos energéticas (Caso 6 da Tabela 16), no entanto, a região de baixa energia gerada junto à costa, apresenta menor expressividade devido à inexistência de barreiras geomorfológicas de grande porte.

A Figura 30 apresenta as condições de agitação do mar durante o verão, enquanto a Figura 31 apresenta os resultados da simulação para as condições de inverno.

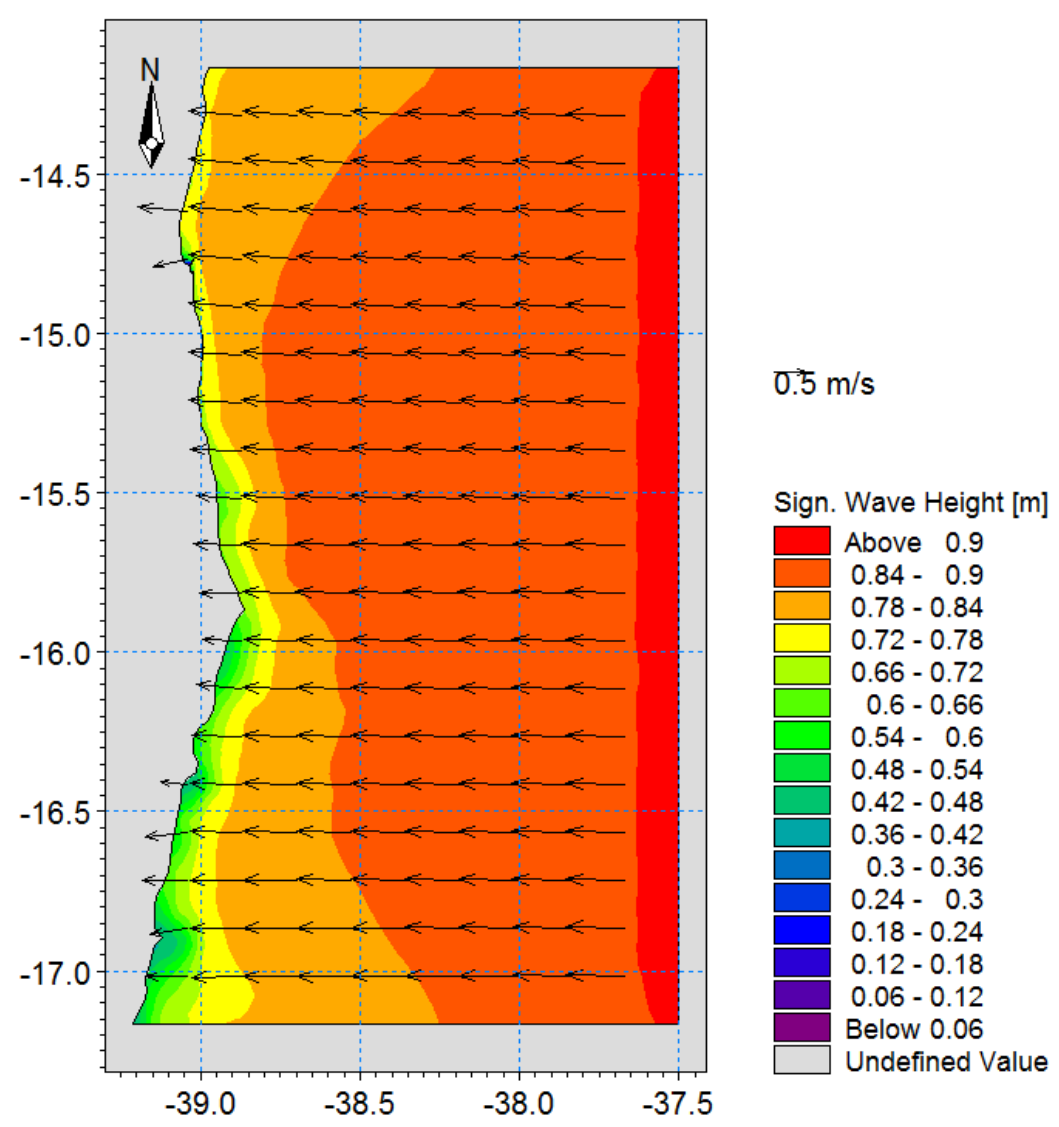

Figura 30: Distribuição das Alturas da onda sobre a plataforma continental de Ilhéus (Bahia), durante o verão, Parâmetros da onda: Hs=0,91 m, Tp=6,19 s e Dir_med=93,85 . 


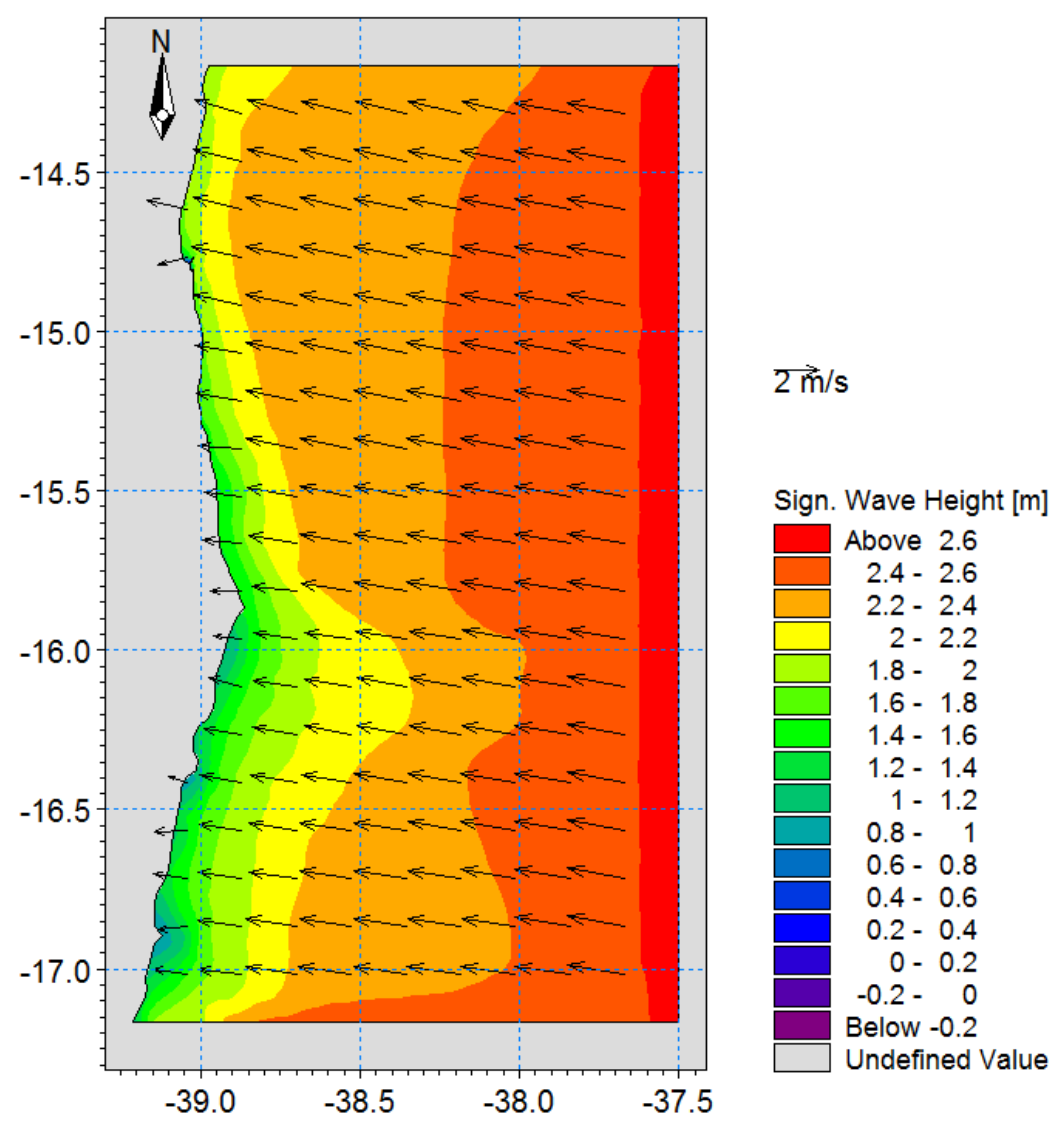

Figura 31: Distribuição das Alturas da onda sobre a plataforma continental de Ilhéus (Bahia), durante o inverno, Parâmetros da onda: Hs=2,69 m, Tp=8,54 s e Dir_med=100,69 ${ }^{\circ}$. (MIKE21 SW)

Apesar de não serem consideradas séries temporais na presente aplicação, e sim cenários de ondas, o modelo numérico foi validado através da comparação de resultados modelados com dados medidos pela empresa Fibria ao longo de quatro meses do ano de 2011. Os fundeios instalados pela Fibria ficam entre a linha de costa e o arco interno de recifes em frente à região de Caravelas $\left(39,19^{\circ} \mathrm{S}\right.$, $\left.17,86^{\circ} \mathrm{W}\right)$. A Figura 33 mostra a comparação entre os dados medidos e modelados para a região (fundeio \#506 Fibria - indicado na Figura 32), sendo que as ondas são 
medidas após o processo de atenuação, em função de sua passagem pelos recifes. Um fator limitante na aplicação é a inexistência de dados medidos ao largo para utilizar como condição de contorno no modelo numérico. Em função disso, conforme mencionado anteriormente, é utilizada a série temporal extraída do modelo global de geração de ondas WAVEWATCH III.

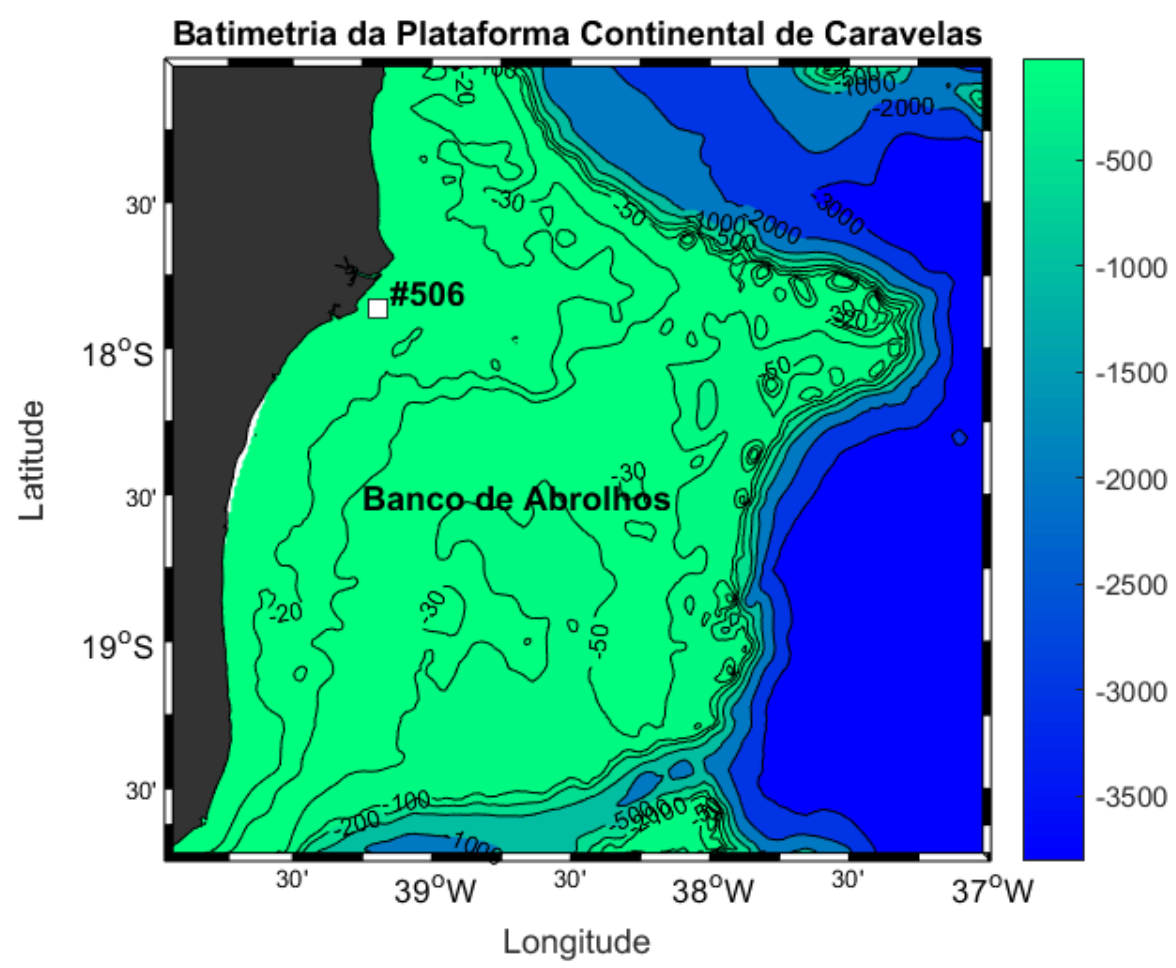

Figura 32: Batimetria da Plataforma de Abrolhos com a localização do ponto de

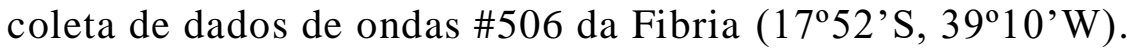

Apesar de diferenças, principalmente na magnitude das ondas, o padrão geral é reproduzido de forma razoável pelo modelo numérico aplicado (Figura 33). Os picos são subestimados pelo modelo numérico, da mesma forma que o observado na aplicação de Siegle e Costa (2017), utilizando os mesmos dados medidos, comparados com a aplicação do modelo Delft3D. Além da limitação existente para as condições de contorno, o fato do ponto \#506 estar relativamente protegido pelo arco interno de recifes, aumenta a complexidade de reprodução de dados nesse ponto. A complexidade morfológica local, e o ponto próximo à costa, resultam em maiores diferenças na comparação. 


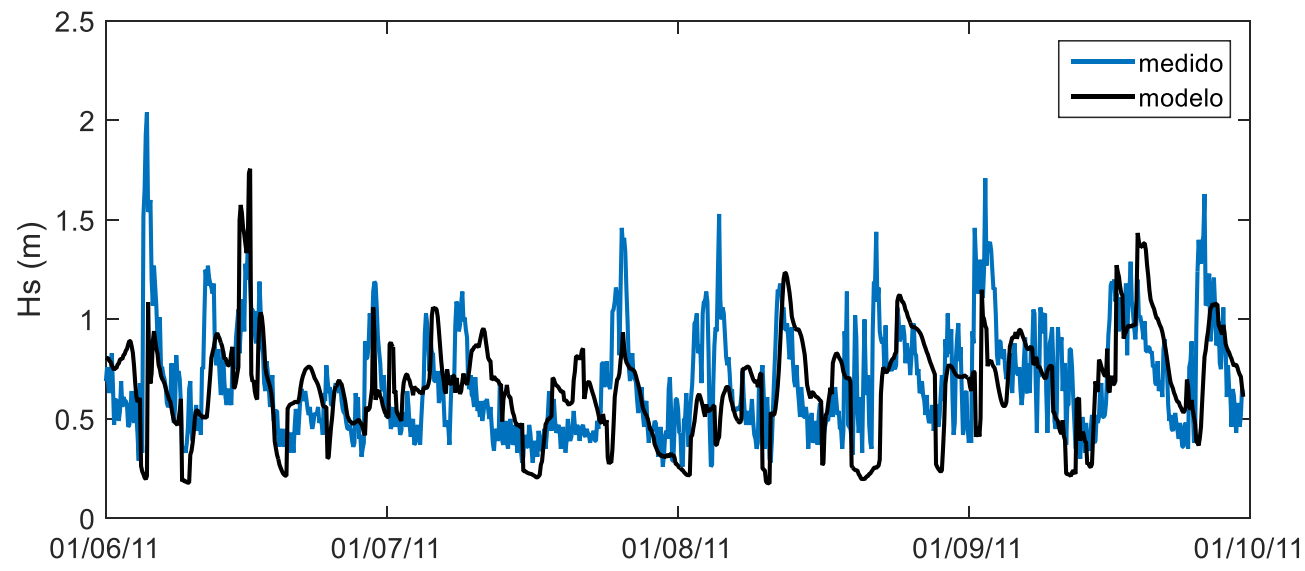

Figura 33: Série temporal comparativa entre dados medidos e modelados de altura significativa de onda (Hs) para o ponto \#506 (Fibria), entre junho e setembro de 2011.

\subsection{MOBILIDADE POTENCIAL DOS SEDIMENTOS}

A Velocidade Orbital Máxima de Fundo foi calculada segundo a equação de Harris e Coleman (1998) enquanto que a Velocidade Crítica de Fundo, necessária à inicialização do movimento dos sedimentos depositados, foi determinada para grãos esféricos, não coesivos, compostos de areia quartzosa com tamanho inferior à areia média (densidade $=2,65$ g.cm ${ }^{-3}$ e $\left.D_{50}<0,05 \mathrm{~cm}\right)$, de acordo com Clifton e Dingler (1984).

A Velocidade Orbital Máxima junto ao fundo (Umax) e a Velocidade Orbital Crítica (Ucr) foram calculadas a partir dos dados de saída do módulo de ondas do modelo MIKE 21, para cada caso simulado (condição de contorno).

\subsubsection{CÁLCULO DO COMPRIMENTO DA ONDA}

Baseado na Teoria da Onda de Airy (Komar e Miller, 1973), a seguinte equação simplificada para águas profundas, onde a profundidade é superior a metade do 
comprimento de onda $(\mathrm{d} / \mathrm{L} \infty>1 / 2)$, foi utilizada para calcular o comprimento da onda para cada ponto da malha do modelo,

$$
L \infty=\frac{g T^{2}}{2 \pi}
$$

onde g é a aceleração da gravidade $\left(9,81 \mathrm{~m} . \mathrm{s}^{-2}\right)$ e T é o período da onda (s) (Komar 1998).

Em águas intermediárias, onde a relação d / L $\infty$ está entre 1/2 e 1/20, a equação para determinação do comprimento de onda (L) é dependente do comprimento de onda (L), dificultando o cálculo (Nielsen 1982), conforme mostrado abaixo.

$$
L=L \infty\left[\tanh \left(\frac{2 \pi d}{L}\right)\right]
$$

onde Lo é o comprimento da onda em águas profundas, $\mathrm{d}$ a profundidade local e $\mathrm{L}$ o comprimento da onda em águas intermediárias. Entretanto, utilizando a aproximação derivada por Eckart (1952 apud Komar 1998), a equação pode ser reduzida a:

$$
L_{i}=L_{\infty}\left[\tanh \left(\frac{2 \pi d}{L_{\infty}}\right)\right]^{1 / 2}
$$

onde o comprimento da onda intermediária é obtido somente a partir do comprimento da onda em águas profundas. Esta equação apresenta uma relação de dispersão aproximada com acurácia de 5\% (Beji 2013).

Fenton e McKee (1990) propõem uma aproximação simples, obtida através da utilização de expoentes determinados empiricamente, que reduziram a acurácia a menos de $1,7 \%$. 


$$
L_{i}=L_{\infty}\left\{\tanh \left[\left(\frac{2 \pi d}{L_{\infty}}\right)^{3 / 4}\right]\right\}^{2 / 3}
$$

Posteriormente, Chang e Lin (1999) considerando o efeito da altura da onda utilizaram coeficientes variáveis nas aproximações; Guo (2002) utilizando uma associação logarítmica, reduziu o erro relativo para 0,75 \% e Beji (2013) melhorou a acurácia para $0,05 \%$ introduzindo uma função de correção empírica. Para efeito do cálculo do comprimento de onda no presente trabalho, a aproximação de Fenton e McKee (1990), com acurácia de 1,7 \% foi considerada satisfatória.

\subsubsection{CÁlCULO DA VELOCIDADE ORBITAL MÁXIMA}

Considerando a Teoria da Onda de Airy de primeira ordem (Komar e Miller, 1973), é possível estimar o transporte de sedimentos induzido por ondas através da determinação das correntes produzidas pela passagem das ondas em águas rasas, possuindo um diâmetro orbital do (Harris e Coleman, 1998), dado pela seguinte equação.

$$
d o=\frac{H s}{\sinh \left(\frac{2 \pi h}{L}\right)}
$$

A Velocidade Máxima junto ao Fundo (Umax) foi, então, calculada segundo a equação de Harris e Coleman (1998):

$$
U \max =\pi \frac{d o}{T}=\pi \frac{H s}{\left[T \sinh \left(\frac{2 \pi h}{L}\right)\right]}
$$

sendo Hs a altura significativa da onda; $\mathrm{T}$ período médio da onda significativa; $\mathrm{h}$ a profundidade e L o comprimento da onda. 


\subsubsection{CÁlCULO DA VELOCIDADE CRÍTICA DE FUNDO}

A velocidade crítica de fundo que determina o limite de movimento (threshold) para os grãos de sedimento é calculada pela seguinte equação de Clifton e Dingler (1984):

$$
\begin{gathered}
\mathrm{Ucr}=33,3(\mathrm{~T} . \mathrm{D})^{1 / 3} \mathrm{~cm} / \mathrm{s} \text { para sedimento com } \mathrm{D}_{50}<0,05 \mathrm{~cm} \\
\text { ou } \\
\mathrm{Ucr}=71,4\left(\mathrm{~T}^{\mathrm{N}} \mathrm{D}^{3}\right)^{1 / 7} \mathrm{~cm} / \mathrm{s} \text { para sedimento com } \mathrm{D}_{50}>0,05 \mathrm{~cm} .
\end{gathered}
$$

Quando os valores da Velocidade Orbital Máxima junto ao fundo (Umax) superam a velocidade crítica de fundo (Ucr) ocorre a movimentação dos grãos de sedimento.

Komar e Miller (1973) descrevem que para grãos de sedimento com diâmetro inferior a $0,05 \mathrm{~cm}$ (areia média), a velocidade crítica é atingida enquanto o fluxo ainda é laminar. Nessas circunstâncias, a velocidade crítica é dada pela relação Ucr $=0,30(d o / \mathrm{D})$, para grãos com densidade $\rho s=2,65 \mathrm{~g} \cdot \mathrm{cm}^{-3}$ (areias de quartzofeldspato), sendo do o diâmetro orbital do movimento da onda e D o diâmetro do grão de sedimento.

Desta forma, a velocidade crítica para movimentação de sedimentos pode ser avaliada para tamanhos de grãos que variam de silte (não coesivos) a sedimentos com diâmetro até $5 \mathrm{~cm}$ (o material mais grosso analisado).

\subsubsection{COBERTURA SEDIMENTAR}

Os dados texturais dos sedimentos foram obtidos de levantamentos previamente realizados por Apoluceno (1998) na plataforma continental da região de Ilhéus, onde a mediana do tamanho do grão foi calculado a partir da média de todos os tamanhos 
de grão (phi) de 105 amostras, Para a região de Caravelas, dados texturais previamente obtidos por Leão et al. (1997), Leão e Ginsburg (1997), Leão e Dominguez (2000), Leão (2002), e Leão et al. (2005) indicaram que os sedimentos de fundo são compostos por areias finas e lamas siliciclásticas na plataforma continental interna $(70 \%)$ e no entorno dos recifes costeiros $(30-70 \%)$ e por sedimentos biogênicos (cascalho, areia e lama), que predominam na plataforma média e externa do Banco de Abrolhos. Assim, a mediana do tamanho do grão utilizado para este trecho da plataforma foi o silte, considerando que o comportamento hidrodinâmico do cascalho biodetrítico pode ser similar ao de areia muito fina a silte arenoso. Os valores do diâmetro mediano dos sedimentos presentes na área foram utilizados no cálculo da Velocidade Crítica para movimentação dos sedimentos de fundo.

O valor do diâmetro mediano dos sedimentos em Ilhéus foi inferior a areia grossa, sendo o $\mathrm{D}_{50}$ utilizado no cálculo da Velocidade Crítica para estimar o transporte de sedimentos igual a $0,063 \mathrm{~mm}$ (areia muito fina). Para a plataforma continental de Caravelas, o valor de $\mathrm{D}_{50}$ foi estimado em $0,031 \mathrm{~mm}$ (silte grosso).

Os sedimentos que recobrem a plataforma continental leste brasileira são compostos por material siliciclástico junto à costa, sedimentos biogênicos junto à quebra da plataforma e no entorno dos recifes de coral e uma mistura destes materiais entre 20 e 30 metros de profundidade (Apoluceno, 1998; Leão, 2002). Areias siliciclásticas possuem densidade próxima a 2,65 g. $\mathrm{cm}^{-3}$, enquanto conchas inteiras ou fragmentos de conchas tem densidade de aproximadamente 2,40 g.cm³ (Soulsby, 1997). Apesar da densidade de partículas sedimentares de calcita e aragonita variar de $2,71 \mathrm{~g} / \mathrm{cm}^{3}$ a $2,95{\mathrm{~g} . \mathrm{cm}^{-3}}^{-3}$, respectivamente, em termos de sedimentos carbonáticos biogênicos, Jell et al. (1965) identificaram uma variação de 1,60 g.cm a 2,95 g.cm ${ }^{-3}$, dependendo do tipo de partícula sedimentar biogênica. Maiklem (1968) demonstrou que devido à influência da forma e da densidade do depósito de sedimentos carbonáticos, diferentes grãos apresentam comportamento hidrodinâmico diferente, no entanto, conforme a granulometria diminui, a velocidade de decantação torna-se similar para todas as formas de grão. A velocidade limite para transporte de sedimentos carbonáticos é similar a para sedimentos quartzosos desde que estes tenham tamanho, forma e densidade similares, entretanto, para densidades menores e sedimentos platifórmicos ou com morfologia irregular a velocidade exigida para o 
início do movimento é reduzida (Prager et al., 1996). Além disso, como os sedimentos de fundo da plataforma continental leste brasileira são predominantemente compostos por areia fina e silte, foi possível considerar que a mobilidade potencial dos sedimentos pode ser corretamente estimada pelas equações utilizadas nesse trabalho.

\subsubsection{POTENCIAL DE MOBILIDADE SEDIMENTAR}

A diferença entre a Velocidade Orbital Máxima junto ao fundo e a Velocidade Crítica para movimentação de sedimentos, calculada para cada ponto da malha do modelo, determina a profundidade máxima em que ocorre a mobilização de sedimentos junto ao fundo, ou seja, a profundidade limite de influência da ação das ondas no fundo. Assim, o transporte de sedimentos na Plataforma Leste Brasileira pode ser estimado.

A velocidade orbital máxima junto ao fundo, calculada a partir de cada altura significativa da onda e período, para cada ponto da malha do modelo, apresentou valores que variaram de 0 a $138 \mathrm{~cm} \cdot \mathrm{s}^{-1}$ em Caravelas durante o inverno e de 0 a $86 \mathrm{~cm} \cdot \mathrm{s}^{-1}$ no verão; enquanto que em Ilhéus as velocidades variaram de 0 a $144 \mathrm{~cm} . \mathrm{s}^{-1}$ em Ilhéus no inverno e de 0 a $103 \mathrm{~cm} . \mathrm{s}^{-1}$ durante o verão.

A velocidade crítica de fundo calculada a partir do período da onda e da mediana do tamanho do sedimento depositado variou de 8,0 a $10,9 \mathrm{~cm} \cdot \mathrm{s}^{-1}$ no inverno e de 7,2 a $10,6 \mathrm{~cm} \cdot \mathrm{s}^{-1}$ durante o verão em Caravelas, enquanto que em Ilhéus, as velocidades críticas variaram de 11,7 a $12,8 \mathrm{~cm} . \mathrm{s}^{-1}$ durante o inverno e de 10,9 a $14,0 \mathrm{~cm} \cdot \mathrm{s}^{-1}$ no verão. Uma vez que o tamanho do sedimento utilizado nos cálculos foi mantido constante, as diferenças entre as estações do ano indicam a influência da variação do período da onda na velocidade limite para o transporte de sedimentos junto ao fundo.

A comparação entre a velocidade orbital máxima junto ao fundo e a velocidade crítica para a movimentação do sedimento determina a profundidade a partir da qual ocorre mobilização do sedimento de fundo. Nos pontos da malha do modelo em que 
a diferença entre a velocidade orbital junto ao fundo e a velocidade crítica para a movimentação de sedimentos é positiva, ocorre mobilização de sedimentos; valores negativos indicam que as ondas não são competentes para induzir o movimento junto ao fundo.

O potencial de mobilidade foi calculado para cada célula da grade do modelo MIKE $21 \mathrm{SW}$. Os eventos de maior e menor potência da onda foram selecionados para ilustrar a região de mobilização do sedimento pelas ondas. A Figura 34 apresenta a linha a partir da qual o sedimento é mobilizado em Caravelas no verão (estação menos energética - Tabela 15, Caso 1) e a Figura 35 apresenta o mesmo limite no período de inverno (Tabela 15, Caso 5). Observa-se que durante o inverno, ondas mais energéticas são capazes de mobilizar sedimentos a maiores profundidades e, uma vez que os contornos batimétricos exibem contornos irregulares, a ação das ondas é distribuída aleatoriamente por toda a plataforma. Já em Ilhéus, o período menos energético é também o verão, sendo utilizado o Caso 6 (Tabela 16) na representação da área suscetível à mobilidade induzida por ondas, mas como as isóbatas são aproximadamente paralelas entre si e em relação à linha de costa, a mobilização de sedimentos acompanha este padrão (Figura 36 e 37). A Figura 37 representa a mobilidade dos sedimentos durante o inverno, período mais energético, Caso 6 (Tabela 16). 


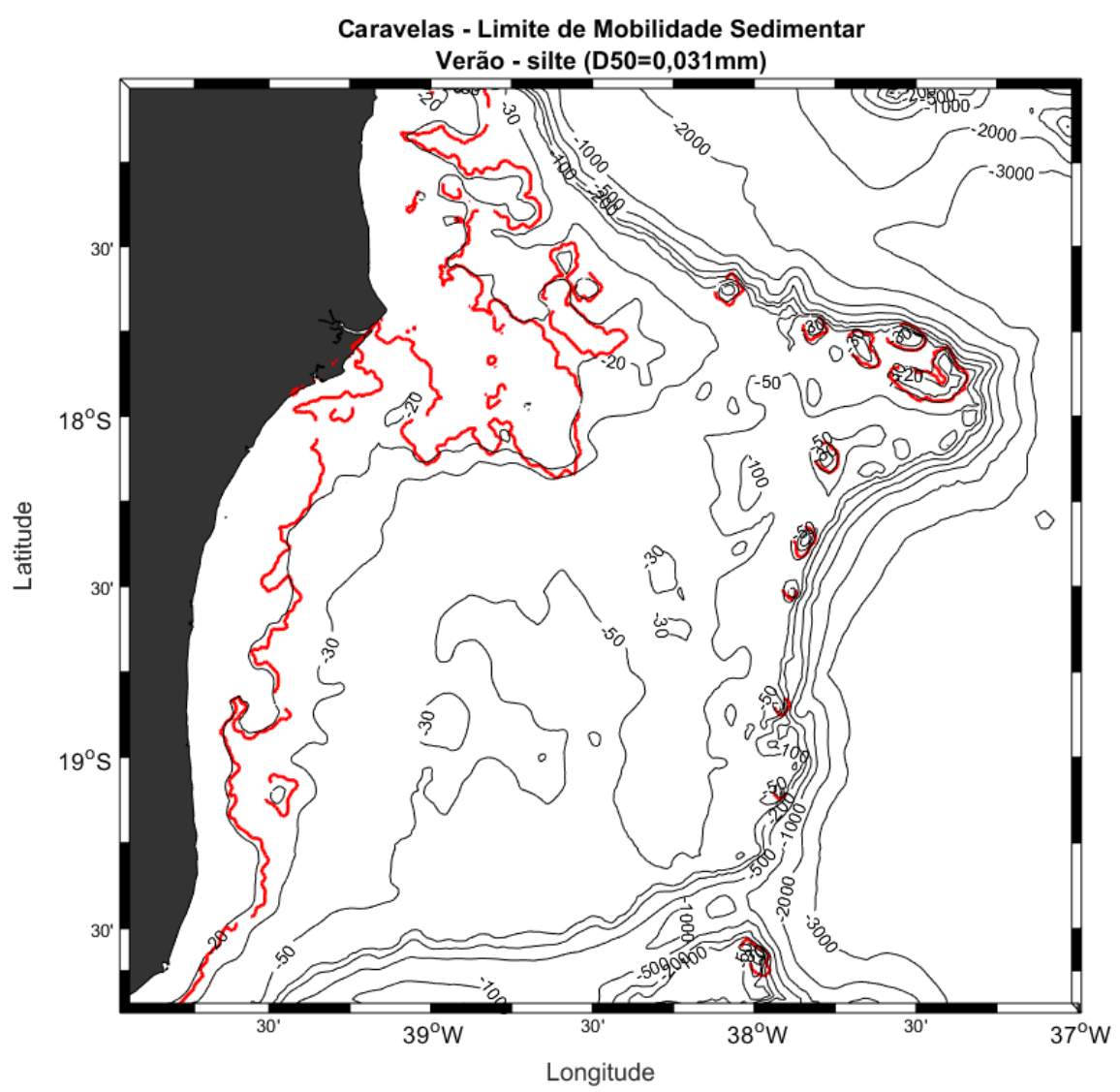

Figura 34: Mobilidade dos sedimentos em condições de ondas, durante o verão, na plataforma continental de Caravelas. A linha vermelha indica o limite para a movimentação de sedimentos com diâmetro de grão $0,031 \mathrm{~mm}$. Parâmetros da onda: $\mathrm{Hs}=1,28 \mathrm{~m} \quad \mathrm{~T}=6,63 \mathrm{~s} \quad \operatorname{Dir}=88,84^{\circ}$. 


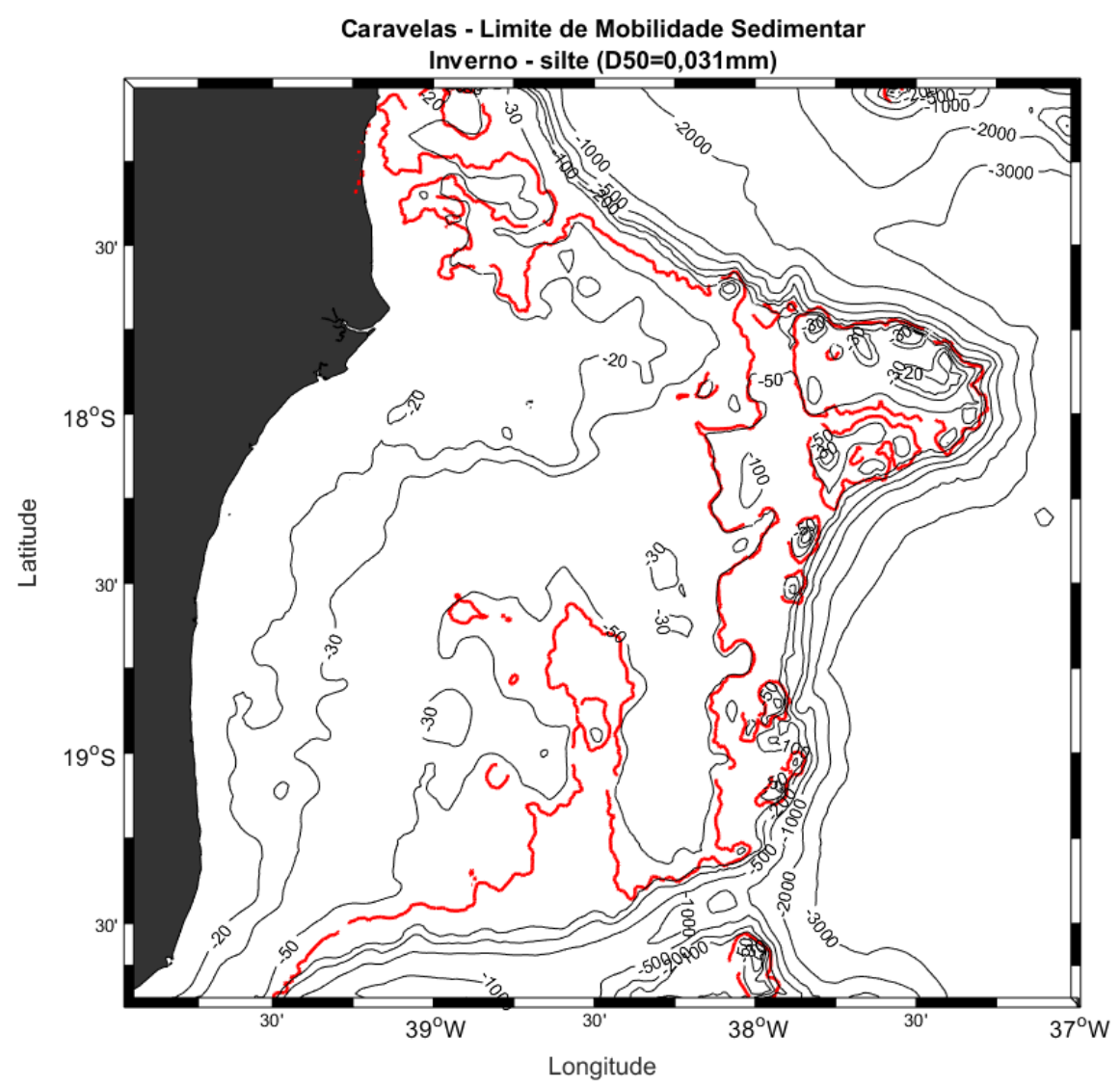

Figura 35: Mobilidade dos sedimentos em condições de ondas, durante o inverno, na plataforma continental de Caravelas. A linha vermelha indica o limite para a movimentação de sedimentos com diâmetro de grão 0,031 mm. Parâmetros da onda: $\mathrm{Hs}=2,71 \mathrm{~m}$ T=11,64 s Dir=188,08 . 


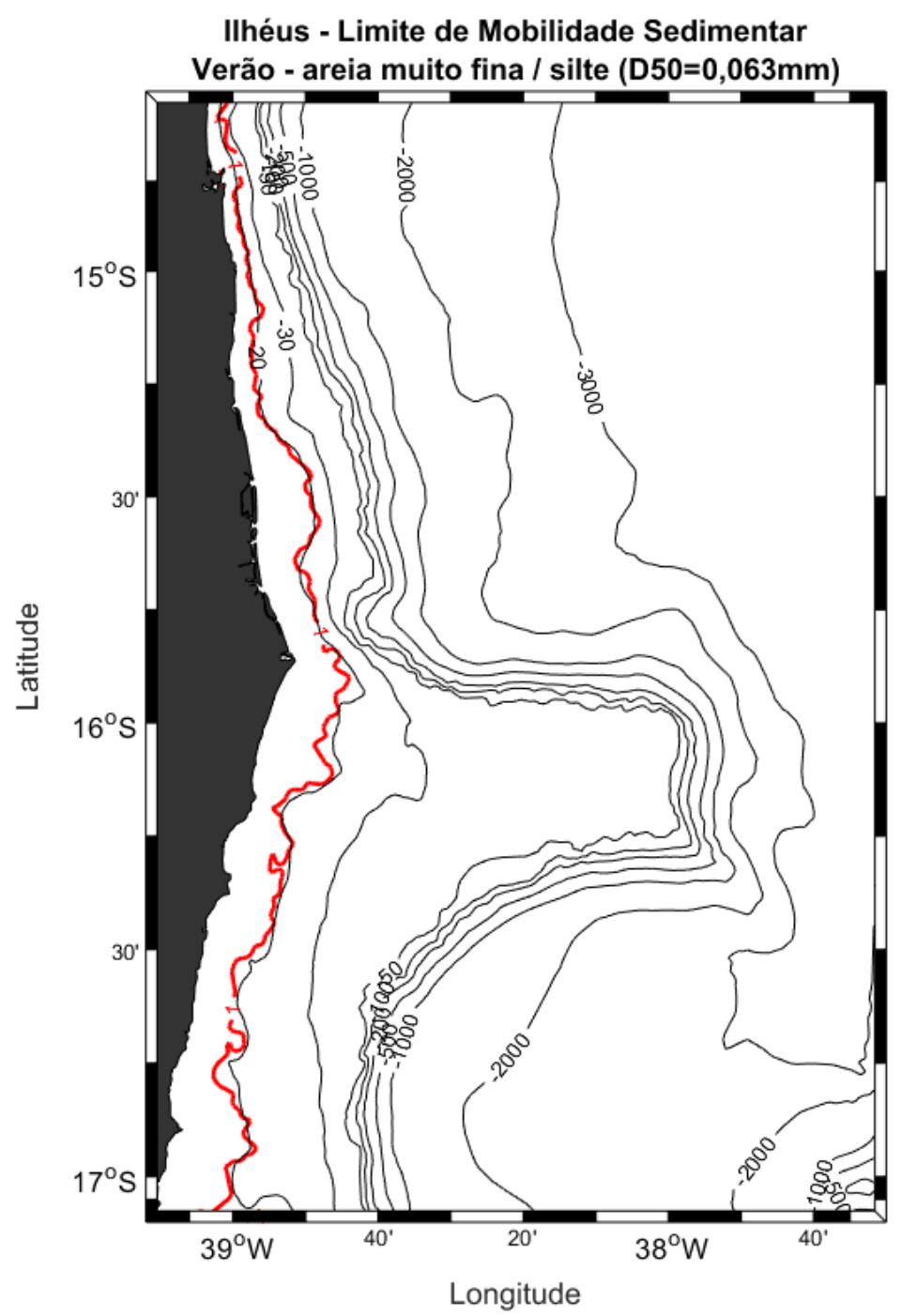

Figura 36: Mobilidade dos sedimentos sob condições de ondas, durante o verão na plataforma continental de Ilhéus. A linha vermelha indica o limite para a movimentação de sedimentos com diâmetro de grão $0,063 \mathrm{~mm}$. Parâmetros da onda: $\mathrm{Hs}=0,91 \mathrm{~m} \quad \mathrm{~T}=6,19 \mathrm{~s} \quad \operatorname{Dir}=93,85^{\circ}$ 


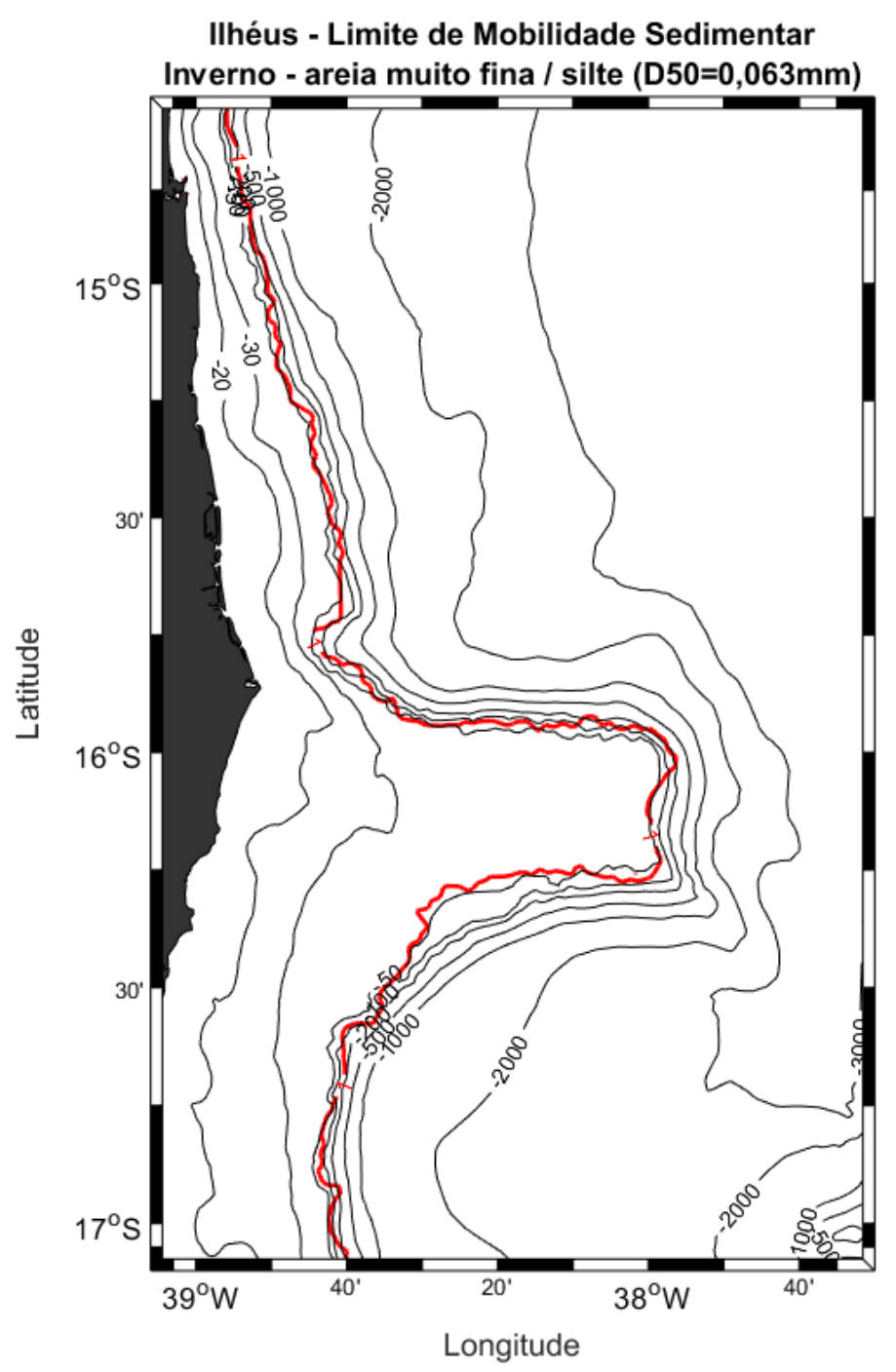

Figura 37: Mobilidade dos sedimentos sob condições de ondas, durante o inverno na plataforma continental de Ilhéus. A linha vermelha indica o limite para a movimentação de sedimentos com diâmetro de grão $0,063 \mathrm{~mm}$. Parâmetros da onda: $\mathrm{Hs}=2,69 \mathrm{~m} \quad \mathrm{~T}=8,54 \mathrm{~s} \quad \operatorname{Dir}=100,69^{\circ}$ 
Observa-se que o transporte de sedimentos induzido por ondas na plataforma continental leste brasileira ocorre em profundidades inferiores a $20 \mathrm{~m}$ para diâmetros medianos de sedimento mais finos que $0,068 \mathrm{~mm}$ (areia muito fina), em condições de baixa energia, enquanto que atinge até $50 \mathrm{~m}$ de profundidade em momentos de alta energia.

A mobilidade dos sedimentos é um indicador da contribuição da plataforma continental com o balanço de sedimentos da linha de costa. Na região sudeste da plataforma continental leste brasileira, os cálculos utilizados no presente trabalho sugerem que a mobilização de sedimentos ocorre em profundidades inferiores a $20 \mathrm{~m}$ durante períodos menos energéticos e chega até $50 \mathrm{~m}$ em períodos de maior energia da onda. Este resultado corrobora a definição do limite externo da plataforma continental interna da costa brasileira que é considerada em torno dos $50 \mathrm{~m}$, no entanto, a potência da onda $(\mathrm{P})$ na região nordeste do Brasil sugere que este transporte deva, nessa região, estar limitado a 20 ou $30 \mathrm{~m}$ de profundidade (Muehe 1998).

Campos e Dominguez (2010) obtiveram, para a plataforma continental norte da Bahia, profundidade máxima de mobilização de sedimentos de $45 \mathrm{~m}$ para altura e período médio da onda e de $60 \mathrm{~m}$ para altura e período significativos da onda. Entretanto, utilizando as mesmas equações de velocidade orbital e velocidade crítica, os cálculos não corroboram essa informação, o que pode estar relacionado às diferenças morfológicas entre os dois trechos da plataforma continental baiana e a presença de feições morfológicas de destaque no trecho estudado, como o Banco Royal Charlote e o Banco de Abrolhos, que interferem na propagação de energia das ondas na costa.

Bittencourt et al. (2000), utilizando as principais alturas e períodos significativos das ondas associados às diferentes frentes de aproximação indicadas pelo atlas da U.S. Navy (1978) - ondas de NE $\left(45^{\circ}\right)$ e E $\left(90^{\circ}\right)$ com Hs= 1,0 m e Ts= 5 s; e ondas de SE $\left(135^{\circ}\right)$ e $\operatorname{SSE}\left(157,5^{\circ}\right)$ com $\mathrm{Hs}=1,5 \mathrm{~m}$ e $\mathrm{Ts}=6,5 \mathrm{~s}$ - estimaram que as ondas provenientes de NE e E passariam a interferir no fundo marinho a profundidade de $20 \mathrm{~m}$, enquanto que as ondas de SE e SSE mobilizariam sedimentos a profundidades de até $35 \mathrm{~m}$. 
Apesar da concordância com alguns resultados obtidos em levantamentos anteriores, o detalhamento dos dados de cobertura sedimentar, grau de consolidação do fundo e variáveis bióticas na plataforma continental irão contribuir para uma melhor interpretação da profundidade limite da influência das ondas sobre o fundo marinho na plataforma continental leste brasileira.

\subsubsection{MOBILIDADE TOTAL DE SEDIMENTOS}

A integração entre a climatologia das ondas atuantes sobre a plataforma continental leste brasileira, através do somatório da frequência de ocorrência das ondas mais frequentes (> 5\%) normatizada a 100\%, e o tipo de cobertura sedimentar presente na área permitiu a quantificação do percentual de tempo em que os sedimentos são mobilizados pelas ondas.

Foi utilizada a relação entre a velocidade orbital junto ao fundo e a velocidade crítica para movimentação de sedimentos em cada ponto da malha do modelo, associada à frequência de ocorrência de cada onda utilizada nas simulações, para quantificar o percentual do tempo que cada região da plataforma continental é mobilizada pela ação das ondas.

O resultado desta análise é apresentado para cada estação do ano em Caravelas (Figuras de 38 a 41) e em Ilhéus (Figuras de 42 a 45). 


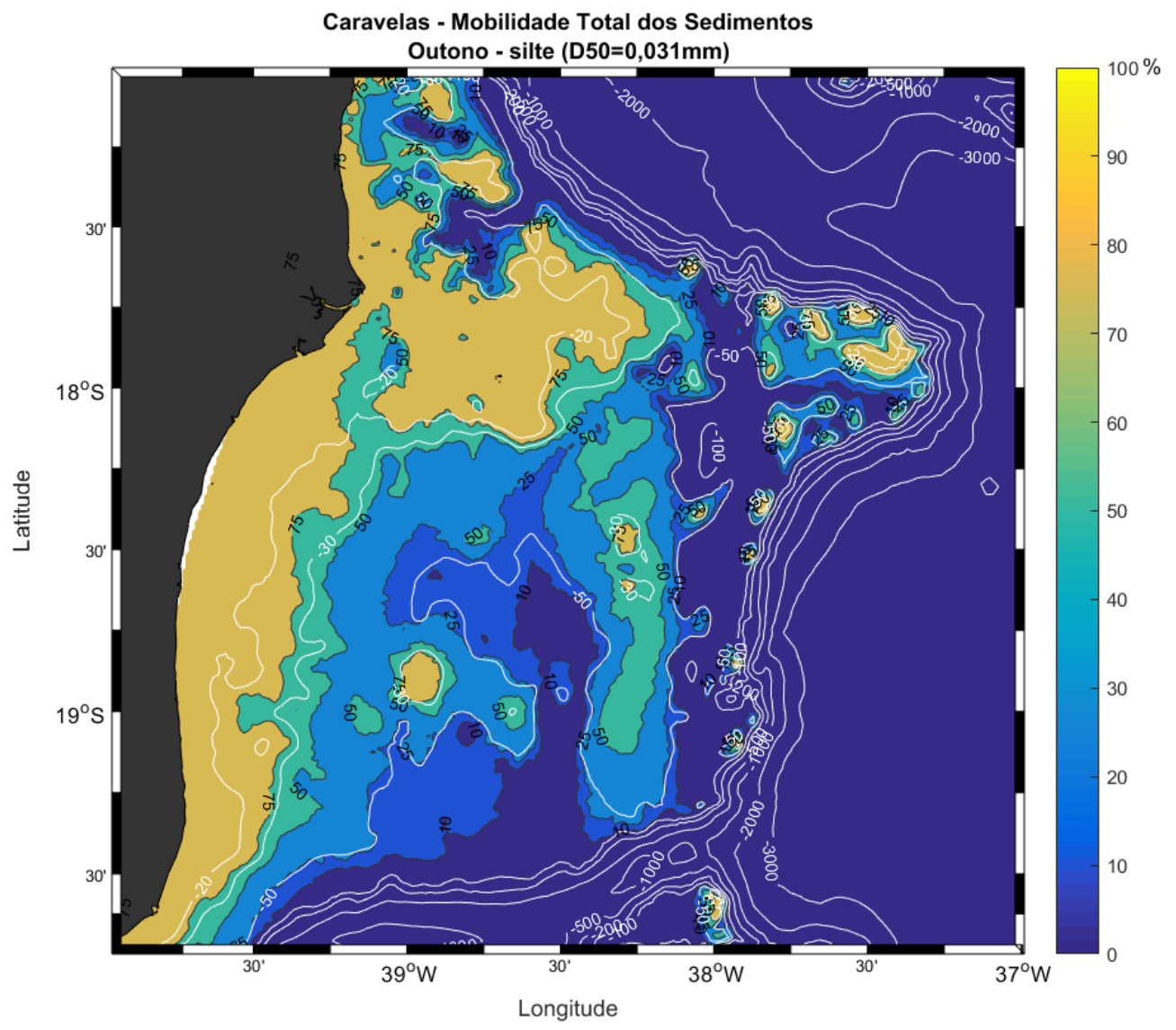

Figura 38: Somatório da taxa de mobilidade dos sedimentos: percentual de tempo em que o sedimento depositado na plataforma continental de Caravelas é mobilizado pelas ondas incidentes durante o outono, para sedimento com $\mathrm{D}_{50}=0,031 \mathrm{~mm}$. 


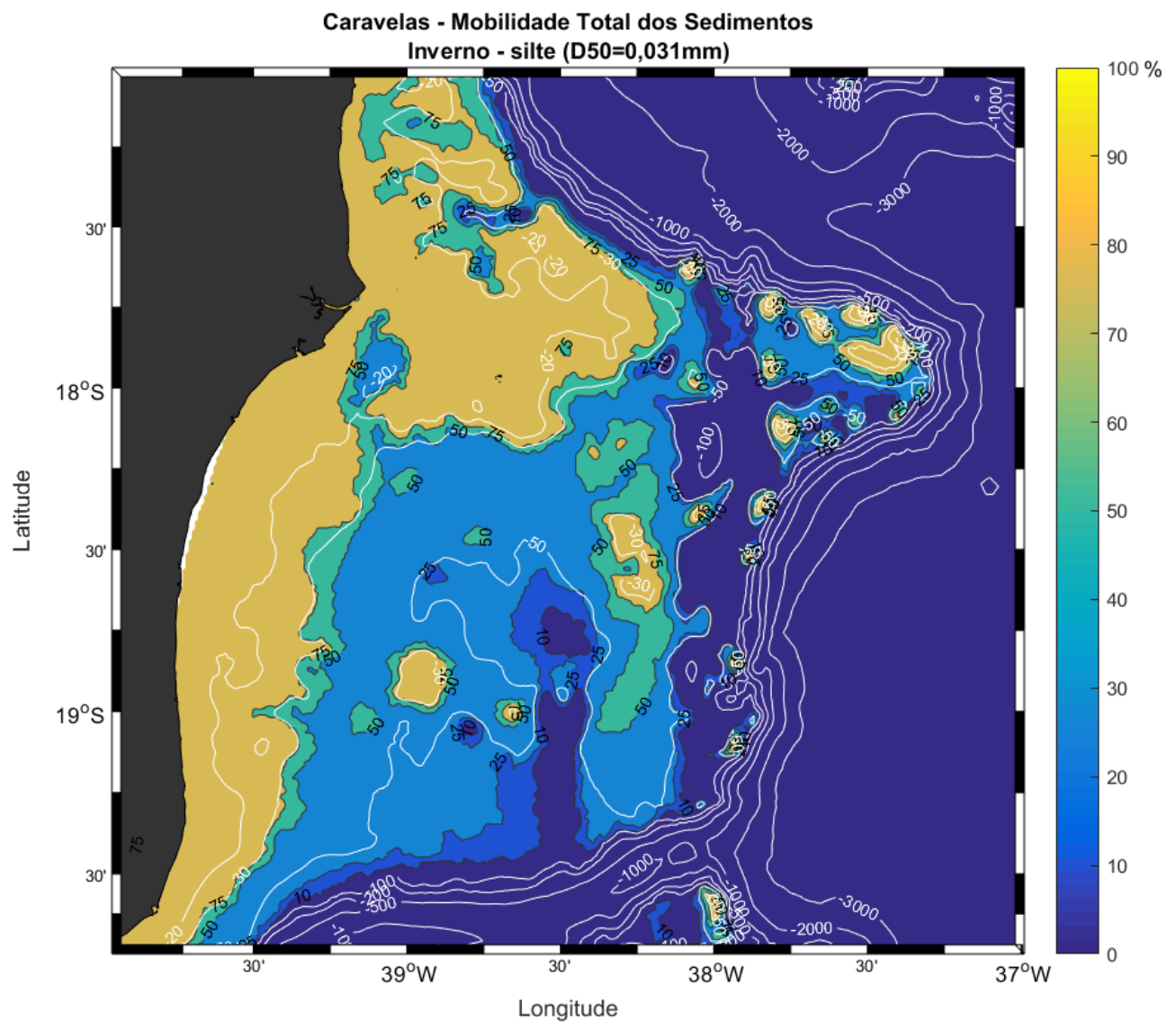

Figura 39: Somatório da taxa de mobilidade dos sedimentos: percentual de tempo em que o sedimento depositado na plataforma continental de Caravelas é mobilizado pelas ondas incidentes durante o inverno, para sedimento com $\mathrm{D}_{50}=0,031 \mathrm{~mm}$. 


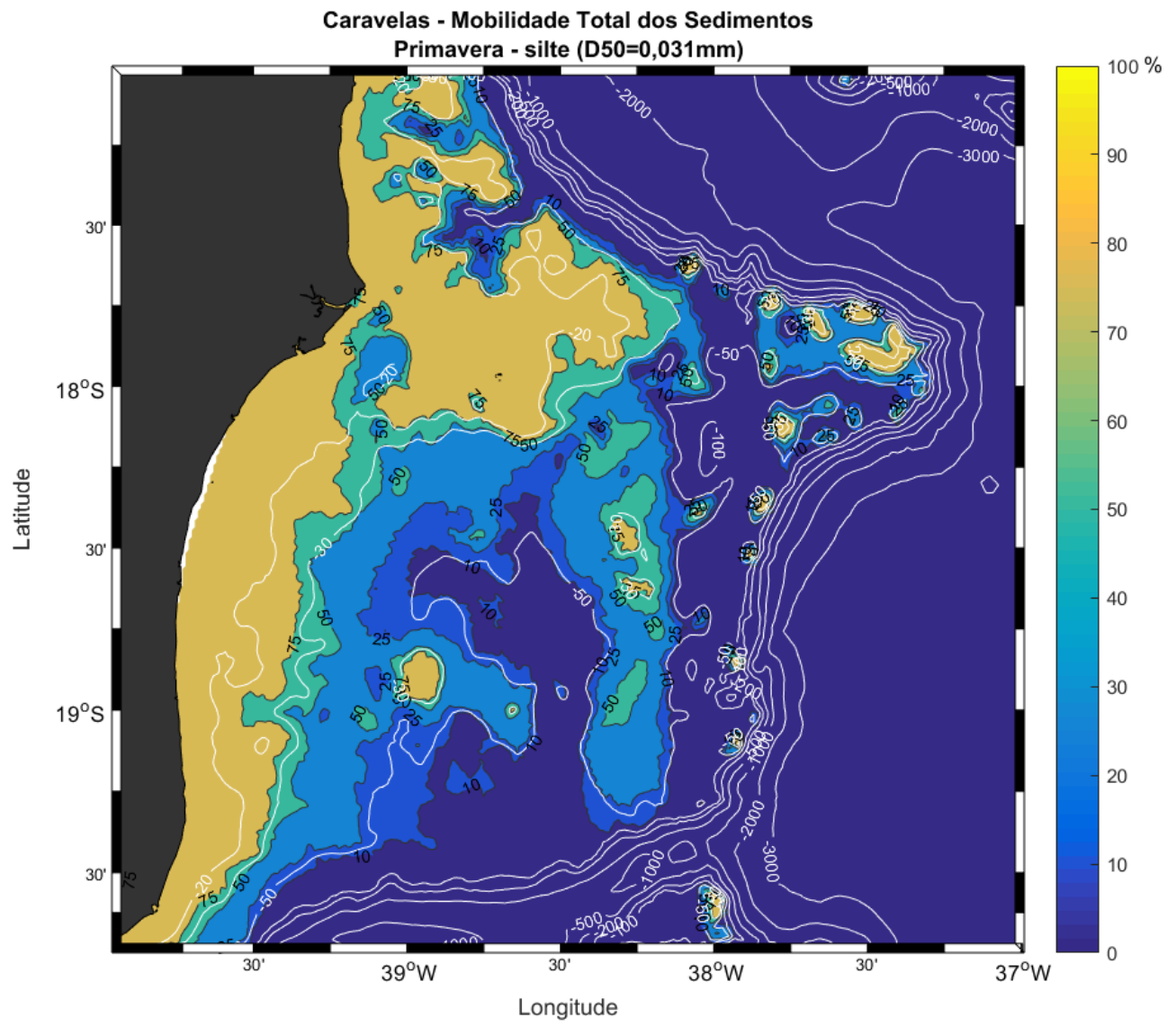

Figura 40: Somatório da taxa de mobilidade dos sedimentos: percentual de tempo em que o sedimento depositado na plataforma continental de Caravelas é mobilizado pelas ondas incidentes durante a primavera, para sedimento com $\mathrm{D}_{50}=0,031 \mathrm{~mm}$. 


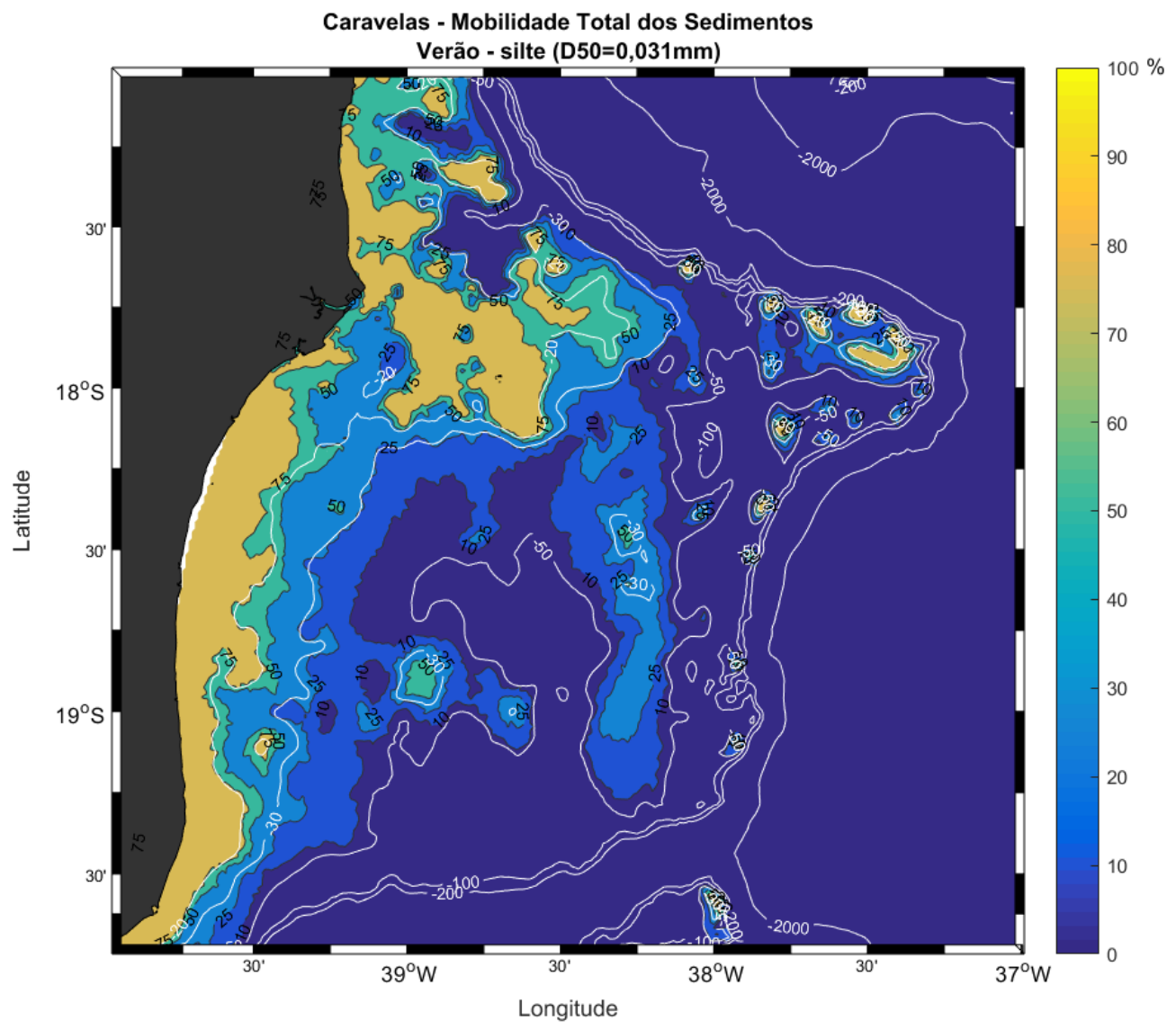

Figura 41: Somatório da taxa de mobilidade dos sedimentos: percentual de tempo em que o sedimento depositado na plataforma continental de Caravelas é mobilizado pelas ondas incidentes durante o verão, para sedimento com $\mathrm{D}_{50}=0,031 \mathrm{~mm}$. 


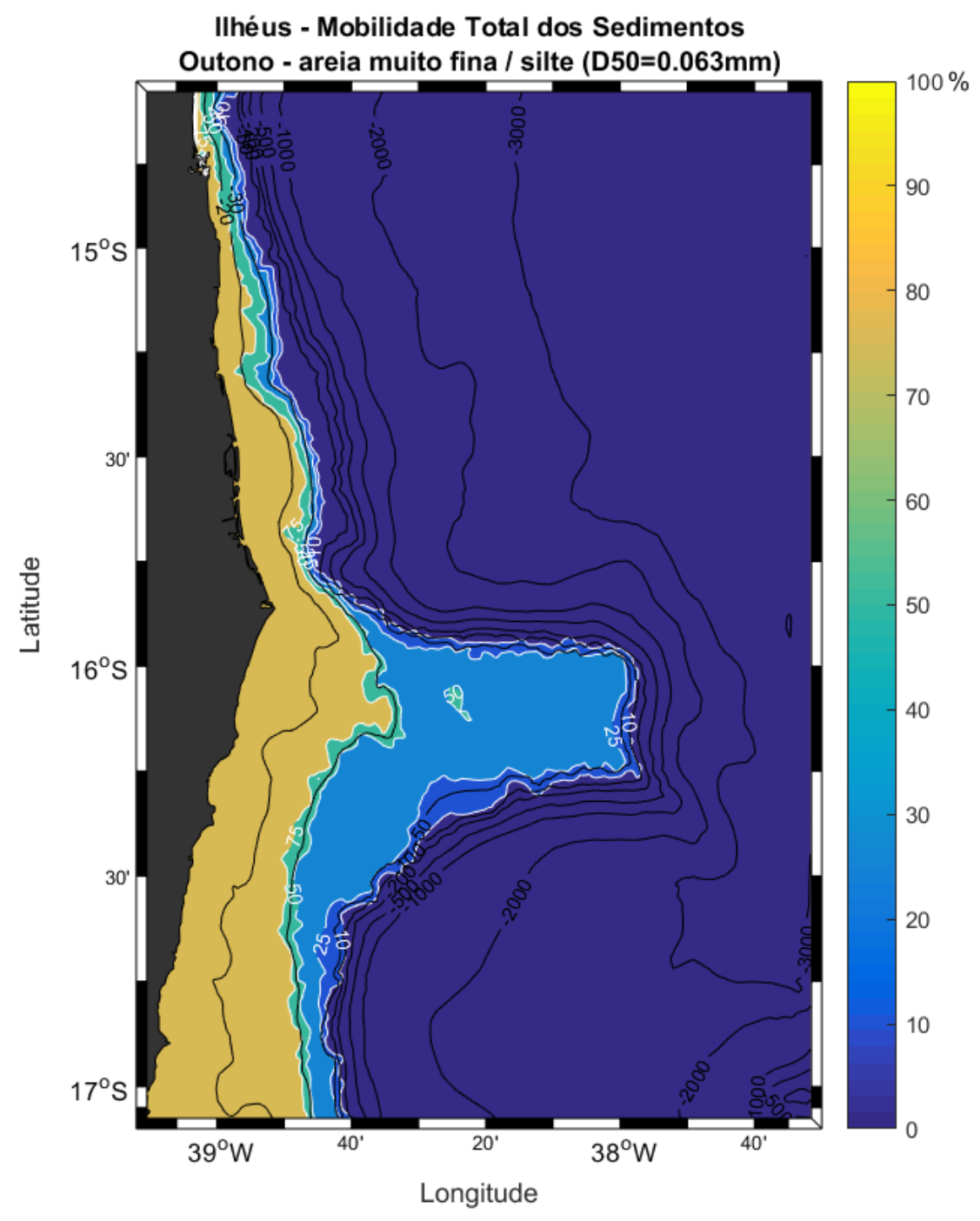

Figura 42: Somatório da taxa de mobilidade dos sedimentos: percentual de tempo em que o sedimento depositado na plataforma continental de Ilhéus é mobilizado pelas ondas incidentes durante o outono, para sedimento com $\mathrm{D}_{50}=0,063 \mathrm{~mm}$. 


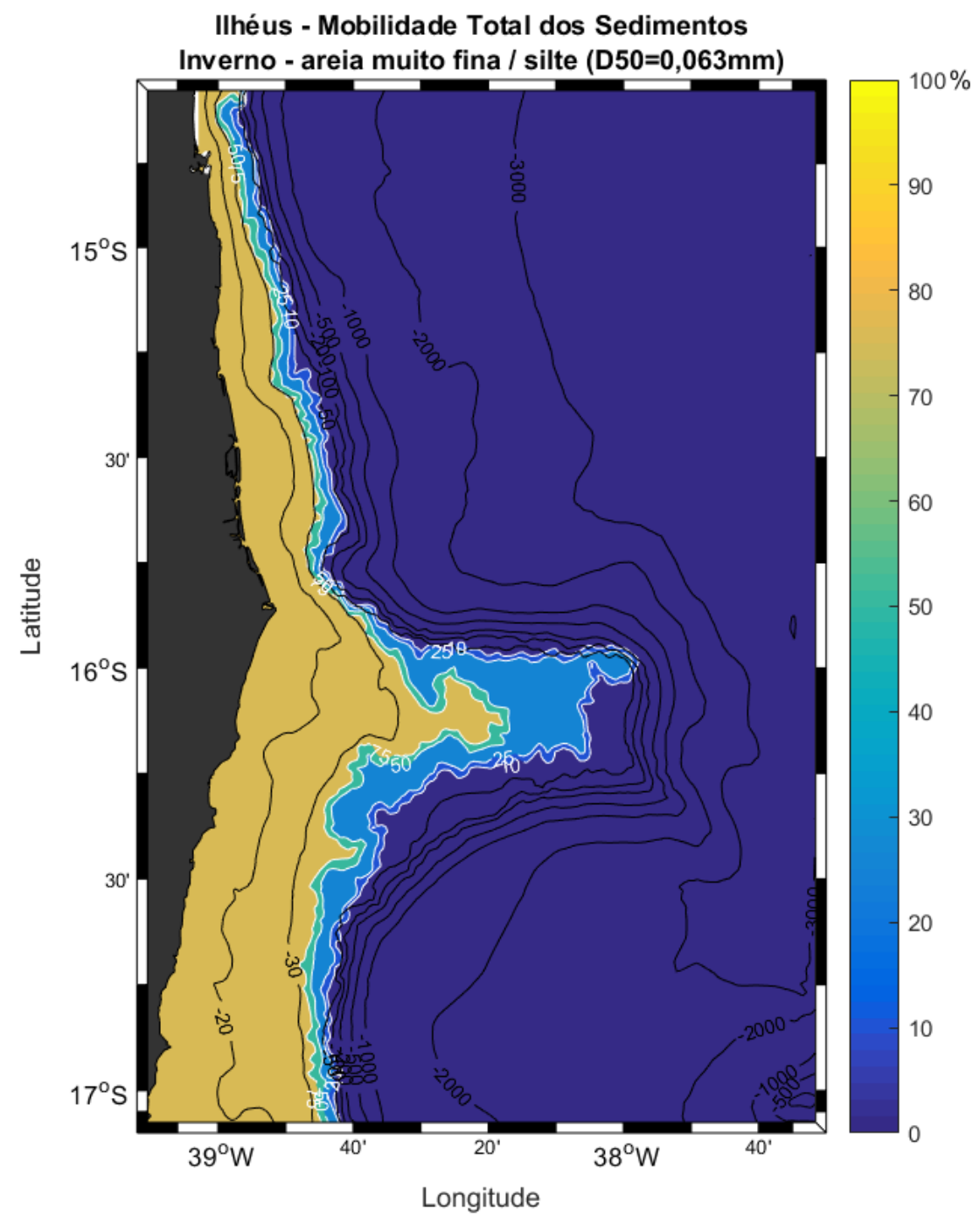

Figura 43: Somatório da taxa de mobilidade dos sedimentos: percentual de tempo em que o sedimento depositado na plataforma continental de Ilhéus é mobilizado pelas ondas incidentes durante o inverno, para sedimento com $\mathrm{D}_{50}=0,063 \mathrm{~mm}$. 


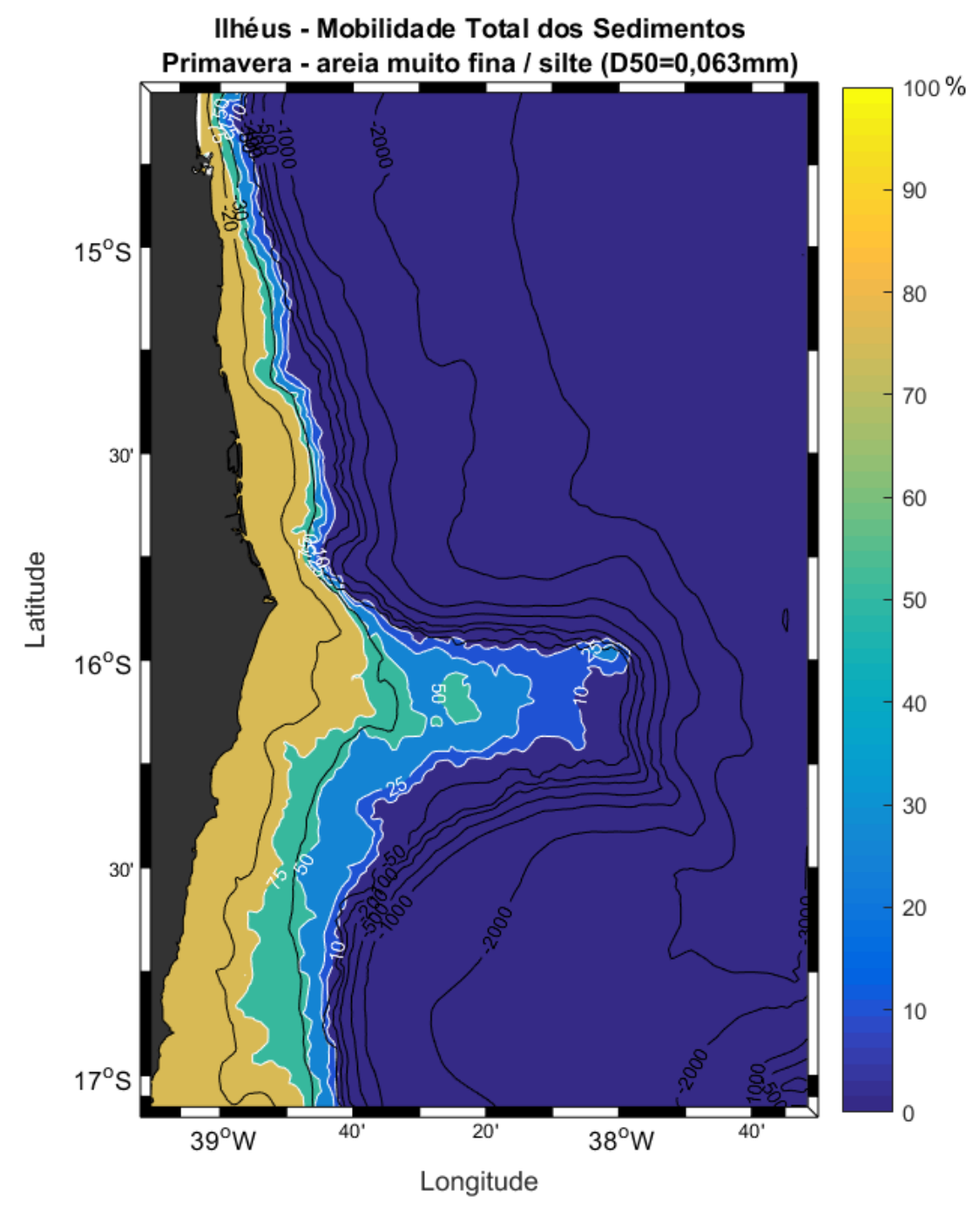

Figura 44: Somatório da taxa de mobilidade dos sedimentos: percentual de tempo em que o sedimento depositado na plataforma continental de Ilhéus é mobilizado pelas ondas incidentes durante a primavera, para sedimento com $\mathrm{D}_{50}=0,063 \mathrm{~mm}$. 


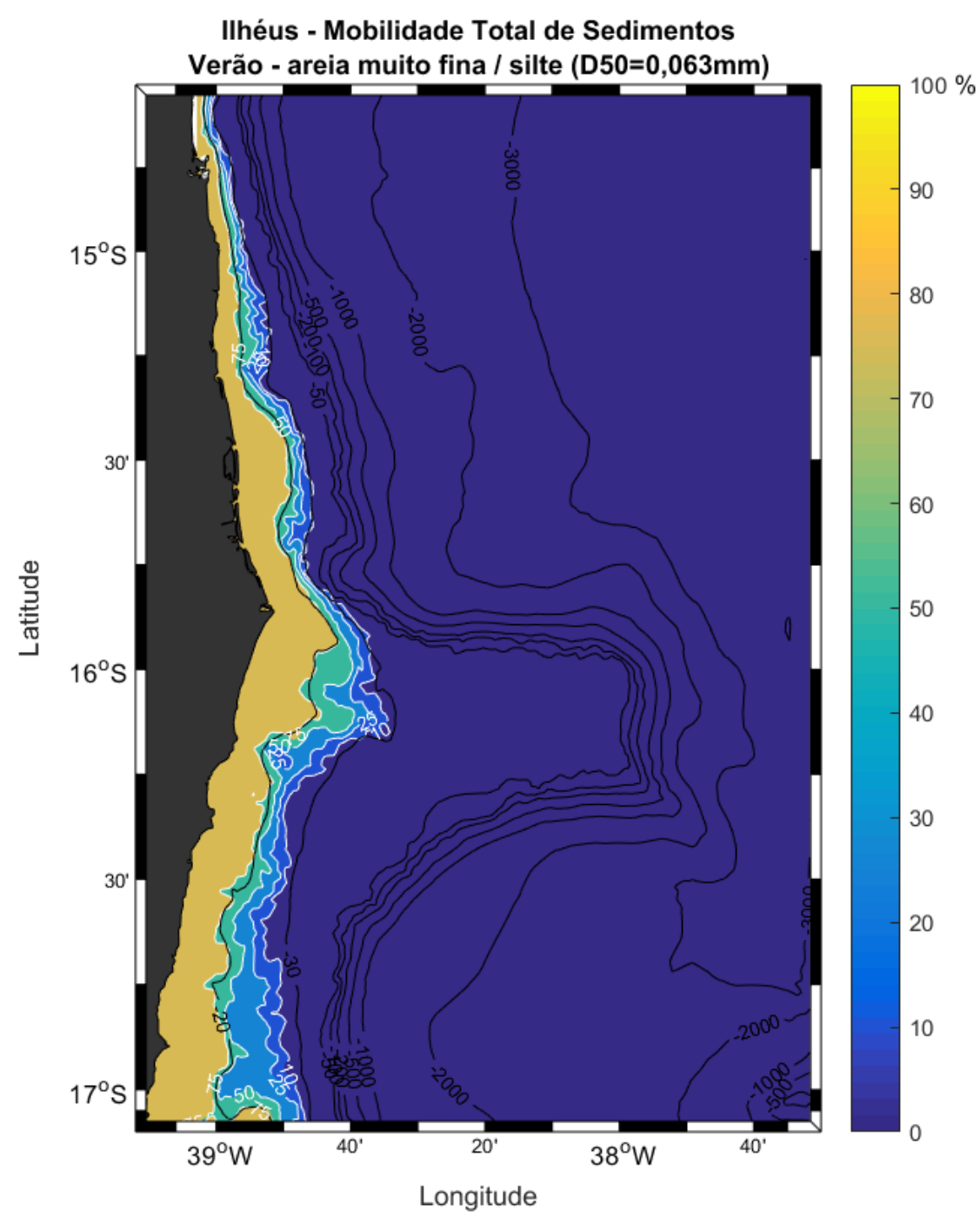

Figura 45: Somatório da taxa de mobilidade dos sedimentos: percentual de tempo em que o sedimento depositado na plataforma continental de Ilhéus é mobilizado pelas ondas incidentes durante o verão, para sedimento com $\mathrm{D}_{50}=0,063 \mathrm{~mm}$. 


\subsection{DISCUSS ÃO - MOBILIDADE SEDIMENTAR}

O clima de ondas fora da plataforma e a propagação desta onda em direção à costa permitiram a avaliação do transporte de sedimentos induzido por ondas na plataforma continental leste brasileira, entre as desembocaduras do Rio de Contas (BA) e do Rio Doce (ES).

A mobilidade dos sedimentos é um indicador da contribuição da plataforma continental no balanço de sedimentos na costa, sendo dependente da sua morfologia e das alterações que esta promove na propagação das ondas. Os resultados demonstram que a mobilidade dos sedimentos ocorre sobre toda a plataforma continental em períodos mais energéticos e na plataforma interna durante a maior parte do tempo.

Um importante fator que controla a mobilidade dos sedimentos é a complexidade da morfologia da plataforma, que na área de estudo varia em largura de cerca de $10 \mathrm{~km} \mathrm{em}$ frente a Ilhéus, para mais de $200 \mathrm{~km}$ em frente a Caravelas. O gradiente batimétrico também é diferenciado entre os dois trechos de plataforma, sendo bastante inclinado em frente a Ilhéus, com as isóbatas aproximadamente paralelas à linha de costa, enquanto que em frente a Caravelas, sobre o Banco de Abrolhos, as isóbatas apresentam contornos irregulares devido à presença dos recifes de coral.

O clima de ondas também é diferenciado entre as duas estações utilizadas na pesquisa. O litoral de Ilhéus está exposto à ação de ondas de nordeste e leste, mas protegido das ondas mais energéticas provenientes dos quadrantes sudeste e sul, devido à presença do Banco de Abrolhos, que dissipa grande parte das ondas provenientes destes quadrantes. Já Caravelas, localizada mais a sul, sofre a influência das ondas de Sul e Sudeste, sendo as mais energéticas, mas apresentando durante a propagação da onda, uma região protegida na costa pela formação recifal. Assim, a região de Abrolhos recebe ondas mais energéticas provenientes de sul (swell) enquanto que a dinâmica em Ilhéus é controlada por ondas de leste. 
Entretanto, apesar de receber ondas mais energéticas costa afora, a plataforma de Abrolhos atenua intensamente as ondas incidentes (Siegle e Costa, 2017), devido a seus dois arcos recifais: o arco interno, onde os recifes costeiros se formam a profundidades de cerca de 10 m, e o arco externo com recifes oceânicos que se desenvolvem próximo à quebra da plataforma (Leão et al., 1988). Por outro lado, trechos mais estreitos da plataforma que ocorrem intercalados aos trechos mais largos, são menos eficientes à atenuação das ondas, estando sujeitos a níveis de energia relativamente mais elevados.

A mobilidade dos sedimentos induzido pela ação das ondas na plataforma continental leste brasileira ocorre durante todo o ano, mesmo nos meses menos energéticos do verão quando está limitado a profundidades inferiores a $50 \mathrm{~m}$, em Ilhéus para sedimentos de tamanho areia muito fina / silte $\left(D_{50}=0,063 \mathrm{~mm}\right)$ e até $20 \mathrm{~m}$ em Caravelas, para sedimentos de tamanho silte $\left(\mathrm{D}_{50}=0,031 \mathrm{~mm}\right)$. Condições de ondas mais energéticas são capazes de mobilizar sedimentos até uma profundidade de $200 \mathrm{~m}$ em frente a Ilhéus, e até $100 \mathrm{~m}$ sobre a plataforma de Abrolhos. Estes resultados corroboram e detalham melhor a definição de limite distal da plataforma interna da região nordeste do Brasil, a qual é considerada como variável entre 20 e 30 m (Muehe, 1998).

Os resultados demonstram a importância do controle morfológico na mobilidade potencial dos sedimentos. Em termos regionais, a mobilidade varia em função da largura da plataforma continental devido a diferenças no grau de atenuação da onda incidente. Em escalas locais, as diferenças observadas são resultado da variabilidade morfológica da plataforma, relacionada à presença de formações recifais, distribuídas por toda a plataforma de Abrolhos. Essas irregularidades morfológicas resultam em áreas protegidas da ação das ondas, entre as formações recifais, onde as ondas não têm competência para mobilizar o sedimento depositado, mesmo em áreas rasas. A Figura 46 apresenta a localização dos perfis de variação da mobilidade sedimentar ilustrados na Figura 47, que apresenta uma comparação entre dois perfis batimétricos em frente a Ilhéus e em frente a Caravelas e a sua interação com as ondas que resulta numa alteração da mobilidade sedimentar.

Bastos et al. (2015), discutem que morfologicamente, a plataforma de Abrolhos pode ser dividida em dois setores, o setor norte, mais raso e apresentando uma plataforma interna ampla e o setor sul, mais profundo e acidentado. A mobilidade dos sedimentos ocorre intensamente na parte norte, mais rasa e ampla, enquanto que os sedimentos na 
porção sul, mais profunda e com muitas depressões, estão menos suscetíveis a mobilização pelas ondas, mesmo durante os eventos mais energéticos nos meses de inverno.

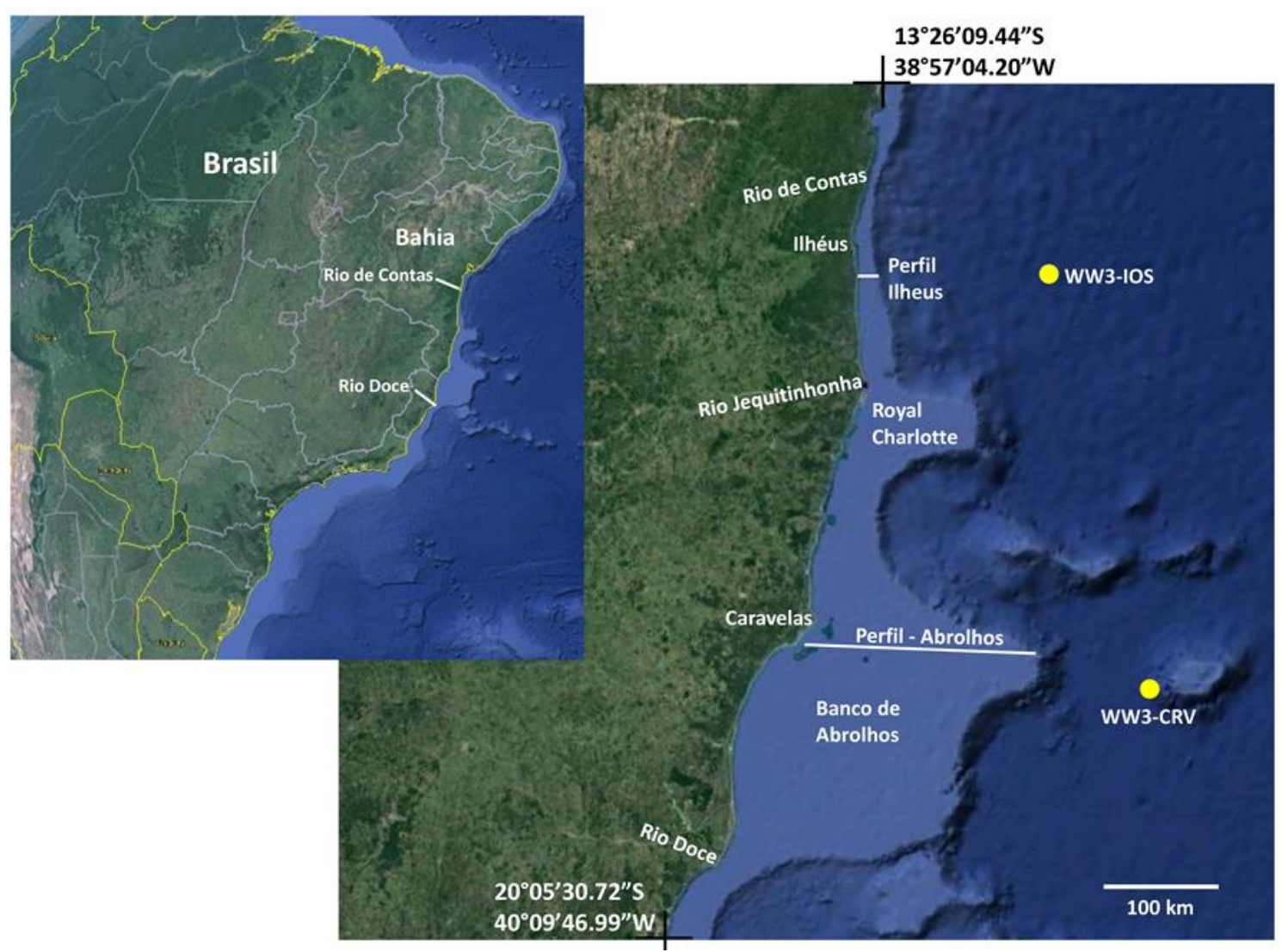

Figura 46: Área de estudo, entre o Rio de Contas (BA) e o Rio Doce (ES), apresentando a posição dos perfis batimétricos e de variação da mobilidade sedimentar mostrados na Figura 47 (Imagem Google Earth). 

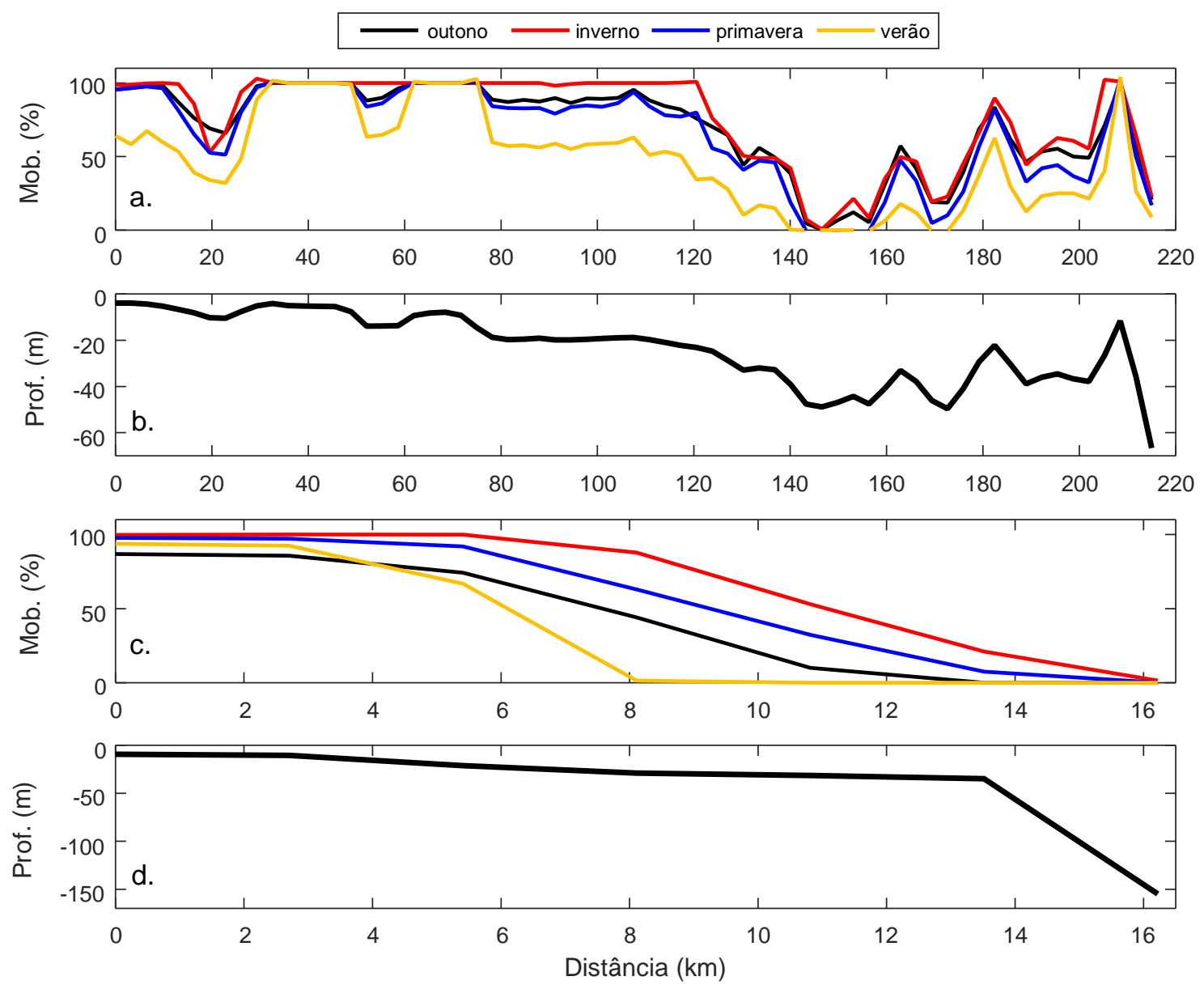

Figura 47: Perfis de mobilidade sedimentar (\%) para Caravelas (a) e Ilhéus (c), para cada estação do ano. (b) e (c) representam o perfil batimétrico para Caravelas e Ilhéus, respectivamente.

Em Ilhéus, a mobilidade dos sedimentos apresenta um comportamento mais homogêneo, condicionado primariamente pela variação de profundidade, que se dá aproximadamente paralela à linha de costa, sendo o verão o período menos energético (Figura 47c e 47d).

A ampla plataforma de Abrolhos abriga o maior sistema de recifes tropicais do oceano Atlântico Sul, sendo os resultados aqui apresentados importantes no entendimento da distribuição de seus diferentes habitats biológicos. A mobilidade dos sedimentos e a exposição do fundo marinho ao estresse de cisalhamento estão relacionadas à distribuição dos sistemas biológicos (Hemer, 2006), especialmente em regiões de águas rasas, mais sujeitas à ação das ondas. Processos induzidos por ondas podem representar fatores estressantes limitantes ao desenvolvimento de organismos bentônicos 
(Carruthers et al., 2002; Cheroske et al., 2000; Aller e Todorov, 1997), ou benéficos em termos de aporte de nutrientes e matéria orgânica consumida pelas diferentes espécies que habitam os ambientes recifais (Gruber et al., 2018; Houlbrèque e Ferrier-Pagès, 2009; Genin et al., 2009; Ribes e Atkinson, 2007). Similarmente, os amplos campos de rodolitos (agregados nodulares de algas vermelhas coralíneas incrustantes) que ocorrem na região (Amado-Filho et al., 2012) também podem se beneficiar do estresse das correntes geradas por ondas junto ao fundo, que podem eventualmente causar o rolamento dos rodolitos (Marrack, 1999; Harris et al., 1996), otimizando a distribuição da luminosidade ou ainda evitando soterramento e incrustação.

Apesar da atividade biológica poder alterar a tensão de cisalhamento no fundo marinho, além de estabilizar ou desestabilizar o sedimento depositado, alterando a velocidade crítica para a mobilização do sedimento (Hemer, 2006), neste trabalho o sedimento de fundo foi considerado homogêneo, composto por partículas siliciclásticas do tamanho areia / silte $\left(D_{50}=0,063 \mathrm{~mm}\right)$ na plataforma de Ilhéus e com partículas do tamanho silte $\left(\mathrm{D}_{50}=0,031 \mathrm{~mm}\right)$ na plataforma de Abrolhos.

Os resultados corroboram com as profundidades máximas de mobilização dos sedimentos estimadas anteriormente, no entanto, a incorporação de dados de distribuição granulométrica dos sedimentos poderá melhorar a interpretação da profundidade limite para a mobilidade sedimentar, conforme discutido por Harris e Colleman (1998). O percentual do tempo durante o qual os sedimentos são potencialmente mobilizados por ondas variou de $90 \%$ a profundidades inferiores a $10 \mathrm{~m}$ a $1 \%$ junto à quebra da plataforma. Esse resultado indica que, na plataforma de Abrolhos, os sedimentos são mobilizados a maior parte do tempo, enquanto em Ilhéus, os sedimentos são mobilizados mais frequentemente junto à costa.

\subsection{CONCLUSÃO - MOBILIDADE SEDIMENTAR}

A mobilidade dos sedimentos induzido pela ação das ondas na plataforma continental sudeste da Bahia ocorre em profundidades inferiores a $20 \mathrm{~m}$, para sedimentos de tamanho areia muito fina $\left(\mathrm{D}_{50}=0,063 \mathrm{~mm}\right)$ durante o verão e até $50 \mathrm{~m}$ durante o inverno. 
Em Ilhéus, os sedimentos depositados se tornam uma mistura de material siliciclástico e carbonático a partir dos $20 \mathrm{~m}$ de profundidade, assim o limite para mobilização de sedimentos pode ter sido subestimado uma vez que a energia necessária para a mobilização de sedimentos carbonáticos é significativamente menor.

Em Caravelas, as isóbatas exibem contornos irregulares o que determina que o limite máximo para mobilização de sedimentos seja distribuído aleatoriamente em toda a área, Sedimentos depositados na plataforma média e externa de Abrolhos são compostos predominantemente por material carbonático (coralíneo), desta forma o limite para mobilização de sedimentos induzido por ondas pode ter sido igualmente subestimado.

Nesta região, a quebra da plataforma ocorre entre 40 e $60 \mathrm{~m}$ de profundidade, desta forma, a velocidade orbital induzida pelas ondas junto ao fundo é suficiente para mobilizar sedimentos da quase totalidade da área de plataforma.

Uma melhor compilação de dados de cobertura sedimentar, com maior detalhamento, poderá contribuir para uma melhor estimativa do transporte de sedimentos na plataforma continental leste brasileira.

O presente capítulo faz uma avaliação do potencial de mobilidade sedimentar na plataforma continental leste brasileira. O conhecimento adquirido é fundamental para o entendimento de processos de ressuspensão e disponibilidade para o transporte de sedimentos na área de estudo. Considerando a sensibilidade ambiental da região, devido à presença do maior sistema de recifes do oceano Atlântico Sul, diversos estuários e o maior campo de rodolitos conhecido do mundo, que se encontram sujeitos a pressões antropogênicas, o presente trabalho apresenta uma importante fonte de informações para a região. 


\section{CAPÍTULO 6 - POTENCIAL DE MOBILIDADE DO CAMPO \\ DE RODOLITOS DA PLATAFORMA CONTINENTAL EXTERNA DE ABROLHOS (CARAVELAS, BA)}

\subsection{INTRODUÇÃO}

O transporte de sedimentos junto à costa é condicionado pelo clima de ondas e sofre influência da forma de propagação das ondas sobre a plataforma continental e da sua variabilidade sazonal.

A plataforma continental leste brasileira compreende uma área de $60.000 \mathrm{~km}^{2}$, onde o padrão de ondas é influenciado por descontinuidades na largura da plataforma e pela distância latitudinal que interfere na influência relativa dos principais centros geradores de ondas do Atlântico Sul: a Zona de Convergência Intertropical do Atlântico Sul, os Ventos Alísios, o Anticiclone do Atlântico Sul e os Sistemas Frontais, formados na região Antártica.

O entendimento das condições de mobilidade sedimentar é fundamental na interpretação do transporte de sedimentos, sendo relevante em estudos sobre morfodinâmica, conservação marinha, instalação de obras de engenharia etc. (Van Rijn, 1993). A importância do padrão de ondas na mobilidade dos sedimentos siliciclásticos sobre a plataforma continental foi discutida no Capítulo 5.

Esse capítulo aborda a mobilidade de rodolitos, agregados calcários nodulares compostos principalmente por algas vermelhas coralíneas não-geniculadas (Foster, 2001), que ocorrem em depósitos de sedimentos biogênicos móveis. A sua distribuição espacial heterogênea é consequência de sua sensibilidade à intensidade luminosa, correntes, ação moderada de ondas, baixa sedimentação e alta salinidade (Birkett et al., 1998). Rodolitos são encontrados em águas relativamente rasas ( 20 m), mas podem ocorrer também em profundidades maiores (Littler et al., 1991; Moura et al., 2016). 
Rodolitos ocorrem em profundidades de até $~ 150$ m, sujeitas assim à ação episódica de ondas e correntes, formando grandes áreas de substrato duro (Foster, 2001). A dinâmica é um fator limitante na distribuição de rodolitos, uma vez que eles requerem certo grau de proteção da ação de ondas, de forma a evitar o soterramento e dispersão para águas profundas, e também circulação de água suficiente para prevenir o soterramento por sedimentos finos (Hall-Spencer, 1998). Esses fundos podem contribuir com grandes quantidades de $\mathrm{CaCO}_{3}$ para ambientes costeiros (Foster et al., 1997; Amado-Filho et al., 2012; Adey et al., 2015; Moura et al., 2016).

Os rodolitos apresentam crescimento intermitente com um padrão sazonal e maiores taxas no verão (Bosence, 1983). Taxas de crescimento de rodolitos, medidas na região de Abrolhos, indicam serem controladas pela profundidade, com rodolitos em profundidades de $20 \mathrm{~m}$ crescendo mais $\left(1,5 \pm 0.4 \mathrm{~mm} \cdot \mathrm{ano}^{-1}\right)$ do que aqueles em profundidades de $40 \mathrm{~m}\left(1,0 \pm 0.5 \mathrm{~mm} . \mathrm{ano}^{-1}\right)$ (Amado-Filho et al., 2012).

Além dos controles ambientais primários de luminosidade e temperatura (Adey e Macintyre, 1973), o movimento da água tem sido considerado um fator importante na determinação da distribuição e morfologia dos rodolitos (Marrack, 1999). Apesar de existirem evidências de uma clara relação entre a hidrodinâmica, morfologia dos rodolitos e mobilidade (Nelson, 2009; Riosmena-Rodríguez et al., 2011), são raros os estudos que relacionam a ação de ondas e a mobilidade de rodolitos. Recentemente, Joshi et al. (2017) abordaram questões relacionadas a velocidades críticas e mobilidade de rodolitos na Baía de Galway (Irlanda). Joshi et al. (2014) demonstraram que a velocidade de sedimentação de rodolitos é menor, assim como a tensão de cisalhamento de fundo crítica, quando comparados a grãos de quartzo de mesmo diâmetro.

Modelos numéricos tradicionais geralmente não resolvem o transporte de "partículas" grandes como os rodolitos; assim, a melhor forma de abordar a questão é através da combinação de resultados de modelos de propagação de ondas e hidrodinâmicos, com as formulações que permitem estimar a mobilidade dos rodolitos. Assim, o objetivo desse capítulo é avaliar o potencial de mobilidade de rodolitos ao longo da plataforma de Abrolhos, pela ação das ondas incidentes.

A plataforma de Abrolhos representa um alargamento da plataforma continental leste brasileira, apresentando uma área de $46.000 \mathrm{~km}^{2}$, uma largura máxima de $200 \mathrm{~km}$ e a quebra da plataforma entre 80 e $90 \mathrm{~m}$ de profundidade (Bastos et al., 2015). Sobre a plataforma de Abrolhos está localizado o maior campo de rodolitos conhecido do 
mundo, cobrindo uma área de $20.902 \mathrm{~km}^{2}$ (Amado-Filho et al., 2012; Brasileiro et al., 2016). As características morfológicas da plataforma de Abrolhos e a localização do campo de rodolitos são apresentadas na Figura 48. Devido a suas características ambientais peculiares, o melhor entendimento da mobilidade dos sedimentos nesse trecho da plataforma continental brasileira é de grande importância no contexto dos estudos em dinâmica e transporte sedimentar.

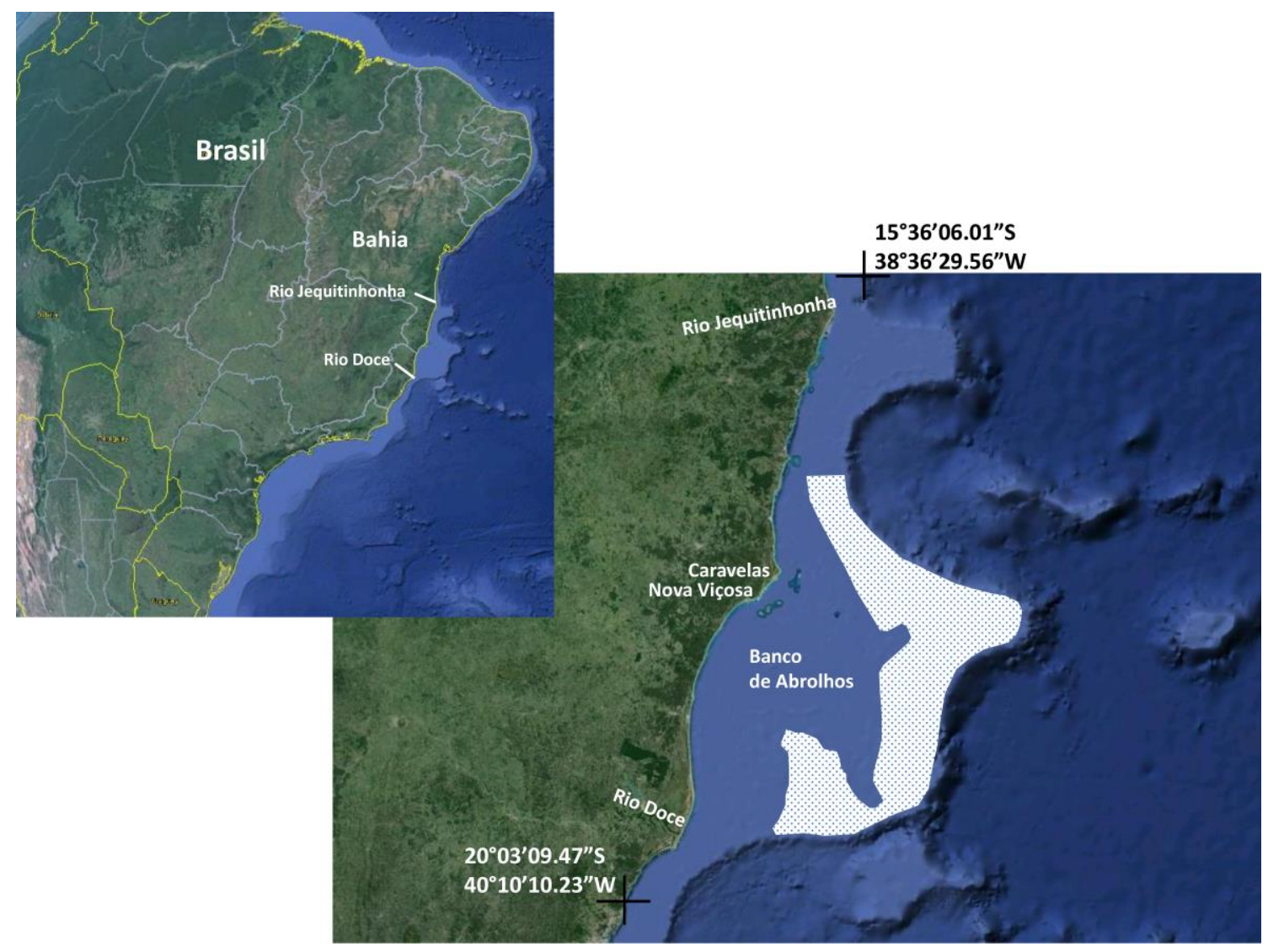

Figura 48: Área de Estudo entre o Rio de Contas (BA) e o Rio Doce (ES) apresentando a localização do Banco de Abrolhos. A área pontilhada representa o campo de rodolitos na região (de acordo com Bastos et al., 2015). 


\subsection{MODELAGEM DE ONDAS}

Os resultados da propagação de ondas sobre a plataforma de Abrolhos, obtidos através das simulações do modelo MIKE21 SW no Capítulo 5 foram utilizados na análise da mobilidade dos rodolitos. Foram utilizadas as mesmas configurações do modelo numérico validado e cenários representativos do clima de ondas local.

Adicionalmente, foram simulados casos de ondas extremos, que são determinantes para as condições de mobilidade dos rodolitos. As condições extremas de ondas foram definidas através da estimativa da potência máxima da onda (wave power), obtida para cada quadrante de aproximação das ondas e da identificação dos parâmetros da onda correspondente, na série temporal de 13 anos (1997 a 2009) da estação WW3_CRV (Tabela 17). Estes casos representam eventos esporádicos, altamente energéticos, que ocorrem com frequência inferior a $5 \%$.

Tabela 17: Características das ondas extremas utilizadas como condição de contorno para os experimentos numéricos.

\begin{tabular}{llllll}
\hline Quadrante & $\mathrm{P}^{*}(\mathrm{~kW} . \mathrm{m}-1)$ & $\mathrm{Hs}(\mathrm{m})$ & \multicolumn{1}{c}{ Tp $(\mathrm{s})$} & \multicolumn{1}{c}{ Dp (grau) } & Período \\
\hline Nordeste & $1,1455 \mathrm{e}+05$ & 3,89 & 7,70 & 53,78 & Primavera \\
Leste & $1,8113 \mathrm{e}+05$ & 4,25 & 10,20 & 104,69 & Primavera \\
Sudeste & $1,5048 \mathrm{e}+05$ & 4,09 & 9,15 & 121,34 & Inverno \\
Sul & $3,1276 \mathrm{e}+05$ & 4,49 & 15,78 & 186,88 & Inverno \\
Sudoeste & $3,2098 \mathrm{e}+05$ & 4,79 & 14,23 & 203,77 & Inverno \\
\hline
\end{tabular}

*P = potência da onda (wave power)

\subsection{CÁlCULO DA MOBILIDADE DOS RODOLITOS}

A mobilidade dos rodolitos foi calculada de forma similar ao realizado no Capítulo 5 que aborda a mobilidade sedimentar da região, a partir do método de Nielsen (1992) para o cálculo da tensão de cisalhamento induzido pelas ondas, com coeficientes ajustados. Assim, a estimativa do comprimento de ondas para águas intermediárias é a 
de Fenton e McKee (1990), utilizando uma aproximação da equação de dispersão da teoria linear de ondas (com precisão mínima de 1,7\%):

$$
\begin{aligned}
& L_{i}=L_{\infty}\left\{\tanh \left[\left(\frac{2 \pi d}{L_{\infty}}\right)^{3 / 4}\right]\right\}^{2 / 3} \\
& L_{\infty}=\frac{g}{2 \pi} T^{2}
\end{aligned}
$$

O diâmetro orbital das ondas, junto ao fundo, $\mathrm{d}_{\mathrm{o}}$, conhecido também como a semiexcursão da partícula de água, é então calculada utilizando a altura significativa das ondas (Hs) e o período da onda (T), como extraída do modelo numérico (Capítulo 6) para cada ponto de grade do modelo ao longo da plataforma continental:

$$
d_{o}=\frac{H T}{2 \pi} \sqrt{\frac{g}{h}}
$$

Sendo $h$ a profundidade local e $g$ a aceleração da gravidade. A velocidade orbital máxima da onda junto ao fundo $\left(u_{\max }\right)$ é a mesma calculada anteriormente (Capítulo 5) segundo a equação de Harris \& Coleman (1998):

$$
u_{\max }=\frac{\pi d_{o}}{T}=\frac{\pi H}{[T \sinh (2 \pi h / L)]}
$$

O fator de fricção das ondas, $f_{w}$ é calculado usando o coeficiente de rugosidade de Nikuradse $\left(k_{s}\right)$, igual à rugosidade superficial:

$$
f_{w}=\exp \left[5.5\left(\frac{k_{s}}{d_{o}}\right)^{0.2}-6.3\right]
$$


A fricção de fundo máxima em função de ondas é definida por:

$$
\tau_{w}=\frac{1}{2} \rho f_{w} u_{\max }^{2}
$$

Sendo a densidade da água $\rho=1027 \mathrm{~kg} \cdot \mathrm{m}^{-3}$. Assim, o parâmetro adimensional de Shields é calculado a partir de:

$$
\theta=\frac{\tau_{w}}{\left(\rho_{s}-\rho\right) g d_{50}}
$$

Onde $\rho_{s}$ é a densidade do sedimento e $d_{50}$ é a mediana do tamanho do grão. Através da aplicação dessa formulação, é possível alterar a densidade da partícula, permitindo assim a sua adaptação para o estudo de mobilidade de rodolitos, por exemplo. Para os rodolitos da região de Abrolhos, não existem estudos que definem a sua densidade. No entanto, medidas de tamanho e volume de amostras da Baía Magdalena (México) (Ávila \& Riosmena-Rodriguez, 2011), do mesmo gênero de rodolitos presentes na região de Abrolhos (Lithophyllum genera), permitem estimar a sua densidade. Ávila \& RiosmenaRodriguez (2011) fornecem dados de peso e volume obtidos a partir de 100 amostras de rodolitos, definindo-se assim as suas densidades variando entre 1200 e $1612 \mathrm{~kg} \cdot \mathrm{m}^{-3}$. Esses foram os valores considerados para $\rho_{s}$ na Equação 6.7. O diâmetro médio de rodolitos na região de Abrolhos foi estabelecido por Brasileiro et al. (2016) como sendo entre $3.1 \pm 1.4$ e $9.4 \pm 3.2 \mathrm{~cm}$. Esses autores observaram um gradiente de tamanho dos rodolitos relacionado com profundidades de até $40 \mathrm{~m}$, com rodolitos entre 20 e $30 \mathrm{~m}$ sendo maiores que aqueles entre 30 e $40 \mathrm{~m}$. Em profundidades maiores, não é possível observar relação entre o tamanho dos rodolitos e a profundidade (Brasileiro et al., 2016). Dessa forma, para a análise geral de mobilidade de rodolitos, o seu diâmetro foi considerado como sendo $6 \mathrm{~cm}$. Análises de sensibilidade foram realizadas com tamanhos variando entre 1 e $14 \mathrm{~cm}$.

A partir da obtenção dos valores do parâmetro de Shields para os rodolitos, eles foram comparados ao valor do parâmetro de Shields crítico para rodolitos. Novamente, não existem estimativas disponíveis para o parâmetro de Shields crítico para os rodolitos de Abrolhos. Assim, foi utilizada a estimativa existente na literatura para rodolitos da Baía de Galway (Irlanda), obtidos através de experimentos de laboratório por Joshi et al. 
(2017). O valor de Shields crítico foi assim considerado constante ao longo do campo de rodolitos como 0,033 .

O próximo passo é a obtenção da porcentagem do tempo em que os rodolitos são mobilizados, ou seja, quando o parâmetro de Shields (Equação 6.7) excede o seu valor crítico. Esses valores são então relativizados em função da frequência de ocorrência de cada onda considerada na modelagem numérica, para o clima de onda sazonal. Os eventos de ondas extremos foram considerados como eventos isolados, com resultados mostrando o potencial de mobilidade sem considerar o seu tempo de atuação.

Os resultados obtidos foram então interpolados em malhas regulares para visualização espacial e em perfis. Em função de limitações causadas por incertezas nos parâmetros utilizados, testes de sensibilidade foram realizados para os parâmetros locais. Essas estimativas podem ser refinadas a partir do estabelecimento de parâmetros específicos para os rodolitos da região de interesse.

\subsection{MOBILIDADE DOS RODOLITOS DO BANCO DE ABROLHOS}

Os resultados do modelo de propagação de ondas refletem o clima sazonal da região, com resultados para o clima de ondas, sendo relativizados em função da frequência de ocorrência. A partir dessa forçante foi definido o potencial de mobilidade de rodolitos na plataforma de Abrolhos, considerando o seu tamanho e densidade. Essa aplicação combinada, entre o resultado do modelo numérico de propagação de ondas e as formulações que permitem estimar o potencial de mobilidade, fornece uma interpretação integrada dos processos físicos atuantes junto ao fundo. O capítulo 5 apresenta o comportamento de sedimentos siliciclásticos na região, sendo aqui a descrição restrita aos rodolitos.

As Figuras 49 a 52 mostram a distribuição do índice de frequência de mobilidade ao longo da área de interesse, para cada estação do ano, com tamanho dos rodolitos variando entre 2 e $8 \mathrm{~cm}$ e densidade de $1400 \mathrm{~kg} \cdot \mathrm{m}^{-3}$. A distribuição da porcentagem do tempo em que existem condições para mobilizar rodolitos mostra a dependência entre profundidade local e clima de ondas incidente, com índices geralmente baixos quando 
considerada a distribuição anual. Apesar de restrito a algumas áreas mais rasas, o outono (Figura 49), inverno (Figura 50) e primavera (Figura 51) são as estações do ano em que acontece o maior potencial de mobilização por ondas na área de interesse, refletindo o clima de ondas mais energético nesse período (Capítulo 4). As áreas com maior potencial de mobilidade por ondas são as porções mais rasas da plataforma, representadas pela porção externa mais ao norte e a projeção rasa voltada para sul (ambas com profundidades entre $\sim 20$ e $40 \mathrm{~m}$ ). Nessa projeção rasa voltada para sul, com exceção do verão (Figura 52), ondas apresentam potencial de mobilização de rodolitos com tamanhos menores $(2 \mathrm{~cm})$. A porção externa mais ao norte apresenta potencial de mobilidade ao longo de todas as estações, inclusive para rodolitos maiores (de até $8 \mathrm{~cm}$ ). Essas porções, em amarelo nas Figuras 49 a 52, apresentam potencial de mobilização de aproximadamente $8 \%$. Ou seja, durante um período mínimo de 7 dias em cada estação, existe o potencial de mobilização de rodolitos nas áreas marcadas. Isso significa que, para as condições do clima médio de ondas, com ondas que possuem frequência de ocorrência maior que 5\%, a mobilidade de rodolitos ocorre durante um período mínimo de 28 dias ao longo do ano, em função das ondas.

A profundidade limite para a ocorrência da mobilização ao longo do ano é em torno de $35 \mathrm{~m}$. Gradativamente, com a redução da profundidade a partir dos $35 \mathrm{~m}$, ocorre um aumento no potencial de mobilização de rodolitos.

Os eventos episódicos de ondas de maior energia possuem maior capacidade de mobilizar rodolitos, apesar de possuírem frequência de ocorrência baixa. Os resultados para os eventos extremos para a região mostram o importante papel que estas podem ter na remobilização de partículas maiores no fundo. A Figura 53 apresenta resultados para alguns dos cenários extremos definidos a partir da série temporal das características de ondas (Tabela 17). Os resultados apresentam a mobilidade para rodolitos de 3 e $6 \mathrm{~cm}$. De forma comparativa, é possível observar que as ondas extremas de S são as mais importantes na definição do potencial de mobilidade, atuando sobre praticamente toda a área da plataforma de Abrolhos e sobre grande parte do campo de rodolitos, quando considerado o tamanho de $3 \mathrm{~cm}$. A onda extrema de SE é a menos efetiva na mobilização de rodolitos, e isso está relacionado ao período de onda menor que os outros dois casos extremos analisados. Se relacionada à área do campo de rodolitos, essa onda não consegue mobilizar rodolitos, com exceção de alguns pontos específicos, principalmente na porção externa ao norte. 
a.

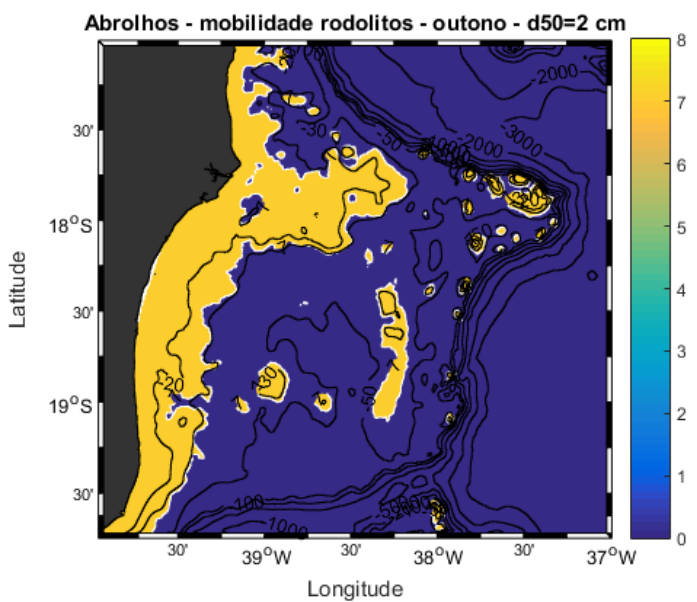

c.

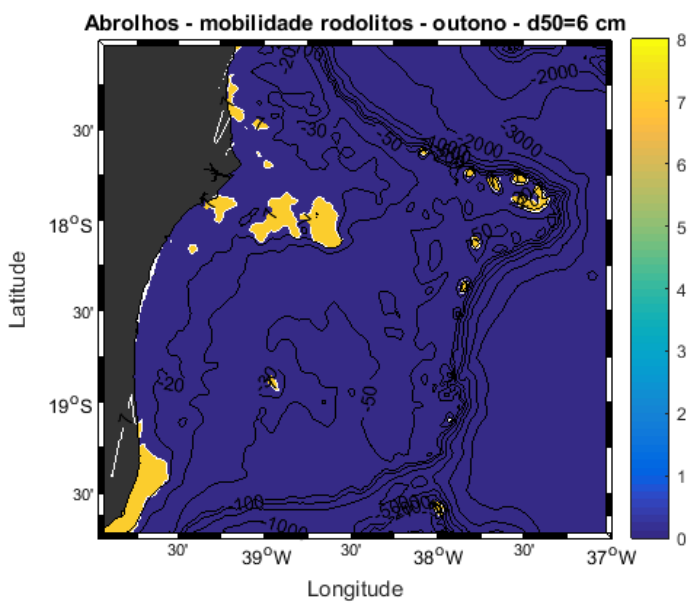

b.

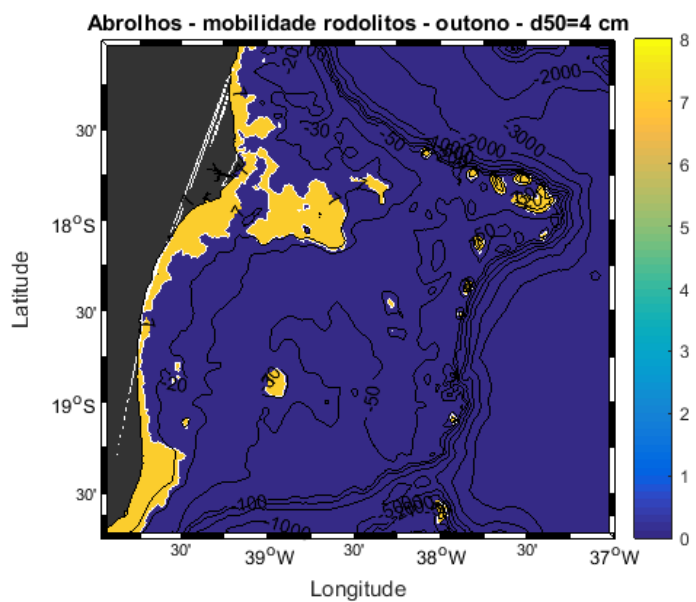

d.

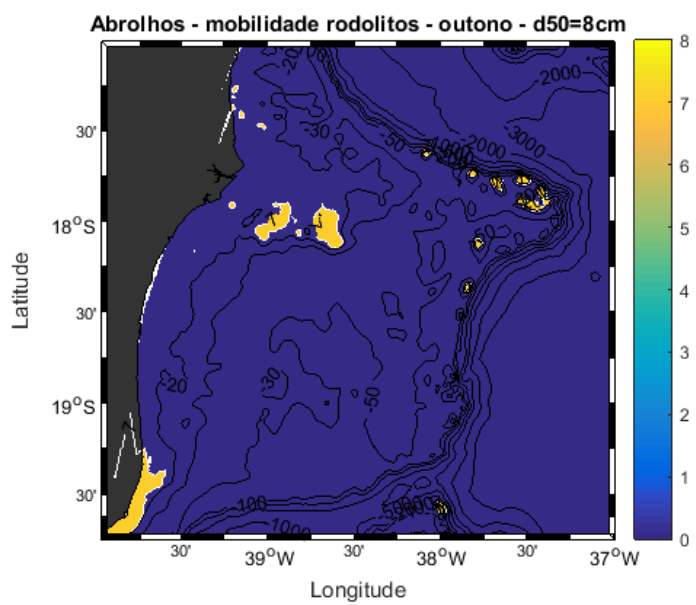

Figura 49: Potencial de mobilidade de rodolitos durante o outono para partículas com tamanho de a. $2 \mathrm{~cm}$; b. $4 \mathrm{~cm}$; c. $6 \mathrm{~cm}$; d. $8 \mathrm{~cm}$. 
a.

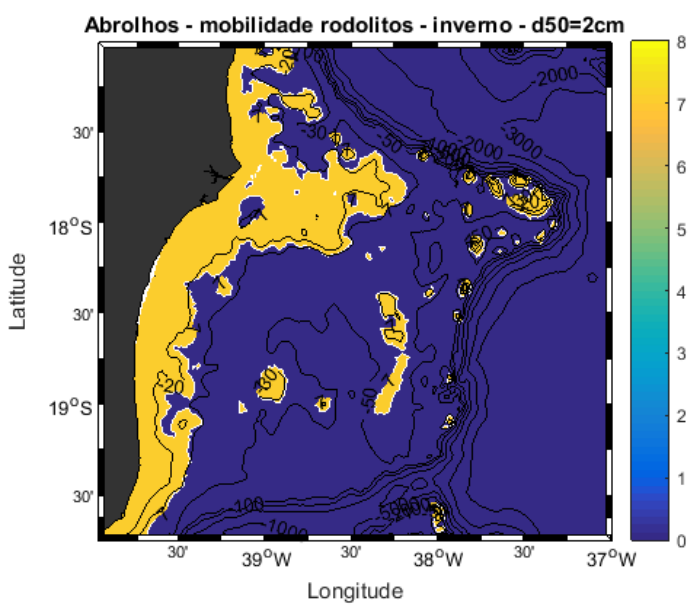

c.

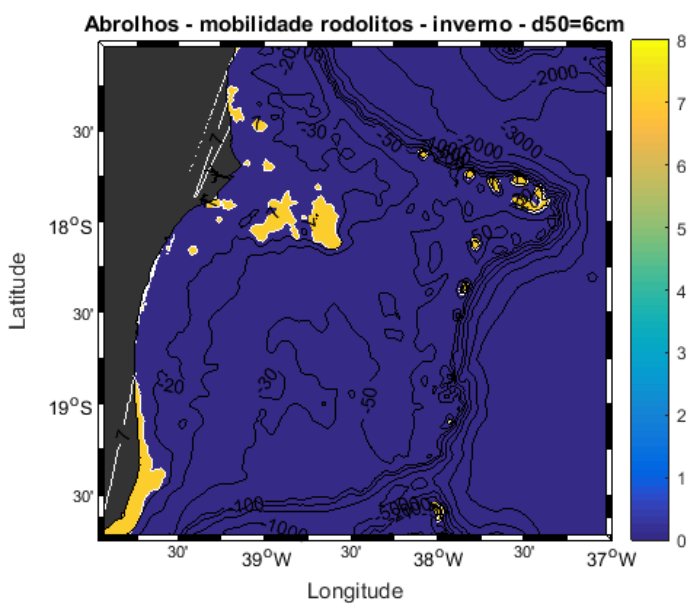

b.

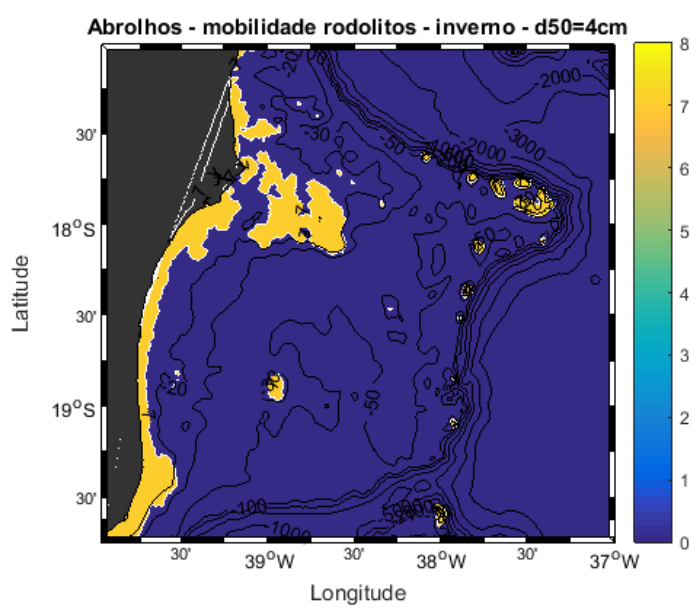

d.

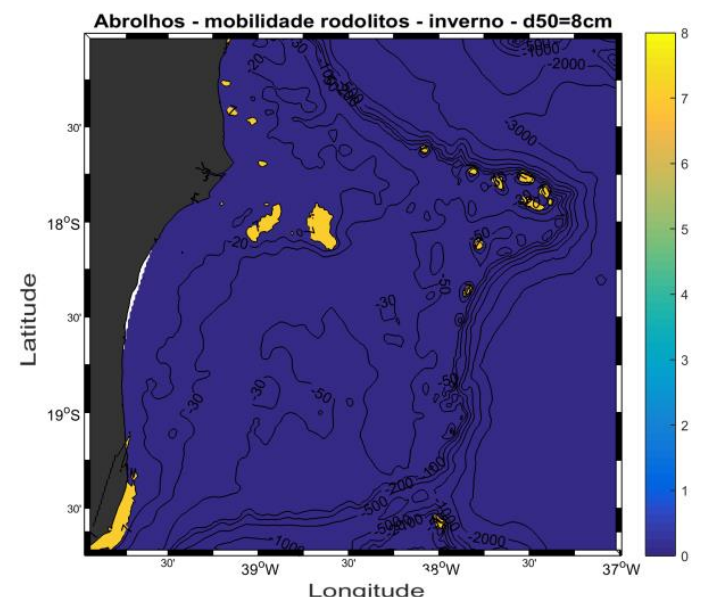

Figura 50: Potencial de mobilidade de rodolitos durante o inverno para partículas com tamanho de a. $2 \mathrm{~cm} ;$ b. $4 \mathrm{~cm}$; c. $6 \mathrm{~cm} ; \mathrm{d} .8 \mathrm{~cm}$. 
a.

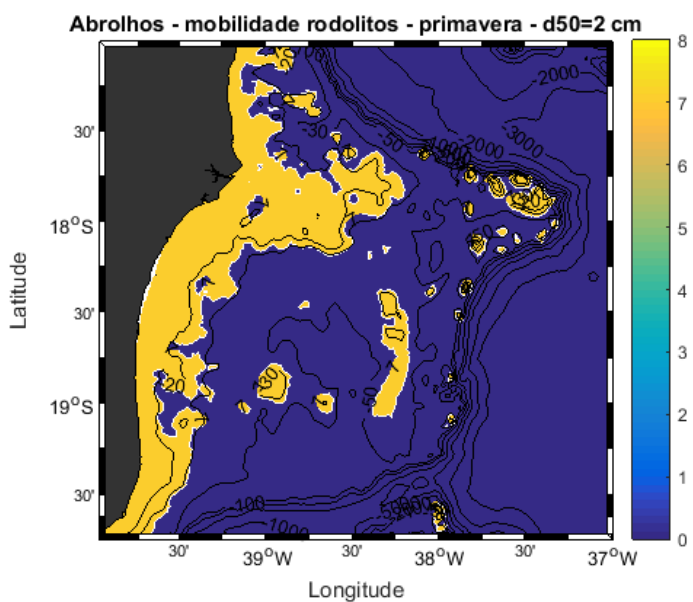

c.

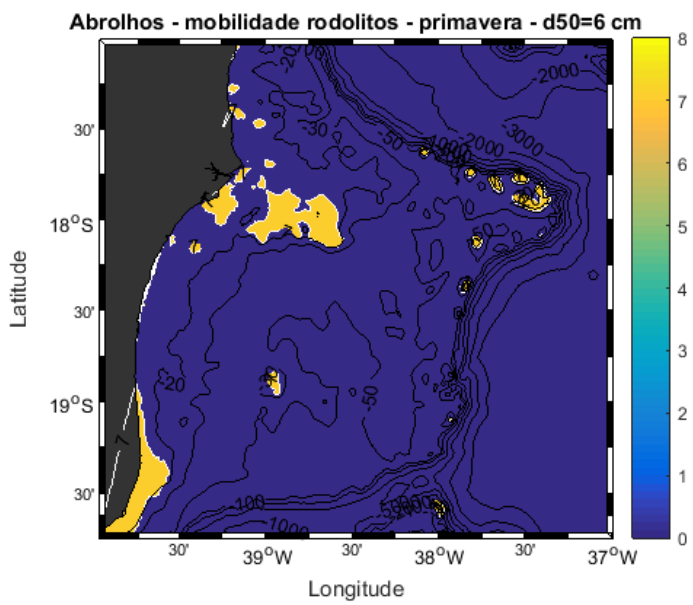

b.

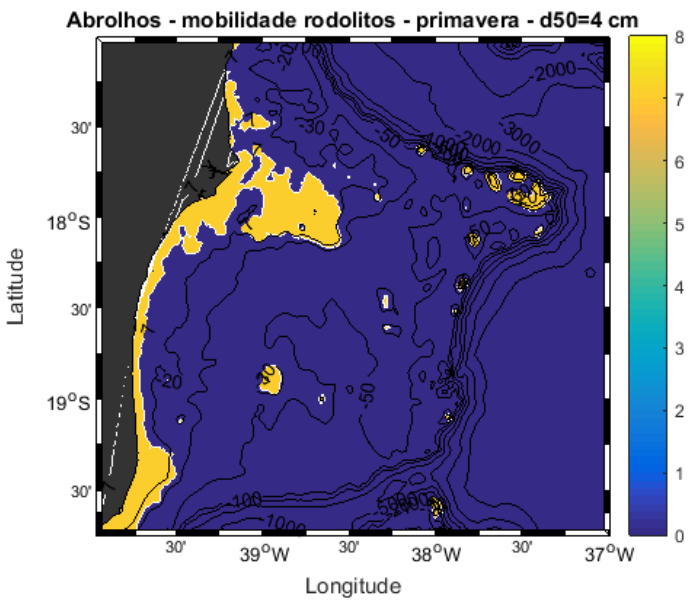

d.

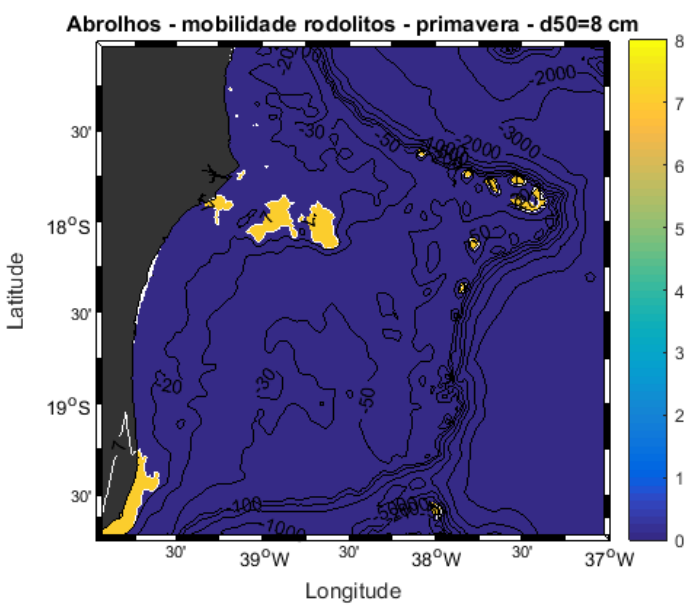

Figura 51: Potencial de mobilidade de rodolitos durante a primavera para partículas com tamanho de a. $2 \mathrm{~cm}$; b. $4 \mathrm{~cm}$; c. $6 \mathrm{~cm} ; \mathrm{d} .8 \mathrm{~cm}$. 
a.

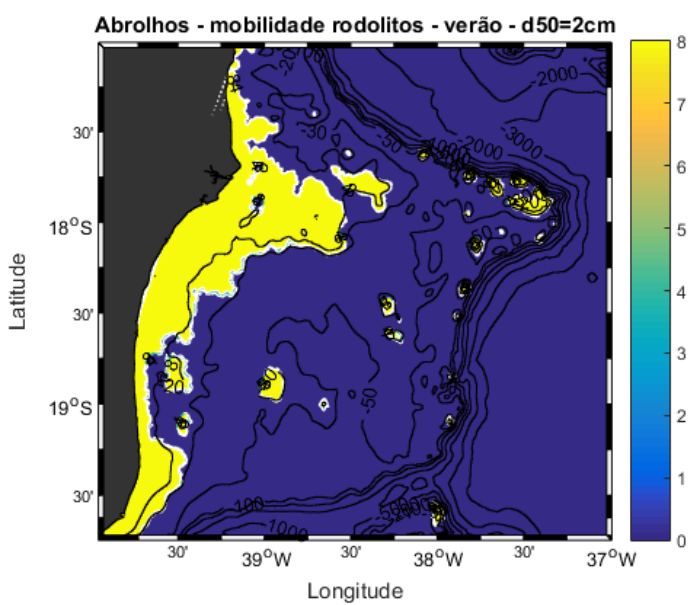

c.

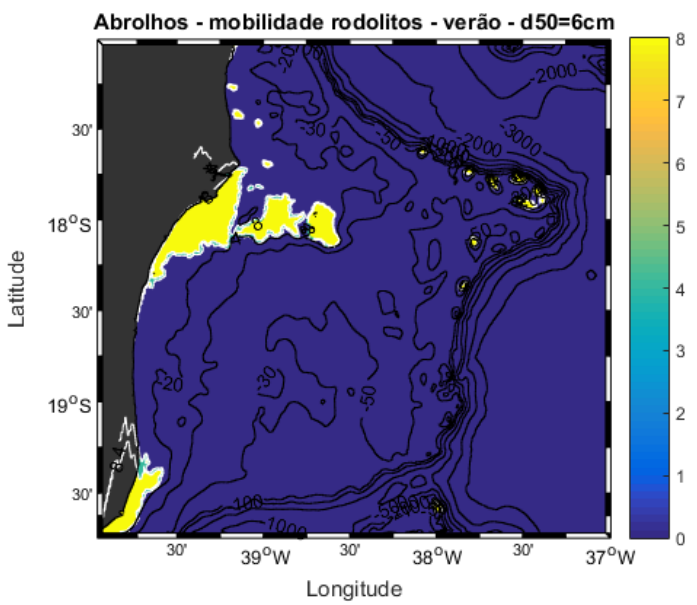

b.

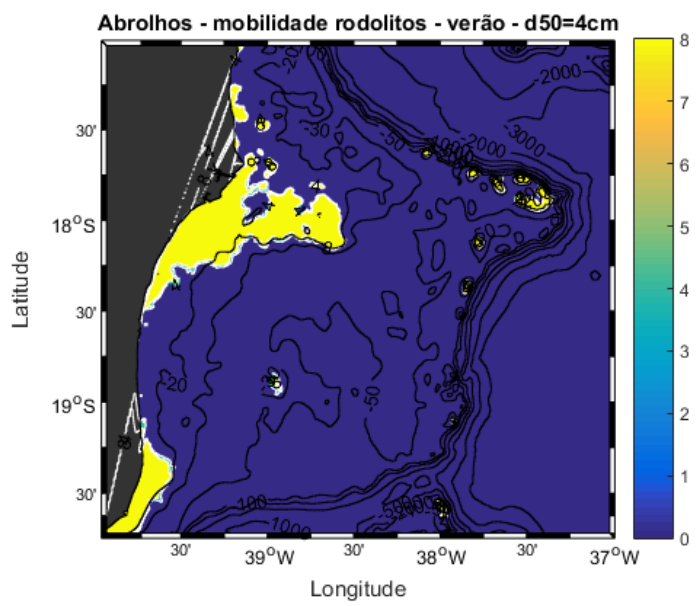

d.

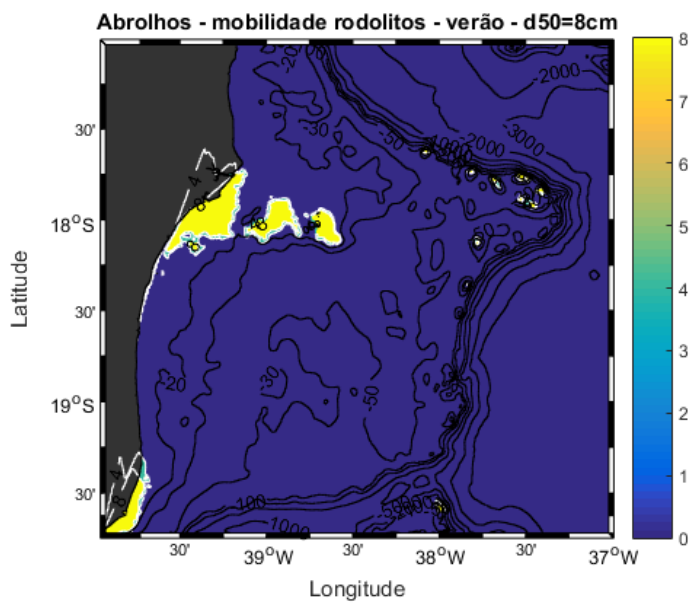

Figura 52: Potencial de mobilidade de rodolitos durante o verão para partículas com tamanho de a. $2 \mathrm{~cm} ;$ b. $4 \mathrm{~cm}$; c. $6 \mathrm{~cm} ;$ d. $8 \mathrm{~cm}$. 
a.

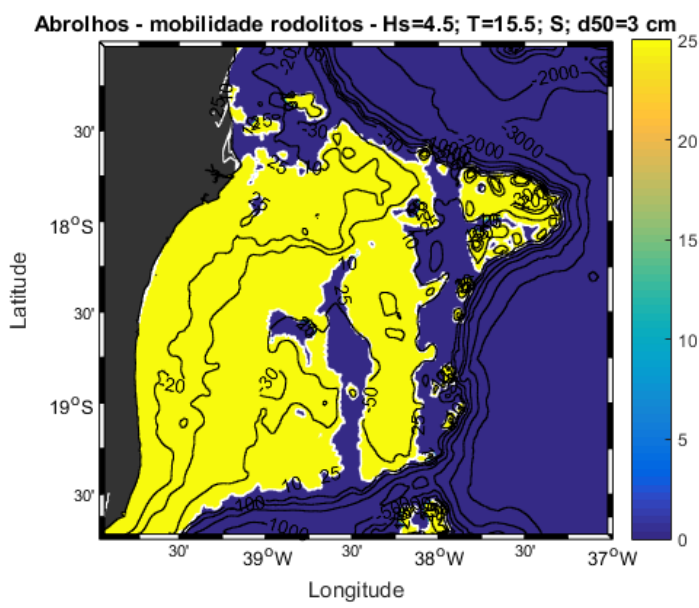

c.

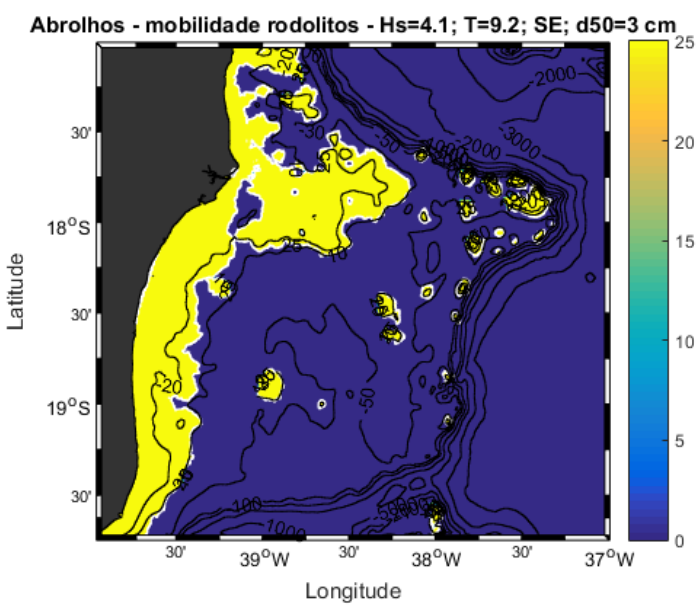

e.

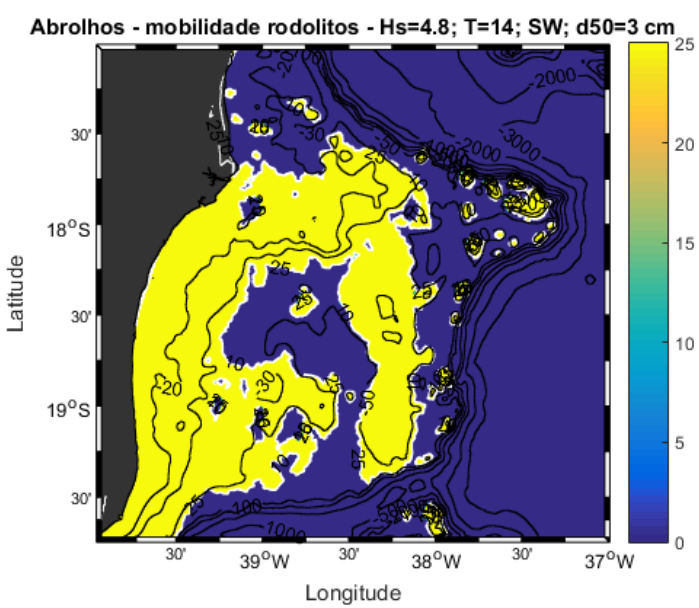

b.

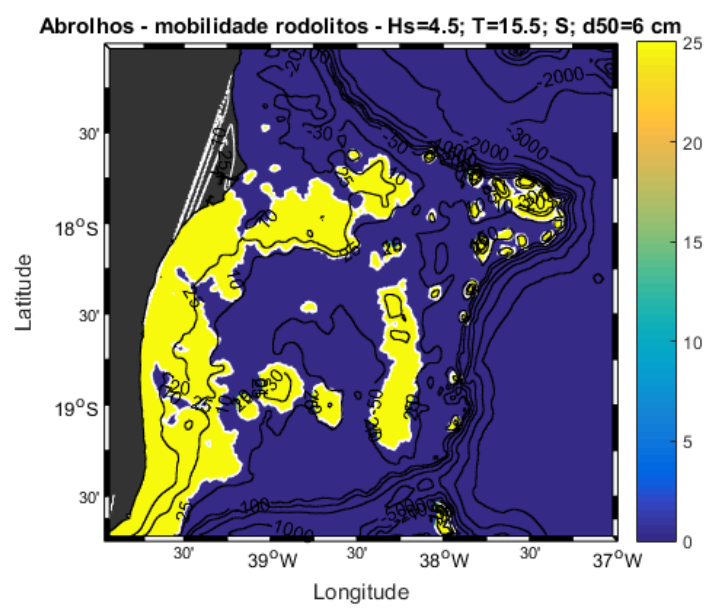

d.

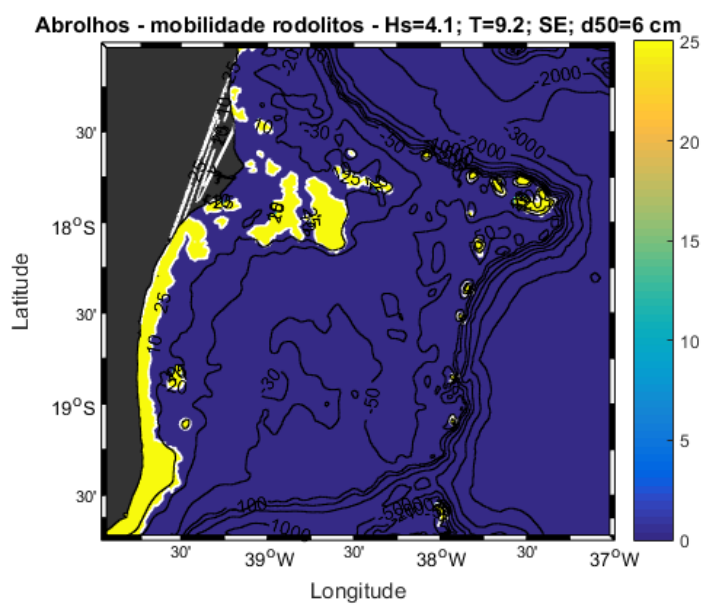

f.

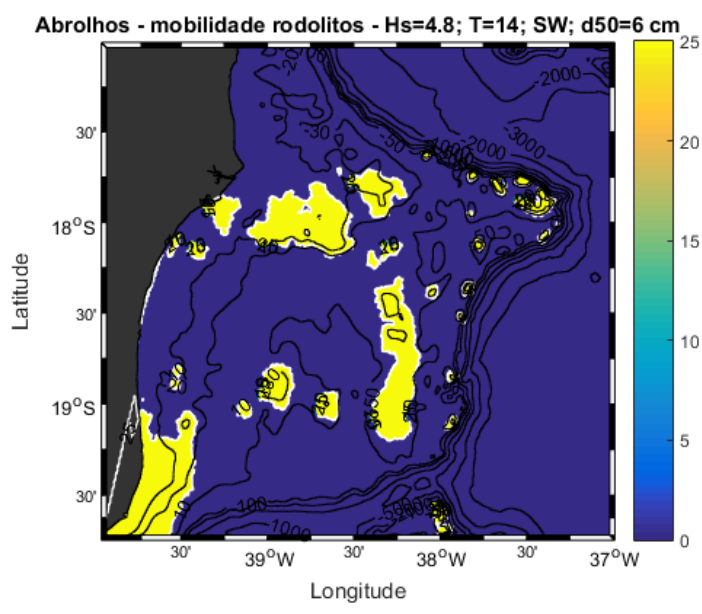

Figura 53: Potencial de mobilidade de rodolitos para cenários de ondas extremas para tamanho de partículas de $3 \mathrm{~cm}$ (a; c; e) e de $6 \mathrm{~cm} \mathrm{(b;d;f).}$ 
Os cenários apresentados e descritos acima apresentam uma ideia geral de comportamento do campo de rodolitos específico, controlado pela morfologia da plataforma de Abrolhos. Como forma de demonstrar a sensibilidade do potencial de mobilização, através do Parâmetro de Shields, diferentes combinações foram realizadas através da aplicação das Equações 6.1 a 6.7. Assim, de forma a avaliar a sensibilidade dos parâmetros utilizados, resultados das combinações de densidade e tamanho dos rodolitos são apresentados na Figura 54. Considerando a profundidade de $20 \mathrm{~m}$, com tamanho da partícula variando (Figura 54a), observa-se que o ponto crítico de mobilização (considerado como 0,033) é alcançado para partículas menores que $8 \mathrm{~cm}$ para a onda de $\mathrm{Hs}=2,7 \mathrm{~m}$ e menores que $5 \mathrm{~cm}$ para a onda de $\mathrm{Hs}=2,0 \mathrm{~m}$. Em relação à densidade, considerando uma partícula de $6 \mathrm{~cm}$ de diâmetro, a onda de $\mathrm{Hs}=2 \mathrm{~m}$ não consegue mobilizar a partícula nem com a densidade mínima testada (1200 kg.m $\left.{ }^{-3}\right)$. A onda de $\mathrm{Hs}=2,7 \mathrm{~m}$ consegue mobilizar partículas de $6 \mathrm{~cm}$ com densidades menores que $1250 \mathrm{~kg} \cdot \mathrm{m}^{-3}$.
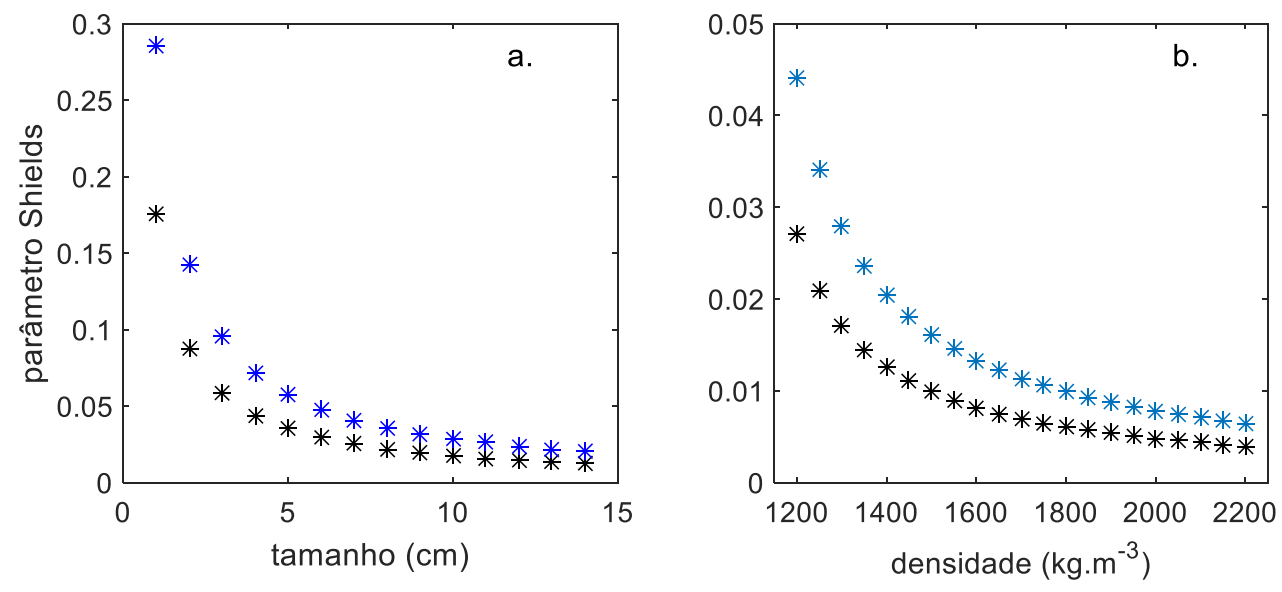

Figura 54: Testes de sensibilidade do parâmetro de Shields em relação ao tamanho da partícula (a) e em relação à densidade da partícula (b). Azul: teste realizado para onda com $\mathrm{Hs}=2,7 \mathrm{~m} ; \mathrm{T}=11 \mathrm{~s}$; Preto: teste realizado para onda com $\mathrm{Hs}=2 \mathrm{~m} ; \mathrm{T}=10 \mathrm{~s}$, em profundidade de $20 \mathrm{~m}$. Na relação com o tamanho do rodolito (a), a densidade foi considerada foi de $1400 \mathrm{~kg} \cdot \mathrm{m}^{-3}$; na relação com a densidade, o tamanho da partícula é $6 \mathrm{~cm}$.

Esses testes, apesar de representarem apenas algumas condições e variáveis encontradas no ambiente, se tornam importantes principalmente em função do grande número de incertezas existentes a respeito das características físicas dos rodolitos de Abrolhos. 
Conforme mencionado anteriormente, existem informações a respeito de sua distribuição espacial, peso e tamanho. No entanto, informações sobre a sua densidade não são encontradas na literatura.

\subsection{DISCUSSÃO - MOBILIDADE DOS RODOLITOS}

Os resultados do modelo numérico de propagação de ondas, combinados com a aplicação de equações que demonstram a influência das ondas junto ao fundo, atuando sobre partículas, permite uma interpretação integrada dos processos físicos que atuam sobre o fundo marinho. Além das restrições ecológicas de luz e temperatura, a distribuição de rodolitos é considerada como sendo altamente afetada pela hidrodinâmica (Bosence, 1983). Rotações periódicas são necessárias para a sobrevivência dos rodolitos, permitindo que a luz atinja todos os seus lados e evitando o soterramento e incrustações (Steneck, 1986). As ondas possuem um papel importante nesse processo, pois atuando em águas mais rasas, as velocidades orbitais por elas geradas podem eventualmente mobilizar rodolitos causando o seu rolamento (Harris et al., 1996). No entanto, seu desenvolvimento demanda o estabelecimento de uma condição de equilíbrio, em que uma relativa proteção da ação das ondas, prevenindo o soterramento ou a dispersão para águas mais profundas, seja balanceada por energia suficiente para prevenir o seu recobrimento por sedimentos mais finos (Hall-Spencer, 1998).

Os rodolitos da plataforma de Abrolhos compõem o maior campo de rodolitos conhecido do mundo (Amado-Filho et al., 2012; Brasileiro et al., 2016) e a sua distribuição compreende profundidades variando entre aproximadamente 20 e $70 \mathrm{~m}$ (Brasileiro et al., 2016). Os resultados aqui apresentados mostram que a mobilidade de rodolitos na plataforma de Abrolhos é principalmente forçada por eventos energéticos relacionados a tempestades, que apesar de serem pouco frequentes, possuem papel importante na mobilização esporádica de rodolitos. Relativamente, pouca mobilidade de rodolitos acontece ao longo das diferentes estações do ano, com o período do outono sendo o mais energético e efetivo na mobilização de rodolitos. Eventos mais energéticos são apontados por outros autores como principais causas de movimentação de rodolitos, 
tanto em locais costeiros mais expostos (Marrack, 1999) como em baías mais abrigadas em que a entrada de eventos energéticos é a única forma de movimentação (Joshi et al., 2017).

Em relação à profundidade, com a maior atuação das ondas em regiões rasas, a maior mobilidade acontece em profundidades menores que $35 \mathrm{~m}$. Em águas rasas, com profundidades menores que $20 \mathrm{~m}$, são observados potenciais de mobilização bem maiores, provavelmente limitando a presença de rodolitos, servindo assim como restrição ambiental. Movimentos mais intensos são potenciais distúrbios para as macroalgas associadas, podendo em adição ao soterramento, resultar em fragmentação das estruturas (Hinojosa-Arango et al., 2009). Nessas áreas rasas a remobilização de sedimentos siliciclásticos é alta (Capítulo 5), podendo levar a um soterramento dos rodolitos. Em Abrolhos, nessas áreas mais rasas, ocorrem os bancos recifais em formato de cogumelo, os chapeirões (Leão e Kikuchi, 2011), contrastando com os campos de rodolitos.

A literatura disponível a respeito da estrutura e composição dos rodolitos de Abrolhos menciona a sua variedade de tamanho e formas (Amado-Filho et al., 2012; Brasileiro et al., 2016); e distribuição de tamanho relacionada à profundidade, com rodolitos maiores encontrados entre 20 e $40 \mathrm{~m}$ e menores em profundidades maiores (Brasileiro et al., 2016). No entanto, não é apresentado se existe relação da sua forma com a profundidade. Relacionado aos aspectos dinâmicos, espera-se encontrar formatos mais esféricos em águas rasas e formatos elipsoidais ou discoidais em águas mais profundas, com mobilidade mais restrita. As formas discoidais são mais comuns em águas com profundidades maiores que $40 \mathrm{~m}$ (Adey e MacIntyre, 1973).

A distribuição do potencial de mobilidade dos rodolitos ao longo da plataforma de Abrolhos está diretamente relacionada à sua morfologia. Nas áreas rasas mais expostas na região da plataforma, ocorre o maior potencial de mobilização. A Figura 55 apresenta de forma esquemática a distribuição do potencial de mobilidade na região do campo de rodolitos. A projeção mais rasa que se estende na porção central da plataforma para o sul é uma área com presença de rodolitos e relativamente exposta. Da mesma forma, a porção norte mais externa da plataforma, relativamente rasa ( 20 a $40 \mathrm{~m}$ ) e bastante exposta às ondas incidentes, também apresenta mobilização em todas as condições de ondas mais energéticas. Essas duas áreas são separadas por um canal mais profundo ( 60 - $80 \mathrm{~m}$ ) em que não ocorre a mobilização pela ação de ondas. Ao 
norte, os rodolitos se encontram em águas mais rasas $(20-30 \mathrm{~m})$ e próximos à costa, enquanto que na porção sul, rodolitos não são encontrados em águas com profundidades menores que $40 \mathrm{~m}$ (Brasileiro et al., 2016). Essa diferença está relacionada à morfologia da plataforma, com regiões mais profundas do banco de Abrolhos na porção sul. No entanto, os resultados mostram a existência de maior potencial de mobilidade na porção sul, apesar da profundidade maior. Isso está relacionado ao clima de ondas mais energético ser principalmente proveniente do quadrante S. Assim, as ondas atingem com força a porção sul e externa do banco de Abrolhos, atenuando na medida em que atravessam as áreas mais rasas (conforme discutido no Capítulo 4). Dessa forma, a porção norte, apesar de ser mais rasa, está mais protegida da ação das ondas.

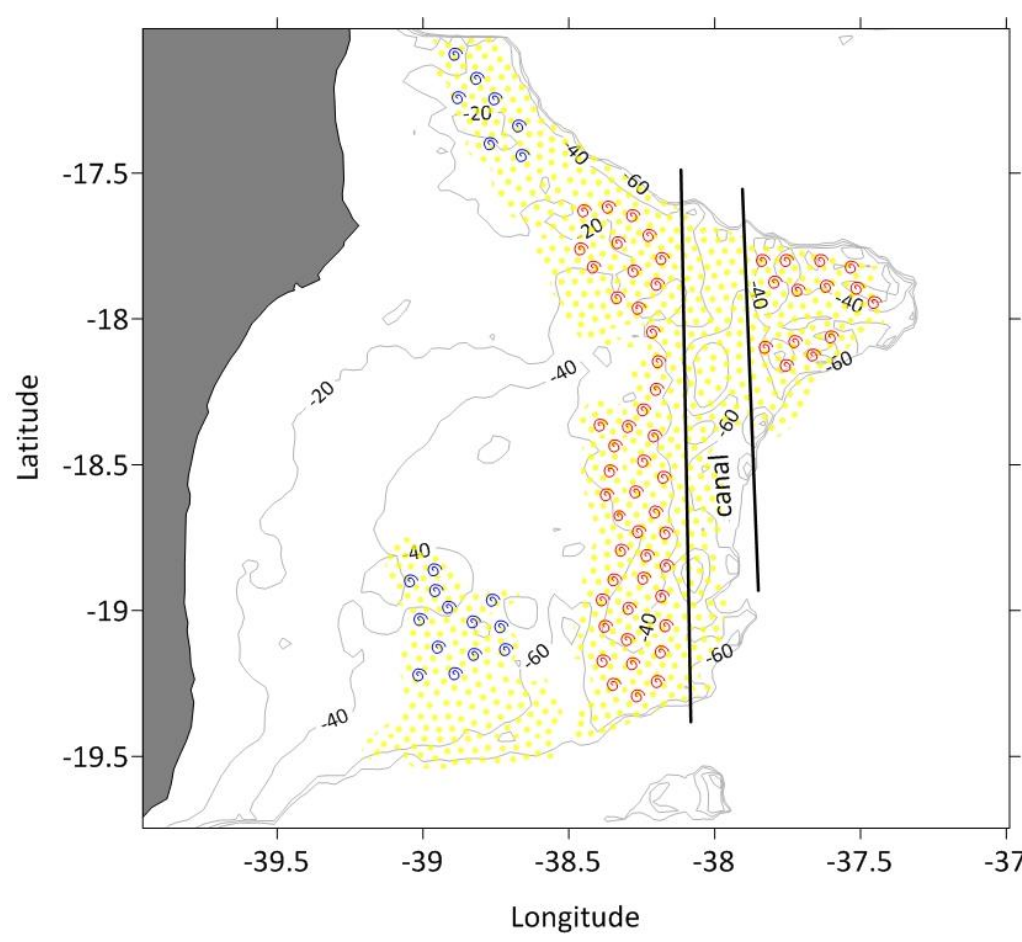

Banco de rodolitos

Maior potencial de mobilidade

() Menor potencial de mobilidade

Figura 55: Esquema representativo de áreas com maior ou menor potencial de mobilidade de rodolitos por ondas. 
Nesse capítulo foi abordado apenas o potencial de mobilização por ondas. Apesar de provavelmente ser esse o aspecto mais importante no controle da mobilidade de rodolitos na região, as correntes também podem exercer papel importante, principalmente em regiões mais profundas. Em regiões mais externas, próximas a quebra da plataforma em que rodolitos são encontrados em profundidades em torno de 70 m e na região do canal externo, provavelmente as correntes atuam na mobilização de rodolitos. Uma vez que são áreas não influenciadas pelas ondas de tempestade que podem atingir a região, a movimentação deve ser bem menor. A inclusão de resultados de modelo numérico hidrodinâmico na definição do parâmetro de Shields permitirá a quantificação da importância de correntes nesse processo. No entanto, o objetivo aqui é avaliar a influência das ondas apenas, que trabalhos realizados em outras regiões apontam como sendo o fator principal na mobilização de rodolitos (Marrack, 1999; Joshi et al., 2017). Para a região de Abrolhos não existem muitas informações a respeito de correntes, principalmente para a região dos bancos de rodolitos. Teixeira et al. (2013), avaliaram o comportamento das correntes na porção mais costeira, no canal formado entre o arco interno de recifes e a costa. Utilizando os fundeios realizados pela Fibria (\#506 e \#106), Teixeira et al. (2013) observaram a existência de correntes mais fortes ao longo do canal (ao longo da costa) com velocidades médias em torno de $0,1 \mathrm{~m} . \mathrm{s}^{-1}$, com picos de velocidade podendo alcançar $0,7 \mathrm{~m} . \mathrm{s}^{-1}$. Já a componente através da costa possui valores bem menores, com velocidades médias em torno de $0,05 \mathrm{~m} . \mathrm{s}^{-1} \mathrm{e}$ eventuais picos de $0,2 \mathrm{~m} \cdot \mathrm{s}^{-1}$. Essas correntes foram medidas em regiões mais próximas à costa, fora da área do campo de rodolitos. Seriam necessárias medidas e a aplicação de modelo numérico hidrodinâmico para a região dos campos de rodolitos, de forma a avaliar a efetividade das correntes de maré e correntes geradas pelo vento sobre a sua mobilidade. Apesar de a avaliação dos efeitos de correntes não fazer parte do objetivo do presente capítulo, e com base nos resultados aqui apresentados em relação à ação de ondas, provavelmente grande parte da mobilidade dos rodolitos na região depende da ação de ondas, principalmente as ondas mais energéticas associadas a tempestades. 


\subsection{CONCLUSÃO - MOBILIDADE DOS RODOLITOS}

Pela primeira vez, foi realizada a modelagem e estimativa do potencial de mobilidade de rodolitos na plataforma de Abrolhos, maior campo de rodolitos conhecido do mundo. Com base no clima de ondas local e a sua propagação através da plataforma, o potencial de mobilidade de rodolitos foi avaliado. Apesar de estarem restritos a regiões mais profundas da plataforma (>20 m), os rodolitos do banco de Abrolhos são mobilizados pela ação das ondas, principalmente aquelas mais energéticas associadas a tempestades. Durante o período de verão a mobilização praticamente não ocorre, devendo estar restrita a eventos esporádicos, mais raros nessa época. No outono são observadas as maiores áreas de mobilização, que devem ser somadas a eventos mais energéticos que ocorrem de forma mais intensa nessa estação, com o aumento da frequência de passagem de frentes frias e ondas mais energéticas associadas.

Ainda existem diversas variáveis que não são bem conhecidas sobre as características e comportamento dos rodolitos de Abrolhos. Nas estimativas aqui apresentadas foram utilizadas várias aproximações, por exemplo, a respeito da densidade dos rodolitos e consequentemente os valores críticos do parâmetro de Shields. De qualquer forma, são apresentados dados inéditos sobre as condições físicas que forçam o seu comportamento. Mesmo associado a incertezas, a definição da distribuição da influência de ondas junto ao fundo, fornece informações fundamentais para o estabelecimento de distribuição de habitats ao longo do banco de Abrolhos. 


\section{CAPÍTULO 7 - CONSIDERAÇÕES FINAIS}

O presente trabalho apresenta uma análise da mobilidade sedimentar induzida por ondas de gravidade na plataforma leste brasileira, utilizando uma abordagem combinada entre a análise do clima de ondas, propagação das ondas para águas rasas através de modelagem numérica e aplicação de equações que estimam o transporte de partículas em função da tensão de cisalhamento causada pelas ondas no fundo marinho. Assim, baseado no clima de ondas da região, são estimados os potenciais de mobilidade sedimentar como resposta a diversas condições forçantes.

A morfologia da plataforma é um fator fundamental condicionante do clima de ondas regional e consequente do potencial de mobilização de sedimentos. Com morfologia complexa, alternando entre plataforma estreita ( 15 km - Ilhéus) e larga ( 200 km Abrolhos) passando por uma projeção intermediária de aproximadamente $100 \mathrm{~km}$ (Royal Charlotte). Essa complexidade da morfologia da plataforma confere características únicas à área de estudo, incluindo o maior complexo recifal do Atlântico Sul sobre a plataforma rasa e extensa do Banco de Abrolhos. As ondas, ao alcançarem essas áreas, e se propagarem sobre a plataforma, apresentam comportamento diferenciado em função da maior dissipação de energia e processos de transformação nas áreas de plataforma extensa, quando comparado aos trechos intercalados de plataforma estreita. Apesar de estarem separados por uma distância relativamente curta $(\sim 350 \mathrm{~km})$, o clima de ondas é diferenciado entre a parte sul (Caravelas) e norte (Ilhéus), também em função da morfologia da plataforma, que acaba atuando como escudo para a ação das ondas do quadrante sul na porção norte da área de estudo. Considerando a atuação das ondas sobre a plataforma, esse efeito acaba compensando a menor largura da plataforma na parte norte, quando comparada à atuação das ondas no Banco de Abrolhos, por exemplo.

Em função de sua largura, tamanho e baixas profundidades, a região do Banco de Abrolhos apresenta o maior campo contínuo de rodolitos do mundo. Sendo assim, a avaliação dos efeitos das ondas sobre o potencial de mobilidade de rodolitos fornece uma interpretação integrada dos processos físicos atuantes junto ao fundo. A definição 
de habitats bentônicos está diretamente relacionada à tensão de cisalhamento junto ao fundo, sendo o papel das ondas fundamental nesse processo.

Assim, a complexidade da morfologia da plataforma, combinada com o clima de ondas incidente é o que define a propagação e transformação das ondas e a sua consequente influência na definição dos processos de mobilização de partículas de diferentes tamanhos e densidades junto ao fundo.

As seguintes conclusões específicas foram obtidas com o desenvolvimento do trabalho:

\section{Clima de ondas}

O clima de ondas obtido a partir da análise estatística dos parâmetros espectrais das ondas geradas pelo modelo WAVEWATCH III em dois pontos da costa leste brasileira indica a predominância da ação de ondas do quadrante leste, durante todo o ano em Ilhéus e em todas as estações a exceção do outono em Caravelas, quando as ondas do quadrante sul representam mais de $40 \%$ das informações.

A importância da análise realizada se refere à sua contribuição como fonte de referência, para trabalhos futuros. Apesar de a análise estar baseada em informações de modelo global de geração de ondas, os resultados aqui apresentados preenchem uma lacuna na descrição do clima de ondas na região, uma vez que não existem séries medidas de longo termo em águas profundas nas regiões estudadas.

O controle estrutural da plataforma rasa do Banco de Abrolhos controla o clima de ondas da área ao norte, atenuando as ondas dos quadrantes S e SE. Esse aspecto acaba compensando os efeitos da menor atenuação das ondas na região norte de plataforma estreita.

\section{Mobilidade sedimentar}

A mobilidade dos sedimentos induzido pela ação das ondas na plataforma continental sudeste da Bahia ocorre em profundidades inferiores a $20 \mathrm{~m}$, para sedimentos de tamanho areia muito fina $\left(\mathrm{D}_{50}=0,063 \mathrm{~mm}\right)$ durante o verão e até $50 \mathrm{~m}$ durante o inverno. 
Em Ilhéus, os sedimentos depositados se tornam uma mistura de material siliciclástico e carbonático a partir dos $20 \mathrm{~m}$ de profundidade, assim o limite para mobilização de sedimentos pode ter sido subestimado uma vez que a energia necessária para a mobilização de sedimentos carbonáticos é significativamente menor.

$\mathrm{Na}$ plataforma de Abrolhos, as isóbatas exibem contornos irregulares o que determina que o limite máximo para mobilização de sedimentos seja distribuído, sem padrão definido, em toda a área. Sedimentos depositados na plataforma média e externa de Abrolhos são compostos predominantemente por material carbonático (coralíneo), desta forma o limite para mobilização de sedimentos induzido por ondas pode ter sido igualmente subestimado.

Nesta região, a quebra da plataforma ocorre entre 40 e $60 \mathrm{~m}$ de profundidade, desta forma, a velocidade orbital induzida pelas ondas junto ao fundo é suficiente para mobilizar sedimentos da quase totalidade da área de plataforma.

Os resultados são fundamentais para o entendimento de processos de ressuspensão e disponibilidade para o transporte de sedimentos na área de estudo. Considerando a sensibilidade ambiental da região, devido à presença do maior sistema de recifes do oceano Atlântico Sul, diversos estuários e o maior campo de rodolitos conhecido do mundo, que se encontram sujeitos a pressões antropogênicas, o presente trabalho apresenta uma importante fonte de informações para a região.

\section{Mobilidade de rodolitos}

Pela primeira vez foi realizada a modelagem e estimativa do potencial de mobilidade de rodolitos na plataforma de Abrolhos, maior campo de rodolitos do mundo. Com base no clima de ondas local e a sua propagação através da plataforma, foi estimado o potencial de mobilidade de rodolitos.

Apesar de estarem restritos a regiões mais profundas da plataforma (>20 m), os rodolitos do banco de Abrolhos são mobilizados pela ação das ondas, principalmente aquelas mais energéticas associadas a tempestades. Durante o período de verão a mobilização praticamente não ocorre, devendo estar restrita a eventos esporádicos, mais raros nessa época. No outono são observadas as maiores áreas de mobilização, que devem ser somadas a eventos mais energéticos que ocorrem de forma mais intensa 
nessa estação, com o aumento da frequência de passagem de frentes frias e ondas mais energéticas associadas.

Ainda existem diversas variáveis que não são bem conhecidas sobre as características e comportamento dos rodolitos de Abrolhos. Nas estimativas aqui apresentadas foram utilizadas várias aproximações, por exemplo, a respeito da densidade dos rodolitos e consequentemente os valores críticos do parâmetro de Shields. De qualquer forma, são apresentados dados inéditos sobre as condições físicas que forçam o seu comportamento. Mesmo associado a incertezas, a definição da distribuição da influência de ondas junto ao fundo, fornece informações fundamentais para o estabelecimento e distribuição de habitats ao longo do banco de Abrolhos. 


\section{REFERENCIAS BIBLIOGRÁFICAS}

Abbott, M.B., Larsen, J., 1985. Modelling circulations in depth-integrated flows. Journal of Hydraulic Research, 23: 309-326.

Abbott, M.B., McCowan, A.D., Warren, I.R., 1981. Numerical modelling of freesurface flows that are two-dimensional in plan. In: Fischer, H.B. (Ed.) Transport Models for Inland and Coastal Waters, Academic Press, pp. 222-283.

Ackers, P., White, W. R., 1973. Sediment Transport: New Approach and Analysis. Journal of the Hydraulic Division, ASCE, 99(11): 2041-2060.

Adey, W. H., Macintyre, I. G., 1973. Crustose Coralline Algae: A Re-evaluation in the Geological Sciences. Bulletin Geol. Soc. Am., 84 (3): 883-904.

Adey, W., Halfar, J., Humphreys, A., Suskiewicz, T., Belanger, D., Gagnon, P., Fox, M., 2015. Sub-arctic rhodolith beds promote longevity of crustose coralline algal buildups and their climate archiving potential. Palaios, 30: 281-293.

Aguirre, J., Braga, J. C., Martín, J. M., Betzler, C., 2012. Palaeoenvironmental and stratigraphic significance of Pliocene rhodolith beds and coralline algal bioconstructions from the Carboneras Basin (SE Spain). Geodiversitas 34 (1): 115136. http://dx.doi.org/10.5252/g2012n1a7

Aller, J.Y., Todorov, J.R., 1997. Seasonal and Spatial Patterns of Deeply Buried Calanoid Copepods on the Amazon Shelf: Evidence for Periodic Erosional/Depositional Cycles. Estuarine, Coastal and Shelf Science, 44(1): 57-66.

Amado-Filho, G.M., Maneveldt, G.W., Pereira-Filho, G.H., Manso, R.C.C., Bahia, R.G., Barros-Barreto, M.B., Guimarães, S.M.P.B., 2010. Seaweed diversity associated with a Brazilian tropical rhodolith bed. Ciencias Marinas, 36 (4): 371391. https://doi.org/10.7773/cm.v36i4.1782

Amado-Filho, G.M., Moura, R.L., Bastos, A.C., Salgado, L.T., Sumida, P.Y., Guth, A.Z., Francini-Filho, R.B., Pereira-Filho, G.H., Abrantes, D.P., Brasileiro, P.S., Bahia, R.G., Leal, R.N., Kaufman, L., Kleypas, J.A., Farina, M., Thompson, F.L., 2012. Rhodolith Beds Are Major CaCO3 Bio-Factories in the Tropical South West Atlantic. PLoS One 7(4): e35171. doi:10.1371/journal.pone.0035171.

Amante, C., Eakins, B. W., 2009. ETOPO1 1 Arc-Minute Global Relief Model: Procedures. Data Sources and Analysis, NOAA Technical Memorandum NESDIS NGDC-24, 19 pp. 
Andrade, A.C.S., Dominguez, J.M.L., 2002. Informações geológicogeomorfológicas como subsídios à análise ambiental: o exemplo da planície costeira de Caravelas - Bahia. Boletim Paranaense de Geociências, 51: 9-17.

Andrade, A.C.S., Dominguez, J.M.L., Martin, L., Bittencourt, A.C.S.P., 2003. Quaternary evolution of the Caravelas strandplain - Southern Bahia State - Brazil. Anais da Academia Brasileira de Ciências, 75(3): 357-382.

Andutta, F.P., Miranda, L.B., Schettini, C.A.F., Siegle, E., Silva, M.P., Izumi, V.M., Chagas, F.M., 2013. Temporal variations of temperature, salinity and circulation in the Peruípe river estuary (Nova Viçosa, BA). Continental Shelf Research 70: 36-45.

Apoluceno, D., 1998. A influência do porto de Ilhéus (BA) nos processos de acresção / erosão desenvolvidos após sua instalação. Dissertação de Mestrado, Curso de Pós-Graduação em Geologia, área de Geologia Marinha, Costeira e Sedimentar, Universidade Federal da Bahia, 132p + anexos.

Avila, E., Riosmena-Rodriguez, R., 2011. A Preliminary Evaluation of ShallowWater Rhodolith Beds In Bahia Magdelena, Mexico. Brazilian J. Oceanogr., 59: $365-375$.

BAHIA, Convênio SRH - UESC, 2001. Programa de Recuperação das Bacias dos Rios Cachoeira e Almada: Diagnóstico Regional - Caracterização Hidrológica, Vol, I, Tomo IV, 2001, 46pp.

Bahia, R.G., Abrantes, D.P., Brasileiro, P.S., Pereira Filho, G.H., Amado Filho, G.M., 2010. Rhodolith bed structure along a depth gradient on the northern coast of Bahia state, Brazil. Brazilian J. Oceanogr., 58: 323-337. https://doi.org/10.1590/S1679-87592010000400007

Barros, S.R., 2005. Avaliação Espaço-Temporal de Parâmetros Microbiológicos na Lagoa Encantada - Bahia. Dissertação de Mestrado (Mestrado em Desenvolvimento Regional e Meio Ambiente) Universidade Estadual de Santa Cruz. 2005.

Basso, D., Babbini, L., Kaleb, S., Bracchi, V.A., Falace, A., 2016. Monitoring deep Mediterranean rhodolith beds. Aquat. Conserv. Mar. Freshw. Ecosyst., 26: 549-561. https://doi.org/10.1002/aqc. 2586

Bastos, A.C., Quaresma, V.S., Marangoni, M.B., D'Agostini, D.P., Bourguignon, S.N., Cetto, P.H., Silva, A.E., Amado Filho, G.M., Moura, R.L., Collins, M., 2015. Shelf morphology as an indicator of sedimentary regimes: A synthesis from a mixed siliciclastic - carbonate shelf on the eastern Brazilian margin. Journal of South American Earth Sciences, 63: 125-136.

Beji, S., 2013, Improved explicit approximation of linear dispersion relationship for gravity waves, Short Communication, Coastal Engineering, 73: 11-12.

Bijker, E.W., 1967. Some considerations about scales for coastal models with movable bed, Publication No, 50, Delft Hydraulics Laboratory, Delft, The Netherlands. 
Birkett, D.A., Maggs, C.A., Dring, M.J., 1998. Maerl (volume V). An overview of dynamic and sensitivity characteristics for conservation management of marine SACs. Scottish Association for Marine Science. (UK Marine SACs Project). 116 p.

Bittencourt, A.C.S.P., 1980. As coberturas terciárias e quaternárias do interior e zona costeira, In: Mapa geológico do Estado da Bahia - Texto explicativo, Cap, VIII, p, 163-181,

Bittencourt, A.C.S.P., Dominguez, J.M.L., Martin, L., Silva, I.R., 2000. Patterns of Sediment Dispersion Coastwise the State of Bahia - Brazil. Anais da Academia Brasileira de Ciências, 72 (2): 271-287.

Bittencourt, A.C.S.P., Dominguez, J.M.L., Martin, L., Silva, I.R., 2005. Longshore transport on the northeastern Brazilian coast and implications to the location of large scale accumulative and erosive zones: An overview. Marine Geology, 219: 219234.

Bosence, D. W. J., 1976. Ecological studies on two unattached coralline algae from western Ireland. Paleontol., 19 (2): 365-395.

Bosence, D. W. J., 1983. The Occurrence and Ecology of Recent Rhodoliths - A Review. Coated Grains (ed. by T. M. Peryt) (C) Berlin (Heidelberg): Springer-Verlag. Pp. 225-242.

Bosence, D. W. J., 1991. Coralline algae: Mineralization, taxonomy, and palaeoecology. In: Riding, R. (Ed.), Calcareous Algae and Stromatolites. Berlin: Springer Verlag, p. 98-113.

Brandão, C.S., 2013. Aspectos Hidroquímicos de Rios na Apa Itacaré/Serra Grande: Estudo de Caso da Bacia Hidrográfica do Rio Tijuípe. 53 folhas, Dissertação (Mestrado em Desenvolvimento Regional e Meio Ambiente) Universidade Estadual de Santa Cruz, Ilhéus (BA).

Brasileiro, P.S., Pereira-Filho, G.H., Bahia, R.G., Abrantes, D.P., Guimarães, S. M. P. B. , Moura, R. L., Francini-Filho, R.B., Bastos, A.C., Amado-Filho, G.M., 2016. Macroalgal composition and community structure of the largest rhodolith beds in the world. Mar Biodiv., 46: 407-420. doi 10.1007/s12526-015-0378-9

Cabral, A.P., Baptista, M.C., Hargreaves, F., Gherardi, D.F.M., Mano, M., 2001. Caracterização de feições oceanográficas e sedimentares na região dos bancos Royal Charlotte e dos Abrolhos (BA, Brasil), através de dados SAR / ERS-1/2, AVHRR / NOAA, Difusômetro / ERS-2, Topex / Poseidon e TM / Landsat. Anais do X Simpósio Brasileiro de Sensoriamento Remoto, Foz do Iguaçu, 2001, Pp. 769 - 776, Disponível em: http://marte.sid.inpe.br/col/dpi.inpe.br/lise/2001/09.19.12.06/doc/0769.776.227.pdf Acesso em: 20/09/2017.

Cacchione, D.A., Drake, D.E., Ferreira, J.T., Tate, G.B., 1994. Bottom stress estimates and sand transport on northern California inner continental shelf. Continental Shelf Research, 14 (10/11): 1273-1289. 
Campos, E.V.M., 2002. O Assoreamento do Baixo Curso do Rio de Contas: uma abordagem hidráulica e sedimentológica. 77f. Dissertação (Mestrado em Geologia) Universidade Federal da Bahia. 2002.

Campos, R.H.S., Dominguez, J.M.L., 2010. Mobility of Sediments due to Wave Action on the Continental Shelf of the Northern Coast of the State of Bahia. Brazilian Journal of Oceanography, 58:57-63.

Carruthers, T.J.B., Dennison, W.C., Longstaff, B.J, Waycott, M., Abal, E.G., McKenzie, L.J., Lee Long, W.J., 2002. Seagrass habitats of northeast Australia: models of key processes and controls. Bull Mar Scie, 71(3): 1153 - 1169.

Carmo, F.F., Kamino, L.H.Y., Tobias Jr., R., Campos, I.C., Carmo, F.F., Castro, K.J.S.X., Mauro, M.L., Rodrigues, N.U.A., Miranda, M.P.S., Pinto, C.E.F., 2017. Fundão tailings dam failures: the environment tragedy of the largest technological disaster of Brazilian mining in global context. Perspectives in Ecology and Conservation, 15: 145-151.

Castro, B.,M., Brandini, F.P., 2005. Multidisciplinary Oceanographic Processes on the Western Atlantic Continental Shelf Between $4^{\circ} \mathrm{N}$ and $34^{\circ} \mathrm{S}(4, \mathrm{~W})$. In: Robinson, A.R., Brink, K.H. (eds), The Sea, Volume 14, Chapter 8: pp. 259-293.

Castro, B.M., 1990. Wind driven currents in the Channel of São Sebastião: winter, 1979. Bol. Inst. Oceanogr., 38(2): 111-132.

Castro, B.M., Miranda, L.B., 1998. Physical Oceanography of the Western Atlantic Continental Shelf Located between $4^{\circ} \mathrm{N}$ and $34^{\circ} \mathrm{S}(4, \mathrm{~W})$. In: Robinson, A.R., Brink, K.H. (eds), The Sea, Volume 11, Chapter 8: pp. 209-251.

Chang, H.-K., Lin, S.-C., 1999. An explicit approximation to the wavelength of nonlinear waves. Ocean Engineering, 26: 147-160.

Cheroske, A.G., Williams, S.L., Carpenter, R.C., 2000. Effects of physical and biological disturbances on algal turfs in Kaneohe Bay, Hawaii. Journal of Experimental Marine Biology and Ecology, 248 (1): 1-34.

Chierice Jr., N., 2013. Análise da Chuva e Vazão na Bacia Hidrográfica do Rio Pardo. Tese de Doutorado. 133f. (Doutorado em Geociências e Meio Ambiente) Instituto de Geociências e Ciências Exatas. Universidade Estadual Paulista. Rio Claro - SP. 2013.

Clifton, H.E., Dingler, J.R., 1984. Wave formed structures and paleoenvironmental reconstruction. Marine Geology, 60: 165-198.

Dalyander, P.S., Butman, B., 2015. Characteristics of storms driving wave-induced seafloor mobility on the U.S. East Coast continental shelf. Continental Shelf Research, 104: 1-14.

De Paula, F.C.F., Silva, D.M.L., Souza, C.M., 2012. Tipologias Hidroquímicas das Bacias Hidrográficas do Leste da Bahia. Rev. Virtual Quim., 4 (4): 365-373. 
De Vriend, H.J. De, Ziserman, J., Roelvink, J.A., Péchon, P., Southgate, H.N., 1993. Médium term 2DH coastal área modeling, Costal Engineering, 21: 193-244.

De Vriend, H.J., 1991. Mathematical modelling and large-scale coastal behaviour, Part 1: physical processes. Journal of Hydraulic Research, 29: 727-740.

Dix, J.K., Lambkin, D.O., Cazenave, P.W., 2007. Development of a Regional Sediment Mobility Model for Submerged Archaeological Sites. English Heritage ALSF project no. 5524. School of Ocean and Earth Science, University of Southampton, U.K., 156pp.

Dominguez, J.M.L., Bittencourt, A.C.S.P., Martin, L., 1992. Controls on Quaternary coastal evolution of the east-northeastern coast of Brazil: roles of sea-level history, trade winds and climate. Sedimentary Geology, 80:213-232.

Dominguez, J.M.L., Silva, R.P., Nunes, A.S., Freire, A.F.M., 2013. The narrow, shallow, low-accommodation shelf of central Brazil: Sedimentology, evolution, and human uses. Geomorphology, 203:46-59.

Drake, D.E., Cacchione, D.A., 1992. Wave-current interaction in the bottom boundary layer during storm and non-storm conditions: observations and model predictions. Continental Shelf Research, 12 (12): 1331-1352.

Dronkers, J., 2005. Dynamics of Coastal Systems. Advanced Series on Ocean Engineering - vol, 25, World Scientific, 519 pp.

Dupont, H., Addad, J., 1997. Erosão costeira: a dança das praias. Ciência Hoje, 22 (128): 42-51.

Engelund, F., Hansen, E., 1976. A monograph on sediment transport in alluvial channels. Nordic Hydrology, 7: 293-306.

Fenton, J.D., McKee, W.D., 1990. On calculating the lengths of water waves, Coastal Engineering, 14: 499-513.

Fernandes, G.W., Goulart, F.F., Ranieri, B.D., Coelho, M.S., Dalesf, K., Boesche, N., Bustamante, M., Carvalho, F.A., Carvalho, D.C., Dirzo, R., Fernandes, S., Galetti Jr., P.M., Millang, V.E.G., Mielke, C., Ramirez, J.L., Neves, A., Rogass, C., Ribeiro, S.P., Scariot, A., Soares-Filho, B., 2016. Deep into the mud: ecological and socio-economic impacts of the dam breach in Mariana, Brazil. Natureza \& Conservação (Brazilian Journal of Nature Conservation), 14:35-45.

Figueiredo, M. a D.O., de Menezes, K.S., Costa-Paiva, E.M.M., Paiva, P.C.C., Ventura, C.R.R.R.R., Santos de Menezes, K., 2007. Experimental evaluation of rhodoliths as living substrata for infauna at the Abrolhos Bank, Brazil. Ciencias Marinas, 33: 427-440. https://doi.org/411-420

Foster, M. S., 2001. Rhodoliths: between rocks and soft places. Journal of Phycology, 37: 659-667. 
Foster, M. S., Riosmena-Rodríguez, R., Steller, D. L., Woelkerling, W. J., 1997. Living rhodolith beds in the Gulf of California and their implications for paleoenvironmental interpretation. Geological Society of America Bulletin, 318: 127-139.

Foster, M.S., Amado Filho, G.M., Kamenos, N. a, Riosmena-Rodriguez, R., Steller, D.L., 2013. Rhodoliths and rhodolith beds. Smithson. Contrib. Mar. Sci., 39: 143155.

Franca, A.M.C., 1979. Geomorfologia da margem continental leste brasileira e da bacia oceânica adjacente. In: Hernani, C. (ed.), Geomorfologia da margem continental brasileira e das áreas oceânicas adjacentes. Rio de Janeiro, PETROBRAS/ CENPES (Serie Projeto REMAC, N. 7), pp. 89-127.

Freire, A.F.M., 2006. A Sequência Holocênica na Plataforma Continental Central do Estado da Bahia - Costa do Cacau. 172f. Dissertação (Mestrado em Geologia). Universidade Federal da Bahia. 2006.

Gagnon, P., Matheson, K., Stapleton, M., 2012. Variation in rhodolith morphology and biogenic potential of newly discovered rhodolith beds in Newfoundland and Labrador (Canada). Bot. Mar., 55: 85-99. https://doi.org/10.1515/bot-2011-0064

Genin, A.; Monismith, S.G.; Reidenbach, M.A.; Yahel, G.; Koseff, J.R. 2009. Intense benthic grazing of phytoplankton in a coral reef. Limnology and Oceanography, 54(3): 938-951.

Genz, F., Lessa, G. C., Cirano, M. Lima, G. M. P., 2003. As tendências de longo prazo das vazões fluviais no litoral do Estado da Bahia. II Congresso sobre Planejamento e Gestão das Zonas Costeiras dos Países de Expressão Portuguesa e IX Congresso da Associação Brasileira de Estudos do Quaternário (ABEQUA) CDRom.

Genz, F., Tanajura, C. A. S., 2012. Trends and variability of climate and river flow in the region of Costa das Baleias, Brazil. Water Science and Technology, 67 (1): 47-54.

Gherardi, D.F.M., 2004. Community Structure and Carbonate Production of a Temperate Rhodolith Bank From Arvoredo Island, Southern Brazil. Brazilian J. Oceanogr., 52: 207-224. https://doi.org/10.1071/BT07186

Griffin, J.D., Hemer, M.A., Jones, B.G., 2008. Mobility of Sediment Grain Size Distributions on a Wave Dominated Continental Shelf, Southeastern Australia. Marine Geology, 252: 13-23.

Gruber, R.K., Lowe, R.J., Falter, J.L., 2018. Benthic uptake of phytoplankton and ocean-reef exchange of particulate nutrients on a tide-dominated reef. Limnology and Oceanography, 63:1545-1561. https://doi.org/10.1002/lno.10790

Guo, J., 2002. Simple and explicit solution of wave dispersion equation, Coastal Engineering, 45: 71-74. 
Hall-Spencer, J., 1998. Conservation Issues Relating to Maerl beds as Habitat for Molluscs . Journal of Conchology. Special Publication, $n^{\circ}$ 2: 271-286.

Harris, C.K., Wiberg, P.L., 2001. A two-dimensional, time-dependent model of suspended sediment transport and bed reworking for Continental Shelves. Computers \& Geosciences, 27: 675-690.

Harris, P.T., Coleman, R., 1998. Estimating Global Shelf Sediment Mobility due to Swell Waves. Marine Geology, 150: 171-177.

Harris, P.T., Tsuji, Y., Marshall, J.F., Davies, P.J., Honda, N., Matsuda, H., 1996. Sand and rhodolith-gravel entrainment on the mid- to outer-shelf under a western boundary current: Fraser Island continental shelf, eastern Australia. Mar. Geol., 129: 313-330. https://doi.org/10.1016/0025-3227(96)83350-0

Hatje, V.; Pedreira, R.M.A.; Rezende, C.E.; Schettini, C.A.F.; Souza, G.C.; Marin; D.C.; Hackspacher, P.C. 2017. The environmental impacts of one of the largest tailing dam failures worldwide. Scientific Reports, 7: 10706. DOI: 10.1038/s41598017-11143-X

Hemer, M.A., 2006. The magnitude and frequency of combined flow bed shear stress as a measure of exposure on the Australian continental shelf. Cont. Shelf Res., 26: $1258-1280$.

Herz, R., 1991. Manguezais do Brasil. São Paulo: Instituto Oceanográfico, Universidade de São Paulo, 233 pp.

Hinojosa-Arango, G. , and Riosmena-Rodríguez, R., 2004. Influence of rhodolith forming species and growth-form on associated fauna of rhodolith beds in the Central-West Gulf of California, México. Marine Ecology, 25: 109-127.

Hinojosa-Arango, G., Maggs, C.A., Johnson, M., 2009. Like a rolling stone: the mobility of maerl (Corallinaceae) and the neutrality of the associated assemblages. Ecology, 90(2): 517-528.

Holt, T.J, Rees, E.I., Hawkins, S.J., Seed, R., 1998. Biogenic Reefs (volume IX). An overview of dynamic and sensitivity characteristics for conservation management of marine SACs. Scottish Association for Marine Science (UK Marine SACs Project). $170 \mathrm{p}$.

Holthuijsen, L.H., Booji, N., Herbers, T.H.S., 1989. A prediction model for stationary, short-crested waves in shallow water with ambient currents. Coastal Eng, Journal, 13: pp. 23-54. 
Horta, P.A., Riul, P., Amado Filho, G.M., Gurgel, C.F.D., Berchez, F., Nunes, J.M.C., Scherner, F., Pereira, S., Lotufo, T., Peres, L., Sissini, M., Bastos, E.O., Rosa, J., Munoz, P., Martins, C., Gouvêa, L., Carvalho, V., Bergstrom, E., Schubert, N., Bahia, R.G., Rodrigues, A.C., Rörig, L., Barufi, J.B., Figueiredo, M., 2016. Rhodoliths in Brazil: Current knowledge and potential impacts of climate change.

Brazilian J. Oceanogr., 64: 335-351. https://doi.org/10.1590/S1679$\underline{875920160870064 \mathrm{sp} 2}$

Houlbrèque, F., Ferrier-Pagès, C., 2009. Heterotrophy in tropical scleractinian corals. Biological Reviews, 84: 1-17.

IBGE, 2011. Censo demográfico de 2010. Brasília, DF.

IBGE, 2011. Atlas Geográfico das Zonas Costeiras e Oceânicas do Brasil. IBGE, Diretoria de Geociências, Rio de Janeiro, 176p.

James, S.C., Jones, C.A., Grace, M.D., Roberts, J.D., 2010. Advances in Sediment Transport Modelling. Journal of Hydraulic Research, 48 (6): 754-763.

Jell, J.S., Maxwell, W.H.G., McKellar, R.G., 1965. The Significance of the Larger Foraminifera in the Heron Island Reef Sediments, Journal of Paleontology, 39 (2): 273-279.

Joshi, S., Duffy, G.P., Brown, C., 2017. Mobility of maerl-siliciclastic mixtures: Impact of waves, currents and storm events. Estuarine, Coastal and Shelf Science, 189: 173-188.

Joshi, S.; Duffy, G.P.; Brown, C. 2014. Settling velocity and grain shape of maerl biogenic gravel. J. Sediment. Res., 84: 718-727.

Knoppers, B., Ekau, W., Figueiredo, A.G., 1999. The Coast and Shelf of East and Northeast Brazil and Material Transport. Geo-Marine Letters, 19: 171-178.

Komar, P.D., 1998. Beach processes and sedimentation. $2^{\text {nd }}$. Edition, Prentice Hall, $544 \mathrm{p}$.

Komar, P.D., Miller, M.C., 1973. The Threshold of Sediment Under Oscillatory Water Waves. Journal of Sedimentary Petrology, 43 (4): 1101-1110.

Leão, Z.L.; Kikuchi, R. 2011. Brazil, Coral Reefs. In: David Hopley. (Org.). Encyclopedia of Modern Coral Reefs. Heidelberg: Springer Science + Business Media. doi: 10.1007/978-90-481-2639-2_50.

Leão, Z.M.A.N., 1982. Morphology, geology and developmental history of the southermost coral reefs of Western Atlantic, Abrolhos Bank, Brazil. Ph.D. Dissertation. Rosenstiel School of Marine and Atmospheric Science, University of Miami, Florida, U.S.A., 218p. 
Leão, Z.M.A.N., 2002. Abrolhos, BA - O complexo recifal mais extenso do Atlântico Sul. In: Schobbenhaus, C., Campos, D.A., Queiroz, E.T., Winge, M, Berbert-Born, M.L.C. (Eds.), Sítios Geológicos e Paleontológicos do Brasil, Brasília: DNPM/CPRM - Comissão Brasileira de Sítios Geológicos e Paleobiológicos, SIGEP 90: 345-359, Disponível em: http://sigep.cprm.gov.br/sitio090/sitio090.pdf

Leão, Z.M.A.N., Araujo, T.M.F.; Nolasco, M.C. 1988. The coral reefs of the coast of eastern Brazil. In: Proceedings of the Sixth International Coral Reef Symposium Australia, Vol. 3, pp. 339-347.

Leão, Z.M.A.N., Dominguez, J.M.L., 2000. Tropical Coast of Brazil. Marine Pollution Bulletin, 41 (1-6): 112-122.

Leão, Z.M.A.N., Dutra, L.X.C., Spanó, S., 2005. Characteristics of bottom sediments. In: Dutra, G.F., Allen, G.R., Werner, T., McKenna, S.A., (eds.) A Rapid Marine Biodiversity Assessment of the Abrolhos Bank, Bahia, Brazil. RAP Bulletin of Biological, Assessment 38, Chapter 5: 75-81.

Leão, Z.M.A.N., Ginsburg, R.N., 1997. Living Reefs surrounded by Siliciclastic Sediments: The Abrolhos Coastal Reefs, Bahia, Brazil. Procedures $8^{\text {th }}$ Int. Coral Reef Sym, 2: 1767-1772.

Leão, Z.M.A.N., Kikuchi, R.K.P., Maia, M.P., Lago, R.A.L., 1997. A Catastrophic Coral Cover Decline since 3,000 Years D.P., Northern Bahia, Brazil. Procedures $8^{\text {th }}$ Int. Coral Reef Sym, 1: 583-588.

Leipe, T., Knoppers, B., Marone, E., Camargo, R., 1999. Suspended matter transport in coral reef waters of the Abrolhos Bank, Brazil. Geo-Marine Letters, 19: $186-195$.

Lessa, G., Teixeira, C.E.P., Castro, C.B., 2005. Variabilidade da Turbidez e Taxas de Sedimentação na Zona Costeira de Caravelas (BA): Existem Evidências de Impacto das Atividades de Dragagem no Canal do Tomba nos Recifes de Coral? Anais do X Congresso da Associação Brasileira de Estudos do Quaternário ABEQUA, 6pp.

Littler, M.M., 1973. The distribution, abundance and communities of deepwater Hawaiian crustose corallines (Rhodophyta, Cryptonemiales). Pac. Sci., 27:281-289.

Littler, M.M., Littler, D.S., Hanisak, M.D., 1991. Deep-water rhodolith distribution, productivity, and growth history at sites of formation and subsequent degradation. Journal of Experimental Marine Biology and Ecology, 150 (2): 163-182.

Maiklen, W.R., 1968. Some Hydraulic Properties of Bioclastic Carbonate Grains. Sedimentology, 10: 101-109.

Marrack, E.C., 1999. The Relationship between Water Motion and Living Rhodolith Beds in the Southwestern Gulf of California, Mexico. Palaios, 14: 159-171. https://doi.org/10.2307/3515371 
Martin, L., Bittencourt, A.C.S.P., Vilas-Boas, G.S., Flexor, J.M., 1980. Mapa Geológico do Quaternário Costeiro do Estado da Bahia. Governo do Estado da Bahia, SME, 2 folhas, escala 1:250.000, texto explicativo, 57p.

Martin, L., Dominguez, J.M.L., Bittencourt, A.C.S.P., 1998. Climatic Control of Coastal Erosion during a Sea-Level Fall Episode. An. Acad. Bras. Ciências, 70 (2): 249-266.

Martins, L.R., Coutinho, P.N., 1981. The Brazilian Continental Margin. EarthScience Reviews, nº 17, pp.87-107.

Meyer-Peter, E., Müller, R., 1948. Formulas for bed-load transport. Proceedings of $2^{\text {nd }}$ IAHR Congress, Stockholm, Sweden.

Moriarty, J.M., Harris, C.K., Hadfield, M.G., 2014. A Hydrodynamic and Sediment Transport Model for the Waipaoa Shelf, New Zealand: Sensitivity of Fluxes to Spatially-Varying Erodibility and Model Nesting. Journal of Marine Science and Engineering, 2014 (2): 336-369.

Moura, R. L., Amado-Filho, G. M., Moraes, F. C., Brasileiro, P. S., Salomon, P. S., Mahiques, M.M., Bastos, A. C., Almeida, M. G., Silva, J. M., Araujo, B. F., Brito, F. P., Rangel, T. P., Oliveira, B. C. V., Bahia, R. G., Paranhos, R. P., Dias, R. J. S., Siegle, E., Figueiredo, A. G., Pereira, R. C., Leal, C. V., Hajdu, E., Asp, N. E., Gregoracci, G. B., Neumann-Leitão, S., Yager, P. L., Francini-Filho, R. B., Fróes, A., Campeão, M., Silva, B. S., Moreira, A. P.B., Oliveira, P., Soares, A. C., Araujo, L., Oliveira, N. L., Teixeira, J. B., Valle, R. A. B., Thompson, C. C., Rezende, C. E., Thompson, F. L., 2016. An extensive reef system at the Amazon River mouth. Science Advances 2, e1501252.

Muehe, D., 1996. Geomorfologia costeira: In: Guerra, A. J. T. e Cunha, S. B. (org.), Geomorfologia: uma atualização de bases e conceitos, Rio de Janeiro: Ed. Bertrand Brasil, Cap. 6, pp. 253-308.

Muehe, D., 1998. O Litoral Brasileiro e sua Compartimentação, In: Cunha, S. B.; Guerra, A. J. T. (org.), Geomorfologia do Brasil. Rio de Janeiro: Ed. Bertrand Brasil, pp.273-345.

Muehe, D., Carvalho, V.G., 1993. Geomorfologia, Cobertura sedimentar e Transporte de Sedimentos na Plataforma Continental Interna entre a Ponta de Saquarema e o Cabo Frio (RJ). Boletim do Inst. Oceanográfico, São Paulo, 41 (1/2): $1-12$.

Nascimento, L., 2006. Caracterização geoambiental da linha de costa da Costa do Cacau - litoral sul da Bahia. Dissertação de Mestrado, Curso de Pós-Graduação em Geologia, área de Geologia Marinha, Costeira e Sedimentar, Universidade Federal da Bahia, 128p.

Nascimento, L., Bittencourt, A.C.S.P., Santos, A., Dominguez, J.M.L., 2007. Deriva Litorânea ao Longo da Costa do Cacau, Bahia: Repercussões na Geomorfologia Costeira. Revista Pesquisas em Geociências, 34 (2): 45-56. 
Nelson, W.A., 2009. Calcified macroalgae - critical to coastal ecosystems and vulnerable to change: a review. Marine and Freshwater Research, 60(8): 787-801 https://doi.org/10.1071/MF08335

Nielsen, P., 1982. Explicit formulae for practical wave calculations. Coastal Engineering, 6: 389-398.

Nielsen, P., Guard, P.A., 2011. Vertical Scales and Shear Stresses in Wave Boundary Layers Over Movable Beds. Coastal Engineering Procedures, [S.1.], n. 32, p. sediment.1, jan. 2011.

Nittrouer, C.A., Kuehl, S.A., Sternberg, R.W., Figueiredo Jr., A.G., Faria, L.E.C., 1995. An Introduction to the Geological Significance of Sediment Transport and Accumulation on the Amazon Continental Shelf. Marine Geology, 125: 177-192.

Oberle, F.K.J., Storlazzi, C.D., Hanebuth, T.J.J., 2014. Wave-driven sediment mobilization on a storm-controlled continental shelf (Northwest Iberia). Journal of Marine Systems, 139: 362-372.

Oliveira, J.C., Aguiar, W., Cirano, M., Genz, F., Amorim, F.N., 2018, A climatology of the annual cycle of river discharges into the Brazilian continental shelves: from seasonal to interannual variability. Environmental Earth Sciences, 77: 192 (17pp.).

Paiva, B.P., Schettini, C.A.F., Pereira, M.D., Siegle, E., Miranda, L.B., Andutta, F.P., 2016. Circulation and suspended sediment dynamics in a tropical estuary under different morphological setting. Anais da Academia Brasileira de Ciências, 88(3): 1265-1276.

Peralta-García, E.C., Rosas-Alquicira, E.F., 2014. Range extension and morphological characterization of rhodolith-forming species (Corallinales, Rhodophyta) from shallow water in the Mexican South Pacific. Helgol. Mar. Res., 68: 503-510. https://doi.org/10.1007/s10152-014-0405-4

Pereira, A.F., Belém, A.L., Castro, B.M., Geremias, R., 2005. Tide-topography interaction along the eastern Brazilian shelf. Continental Shelf Research, 25: 15211539.

Pereira, M.D., Siegle, E., Miranda, L.B., Schettini, C.A.F., 2010. Hidrodinâmica e Transporte de Material Particulado em Suspensão Sazonal em um Estuário Dominado por Maré: Estuário de Caravelas (BA). Revista Brasileira de Geofísica, 28 (3): 427-444.

Pianca, C., Mazzini, P., Siegle, E., 2010. Brazilian Offshore Wave Climate Based on NWW3 Reanalysis. Brazilian Journal of Oceanography, 58 (1): 53-70.

Porter-Smith, R., Harris, P.T., Andersen, O.B., Coleman, R., Greenslade, D., Jenkins, C.J., 2004. Classification of the Australian continental shelf based on predicted sediment threshold exceedance from tidal currents and swell waves. Marine Geology, 211: 1 - 20. 
Prager, E.J., Southard, J.B., Vivoni-Gallart, E.R., 1996. Experiments on the Entrainment Threshold of Well-sorted and poorly sorted carbonate sands. Sedimentology, 43: 33-40.

Quaresma, V.S., Catabriga, G., Bourguignon, S.N., Godinho, E., Bastos, A.C., 2015. Modern sedimentary processes along the Doce river adjacent continental shelf. Brazilian Journal of Geology, 45(4): 635-644.

Queiroz, E.V. de, Araújo, P.V. do N., Hammill, E., Amaral, R.F. do, 2016. Morphological characteristics of rhodolith and correlations with associated sediment in a sandstone reef: Northeast Brazil. Reg. Stud. Mar. Sci., 8: 133-140. https://doi.org/10.1016/j.rsma.2016.10.005

Ribes, M.; Atkinson, M.J. 2007. Effects of water velocity on picoplankton uptake by coral reef communities. Coral Reefs, 26(2): 413-421.

Riosmena-Rodríguez, R., López-Calderón, J.M., Mariano-Meléndez, E., SánchezRodríguez, A., Fernández-Garcia, C., 2012. Size and Distribution of Rhodolith Beds in the Loreto Marine Park: Their Role in Coastal Processes. Journal of Coastal Research, 28 (1): 255 - 260.

Riul, P., Lacouth, P., Pagliosa, P.R., Christoffersen, M.L., Horta, P.A., 2009. Rhodolith beds at the easternmost extreme of South America: Community structure of an endangered environment. Aquat. Bot., 90: 315-320. https://doi.org/10.1016/j.aquabot.2008.12.002

Romeu, M.A.R., Fontoura, J.A.S., Melo, E., 2015. Typical Scenarios of Wave Regimes off Rio Grande do Sul, Southern Brazil. Journal of Coastal Research, 31(1):61-68.

Sañé, E., Chiocci, F.L., Basso, D., Martorelli, E., 2016. Environmental factors controlling the distribution of rhodoliths: An integrated study based on seafloor sampling, ROV and side scan sonar data, offshore the W-Pontine Archipelago. Cont. Shelf Res., 129: 10-22. https://doi.org/10.1016/j.csr.2016.09.003

Santos, L.A.S., 2010. Modelagem Numérica da Dinâmica do Sistema Estuarino Caravelas-Peruipe, BA. 85f. Dissertação de Mestrado, Instituto Oceanográfico, Universidade de São Paulo. 85f. 2010.

Schettini, C.A.F., Pereira, M.D., Siegle, E., Miranda, L.B., Silva, M.P., 2013. Residual fluxes of suspended sediment in a tidally dominated tropical estuary. Continental Shelf Research, 70: 27-35.

Segal, B., Castro, C.B., 2011. Coral Community Structure and Sedimentation at Different Distances from the Coast of the Abrolhos Bank, Brazil. Brazilian Journal of Oceanography, 59 (2):119-129.

SEI, Superintendência de Estudos Econômicos e Sociais da Bahia. 1999. Balanço hídrico do Estado da Bahia, 250 p. 
Shemdin, O., Hasselmann, K., Hsiao, S.V., Herterich, K., 1978. Nonlinear and linear bottom interaction effects in shallow water, in Turbulent Fluxes through the Sea Surface, Wave Dynamics and Prediction. In: A. Farve and K. Hasselmann (eds.) Plenum Press, pp. $347-372$.

Siegle, E., Asp, N.E., 2007. Wave refraction and longshore transport patterns along the southern Santa Catarina coast. Brazilian Journal of Oceanography, 55 (2): 109120.

Siegle, E., Costa, M.B., 2017. Nearshore Wave Power Increase on Reef-Shaped Coasts Due to Sea-Level Rise. Earth's Future, 5: 1054-1065.

Siegle, E., Schettini, C.A.F., Petersen, O.S., Truccolo, E.C., Vested, H.J., 2004. Hydrodynamic modelling of the Itajaí-Açú estuary. Congresso Brasileiro de Oceanografia 2004, Livro de Resumos.

Silva, A.C.R.S., Bernardes, M.E.C., Assireu, A.T., Siegle, E., Sousa, P.H.G.O., Brow, D., 2018. Hydrodynamics of a tropical estuary: Buranhém River, Porto Seguro, Brazil. Revista Brasileira de Recursos Hídricos, 23: e5.

Silva, A.S., 2011. Evolução da Sedimentação nos Recifes Costeiros de Abrolhos nas Ultimas Décadas. 114f. Dissertação (Mestrado em Geologia). Universidade Federal da Bahia. 2011.

Silva, A.S., Leão, Z.M.A.N., Kikuchi, R.K.P., Costa, A.B., Souza, J.R.B., 2013. Sedimentation in the coastal reefs of Abrolhos over the last decades. Cont. Shelf. Res., 20: 159-167.

Silva, I.R., Bittencourt, A.C.S.P., Dominguez, J.M.L., 2007. Modelagem de ondas como subsídio para a gestão ambiental das praias da Costa do Descobrimento, sul do Estado da Bahia. Anais do XIII Simpósio Brasileiro de Sensoriamento Remoto, Florianópolis, Brasil, INPE, pp. 4691-4697.

Silva, I.R., Bittencourt, A.C.S.P., Dominguez, J.M.L., Martin, L,, 2001. Principais padrões de dispersão de sedimentos ao longo da Costa do Descobrimento - sul do Estado da Bahia. Revista Brasileira de Geociências, 31 (3): 335-340.

Small, C., Nicholls, R.J., 2003. A Global Analysis of Human Settlement in Coastal Zones. Journal of Coastal Research, 19 (3): 584-599.

Smith, W. H. F., Sandwell, D. T., 1997. Global seafloor topography from satellite altimetry and ship depth soundings. Science, 277: 1957-1962.

Sorensen, O.R., Kofoed-Hansen, H., Rugbjerg, M., Sorensen, R.S., 2004. A ThirdGeneration Spectral Wave Model Using un Unstructured Finite Volume Technique. Proccedings of the $29^{\text {th }}$ Intern. Conf. on Coastal Eng. 2004.

Soulsby, R., 1997. Dynamics of Marine Sands: a manual for practical applications. Thomas Telford Services Limited, London, UK, 249p. 
Sousa, S.H.M., Ferreira, P.A.L., Martins, M.V.A., Siegle, E., Amaral, P.G.C., Figueira, R.C.L., Yamashita, C., Rodrigues, A.R., Mahiques, M.M., 2016. Spatial sediment variability in a tropical tide dominated estuary: Sources and drivers. Journal of South American Earth Sciences, 72: 115 - 125.

Steller, D.L., Foster, M.S., 1995. Environmental factors influencing distribution and morphology of rhodoliths in Bahia Concepcion, B.C.S., Mexico. J. Exp. Mar. Bio. Ecol., 194: 201-212. https://doi.org/10.1016/0022-0981(95)00086-0

Steneck, R.S., 1986. The ecology of coralline algal crusts - convergent patterns and adaptative strategies. Annu. Rev. Ecol. Syst., 17:273-303.

Storlazzi, C.D.,Reid, J.A., 2010. The influence of El Niño-Southern Oscillation (ENSO) cycles on wave-driven sea-floor sediment mobility along the central California continental margin. Cont. Shelf Res., 30: 1582-1599.

Sutherland, J., Soulsby, R., 2003. The use of model performance statistics in modelling coastal morphodynamics, Coastal Sediments'03 (ASCE), CD-ROM.

Teixeira, C.E.P., Lessa, G.C., Cirano, M., Lentini, C.A.D., 2013. The inner shelf circulation on the Abrolhos Bank, $18^{\circ} \mathrm{S}$, Brazil. Continental Shelf Research, 70: 1326.

Tessler, M. G., Cazzoli y Goya, S., 2005. Processos Costeiros Condicionantes do Litoral Brasileiro. Revista do Departamento de Geografia, 17: 11-23.

Tolman, H.L. 2002. User Manual and System documentation of WAVEWATCH-III version 2.22, National Oceanic and Atmospheric Administration - NOAA.

Tolman, H.L., 1999. User manual and system documentation of WAVEWATCH-III version 1.18, NOAA/NWS/NCEP/OMB, Tech, Note 166, 110p, Disponível em: http://polar,ncep,noaa,gov/wwaves/wavewatch.

Van Rijn, L.C., Nieuwjaar, M.W.C., Van Der Kaaij, T. H., Nap, E., Van Kampen, A., 1993. Transport of Fine Sands by Currents and Waves. Journal of Waterway, Port, Coastal, and Ocean Engineering, 119 (2): 123-143.

Villas-Boas, A.B., Riosmena-Rodriguez, R., de Oliveira Figueiredo, M.A., 2014. Community structure of rhodolith-forming beds on the central Brazilian continental shelf. Helgol. Mar. Res., 68: 27-35. https://doi.org/10.1007/s10152-013-0366-z

Walker, R.G., 1984. Shelf and shallow marine sands. In: Walker, R.G. (Ed.), Facies Models. Geological Association of Canada, Toronto, pp. 141-170.

Wiberg, P.L., Sherwood, C.R., 2008. Calculating wave-generated bottom orbital velocities from surface-wave parameters, Computers and Geosciences, 34: 11671416.

Wiegel, R.L., 1964. Waves and Their Effects on Pile-Supported Structures. University of California, Berkeley, U.S.A., General Lecture.43p. 
Wilson, S., Blake, C., Berges, J.A., Maggs, C.A., 2004. Environmental tolerances of free-living coralline algae (maerl): implications for European marine conservation. Biological Conservation, 120: 283-293.

Yokoyama, C.K., 2012. Mobilidade Sedimentar da Plataforma Continental do Estado de São Paulo em Função da Propagação de Ondas, Dissertação de Mestrado, Programa de Pós-Graduação em Oceanografia, Área de Concentração em Oceanografia Geológica, Instituto Oceanográfico, Universidade de São Paulo, 2012, $68 \mathrm{f}$.

Yoon, H.-D., Cox, D., Albert, D., Smith, H., Mori, N., Blackmar, P., 2014. Vertical Structure Of Wave Induced Currents, Orbital Velocity And Turbulence Observed In Natural Vegetation. Coastal Engineering Proceedings, 34 (waves 61). Disponível em: //icce-ojs-tamu.tdl.org/icce/index.php/icce/article/view/7607/pdf_986.

Zyserman, J.A., Fredsøe, J., 1994. Data analysis of bed concentration of suspended sediment. Journal of Hydraulic Engineering, 120(9): 1021-1042. 